INSTITUTO DE PESQUISAS ENERGÉTICAS E NUCLEARES

Autarquia associada à Universidade de São Paulo

\title{
DESENVOLVIMENTO FARMACOTÉCNICO DE UM RADIOIMUNOCONJUGADO PARA TERAPIA DE LINFOMA NÃO-HODGKIN
}

\author{
ADRIANA VIDAL FERNANDES MASSICANO
}

Tese apresentada como parte dos requisitos para obtenção do Grau de Doutor em Ciências na Área de Tecnologia Nuclear - Aplicações

Orientadora:

Profa. Dra. Elaine Bortoleti de Araújo 
Aos meus pais, meu irmão, meu esposo e aos meus filhos caninos, que nos últimos anos conviveram com a minha ausência em prol deste trabalho.

Amo todos vocês! 


\section{AGRADECIMENTOS}

Em dezembro de 2015, minha trajetória no IPEN completou 9,5 anos. Aqui fiz iniciação científica, mestrado, doutorado e amigos para uma vida inteira. Depois de tanto tempo, é inevitável que eu tenha muitas pessoas a agradecer e por mais que o coração lembre, a memória insiste em falhar.

Primeiramente agradeço a Deus pelo dom da vida e por ter colocado em meu caminho pessoas de bom coração que me ensinaram e ajudaram nestes anos.

À minha família pelo amor que me fez ser quem sou e pela paciência para esperar que este sonho se concretizasse.

Ao meu esposo pela parceria, por sonhar junto e por sacrificar nossos momentos juntos em prol deste trabalho.

À Dra. Elaine Bortoleti de Araújo pela confiança, conhecimento transmitido e amizade ao longo destes 7 anos.

À Dra. Priscilla Brunelli Pujatti, Dra. Josefina da Silva Santos e Dra. Renata Martinussi Couto por me ensinarem quase tudo o que eu sei sobre prática laboratorial e sobre parceria no ambiente de trabalho. O exemplo e amizade de vocês eu levarei para toda a vida.

À Dra. Miriam Fussae Suzuki, ao Dr. João Ezequiel de Oliveira e ao Sr. José Maria de Sousa pela boa vontade em ajudar. Raras vezes em minha vida vi pessoas tão dispostas, comprometidas e dedicadas. Parabéns! Sem vocês este trabalho não teria a mesma qualidade. Em especial agradeço à Dra. Miriam, acima de tudo, pela amizade e simpatia.

A todos os funcionários do Centro de Radiofarmácia pela boa convivência e auxílio nestes quase 10 anos. Vou sentir muita falta de todos vocês.

Especialmente agradeço:

À Dra. Neuza Taeko O. Fukumori e à Dra. Margareth Mie N. Matsuda que sempre compreenderam as minhas "urgências" e fizeram o possível para atendê-las.

À Rosana Herrerias, Adriano Aparecido de Sousa, José Antônio Pires e Jorge Alberto pelo cuidado e comprometimento em separarem minhas amostras de lutécio-177. 
À Dra. Maria Tereza Colturato pela amizade e por acompanhar este trabalho desde sempre.

À Dra. Duclerc Fernandes Parra e ao Sr. Eleosmar Gasparin por realizarem as análises por DSC de maneira tão gentil.

Ao Dr. Marco Antônio Stephano por permitir as análises no liofilizador óptico.

À Dra. Maria Inês Calil C. Guimarães pelas análises dosimétricas tão minuciosamente calculadas.

Aos funcionários do Biotério, em especial à Neide, Cecília, Mara, Dra. Nanci Nascimento, Dra. Glauce e Dra. Cleide Falcone, pelo cuidado e orientações em relação aos animais.

Aos amigos Beatriz Correia, Daniele Seo, Lais Alcarde, Thaís Castro, Raquel Benedetto, Juliana Marques, Ricardo Oliveira, Cristian Villas Boas, Jefferson Silva, Camila Zanette e Luis Alberto Dias. Para realizar pesquisa em nosso país, nós enfrentamos muitos obstáculos, mas com vocês ao meu lado, tudo foi mais fácil e divertido. Vocês são anjos que Deus colocou em minha vida para torná-la mais suave. Com vocês, as únicas vezes que chorei foi de tanto rir. A sinceridade e intensidade desta amizade sempre fizeram com que eu me sentisse em família. Uma família que o coração escolheu e aprendeu a amar. Mesmo que o tempo e a distância atenuem os laços, sempre me lembrarei dos nossos momentos com um sorriso e uma saudade enorme. Que Deus abençoe cada um de vocês!

À Tatiane Lavinas (in memoriam), por me dar a lembrança viva do seu sorriso que abranda a saudade.

Aos membros da banca examinadora por aceitarem o convite.

Aos demais amigos e familiares de todos os lugares.

Ao IPEN pelo auxílio financeiro.

Ao CNPq pela bolsa concedida. 


\title{
DESENVOLVIMENTO FARMACOTÉCNICO DE UM RADIOIMUNOCONJUGADO PARA TERAPIA DE LINFOMA NÃO-HODGKIN
}

\author{
Adriana Vidal Fernandes Massicano
}

\begin{abstract}
RESUMO
A radioimunoterapia tem se mostrado uma modalidade terapêutica promissora, especialmente para terapia de tumores hematológicos o que tem impulsionado o desenvolvimento deste tipo de radiofármaco. Existe hoje apenas um radioimunoconjugado aprovado pelo Food and Drug Administration (FDA), ibritumomabe-tiuxetan- ${ }^{90} \mathrm{Y}$ (Zevalin ${ }^{\circledR}$ ), e ele apresenta maior taxa de resposta global e de remissão completa quando comparados aos tratamentos convencionais. Entretanto, nenhum deles é comercialmente disponível no Brasil. Neste contexto, o objetivo deste trabalho foi estudar as etapas envolvidas no processo de conjugação e radiomarcação com Lu-177 do anticorpo monoclonal anti-CD20, de forma que fosse possível consolidar nacionalmente a metodologia para desenvolvimento de outros radioimunoconjugados. Nos estudos realizados para determinar a melhor razão molar anticorpo:quelante (DOTA), a razão molar 1:50, apresentou pureza radioquímica elevada (superior a 95\%, após a purificação) e imunorreatividade superior a muitos estudos publicados. Além disto, o imunoconjugado apresentou estabilidade de, no mínimo 3 meses, sob refrigeração quando conjugado por dois métodos diferentes. $O$ estudo dos parâmetros de radiomarcação permitiu a obtenção de um radioimunoconjugado com atividade específica de $740 \mathrm{MBq} / \mathrm{mg}$, com estabilidade suficientemente longa que permitirá seu transporte às clínicas médicas. Os perfis de biodistribuição e farmacocinético foram compatíveis com outros radioimunoconjugados encontrados na literatura. 0 radioimunoconjugado apresentou captação tumoral e estabilidade in vivo apreciáveis, esta última evidenciada pela baixa captação óssea. Realizaram-se estudos de liofilização da formulação aperfeiçoada do imunoconjugado que promoveram a liofilização sem dano estrutural evidenciado por eletroforese em gel de poliacrilamida com manutenção da imunorreatividade. A pureza radioquímica foi acima de $95 \%$ (após purificação) quando radiomarcado com atividade específica de $740 \mathrm{MBq} / \mathrm{mg}$, com estabilidade relevante quando armazenado à $-20^{\circ} \mathrm{C}$ por até 48 horas. Foi possível não somente padronizar as metodologias de conjugação e radiomarcação de anticorpos monoclonais, mas também aprimorá-las de forma que o radioimunoconjugado produzido foi superior em muitos aspectos quando comparado com a literatura publicada. Conclui-se, portanto, que o radioimunoconjugado anti-CD20-DOTA- ${ }^{177} \mathrm{Lu}$ é uma ferramenta promissora para o tratamento de tumores linfáticos que expressam o receptor CD20.
\end{abstract}




\title{
PHARMACOTECHNICAL DEVELOPMENT OF A RADIOIMMUNOCONJUGATE FOR NON-HODGKIN LYMPHOMA THERAPY
}

\author{
Adriana Vidal Fernandes Massicano
}

\begin{abstract}
The radioimmunotherapy (RIT) has proven to be a promising therapeutic modality, especially for therapy of hematological malignancies, which has stimulated the development of this type of radiopharmaceutical. Currently, there is one radioimmunoconjugated approved by Food and Drug Administration (FDA) for refractory or relapsed non-Hodgkin lymphoma (NHL) therapy, ${ }^{90} \mathrm{Y}$-ibritumomab tiuxetan $\left(\right.$ Zevalin $\left.^{\circledR}\right)$, and it has higher overall response and complete remission rates compared to conventional treatments. However, Zevalin ${ }^{\circledR}$ is not commercially available in Brazil. In this context, the goal of this work was to study the steps involved in the process of conjugation and radiolabeling with Lu-177 of anti-CD20 monoclonal antibody, in order to consolidate the in house methodology for development of this radioimmunoconjugate, contributing for the treatment of patients with NHL and also contributing for the future development of other radioimmunoconjugates. In the studies performed to determine the best antibody: chelator (DOTA) molar ratio, the molar ratio 1:50, showed high radiochemical purity (greater than $95 \%$ after purification) and the immunoreactivity was higher than many published studies. Additionally, the immunoconjugate was stable for, at least, 3 months under refrigeration when conjugated by two different methods. The study of radiolabeling parameters, produced a radioimmunoconjugate with specific activity of $740 \mathrm{MBq} / \mathrm{mg}$, with adequate stability that allowed the transportation of the radiopharmaceutical to nuclear medicine centers. The biodistribution and pharmacokinetic profiles were consistent with other radioimmunoconjugates in the literature. The radioimmunoconjugate showed tumor uptake and in vivo stability appreciable, the latter evidenced by low bone uptake. The lyophilization studies were performed for the optimized formulation of immunoconjugate that allowed the lyophilization without structural damage, evidenced by polyacrylamide gel electrophoresis, and with maintenance of immunoreactivity. The radiochemical purity was above $95 \%$ (after purification) when radiolabeled with a specific activity of $740 \mathrm{MBq} / \mathrm{mg}$, with significant stability when stored at $-20^{\circ} \mathrm{C}$ for 48 hours. It was possible, not only to standardize the conjugation of the monoclonal antibody and radiolabelling methodologies, but also improve them so that the radioimmunoconjugate produced was superior in many aspects when compared with the published literature. In conclusion, the radioimmunoconjugate ${ }^{177} \mathrm{Lu}$ DOTA-anti-CD20 is a promising tool for the therapy of tumors that express CD20.
\end{abstract}




\section{SUMÁRIO}

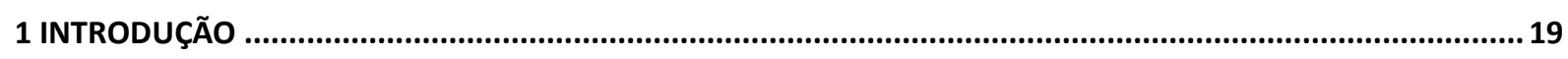

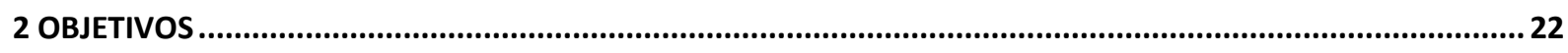

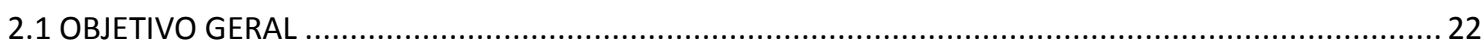

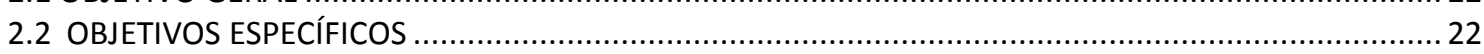

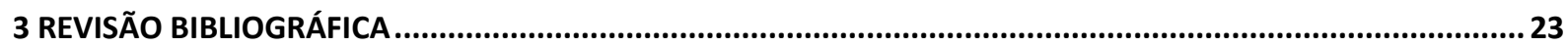

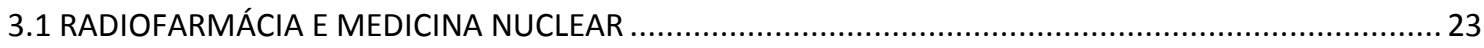

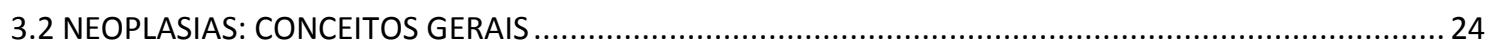

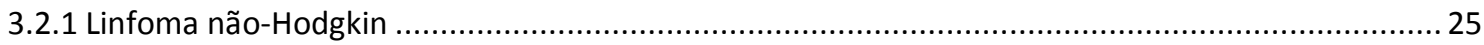

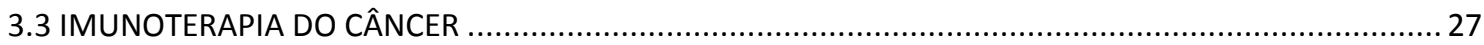

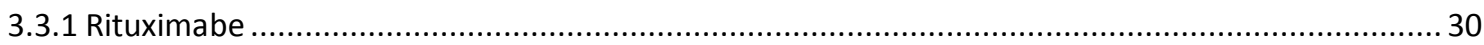

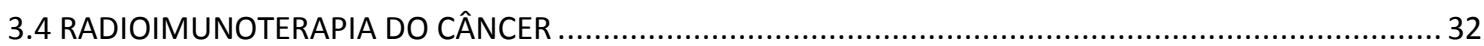

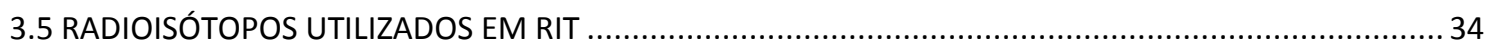

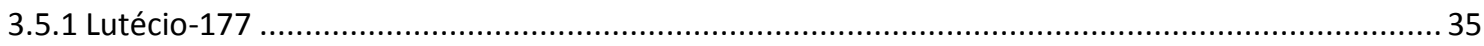

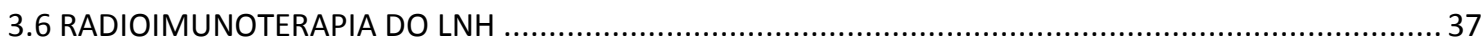

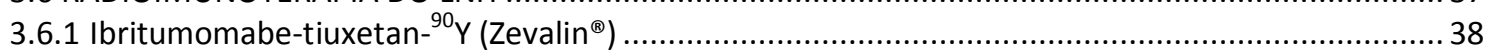

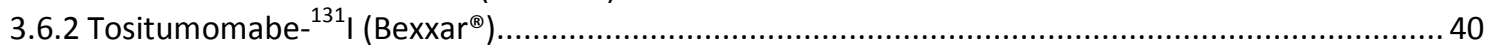

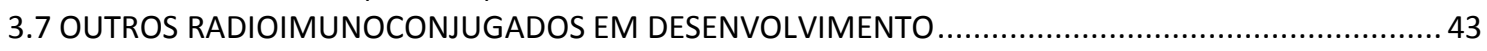

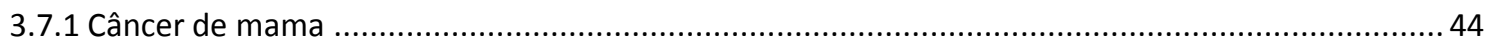

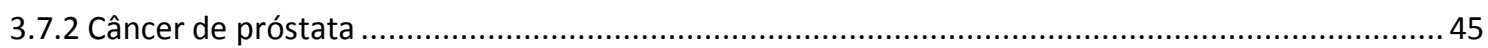

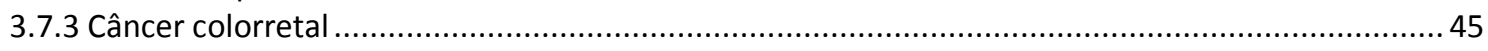

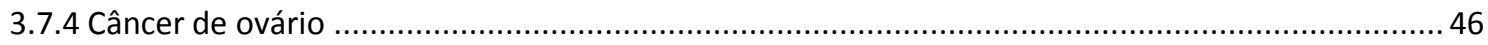

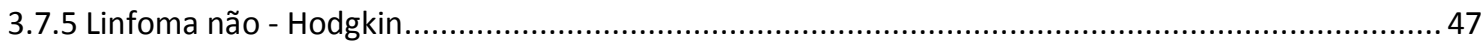

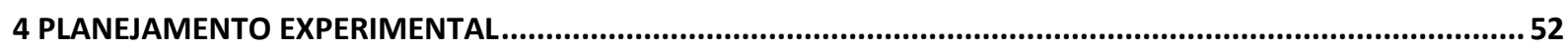

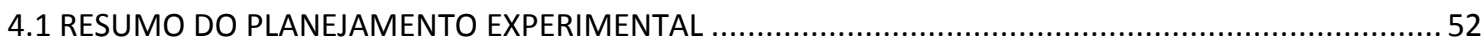

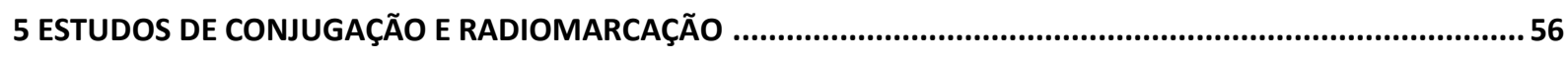

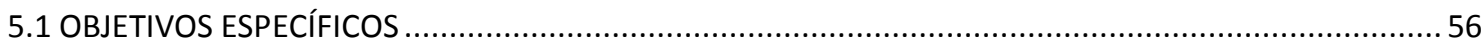

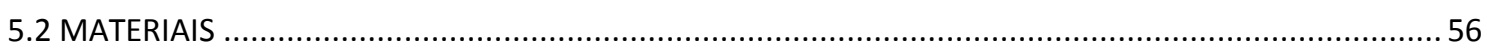

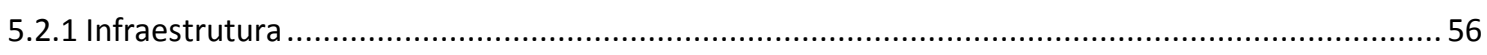

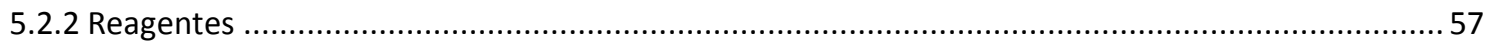

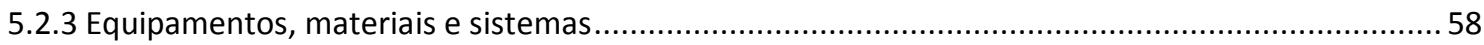

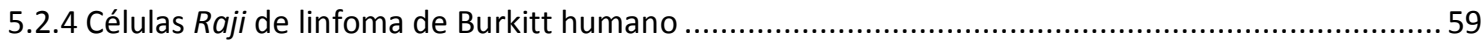

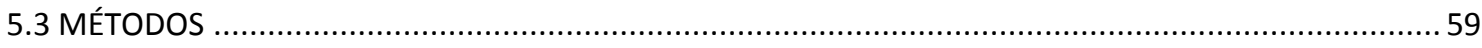

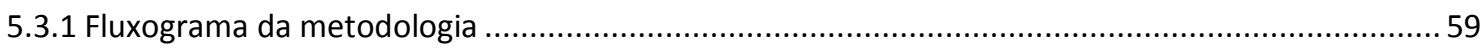

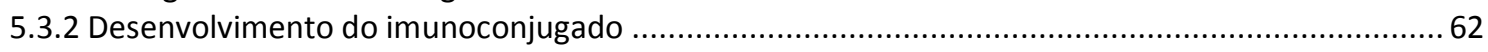

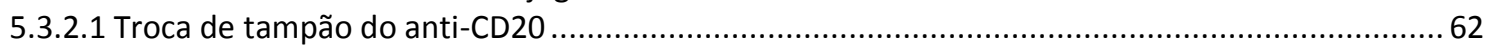

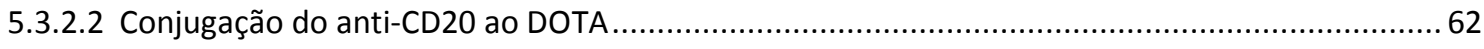

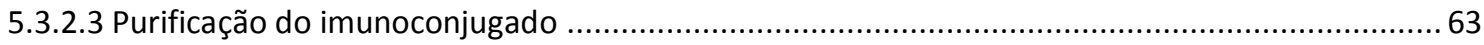

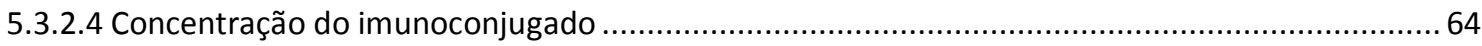

5.3.2.5 Cálculo da concentração proteica do imunoconjugado ....................................................6. 64

5.3.2.6 Determinação do número de quelantes por anticorpo .........................................................64

5.3.2.7 Análise da integridade estrutural do imunoconjugado por eletroforese em gel de poliacrilamida 


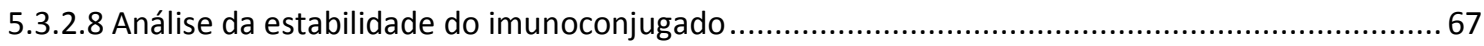

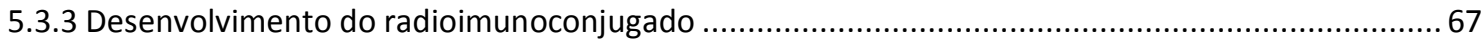

5.3.3.1 Análise da pureza radioquímica ...................................................................................6. 67

5.3.3.2 Aperfeiçoamento do método de radiomarcação do imunoconjugado com lutécio-177 .............68

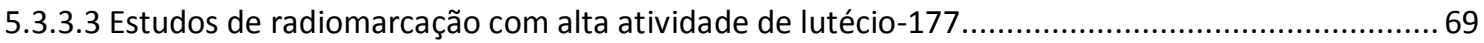

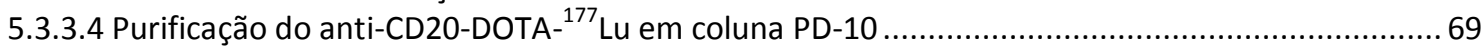

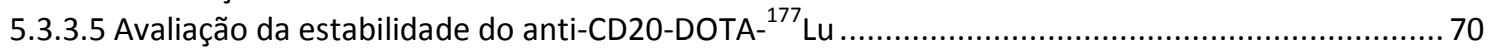

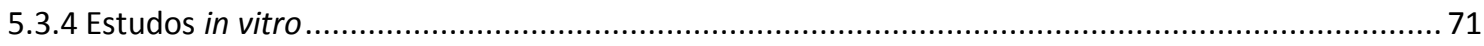

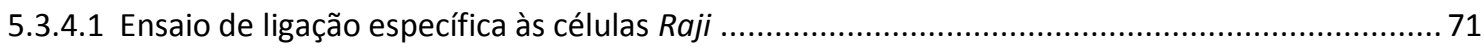

5.3.4.2 Análise da Influência da atividade específica na ligação às células ....................................... 72

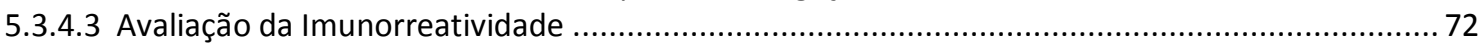

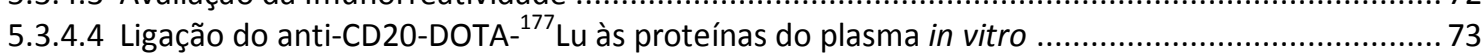

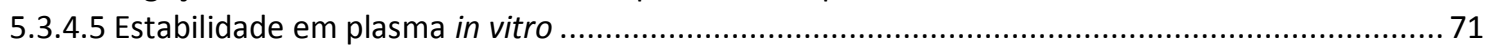

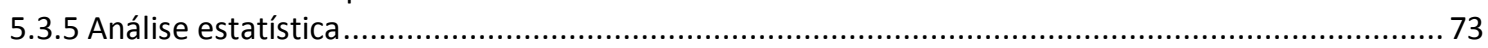

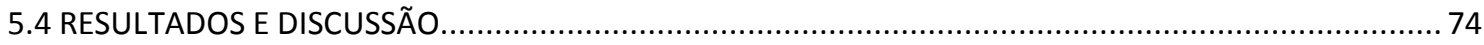

5.4.1 Desenvolvimento do imunoconjugado: escolha da razão molar ............................................ 74

5.4.2 Análise da integridade estrutural do imunoconjugado por eletroforese em gel de poliacrilamida 92

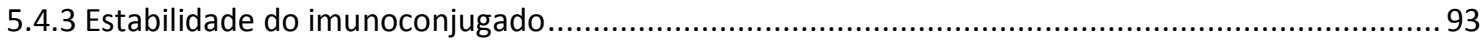

5.4.4 Desenvolvimento do radioimunoconjugado: estudo das condições de radiomarcação ..................97

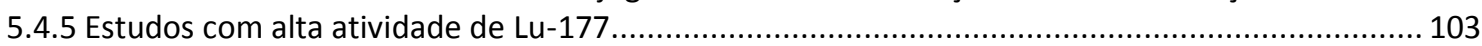

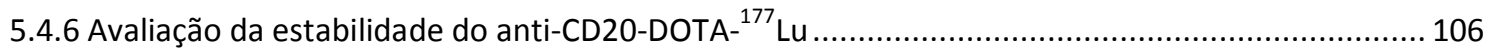

5.4.7 Radiomarcação com alta atividade específica do AcM conjugado pelos métodos 1 e 2 ............. 114

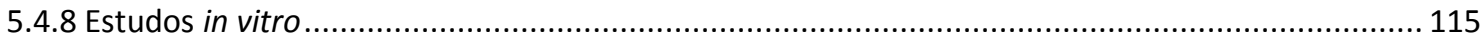

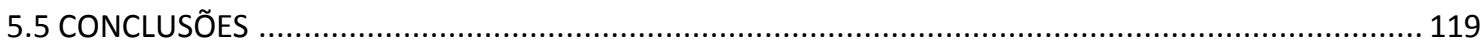

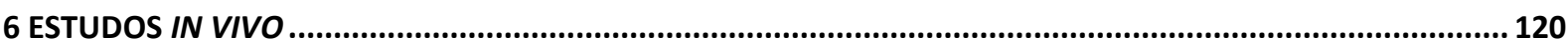

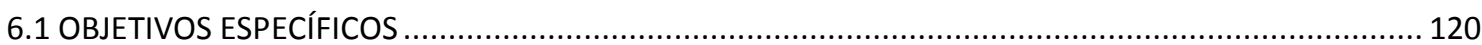

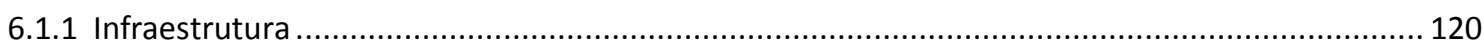

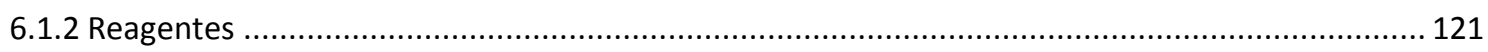

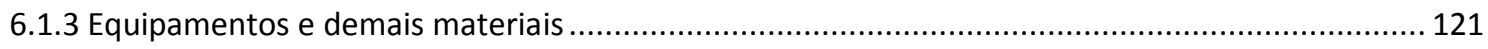

6.1.4 Células Raji de linfoma de Burkitt humano .................................................................... 121

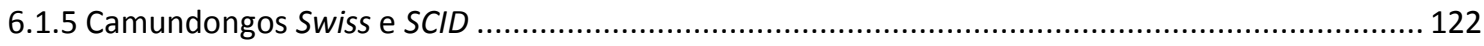

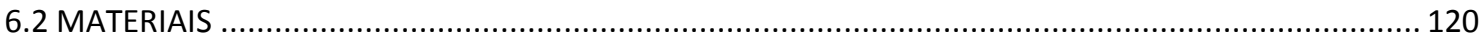

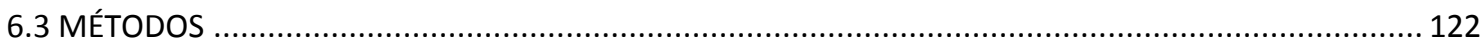

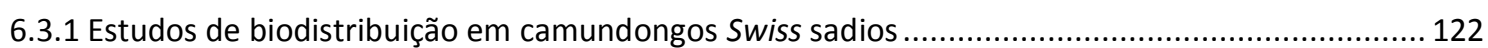

6.3.2 Estabilidade do Rituximabe-DOTA $-{ }^{177}$ Lu em plasma in vivo................................................... 123

6.3.3 Identificação dos principais metabólitos encontrados na urina ............................................... 123

6.3.4 Estudos farmacocinéticos em camundongos Swiss sadios ..................................................... 124

6.3.5 Estudos de captação de corpo inteiro em camundongos Swiss sadios ..................................... 125

6.3.6 Desenvolvimento de modelo tumoral em camundongos SCID .............................................. 125

6.3.7 Estudos de biodistribuição em animais com tumor............................................................ 126

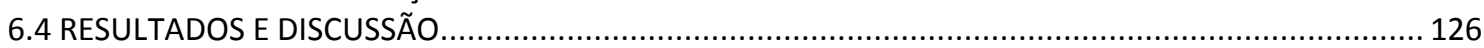

6.4.1 Estudos farmacocinéticos ............................................................................................... 126

6.4.2 Biodistribuição, metabolismo e estabilidade em plasma do rituximabe-DOTA- ${ }^{177}$ Lu ................... 129

6.4.3 Estudos de captação de corpo inteiro ............................................................................. 132

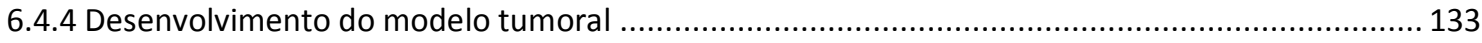

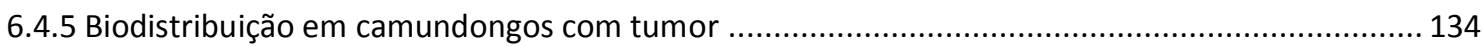

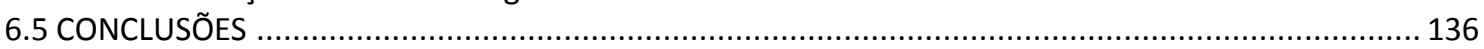

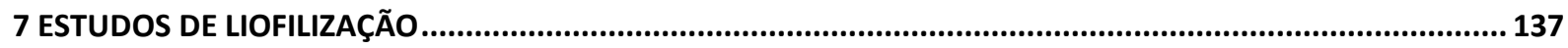

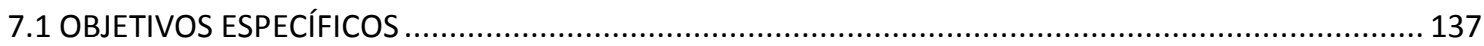

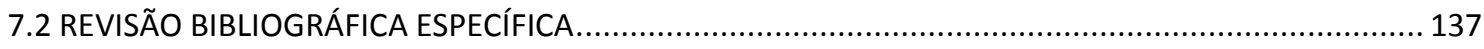

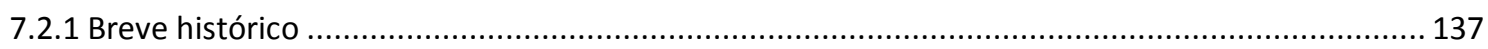

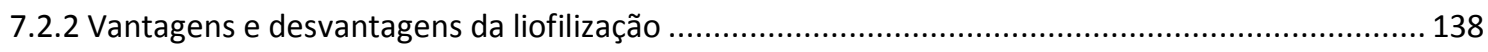


7.2.3 Etapas da liofilização e do desenvolvimento de uma proteína liofilizada ................................. 140

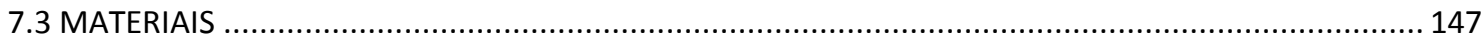

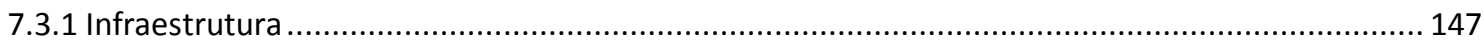

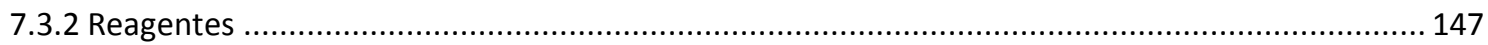

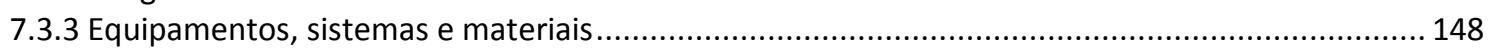

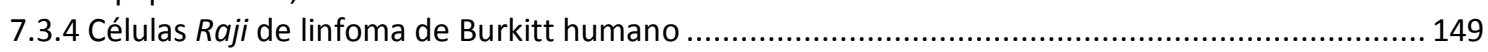

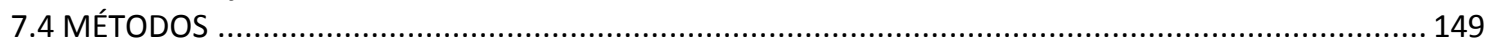

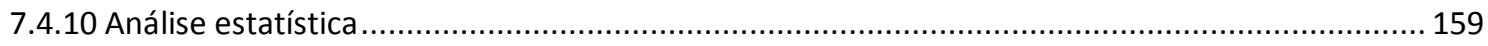

7.4.2 Estudo de diferentes formulações de imunoconjugado ....................................................... 151

7.4.3 Determinação da temperatura de transição vítrea e temperatura de fusão ............................. 153

7.4.4 Determinação da temperatura de cristalização e temperatura de colapso ................................ 153

7.4.5 Estudo de diferentes protocolos de liofilização......................................................................... 154

7.4.6 Análise do produto liofilizado antes da reconstituição ......................................................... 155

7.4.7 Análise do produto liofilizado após reconstituição............................................................. 156

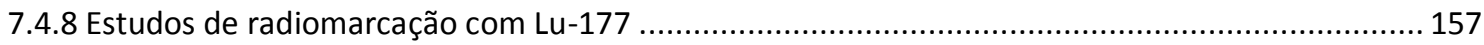

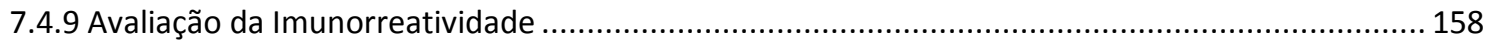

7.5 RESULTADOS E DISCUSSÃO.................................................................................. 159

7.5.1 Determinação das temperaturas de cristalização, transição vítrea, fusão e colapso .................... 159

7.5.2 Analise do liofilizado antes e após a reconstituição ............................................................ 164

7.5.3 Análise da integridade estrutural do imunoconjugado liofilizado por eletroforese em gel de

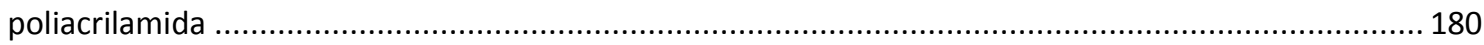

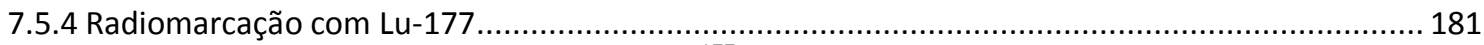

7.5.5 Estudo da estabilidade do anti-CD20-DOTA- ${ }^{177}$ Lu em condições de transporte........................... 182

7.5.6 Análise da Imunorreatividade do kit liofilizado ............................................................ 186

7.5.7 Comparação entre o imunoconjugado não liofilizado e liofilizado ......................................... 187

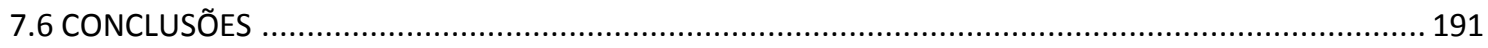

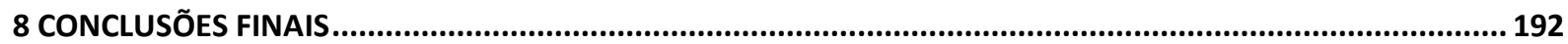

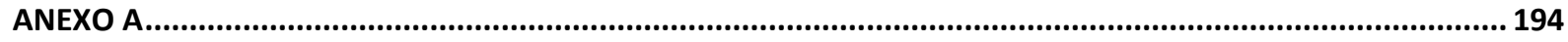

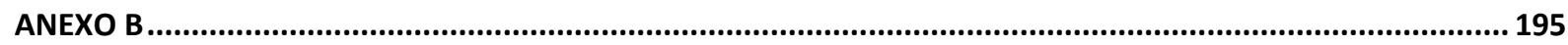

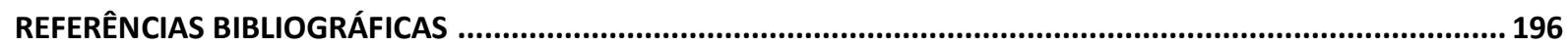




\section{LISTA DE TABELAS}

TABELA 1 - Anticorpos monoclonais aprovados pelo FDA para tratamento oncológico. Adaptado de Glassman e

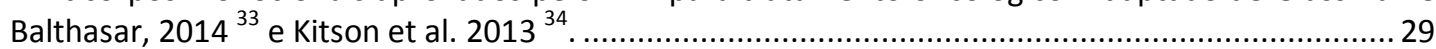

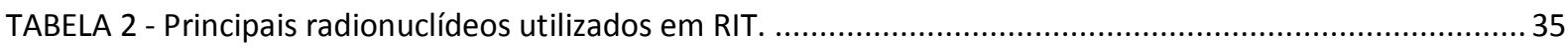

TABELA 3 - Estudos realizados, indicadores e questões investigativas da primeira etapa do trabalho. ...............53

TABELA 4 - Estudos realizados, indicadores e questões investigativas da segunda etapa do trabalho. ..............54

TABELA 5 - Estudos realizados, indicadores e questões investigativas da terceira etapa do trabalho. ...............55

TABELA 6 - Estudos realizados, indicadores e questões investigativas da quarta etapa do trabalho. .................55

TABELA 7 - Tempo de retenção (TR) do anticorpo não conjugado e conjugado ao DOTA analisados por CLAE.

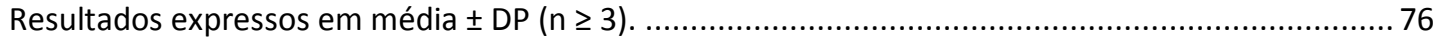

TABELA 8 - Número de quelantes acoplados ao anticorpo. Resultados expressos em média \pm DP....................8 82

TABELA 9 - Comparação dos métodos de conjugação e número de quelantes por AcM obtidos para diferentes AcMs conjugado ao quelante DOTA-NHS.

TABELA 10 - Comparação dos métodos de conjugação, número de quelantes por AcM e imunorreatividade obtidos para diferentes AcMs conjugados a diferentes quelantes.

TABELA 11 - Estabilidade do anti-CD20-DOTA (1:50), conjugado pelo método 1 e armazenado a 2-8 ${ }^{\circ} \mathrm{C}$. Resultados expressos em média \pm DP

TABELA 12 - Análise dos parâmetros de qualidade do anti-CD20-DOTA (1:50), conjugado pelo método 2 e armazenado a $2-8{ }^{\circ} \mathrm{C}$. Resultados expressos em média \pm DP................................................. 94

TABELA 13 - Estudo da influência da atividade específica na pureza radioquímica do Anti-CD20-DOTA- ${ }^{177}$ Lu.

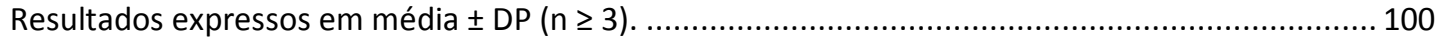

TABELA 14 - Estabilidade do anti-CD20-DOTA- ${ }^{177} \mathrm{Lu}(2 \mathrm{mg} / 1.480 \mathrm{MBq}$ ), purificado em PD-10, após armazenamento sob congelamento $\left(-20^{\circ} \mathrm{C}\right)$ Pureza radioquímica determinada por CCD (Média \pm DP) $(n=3)$.

TABELA 15 - Estabilidade in vitro do anti-CD20-DOTA- ${ }^{177} \mathrm{Lu}(740 \mathrm{MBq} / \mathrm{mg}$ ) diluído em plasma humano (proteínas precipitadas). Resultados expressos em média $\pm \mathrm{DP}(\mathrm{N}=2)$. 113

TABELA 16 - Parâmetros farmacocinéticos do anti-CD20-DOTA- ${ }^{177}$ Lu determinados em camundongos Swiss fêmeas sadias $(\mathrm{N}=4)$

TABELA 17 - Estabilidade do anti-CD20-DOTA- ${ }^{177}$ Lu in vivo em plasma de camundongos Swiss fêmeas sadias. Pureza radioquímica determinada por $C C D$ e resultados expressos em média \pm DP $(n=4)$. ... 132

TABELA 18 - Razões tumor:tecido calculadas para o anti-CD20-DOTA- ${ }^{177}$ Lu. Os dados utilizados para o cálculo foram os \%Al/g ou $\mathrm{mL}$ obtidos por meio da biodistribuição do anti-CD20-DOTA- ${ }^{177}$ Lu em camundongos SCID implantados com Raji.

TABELA 19 - Formulações estudadas do imunoconjugado diluído em acetato de amônio 0,25 M pH 6,5 acrescido ou não de excipientes. .................................................................................... 152

TABELA 20 - Protocolos estudados para a liofilização do imunoconjugado. 154

TABELA 21 - Tabela de correlação entre as formulações estudadas e o protocolo empregado na liofilização. . 155

TABELA 22 - Transição vítrea $\left(T_{g}\right)$, ponto de fusão $\left(T_{m}\right)$, temperatura de cristalização $\left(T_{\text {cris }}\right)$ e temperatura de colapso $\left(T_{c}\right)$ das formulações estudadas. Valores expressos em média $\pm \mathrm{DP}(\mathrm{N}=3)$. 
TABELA 23 - Avaliação do imunoconjugado $(2 \mathrm{mg} / \mathrm{mL}$ ) liofilizado sem adição de excipientes (formulação 1). Resultados expressos em média $\pm \mathrm{DP}(\mathrm{N}=3)$

TABELA 24 - Avaliação do imunoconjugado $(2 \mathrm{mg} / \mathrm{mL})$ liofilizado com adição de excipientes e liofilizado pelo protocolo 2. Resultados expressos em média $\pm \mathrm{DP}(\mathrm{N}=3)$.

TABELA 25 - Avaliação do imunoconjugado e do AcM não conjugado, ambos não acrescidos de excipientes e liofilizados pelo protocolo 3. Resultados expressos em média $\pm \mathrm{DP}(\mathrm{N}=3)$.

TABELA 26 - Avaliação do imunoconjugado liofilizado em diferentes concentrações e acrescido de diferentes massas de manitol. As amostras foram liofilizadas pelo protocolo 4. Resultados expressos em média $\pm \mathrm{DP}(\mathrm{N}=3)$.

TABELA 27 - Comparação entre o AcM conjugado pelo método 1 e 2 de conjugação, acrescido de excipientes (formulação 16) e liofilizado pelo protocolo 4. Resultados expressos em média \pm DP $(N=3)$. 


\section{LISTA DE FIGURAS}

FIGURA 1 - Ácido 1,4,7,10-tetraazociclododecano N,N',N", N"'-tetracético (DOTA-NHS-éster).....

FIGURA 2 - Representação esquemática da conjugação do AcM ao DOTA e posterior radiomarcação com radionuclídeo $\beta$ emissor. Adaptado de Kitson e colaboradores (2013) ${ }^{34}$.

FIGURA 3 - Fluxograma dos métodos empregados no desenvolvimento do imunoconjugado. ........................60

FIGURA 4 - Fluxograma dos métodos empregados no desenvolvimento do radioimunoconjugado.

FIGURA 5 - Esquema da reação geral de ésteres com aminas primárias (A) e esquema geral da reação do grupamento NHS-éster do DOTA com grupamentos aminas presentes no AcM. Adaptado de Solomons et al., $2002^{106}$ e Liu et al., $2001^{105}$ 75

FIGURA 6 - Absorbância (UV, $280 \mathrm{~nm}$ ) das frações de purificação do imunoconjugado em coluna de exclusão molecular (PD-10), utilizando tampão acetato de sódio 0,4 M pH 7,0 como eluente ( $\mathrm{N}=6)$. Em (1) frações correspondentes ao AcM; em (2) fração correspondente ao AcM-DOTA e em (3) frações correspondentes ao DOTA.

FIGURA 7 - Perfil cromatográfico (UV, $280 \mathrm{~nm}$ ) do imunoconjugado após purificação em coluna de exclusão molecular, utilizando tampão acetato de sódio $0,4 \mathrm{M} \mathrm{pH} \mathrm{7,0} \mathrm{como} \mathrm{eluente.} \mathrm{Em} \mathrm{(A),} \mathrm{fração} \mathrm{3;} \mathrm{(B)}$ fração 4; (C) fração 5; (D) fração 6; (E) fração 7 e (F) fração .. 78

FIGURA 8 - Perfil de CLAE do imunoconjugado purificado e concentrado. 79

FIGURA 9 - Curva de calibração do anticorpo não conjugado. Resultados expressos em média \pm EPM $(n=3)$...80

FIGURA 10 - Pureza radioquímica do anti-CD20-DOTA $-{ }^{177}$ Lu antes e após a purificação em coluna de exclusão molecular (PD-10). Condições de radiomarcação: $1 \mathrm{mg}$ de imunoconjugado; $37 \mathrm{MBq}(1 \mathrm{mCi})$ de ${ }^{177} \mathrm{Lu}$;

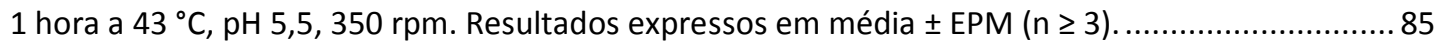

FIGURA 11 - Ligação específica do anti-CD20-DOTA- ${ }^{177}$ Lu às células Raji em diferentes razões molares de conjugação. Resultados expressos em média $\pm \operatorname{EPM}(\mathrm{N} \geq 3)$.

FIGURA 12 - Ligação específica do anti-CD20-DOTA- ${ }^{177}$ Lu à $1 \times 10^{6}$ células Raji em diferentes razões molares de conjugação. Resultados expressos em Média \pm EPM $(\mathrm{N} \geq 3)$. Diferença estatística representado por *.

FIGURA 13 - Imunorreatividade do anti-CD20-DOTA- ${ }^{177}$ Lu conjugado em diferentes razões molares de conjugação (atividade específica de $37 \mathrm{MBq} / \mathrm{mg}$ ). 88

FIGURA 14 - Eletroforese em gel de poliacrilamida do (1) AcM não conjugado; (2) AcM conjugado pelo método 1 e (3) AcM conjugado pelo método $2 . M=$ marcador de peso molecular.

FIGURA 15 - Perfil de CLAE do ACM anti-CD20 conjugado ao DOTA pelos dos dois métodos. (1) = agregados; (2) = anti-CD20-DOTA.

FIGURA 16 - Estudo de estabilidade por CLAE do ACM anti-CD20 (1:50) conjugado pelo método 1 e armazenado a $2-8{ }^{\circ} \mathrm{C} .(1)=$ agregado; $(2)$ = anti-CD20-DOTA e (3) = DOTA livre.

FIGURA 17 - Influência da massa de imunoconjugado na pureza radioquímica. Condições de radiomarcação: imunoconjugado 1:50, $37 \mathrm{MBq}(1 \mathrm{mCi})$ de ${ }^{177} \mathrm{LuCl}_{3}, 350 \mathrm{rpm}$. Resultados obtidos por CCD e expressos em média $\pm \operatorname{EPM}(n \geq 3)$.

FIGURA 18 - Influência da atividade na pureza radioquímica da marcação de $\mathbf{0 , 2} \mathbf{~ m g}$ de imunoconjugado (1:50). Resultados obtidos por CCD e expressos em média \pm EPM $(n \geq 3)$.

FIGURA 19 - Influência da atividade na pureza radioquímica da marcação de $\mathbf{0 , 5}$ mg de imunoconjugado (1:50). 
Resultados obtidos por CCD e expressos em média $\pm \operatorname{EPM}(n \geq 3)$.

FIGURA 20 - Influência da temperatura, tempo e pH na radiomarcação. Condições de radiomarcação: 0,2 mg do imunoconjugado, $185 \mathrm{MBq}(5 \mathrm{mCi})$ de ${ }^{177} \mathrm{LuCl}_{3}, 350 \mathrm{rpm}$. Resultados obtidos por CCD e expressos em média $\pm \operatorname{EPM}(n=3)$. 102

FIGURA 21 - Influência do volume de tampão na radiomarcação. Condições: $2 \mathrm{mg}$ (1:50); $1.480 \mathrm{MBq}$ (40 mCi) de ${ }^{177} \mathrm{LuCl}_{3} ; 1$ hora a $43{ }^{\circ} \mathrm{C}$; tampão acetato de sódio $0,4 \mathrm{M} \mathrm{pH} \mathrm{5,5;} \mathrm{agitação} \mathrm{de} 500$ rpm (imediato não purificado). Resultados obtidos por CCD e expressos em média \pm EPM $(n \geq 4)$. . . 103

FIGURA 22 - Influência da massa de imunoconjugado na radiomarcação. Condições de radiomarcação: 1.480 $\mathrm{MBq}\left(40 \mathrm{mCi}\right.$ ) de ${ }^{177} \mathrm{LuCl}_{3} ; 1$ hora a $43{ }^{\circ} \mathrm{C}$; tampão acetato de sódio 0,4 M pH 5,5; volume final de 1 $\mathrm{mL}$ e agitação de $500 \mathrm{rpm}$ (Imediato não purificado). Resultados obtidos por CCD e expressos em média $\pm \operatorname{EPM}(n \geq 4)$...... 104

FIGURA 23 - Influência do tampão na radiomarcação. Condições: 2 mg (1:50); $1.480 \mathrm{MBq}(40 \mathrm{mCi})$ de ${ }^{177} \mathrm{LuCl}_{3} ; 1$ hora a $43^{\circ} \mathrm{C} ; \mathrm{pH} 5,5$. Pureza radioquímica determinada por CLAE. Resultados expressos em média \pm $\operatorname{EPM}(n \geq 3)$. 105

FIGURA 24 - Influência do pH na radiomarcação utilizando-se tampão acetato de amônio 0,25 M. Condições: 2 $\mathrm{mg}$ (1:50); $1.480 \mathrm{MBq}(40 \mathrm{mCi})$ de ${ }^{177} \mathrm{LuCl}_{3} ; 1$ hora a $43{ }^{\circ} \mathrm{C}$. Pureza radioquímica determinada por CLAE. Resultados expressos em média $\pm \operatorname{EPM}(n=3)$. 106

FIGURA 25 - Estabilidade do anti-CD20-DOTA radiomarcado com alta atividade de Lu-177 (2 mg/1.400 MBq; $740 \mathrm{MBq} / \mathrm{mg}$ ). Em (A), resultados da estabilidade após armazenamento por 4 horas à $-20^{\circ} \mathrm{C}$; em (B), após armazenamento por 24 horas à $-20^{\circ} \mathrm{C}$, seguido de armazenamento por 6 horas a $2-8^{\circ} \mathrm{C}$ e em (C), após armazenamento por 48 horas à $-20^{\circ} \mathrm{C}$, seguido de armazenamento por 6 horas a $2-8{ }^{\circ} \mathrm{C}$. Resultados obtidos por CCD e expressos em média $\pm \mathrm{DP}(\mathrm{N}=2)$. 109

FIGURA 26 - Perfis cromatográficos (CLAE) do radioimunoconjugado ( 740 MBq/mg) armazenado em diferentes condições. $D$ = Diluição; $C=$ Congelamento e $R=$ refrigeração. 110

FIGURA 27 - Estabilidade do anti-CD20-DOTA radiomarcado com alta atividade de Lu-177 (2 mg/1.400 MBq; $296 \mathrm{MBq} / \mathrm{mg}$ ). Em (A), resultados da estabilidade após armazenamento por 24 horas à $-20{ }^{\circ} \mathrm{C}$, seguido de armazenamento por 6 horas a $2-8^{\circ} \mathrm{C}$ e em (B), após armazenamento por 48 horas à -20 ${ }^{\circ} \mathrm{C}$, seguido de armazenamento por 6 horas a $2-8{ }^{\circ} \mathrm{C}$. Resultados obtidos por CCD e expressos em média $\pm \mathrm{DP}(\mathrm{N}=2)$.

FIGURA 28 - Estabilidade do anti-CD20-DOTA radiomarcado com alta atividade de Lu-177 (2 mg/1.850 MBq; $925 \mathrm{MBq} / \mathrm{mg}$ ). Em (A), resultados da estabilidade após armazenamento por 24 horas à $-20{ }^{\circ} \mathrm{C}$, seguido de armazenamento por 6 horas a $2-8^{\circ} \mathrm{C}$ e em (B), após armazenamento por 48 horas à -20 ${ }^{\circ} \mathrm{C}$, seguido de armazenamento por 6 horas a $2-8{ }^{\circ} \mathrm{C}$. Resultados obtidos por CCD e expressos em média $\pm \mathrm{DP}(\mathrm{N}=2)$ 112

FIGURA 29 - Pureza radioquímica do AcM conjugado pelos dos dois métodos e radiomarcado com Lu-177 (740 $\mathrm{MBq} / \mathrm{mg})$. INP = Imediato não purificado e IP = Imediato purificado em coluna de exclusão molecular. Resultados expressos em média \pm DP $(\mathrm{N}>4)$. 114

FIGURA 30 - Ligação in vitro do anti-CD20-DOTA- ${ }^{177} \mathrm{Lu}(740 \mathrm{MBq} / \mathrm{mg})$ às proteínas do plasma. Resultados expressos em média $\pm \mathrm{DP}(\mathrm{N}=2)$. 116

FIGURA 31 - Influência da atividade específica do anti-CD20-DOTA- ${ }^{177}$ Lu na ligação às células Raji. Estudo realizado com $1,5 \times 10^{6}$ células por atividade específica. Resultados expressos em média $\pm \mathrm{EPM}(\mathrm{N}=1)$.

FIGURA 32 - Imunorreatividade do AcM conjugado pelos dois métodos de conjugação e radiomarcado com atividade específica de $740 \mathrm{MBq} / \mathrm{mg}(\mathrm{N}=3)$.

FIGURA 33 - Curva de clareamento sanguíneo do anti-CD20-DOTA- ${ }^{177}$ Lu em camundongos Swiss fêmeas sadias $(\mathrm{N}=4)$.

FIGURA 34 - Biodistribuição do anti-CD20-DOTA- ${ }^{177} \mathrm{Lu}(2,22 \mathrm{MBq}, 60 \mu \mathrm{Ci})$ em camundongos Swiss fêmeas sadios $(\mathrm{N}=4)$. 130

FIGURA 35 - Perfil cromatográfico (CCD) da urina coletada em diferentes tempos de camundongos sadios após 
a administração endovenosa do anti-CD20-DOTA- ${ }^{177} \mathrm{Lu}$. Resultados expressos em média (N=4)..... 131

FIGURA 36 - Cinética de corpo inteiro do anti-CD20-DOTA- ${ }^{177}$ Lu em camundongos Swiss fêmeas sadias (N=4).

FIGURA 37 - Corte histológico do tumor desenvolvido em camundongos SCID. Em (A), aumento de 100 X; em

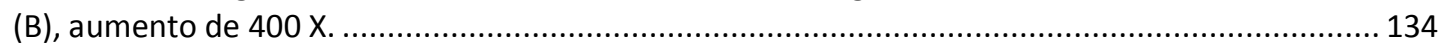

FIGURA 38 - Biodistribuição do anti-CD20-DOTA- ${ }^{177}$ Lu em camundongos SCID fêmeas (N=3) ....................... 135

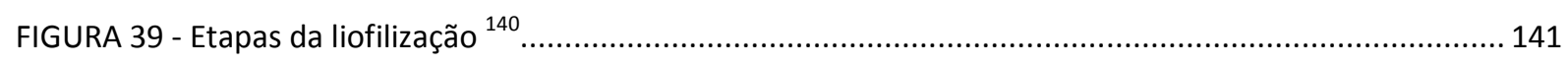

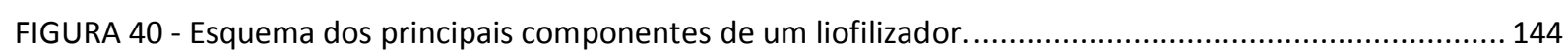

FIGURA 41 - Fluxograma do desenvolvimento do imunoconjugado liofilizado............................................. 150

FIGURA 42 - Exemplo de curva (perfil) obtido após análise por DSC do imunoconjugado sem adição de

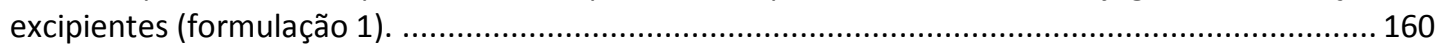

FIGURA 43 - Análise do imunoconjugado não acrescido de excipientes (formulação 1) por liofilizador óptico. Em (A), visualiza-se a borda da gota da amostra analisada; em (B), amostra cristalizada; em (C), início da liofilização da amostra, a seta indica a frente de sublimação e em (D), identificação visual do colapso da matriz liofilizada (seta)...... 161

FIGURA 44 - Aparência do produto liofilizado classificado como: pó (A e B), colapsado (C e D) e gelificado (E e F). 165

FIGURA 45 - Perfis cromatográficos por CLAE do imunoconjugado liofilizado pelos protocolos 1 (A), 2 (B), 3 (C) e 4 (D) não acrescido de quaisquer excipientes (formulação 1). (1) = agregado; (2) = anti-CD20-DOTA. 167

FIGURA 46 - Perfis cromatográficos por CLAE do imunoconjugado acrescido de diferentes excipientes e liofilizado pelo protocolo 2 . (1) = agregado; (2) = anti-CD20-DOTA. 169

FIGURA 47 - Perfis cromatográficos por CLAE do imunoconjugado (formulações 1, 12 e 17) e do AcM não conjugado (formulações 21,22 e 23) não acrescidos de quaisquer excipientes e liofilizados pelo protocolo 2 . (1) = agregado; $(2)=$ anti-CD20-DOTA.

FIGURA 48 - Exemplo de formação de pastilha para o imunoconjugado liofilizado na concentração final de 5 $\mathrm{mg} / \mathrm{mL}$. 173

FIGURA 49 - Perfis cromatográficos por CLAE do imunoconjugado em diferentes concentrações finais e liofilizado pelo protocolo 4. O imunoconjugado foi acrescido ou não de diferentes excipientes. $(1)=$ agregado; $(2)$ = anti-CD20-DOTA......

FIGURA 50 - Perfis cromatográficos por CLAE do imunoconjugado (formulação 16) liofilizado pelo protocolo 4 , Em (A), AcM conjugado pelo método 1 de conjugação e em (B), AcM conjugado pelo método 2 de conjugação. (1) = agregado; $(2)=$ anti-CD20-DOTA. 179

FIGURA 51 - SDS-PAGE do imunoconjugado liofilizado pelo protocolo 4 após a reconstituição. Em (1) AcM antiCD20 não conjugado; em (2) AcM conjugado ao DOTA pelo método 1 de conjugação e em (3) AcM conjugado ao DOTA pelo método 2 de conjugação. $M=$ marcador de peso molecular. 180

FIGURA 52 - Pureza radioquímica (imediato não purificado) do AcM conjugado pelos dois métodos de conjugação e liofilizados pelo protocolo 4. Condições de radiomarcação: $\mathbf{0 , 2} \mathbf{~ m g ; ~} 148 \mathbf{~ M B q}(740$ $\mathrm{MBq} / \mathrm{mg})$; tampão acetato de amônio $0,25 \mathrm{M} \mathrm{pH}$ 6,5. Resultados expressos em média $\pm \mathrm{DP}(\mathrm{N}=5)$.

181

FIGURA 53 - Pureza radioquímica do AcM conjugado pelos dois métodos de conjugação e liofilizados pelo protocolo 4. Condições de radiomarcação: $2 \mathrm{mg} ; 1.480 \mathrm{MBq}(740 \mathrm{MBq} / \mathrm{mg})$; tampão acetato de amônio 0,25 M pH 6,5 (NP= não purificado e $\mathrm{P}=$ purificado). Resultados expressos em média $\pm \mathrm{DP}$ ( $N=5$ para método 1 de conjugação e $\mathrm{N}=2$ para método 2 de conjugação). 182

FIGURA 54 - Estabilidade do ACM conjugado pelo método 1 de conjugação, liofilizado e radiomarcado com alta atividade de Lu-177 (2 mg / $1.480 \mathrm{MBq} ; 740 \mathrm{MBq} / \mathrm{mg}$ ). Em (A), resultados da estabilidade após armazenamento por 24 horas à $-20^{\circ} \mathrm{C}$, seguido de armazenamento por 6 horas a $2-8^{\circ} \mathrm{C}$ e em (B), após armazenamento por 48 horas à $-20^{\circ} \mathrm{C}$, seguido de armazenamento por 6 horas a $2-8{ }^{\circ} \mathrm{C}$. 
Resultados obtidos por CCD e expressos em média $\pm \mathrm{DP}(\mathrm{N}=2)$

FIGURA 55 - Estabilidade do AcM conjugado pelo método 2 de conjugação, liofilizado e radiomarcado com alta atividade de Lu-177 (2 mg / $1.480 \mathrm{MBq} ; 740 \mathrm{MBq} / \mathrm{mg}$ ). Em (A), resultados da estabilidade após armazenamento por 24 horas à $-20^{\circ} \mathrm{C}$, seguido de armazenamento por 6 horas a $2-8{ }^{\circ} \mathrm{C}$ e em (B), após armazenamento por 48 horas à $-20^{\circ} \mathrm{C}$, seguido de armazenamento por 6 horas a $2-8{ }^{\circ} \mathrm{C}$. Resultados obtidos por CCD e expressos em média $\pm \mathrm{DP}(\mathrm{N}=2)$. 184

FIGURA 56 - Quantificação das impurezas presentes no estudo de estabilidade do AcM conjugado pelo método 2 de conjugação, liofilizado e radiomarcado com alta atividade de Lu-177 (2 mg / 1.400 MBq; 740 $\mathrm{MBq} / \mathrm{mg})$. Em (A), resultados da estabilidade após armazenamento por 24 horas à $-20^{\circ} \mathrm{C}$, seguido de armazenamento por 6 horas a $2-8^{\circ} \mathrm{C}$ e em (B), após armazenamento por 48 horas à $-20^{\circ} \mathrm{C}$, seguido de armazenamento por 6 horas a $2-8{ }^{\circ} \mathrm{C}$. Resultados obtidos por CCD e expressos em média \pm DP $(\mathrm{N}=2)$.

FIGURA 57 - Imunorreatividade após a liofilização do anti-CD20 conjugado pelos dois métodos de conjugação $(\mathrm{N}=3)$. 186

FIGURA 58 - Comparação da pureza radioquímica obtida após a radiomarcação de 2 mg de AcM conjugado pelo método 1 e radiomarcado com $1.480 \mathrm{MBq}$ de Lu-177 (740 MBq/mg). Radiomarcações realizadas com o imunoconjugado não liofilizado $(\mathrm{N}=5)$ e liofilizado $(\mathrm{N}=2)$. Resultados expressos em média $\pm \mathrm{EPM}$. 188

FIGURA 59 - Comparação da pureza radioquímica obtida após a radiomarcação de $2 \mathrm{mg}$ de AcM conjugado pelo método 2 e radiomarcado com $1.480 \mathrm{MBq}$ de $\mathrm{Lu}-177$ (740 MBq/mg). Radiomarcações realizadas com o imunoconjugado não liofilizado $(\mathrm{N}=5)$ e liofilizado $(\mathrm{N}=2)$. Resultados expressos em média \pm EPM. 


\section{LISTA DE ABREVIATURAS}

\begin{tabular}{|c|c|}
\hline$\alpha$ & Constante de distribuição; radiação alfa \\
\hline$\beta$ & Constante de eliminação; radiação beta \\
\hline $\boldsymbol{\gamma}$ & Radiação gama \\
\hline$\% \mathrm{Al}$ & Porcentagem de atividade injetada \\
\hline$\% \mathrm{Al} / \mathrm{g}$ & Porcentagem de atividade injetada por grama de tecido \\
\hline$\mu \mathrm{Ci}$ & Micro currie \\
\hline$\mu g$ & Micrograma \\
\hline$\mu L$ & Microlitro \\
\hline$\mu \mathrm{M}$ & Micromolar \\
\hline AAIII & Arsenazo III \\
\hline Abs & Absorbância \\
\hline Ac & Anticorpo \\
\hline AcM & Anticorpo monoclonal \\
\hline AcMs & Anticorpos moniclonais \\
\hline ACM:DOTA & Razão molar anticorpo monoclonal: quelante \\
\hline $\mathrm{Ag}$ & Antígeno \\
\hline ANVISA & Agência Nacional de Vigilância Sanitária \\
\hline Anti-CD20-DOTA & Anticorpo monoclonal anti-CD20 conjugado com DOTA-NHS éster \\
\hline Anti-CD20-DOTA- ${ }^{177}$ Lu & Anticorpo monoclonal anti-CD20 conjugado com DOTA-NHS éster \\
\hline AUC & Área sob a curva \\
\hline CB & Centro de Biotecnologia \\
\hline CCD & Cromatografia de camada delgada \\
\hline cpm & Contagens por minuto \\
\hline CHOP & Ciclofosfamida, hidroxirubicina, oncovin e prednisona \\
\hline CL & Depuração \\
\hline CLAE & Cromatografia líquida de alta eficiência \\
\hline CQMA & Centro de Química e Meio Ambiente \\
\hline CR & Centro de Radiofarmácia \\
\hline DNA & Ácido desoxirribonucléico \\
\hline DOTA & Ácido 1,4,7,10-tetraazaciclododecano-1,4,7,10-tetracético \\
\hline DP & Desvio padrão \\
\hline DTPA & Ácido dietileno-triamino-pentacético \\
\hline DSC & Differential Scanning Calorimetry \\
\hline EGF & Fator de crescimento epidérmico \\
\hline EPM & Erro padrão da média \\
\hline EQ. & Equação \\
\hline FCF/USP & Faculdade de Ciências Farmacêuticas da Universidade de São Paulo \\
\hline FDA & Food and Drug Administration \\
\hline FDG & Fluordesoxiglicose \\
\hline $\mathbf{F I}$ & Fração imunorreativa \\
\hline$g$ & Força centrífuga \\
\hline g & Grama \\
\hline
\end{tabular}




\begin{tabular}{|c|c|}
\hline $\mathrm{g} / \mathrm{mol}$ & grama (s) por mol \\
\hline Gly & Glicina \\
\hline h & Hora (s) \\
\hline HAMA & Human anti-mouse-antibodies \\
\hline $\mathrm{HCl}$ & Ácido clorídrico \\
\hline HIV/AIDS & Síndrome da imunodeficiência adquirida \\
\hline Ig & Imunoglobulina \\
\hline IgA & Imunoglobulina do tipo A \\
\hline IgM & Imunoglobulina do tipo M \\
\hline IgG & Imunoglobulina do tipo G \\
\hline INP & Imediato não purificado \\
\hline IP & Imediato purificado \\
\hline INCA & Instituto Nacional do Câncer \\
\hline IPEN & Instituto de Pesquisas Energéticas e Nucleares \\
\hline ITLC-SG & Suporte cromatográfico para cromatografia em camada delgada \\
\hline $\mathrm{K}_{\mathrm{a}}$ & Constante de afinidade celular \\
\hline KDa & Kilo Dalton \\
\hline$K_{\mathrm{el}}$ & Constante de eliminação do organismo \\
\hline kg & Quilograma \\
\hline $\mathbf{L}$ & Litros \\
\hline LNH & Linfoma não-Hodgkin \\
\hline M & Molar \\
\hline Ma & Manitol \\
\hline $\mathrm{MBq}$ & Mega Becquerel \\
\hline $\mathrm{MBq} / \mathrm{mg}$ & Mega Becquerel por miligrama \\
\hline $\mathrm{mCi}$ & Mili curiie \\
\hline mg & Miligrama \\
\hline $\mathrm{mg} / \mathrm{mL}$ & Miligramas por mililitro \\
\hline $\mathrm{mL}$ & Mililitro \\
\hline $\min$ & Minuto (s) \\
\hline$n, \mathbf{N}$ & Número \\
\hline $\mathrm{NaCl}$ & Cloreto de sódio \\
\hline nd & Não determinado \\
\hline NHS & N-hidroxilsuccinamida \\
\hline ng & nanograma \\
\hline nmol & Nanomol \\
\hline $\mathrm{nm}$ & nanometros \\
\hline $\mathrm{Pb}$ & Chumbo \\
\hline PBS & Tampão fosfato-salina \\
\hline PET & Tomografia computadorizada por emissão de pósitrons \\
\hline pH & Potencial hidrogeniônico \\
\hline $\mathbf{Q}$ & Quelante \\
\hline $\mathbf{R}_{\mathbf{f}}$ & Fator de retenção \\
\hline RID & Radioimunodiagnóstico \\
\hline RIT & Radioimunoterapia \\
\hline rpm & Rotações por minuto \\
\hline Sa & Sacarose \\
\hline SBCAL & Sociedade Brasileira de Ciência em Animais de Laboratório \\
\hline SFB & Soro fetal bovino \\
\hline SPECT & Tomografia computadorizada por emissão de fóton único \\
\hline
\end{tabular}


$t 1 / 2$

$t 1 / 2 E$

$t^{1} / 2 \alpha$

$t_{1 / 2} \beta$

TLC-SG

$T_{c}$

$T_{\text {cris }}$

$\mathbf{T}_{\mathrm{g}}$

$\mathbf{T}_{\mathrm{m}}$

TR

USP

UV

$\mathbf{v} / \mathbf{v}$

Vd
Meia vida

Meia vida efetiva

Meia-vida de distribuição

Meia-vida de eliminação

Suporte cromatográfico para cromatografia em camada delgada

Temperatura de colapso

Temperatura de cristalização

Temperatura de transição vítrea

Temperatura de fusão

Tempo de retenção

Universidade de São Paulo

Ultra violeta

Volume por volume

Volume de distribuição 


\section{1 \\ INTRODUÇÃO}

Os anticorpos monoclonais (AcMs) têm sido amplamente explorados como agentes terapêuticos contra o câncer desde o seu desenvolvimento inicial, quando Kohler e Milstein em meados de 1970, fundiram com sucesso células imortalizadas de mieloma com linfócito $B$ produtor de anticorpo ${ }^{1,2}$. Em contraste com a quimioterapia, os anticorpos possuem suficiente especificidade pelo antígeno e se ligam preferencialmente às células tumorais ao invés dos tecidos sadios. Esta especificidade promove a morte de células alvo malignas e poupam relativamente o tecido normal ${ }^{1}$.

O rituximabe é um anticorpo anti-CD20 aprovado pelo Food and Drug Administration (FDA) que mostrou efeito antitumoral quando usado como agente único ou em combinação com uma variedade de regimes quimioterapêuticos ${ }^{3}$. É um anticorpo monoclonal quimérico (murínico-humano), o qual se liga seletivamente com alta afinidade ao antígeno CD20, uma proteína transmembranar hidrofóbica que é expressa em linfócitos $B$ e em mais de $90 \%$ das células B de Linfoma não-Hodgkin (LNH) ${ }^{4,5}$.

Com o objetivo de aumentar o efeito citotóxico, radionuclídeos têm sido conjugados aos AcMs para radioimunoterapia (RIT). A RIT permite a entrega seletiva da radiação ao alvo de interesse, enquanto poupa o tecido normal ${ }^{6}$. Ela combina o efeito biológico dos anticorpos com os mecanismos radiolíticos para destruir as células tumorais. Além disso, o efeito de fogo cruzado da radiação $\beta^{-}$pode destruir células vizinhas que não expressam o antígeno alvo do anticorpo ou que são pobremente vascularizadas ${ }^{7}$.

Atualmente, apenas um anticorpo radiomarcado está disponível para o tratamento de LNH de baixo grau ou LNH folicular: Zevalin ${ }^{\circledR}$ que é composto pelo AcM ibritumomabe, de origem murínica, radiomarcado $\operatorname{com}^{90} \mathrm{Y}^{3}$. Ele é indicado para o tratamento de pacientes com LNH de baixo grau, folicular ou de células B transformadas que 
sejam resistentes ou reincidentes, incluindo pacientes com LNH folicular rituximaberesistente ${ }^{6}$.

A radioimunoterapia tem se mostrado uma modalidade terapêutica promissora, especialmente para terapia de tumores hematológicos o que tem impulsionado o desenvolvimento deste tipo de radiofármaco. Muitos trabalhos utilizam anticorpos monoclonais já disponíveis no mercado e muitas vezes já utilizados em imunoterapia. É possível citar o trastuzumabe ${ }^{8}$ e pertuzumabe ${ }^{9}$ para tratamento de câncer de mama, o cetuximabe ${ }^{10}$ e nimotuzumabe ${ }^{11}$ para tratamento de tumores que expressam receptores para o fator de crescimento epidérmico (EGFR), como o câncer coloretal. Muitos desses trabalhos apresentaram resultados animadores.

A marcação de anticorpos monoclonais com radionuclídeos metálicos é possível geralmente pelo uso de agentes quelantes bifuncionais, que possuem uma porção reativa para ligação covalente às proteínas e uma porção capaz de se ligar fortemente ao radiometal, formando assim, um complexo fisiologicamente estável. Tal estabilidade in vivo é desejável para radioimunocintilografia (ou radioimunodiagnóstico - RID) e RIT, a fim de reduzir os danos da radiação e toxicidade aos órgãos e tecidos normais. Uma classe de agentes quelantes que tem se mostrado promissora para aplicações com anticorpos monoclonais são os derivados de DOTA (ácido 1,4,7,10-tetraazaciclododecano-1,4,7,10tetracético) ${ }^{12}$.

A conjugação de anticorpos monoclonais ao DOTA normalmente envolve uma técnica de múltiplas etapas ${ }^{12}$. Além disto, existem dificuldades na radiomarcação de anticorpos conjugados, devido à lenta taxa de formação de complexos metálicos com o DOTA e da presença de vestígios de metais (contaminantes), que podem competir com o radiometal, interferindo diretamente na eficiência da radiomarcação ${ }^{12}$.

O desenvolvimento, portanto, de um radioimunoconjugado requer cuidados em suas diversas etapas, além de ser oneroso. Talvez por este motivo, ainda não tenhamos no Brasil nenhum radioimunoconjugado disponível para tratamento ou diagnóstico de doenças. Pensando nesta necessidade nacional, o Instituto de Pesquisas Energéticas e Nucleares (IPEN), maior desenvolvedor e produtor de radiofármacos no país, deseja por intermédio deste trabalho, disponibilizar à sociedade um radioimunoconjugado que contribua com o tratamento de LNH. Além de desenvolver uma metodologia sólida que contribua com o 
desenvolvimento de outros radioimunoconjugados potencialmente destinados ao diagnóstico e terapia de diversas doenças. 
Neste capítulo apresentam-se os objetivos gerais e específicos deste trabalho.

\subsection{OBJETIVO GERAL}

Desenvolver no IPEN a metodologia de produção de um radioimunoconjugado por meio da conjugação do anticorpo monoclonal anti-CD20 (rituximabe) ao quelante bifuncional DOTA-NHS-éster, contribuindo para o desenvolvimento de outros radioimunoconjugados nacionais.

Para o radiofármaco objeto deste estudo, pretendeu-se ainda caracterizar suas propriedades in vivo e in vitro e desenvolver a formulação de um produto liofilizado para a radiomarcação com ${ }^{177} \mathrm{Lu}$.

\subsection{OBJETIVOS ESPECÍFICOS}

Aperfeiçoar a reação de conjugação do quelante DOTA-NHS-éster ao rituximabe de forma a preservar a imunorreatividade do anticorpo e garantir rendimento de marcação satisfatório;

Aperfeiçoar as condições de radiomarcação do imunoconjugado com o ${ }^{177}$ Lu de modo a obter alta pureza radioquímica;

$\checkmark$ Estudar a estabilidade do anti-CD20-DOTA- ${ }^{177} \mathrm{Lu}$;

$\checkmark$ Analisar a biodistribuição e farmacocinética do anti-CD20-DOTA- ${ }^{177} \mathrm{Lu}$;

$\checkmark$ Desenvolver um imunoconjugado liofilizado para radiomarcação com ${ }^{177} \mathrm{Lu}$. 


\section{REVISÃO BIBLIOGRÁFICA}

Neste capítulo apresenta-se a revisão bibliográfica aplicada ao presente trabalho.

\subsection{RADIOFARMÁCIA E MEDICINA NUCLEAR}

A Radiofarmácia é uma ciência essencial para a Medicina Nuclear (MN), pois se encarrega de desenvolver, produzir e dispensar os radiofármacos, que são o instrumento primário da MN. Radiofármacos são preparações farmacêuticas com finalidade diagnóstica ou terapêutica que, quando prontas para o uso, contêm um ou mais radionuclídeos ${ }^{13}$.

Os radiofármacos fornecem a fisiologia, bioquímica ou a patologia do corpo sem causar nenhuma perturbação ou função (efeito farmacológico). Eles são referidos como radiotraçadores porque são administrados em doses sub-farmacológicas para "marcar" um processo patológico ou fisiológico no corpo ${ }^{14}$.

O elemento radioativo ou radionuclídeo é a matéria prima principal da composição de um radiofármaco, podendo emitir diferentes tipos de radiação como as particuladas (partícula $\alpha$ ou $\beta$ ) ou emissão de raio $X$ ou gama $(\gamma)^{15}$. Emissores de pósitron $\left(\beta^{+}\right)$e gama são usados para fins diagnósticos, ao passo que emissores alfa e beta $\left(\beta^{-}\right)$são para fins terapêuticos, pois possuem uma maior capacidade de causar lesão às células ${ }^{15}$. Os radionuclídeos comumente utilizados na clínica são produzidos artificialmente. De maneira geral, as formas de obtenção são por:

a) bombardeamento de alvos estáveis com nêutrons, normalmente em reatores nucleares;

b) bombardeamento com partículas positivamente carregadas, normalmente em aceleradores de partículas (cíclotrons); 
c) fissão nuclear de nuclídeos pesados, após bombardeamento com nêutrons ou partículas $^{16}$.

Algumas características são desejáveis a um radiofármaco tais como fácil disponibilidade e custo razoável de produção; biodistribuição adequada para atingir o tecido alvo e promover uma alta relação órgão alvo:órgão não alvo; ausência de toxicidade e efeitos secundários; atividade específica alta. Além disso, o tipo, a energia e a meia-vida física do elemento radioativo devem ser compatíveis com a aplicação desejada ${ }^{15}$.

Em Medicina Nuclear, as imagens são obtidas por meio da administração de radiofármacos seguida da medida da radiação emitida, que atravessa o organismo. Já as técnicas radiológicas convencionais, medem a absorção da radiação aplicada externamente.

Os procedimentos realizados em MN, em sua maioria, são diagnósticos, mas a utilização de radiofármacos em terapia vem crescendo consideravelmente, particularmente na área de oncologia. Atualmente, o ${ }^{99 m}$ Tc é utilizado em cerca de $90 \%$ de todos os procedimentos diagnósticos, enquanto que o ${ }^{131}$ I está presente em aproximadamente $97 \%$ de todos os procedimentos terapêuticos ${ }^{17}$. Em oncologia, as aplicações da MN incluem a deteç̧ão e caracterização da lesão primária, o estadiamento, tratamento do câncer e controle da resposta terapêutica ${ }^{18}$.

\subsection{NEOPLASIAS: CONCEITOS GERAIS}

O termo neoplasia significa "novo crescimento". O termo tumor foi originalmente aplicado ao edema causado pela inflamação, mas o uso não neoplásico de tumor praticamente desapareceu; portanto o termo se iguala a neoplasia ${ }^{19}$.

As neoplasias podem ser classificadas como benignas e malignas. Esta classificação deve sempre partir de critérios morfológicos macro e microscópicos ${ }^{20}$.

Um tumor benigno apresenta características micro e macroscópicas que o classificam como "inocentes", isto significa que ele permanece localizado, não consegue se disseminar para outros sítios e geralmente pode ser removido por cirurgia local. De modo simplificado, eles tendem a se apresentar como massas teciduais de crescimento lento e expansivo, comprimindo e não propriamente infiltrando o tecido vizinho. Além disso, 
possuem aspecto circunscrito, capsulado ou pseudocapsulado e com limites facilmente identificáveis. Nestes casos, o paciente geralmente sobrevive ${ }^{19,20}$.

Os tumores malignos são referidos coletivamente como cânceres. Quando se aplica o termo maligno a um neoplasma, significa dizer que a lesão pode invadir e destruir as estruturas adjacentes e se disseminar para sítios distantes, levando à morte ${ }^{19}$.

Estas disseminações do tumor são chamadas de metástases. As células tumorais malignas são muito invasivas, penetrando nos vasos sanguíneos, linfáticos e nas cavidades corpóreas, promovendo a oportunidade de disseminação ${ }^{19}$.

Acima de tudo, o câncer é uma doença da expressão descontrolada de genes, por isso é considerada uma doença genética. O ser humano está vivendo mais e devido à industrialização, está se expondo mais a uma crescente lista de agentes potencialmente mutagênicos e carcinogênicos. Isto explicaria, em parte, a incidência cada vez maior da doença $^{21}$.

\subsubsection{Linfoma não - Hodgkin}

Linfomas são transformações neoplásicas de células linfoides normais que residem predominantemente em tecidos linfoides. São morfologicamente divididos em Linfoma de Hodgkin (LH) e Linfoma não - Hodgkin (LNH) ${ }^{22}$.

Os LNH representam um grupo amplo e heterogêneo de neoplasias linfoides e podem ser divididos em indolentes (baixo grau) e agressivos (alto grau). Os indolentes, que correspondem a $40 \%$ dos diagnósticos, possuem baixo índice de proliferação celular, células de tamanho pequeno, formação de grandes massas linfonodais, envolvimento frequente de medula óssea e de sítios extranodais. Paradoxalmente, são tumores de baixa agressividade, com sobrevida de anos mesmo sem tratamento específico, mas geralmente são incuráveis. Por outro lado, linfomas de alto grau, que representam $60 \%$ dos diagnósticos, apresentam alto índice de proliferação celular, células grandes, linfonodomegalias localizadas e como possuem alta agressividade, levam a óbito rapidamente se não tratados, no entanto, são curáveis $^{22-24}$.

Em 2012, foram estimados cerca de 390 mil casos novos e 199 mil óbitos por LNH no mundo ${ }^{25}$. Nos Estados Unidos, este é o tumor hematológico mais comum e estimase que represente aproximadamente $5 \%$ de todos os cânceres diagnosticados no país em 
2014. Para este mesmo ano, cerca de 71.000 novos casos de LNH foram estimados no país 23

No Brasil, ele é a décima terceira neoplasia mais comum e estimam-se 4.940 casos novos de LNH em homens e 4.850 em mulheres para o ano de 2014. Tais valores correspondem a um risco estimado de 5,04 casos novos a cada 100 mil homens e 4,77 a cada 100 mil mulheres ${ }^{25}$.

A incidência de cada tipo de LNH varia entre as populações. A América do Norte, Austrália/ Nova Zelândia e algumas partes da Europa possuem as mais altas taxas de incidência desse tipo de câncer ${ }^{25}$. Os subtipos de LNH associados etiologicamente a infecções virais ocorrem com maior frequência nas regiões endêmicas para a infecção viral, como por exemplo, o linfoma de Burkitt que é associado ao vírus Epstein-Barr, é mais frequente na África Equatorial. No geral, homens e indivíduos da raça branca têm maior incidência da maioria dos subtipos de $\mathrm{LNH}^{26}$.

Esta é uma neoplasia em que a incidência aumenta com a idade, e uma vez que a média de vida da população está ficando maior, o número de casos vêm aumentando cerca de $4 \%$ ao ano. A razão deste aumento não é clara, mas acredita-se estar relacionado a fatores ambientais ${ }^{25,27}$. Alguns estudos demonstram aumento de risco em fazendeiros e agricultores, além de pessoas com a exposição de herbicidas e solventes orgânicos. Também há uma associação, questionável, com a dieta e alguns estudos relacionam a alta ingestão de carne e gordura, como um fato de risco ${ }^{26}$.

Além disso, existe uma associação entre o desenvolvimento desse câncer e a função imune alterada. Com isso, pessoas transplantadas que receberam tratamento com imunossupressores para prevenção de rejeição do transplante, indivíduos portadores de doenças autoimunes, tais como atrite reumatoide, psoríase e síndrome de Sjögren possuem um maior risco para o desenvolvimento de LNH. Há também subtipos de LNH associados a agentes infecciosos, tais como vírus da imunodeficiência adquirida (IDA), hepatite C, vírus Tlinfotrópico humano, herpes vírus humano tipo 8, Epstein-Barr ${ }^{25,} 26$.

Muitos protocolos de tratamento podem der usados contra o LNH, mas a escolha depende do subtipo de LNH e do estágio em que se encontra a doença, bem como de outros fatores prognósticos. Os principais tipos de tratamento são a quimioterapia, a imunoterapia, 
a radioimunoterapia, o transplante de células tronco e, em alguns casos, a cirurgia também é usada ${ }^{24}$.

\subsection{IMUNOTERAPIA DO CÂNCER}

Os seres humanos possuem milhões de moléculas de imunoglobulina (Ig) diferentes. Elas fornecem ao corpo uma vasta diversidade imunológica. Cada Ig exibe um grau de especificidade para um epítopo em particular. Se um clone específico para um epítopo é isolado e reproduzido, têm-se uma população de anticorpos monoclonais (AcMs) em que cada Ig desta população se liga ao mesmo epítopo ${ }^{28}$.

Os AcMs vêm de encontro com a ideia de "comprimidos mágicos" (do inglês, magic bullets). Segundo Wright e Lapi (2013), este conceito foi sugerido pela primeira vez por Paul Ehrlich há mais de um século atrás. Ele teorizou que se um composto pudesse marcar uma doença de forma seletiva, então aquele composto poderia ser combinado com um agente terapêutico para tratar a doença. Este conceito inspirou muitas drogas tanto para tratamento quanto para detecção de diversas doenças ${ }^{29}$.

A produção de AcM e, portanto o uso destes "comprimidos mágicos" em terapia do câncer tem sido explorado a partir de 1970, graças ao desenvolvimento da tecnologia do hibridoma ${ }^{1}$. Em poucas palavras, esta tecnologia consiste em fundir um linfócito $B$ isolado produtor de um anticorpo monoespecífico (AcM) com células transformadas de mieloma, resultando em células híbridas com suas características imortalizadas. Estas células podem ser cultivadas in vitro para produzir grandes quantidades do anticorpo monoespecífico ${ }^{2}$.

Estes linfócitos B específicos são gerados por meio da imunização de camundongos, produzindo assim um anticorpo monoclonal murínico. Isto faz com que muitos pacientes desenvolvam uma resposta imunológica a estas proteínas murínicas, comprometendo sua utilização em certas aplicações ${ }^{30}$. Em cerca de $30 \%$ dos pacientes, uma simples administração do AcM murínico pode estimular o sistema imune a produzir anticorpos contra o agente terapêutico ${ }^{30,31}$. Esta resposta imune à AcM murínicos chama-se resposta HAMA (do inglês Human anti-mouse antibodies) e ela destroi os AcM administrados em doses subsequentes. Na prática a eficácia terapêutica dos AcM murínicos é limitada à primeira ou no máximo à segunda administração ${ }^{2,30}$. Além da resposta HAMA, as sequências não humanas dos AcMs provocavam reações do tipo alérgicas e estas consistiam 
no principal efeito colateral observado ${ }^{32}$.

A partir de 1980, o advento da tecnologia do DNA recombinante permitiu reduzir a imunogenicidade destes anticorpos murínicos ${ }^{31}$. Desde então se iniciou o desenvolvimento de AcMs quiméricos e humanizados. Os AcM quiméricos são construídos combinando-se os domínios $V$, que são responsáveis pela ligação ao antígeno e localizados na porção Fab (do inglês antigen-binding fragments), de AcM murínicos com os domínios C, localizados na cadeia constante $(\mathrm{Fc})$, de moléculas IgG humanas. AcM humanizados possuem apenas os resíduos de aminoácidos dos domínios $\mathrm{V}$ de origem murínica, já que estes estão envolvidos no reconhecimento do antígeno ${ }^{30}$.

Com o desenvolvimento de AcMs quiméricos, a chance de induzir uma resposta alérgica diminuiu significativamente em comparação aos AcM murínicos, mas mesmo assim continua sendo um efeito colateral significativo. O rituximabe, um dos AcM quiméricos amplamente utilizados, produz reações alérgicas agudas em 20 a 30\% dos pacientes e há ainda a incidência de febre, arrepios, erupções cutâneas, hipotensão e angioedema em até $75 \%$ dos casos. Contudo, menos de $1 \%$ dos pacientes apresentam reações alérgicas graves (choque anafilático) que impossibilitam o uso recorrente do $\mathrm{AcM}^{32}$.

A nomenclatura padrão para os AcM segue as seguintes regras: o sufixo genérico para nomear um AcM é "mab". AcM murínicos são "momab"; as moléculas quiméricas são "ximab" e as moléculas humanizadas são "zumab". Quando o AcM é direcionado a um antígeno tumoral, utiliza-se a sílaba "tu" antes do sufixo (tumomab, tuximab e tuzumab) ${ }^{3}$.

Diferentemente da quimioterapia e, até certo ponto da radioterapia, os AcM se ligam especificamente às células tumorais e esta especificidade promove a morte de células malignas enquanto perserva os tecidos normais ${ }^{1}$.

Após a ligação de um AcM ao seu receptor várias respostas são induzidas e irão conduzir à morte celular e, embora mais de um mecanismo de ação seja exercido por um determinado AcM, os principais são a citotoxicidade mediada por células dependentes de anticorpo (CCDA) e a citotoxicidade dependente do complemento (CDC), que serão detalhados mais adiante.

Os AcMs revolucionaram a terapia de câncer e de 1997 até 2014, o FDA aprovou quatorze imunoterápicos contra o câncer. Destes, dez são administrados como agente único, dois são conjugados a drogas e dois são conjugados a radioisótopos ${ }^{33}$. Na TABELA 1 são 
apresentados os quatorze AcMs aprovados pelo FDA até 2014.

TABELA 1 - Anticorpos monoclonais aprovados pelo FDA para tratamento oncológico. Adaptado de Glassman e Balthasar, $2014^{33}$ e Kitson et al. $2013^{34}$.

\begin{tabular}{|c|c|c|c|c|}
\hline NOME DA DROGA & $\begin{array}{c}\text { ANO DE } \\
\text { APROVAÇÃO }\end{array}$ & TIPO & ALVO & $\begin{array}{l}\text { INDICAÇÕES DE } \\
\text { TERAPIA }\end{array}$ \\
\hline $\begin{array}{l}\text { Ibritumomab- }{ }^{131} \text { I } \\
\left(\text { Bexxar }^{\oplus}\right)\end{array}$ & 2003 & Murínico & CD20 & $\begin{array}{c}\text { LNH, LCB, LDGCB, LH e } \\
\text { MM }\end{array}$ \\
\hline $\begin{array}{l}\text { Ibritumomabe- } \\
\text { tiuxetan- }{ }^{90} Y /{ }^{111} \text { In } \\
\left(\text { Zevalin }{ }^{\circledast}\right)\end{array}$ & 2002 & Murínico & CD20 & $\begin{array}{c}\text { LNH, LCB, LDGCB, LF, } \\
\text { linfoma da célula do } \\
\text { manto }\end{array}$ \\
\hline $\begin{array}{c}\text { Trastuzumabe } \\
\text { Emtansine }\left(\text { Kadcyla }^{\circledR}\right)\end{array}$ & 2013 & Humanizado & HER2 & $\begin{array}{l}\text { Câncer de mama } \\
\text { metastático HER2 } \\
\text { positivo }\end{array}$ \\
\hline $\begin{array}{l}\text { Pertuzumabe } \\
\left.\text { (Perjecta }{ }^{\circledR}\right)\end{array}$ & 2012 & Humanizado & HER2 & Câncer de mama \\
\hline $\begin{array}{c}\text { Brentuximabe Vedotin } \\
\left.\text { (Adcetris }{ }^{\circledR}\right)\end{array}$ & 2011 & Quimérico & CD30 & $\begin{array}{l}\text { LH, linfoma anaplásico } \\
\text { de grandes células }\end{array}$ \\
\hline Ipilimumabe (Yervoy ${ }^{\circledR}$ ) & 2011 & Humano & CTLA-4 & Melanoma metastático \\
\hline $\begin{array}{l}\text { Ofatumumabe } \\
\left.\text { (Arzerra }{ }^{\circledR}\right)\end{array}$ & 2009 & Humano & CD20 & LLC \\
\hline $\begin{array}{l}\text { Panitumumabe } \\
\left(\text { Vectibix }^{\oplus}\right)\end{array}$ & 2004 & Humano & EGFR & Câncer colorretal \\
\hline Cetuximabe $\left(\right.$ Erbitux $\left.^{\circledR}\right)$ & 2004 & Quimérico & EGFR & Câncer colorretal \\
\hline $\begin{array}{l}\text { Bevacizumabe } \\
\quad\left(\text { Avastin }^{\circledast}\right)\end{array}$ & 2004 & Humanizado & VEGF-A & Câncer colorretal \\
\hline $\begin{array}{l}\text { Alemtuzumabe } \\
\left.\text { (Campath }{ }^{\circledR}\right)\end{array}$ & 2001 & Humanizado & CD52 & LLC, LMA, EM \\
\hline $\begin{array}{l}\text { Gemtuzumabe } \\
\left.\text { (Mylotarg }{ }^{\circledR}\right)\end{array}$ & 2000 & $\begin{array}{l}\text { Caliquemicina } \\
\text { conjugada ao IGg4 } \\
\text { humanizado }\end{array}$ & CD33 & LMA \\
\hline $\begin{array}{l}\text { Trastuzumabe } \\
\left.\text { (Herceptin }^{\circledR}\right)\end{array}$ & 1998 & Humanizado & HER2 & Câncer de mama \\
\hline Rituximabe (Rituxan ${ }^{\circledR}$ ) & 1997 & Quimérico & CD20 & LNH, LCB, LLC \\
\hline
\end{tabular}

LH = Linfoma de Hodgkin; LLC = Leucemia linfocítica crônica; LMA = Leucemia mieloide aguda; LNH = Linfoma não-Hodgkin; $\mathbf{L C B}=$ linfoma de células $B ; \mathbf{L F}=$ linfoma folicular; $\mathbf{L D G C B}=$ linfoma difuso de grandes células $B$; $\mathbf{M M}=$ mieloma múltiplo; $\mathbf{E M}$ = esclerose múltipla.

No Brasil, todos estes AcMs não radiomarcados possuem registro na Agência Nacional de Vigilância Sanitária (ANVISA) e podem ser comercializados, exceto o Gemtuzumabe (Mylotarg ${ }^{\circledR}$ ) que teve seu registro vencido em março de $2011^{35}$.

Contudo, nenhum dos radioimunoconjugados possui registro na ANVISA ${ }^{35}$. Isto representa uma perda muito grande na opção terapêutica de alguns tumores. E neste aspecto ressalta-se a importância do desenvolvimento de uma tecnologia nacional de 
produção de radioimunoconjugados com o intuito de ampliar a opção terapêutica do paciente/médico além de reduzir os custos com importação destes radiofármacos pelo Ministério da Saúde.

Dentre todos os AcMs não radiomarcados citados, destaca-se, para este trabalho, o rituximabe.

\subsubsection{Rituximabe}

O rituximabe foi o primeiro AcM aprovado pelo FDA para terapia de neoplasias de células B CD20 positivas, como o LNH indolente de células B e a leucemia linfocítica crônica. No entanto, seu uso se expandiu consideravelmente e hoje ele também é usado no tratamento de doenças autoimunes ${ }^{27,36}$. No Brasil, ele é comercializado pela Roche sob o nome fantasia de MabThera ${ }^{\circledR}$.

O CD20 é um marcador celular de células B que é expresso durante a diferenciação das células pró-B em células $B$. Na membrana celular ele é muito estável e não sofre mudança, modulação ou internalização após se ligar ao anticorpo ${ }^{36,37}$. Ele também está presente em $90 \%$ das células B malignas de LNH e em cerca de metade dos casos de leucemia linfoblástica aguda. Sua função precisa ainda não é conhecida, mas aparentemente ele desempenha um papel importante na ativação, diferenciação e crescimento das células B 37.

O sucesso do rituximabe provém de diversos fatores, um dos quais é devido a sua estrutura quimérica. Ele preserva as regiões responsáveis pela ligação ao receptor com origem murínica, mas sua porção Fc é de origem humana. Esta estrutura desencadeia menos reação HAMA no paciente e a meia vida do anticorpo é prolongada, devido à presença da porção Fc de origem humana. Além disto, esta porção contém os aspectos efetores da molécula, incluindo a ativação do complemento e atração de células citotóxicas, portanto, a porção Fc humana é mais efetiva em ativar estes efetores em humanos ${ }^{27}$.

Muitos mecanismos de ação do rituximabe têm sido propostos e avaliados in vitro, mas o mecanismo exato ou predominante in vivo permanece desconhecido ${ }^{25}$. Esses estudos in vitro demonstraram que o rituximabe é capaz de lisar células CD20 positivas por meio dos seguintes mecanismos: 
a) Citotoxicidade mediada por células dependentes de anticorpo (CCDA): envolve a união de um anticorpo e seu receptor de membrana e reconhecimento dos receptores Fc por células "Natural Killers", eosinófilos e neutrófilos. Posteriormente, há a indução de eventos celulares que levam à lise celular ${ }^{32}$.

b) Citotoxicidade dependente do complemento $(C D C)$ : envolve a ligação de um anticorpo à uma proteína do complemento, posteriormente desencadeando a via do complemento com a criação subsequente dos complexos do complemento na membrana externa e lise celular ${ }^{32}$.

c) Efeitos diretos induzidos pela ligação do AcM ao receptor tais como: inibição do crescimento, alteração no ciclo celular e apoptose ${ }^{38}$.

d) Sensibilização a quimioterápicos convencionais: algumas evidências de sinergismo e efeitos aditivos têm sido reportadas in vitro. Já em pacientes, estudos sugerem aumento da atividade clínica quando o rituximabe é administrado em combinação com a quimioterapia convencional ${ }^{36,38}$.

A eliminação do AcM é provavelmente pelo sistema reticuloendotelial via fagocitose e metabolismo. A meia vida ( $\mathrm{t} 1 / 2$ ) do rituximabe aumenta conforme o número de doses administradas; uma dose inicial de $375 \mathrm{mg} / \mathrm{m}^{2}$ produz uma t $1 / 2$ média de 60 horas; aumentando para 174 horas após a quarta dose. É possível detectá-lo no soro de 3 a 6 meses após a última infusão ${ }^{1,39}$.

O rituximabe é menos efetivo em LNH agressivos e por este motivo muitos protocolos o combinam com a quimioterapia convencional (CHOP - ciclofosfamida, hidroxirubicina, oncovin e prednisona) ${ }^{1,40}$.

Em 2002, Coiffer e colaboradores, publicaram um estudo comparando a quimioterapia CHOP com a CHOP associada ao rituximabe em pacientes idosos (60 a 80 anos) portadores de linfoma difuso de células B grandes sem tratamento prévio. A taxa de resposta completa foi significativamente maior para os pacientes tratados com $\mathrm{CHOP}+$ rituximabe (73\%) comparada aos que receberam apenas o tratamento convencional (63\%) 41.

Todavia, um trabalho publicado em 2015 por Jia e colaboradores, que avaliaram 140 pacientes portadores de linfoma difuso de células B grandes sem tratamento prévio, não apresentou os mesmos resultados. Os pesquisadores fizeram esta avaliação entre 2003 e 2009 e dividiram os pacientes em dois grupos: (1) 78 pacientes foram tratados com CHOP + 
rituximabe e (2) 62 pacientes foram tratados apenas com CHOP. Destes pacientes, 91 receberam radioterapia após a quimioterapia. Eles obtiveram taxa de resposta completa de 77\% em ambos os grupos e após um acompanhamento de 56 meses, todos apresentaram 5 anos de sobrevida global. Com este trabalho eles concluíram que a CHOP sozinha pode ser tão efetiva quando a CHOP + rituximabe, no entanto, a radioterapia poderá ser necessária ${ }^{42}$.

Um aspecto muito discutido sobre a terapia com rituximabe, é a resistência ao tratamento. Alguns pacientes desenvolvem mecanismos de resistência após o tratamento e ainda há aqueles que possuem resistência inata. Esta resistência inata pode ser explicada em partes, pelos diferentes níveis de expressão de CD20 nos diferentes tipos de $L N H$, além da diferenciação particular de cada indivíduo ${ }^{37,38}$.

A forma mais comum de demonstrar a resistência adquirida por pacientes é por meio de protocolos de re-tratamento. Somente $40 \%$ dos pacientes que responderam bem ao tratamento prévio com rituximabe, responderão ao re-tratamento e os mecanismos desta resistência são pouco conhecidos ${ }^{38}$. Uma das hipóteses, é que o tratamento diminui a expressão do antígeno CD20 na superfície das células ${ }^{43}$.

Para estes pacientes, a alternativa seria o tratamento com AcMs que se ligam a antígenos diferentes do CD20, e que também são expressos em células $B$ de LNH, como por exemplo, o $\operatorname{CD} 37^{43}$.

Além disso, estes pacientes são, sem dúvida alguma, fortes candidatos para o tratamento com radioimunoterapia, que será abordado a seguir.

\subsection{RADIOIMUNOTERAPIA DO CÂNCER}

Uma maneira potente de aumentar o poder citotóxico dos AcM é conjugá-los à radionuclídeos, formando radioimunoconjugados. A esta modalidade médica, dá-se o nome de Radioimunoterapia (RIT) ${ }^{6}$.

Comparada à radioterapia, a RIT possui a grande vantagem de ser capaz de atacar não somente o tumor primário, mas também as lesões metastáticas ${ }^{44}$. Além disto, o tratamento com RIT é simples da perspectiva do paciente e pode ser mais conveniente do que a quimioterapia convencional. Isto porque a RIT é aplicada em questão de minutos e como o protocolo de doses é espaçado, o paciente não precisa retornar à clínica/hospital 
várias vezes para novas seções ${ }^{45}$.

A seleção do antígeno de superfície ideal e do anticorpo a se ligar neste antígeno é crucial para o sucesso do programa terapêutico. O antígeno ideal para RIT é altamente expresso e possui uma densidade uniforme na superfície de todas as células tumorais enquanto que não se expressa em células normais ${ }^{45}$.

As células irradiadas absorvem uma grande quantidade de energia na forma de fótons ou cargas particuladas, o que promove um dano macromolecular direto, bem como a geração de espécies de hidrogênio e /ou oxigênio (radicais livres). Ambos, os radicais livres e o dano molecular, causam danos à cadeia de DNA e os danos incluem não somente apoptose, mas também necrose programada ${ }^{44,46}$.

Clinicamente, a RIT é mais comumente empregada no tratamento de linfomas e leucemias, pois os linfócitos são células extremamente radiossensíveis. Tumores sólidos são mais radiorresistentes e requerem uma dose depositada de radiação cerca de cinco ou dez vezes maior quando comparado com tumores hematológicos ${ }^{45}$.

Além disso, os tumores sólidos são caracterizados pela vascularização limitada, que pode causar captação heterogênea destes AcMs. Portanto, a RIT é mais adequada para tratamento de pequenos tumores, pois nestes tumores o anticorpo radiomarcado possui uma captação tumoral suficientemente alta capaz de induzir um efeito tumoricida mediado pela radiação ${ }^{47}$.

O avanço mais recente em RIT tem sido o desenvolvimento de métodos quantitativos para estimar a dose de radiação absorvida tanto no tumor quanto nos tecidos sadios. Esta é a base da individualização do tratamento por paciente e com isto, previne-se a toxicidade que é associada com a exposição excessiva à radiação. Este conceito fundamental é um exemplo de abordagem teranóstica ${ }^{45}$.

AcMs radiomarcados com radiometais como o ${ }^{90} \mathrm{Y}$ e ${ }^{177} \mathrm{Lu}$, exibem prolongada retenção no alvo, ao passo que AcM radioiodados são degradados após a endocitose liberando peptídeos e aminoácidos radioiodados ${ }^{6}$. 


\subsection{RADIOISÓTOPOS UTILIZADOS EM RIT}

No desenvolvimento de um radioimunoconjugado devem-se considerar muitos aspectos do radioisótopo. Os principais são meia-vida física, tipo de emissão radioativa, energia da radiação, radionuclídeos filhos produzidos após o decaimento, método de produção e pureza radionuclídica. Para terapia, deseja-se radiação com alta transferência linear de energia, como oriundas de partículas $\alpha$ e $\beta^{-}$, pois elas promovem uma alta ionização em curto espaço percorrido ${ }^{48}$. É possível também a utilização de emissores de elétrons Auger, mas eles precisam ser localizados próximo ao DNA, pois possuem alcance limitado ${ }^{44}$ (TABELA 2).

É desejável também que haja emissão simultânea de radiação gama ou $X$, para permitir a realização de imagens e ajudar na medida dos parâmetros farmacocinéticos e cálculo da dosimetria ${ }^{44}$.

Radioisótopos tais como ${ }^{131} \mathrm{I},{ }^{90} \mathrm{Y}$ e ${ }^{177} \mathrm{Lu}$, os quais são $\beta^{-}$emissores, são largamente utilizados em RIT. A $\beta^{-}$radiação possui uma transferência linear de energia de aproximadamente $0,2 \mathrm{keV} / \mu \mathrm{m}$, com penetração nos tecidos de alguns milímetros dependendo da energia da partícula. Esta penetração relativamente longa promove a deposição de energia em células vizinhas, tumorais ou não. Este fenômeno é conhecido como "fogo cruzado" (crossfire) ${ }^{49}$ e é particularmente interessante, pois pode destruir células vizinhas que não expressam o alvo do anticorpo ou que são pobremente vascularizadas ${ }^{6}$. 
TABELA 2 - Principais radionuclídeos utilizados em RIT.

\begin{tabular}{cccc}
\hline RADIONUCLÍDEO & MEIA-VIDA & ENERGIA MÁXIMA (MEV) & ALCANCE MÉDIO \\
\hline \multicolumn{4}{c}{ Emissores beta } \\
${ }^{188} \mathrm{Re}$ & $16,9 \mathrm{~h}$ & 2,12 & $3,5 \mathrm{~mm}$ \\
${ }^{186} \mathrm{Re}$ & $3,7 \mathrm{~d}$ & 1,07 & $1,8 \mathrm{~mm}$ \\
${ }^{90} \mathrm{Y}$ & $2,7 \mathrm{~d}$ & 2,28 & $3,9 \mathrm{~mm}$ \\
${ }^{67} \mathrm{Cu}$ & $2,6 \mathrm{~d}$ & 0,58 & $0,71 \mathrm{~mm}$ \\
${ }^{131} \mathrm{I}$ & $8,0 \mathrm{~d}$ & 0,61 & $0,91 \mathrm{~mm}$ \\
${ }^{177} \mathrm{Lu}$ & $6,7 \mathrm{~d}$ & 0,50 & $0,67 \mathrm{~mm}$ \\
\hline & $7,2 \mathrm{~h}$ & Emissores alfa \\
${ }^{211} \mathrm{At}$ & $46 \mathrm{~min}$ & 6,8 & $80 \mu \mathrm{m}$ \\
${ }^{213} \mathrm{Bi}$ & $10 \mathrm{~d}$ & 8,3 & $84 \mu \mathrm{m}$ \\
${ }^{225} \mathrm{Ac}$ & Emissores de elétrons Auger & $60-90 \mu \mathrm{m}$ \\
\hline & $60.5 \mathrm{~d}$ & - & $2-500 \mathrm{~nm}$ \\
\hline
\end{tabular}

\subsubsection{Lutécio-177}

O ${ }^{177}$ Lu possui características físicas que o tornam promissor para RIT. Ele pode ser produzido em grande escala em reatores, com um custo relativamente baixo e alta atividade específica ${ }^{8}$. A baixa energia das suas partículas $\beta^{-}$fornece um alcance médio de $670 \mu \mathrm{m}$, o qual é ideal para destruir pequenos tumores malignos e causar pouco dano às células sadias ${ }^{50}$.

A meia-vida física do ${ }^{177}$ Lu é de 6,7 dias e permite aplicação de métodos de síntese e purificação do radiofármaco que demandem certo tempo para sua conclusão. Outra vantagem deste radioisótopo é a emissão concomitante de fótons gama, que permite a realização de imagem do paciente usando gama-câmaras convencionais. Esta característica é muito útil na determinação da dose entregue ao tumor e aos órgãos não alvo (dosimetria) $8,51,52$

O ${ }^{177}$ Lu possui natureza metálica que o torna tipicamente incapaz de formar ligações covalentes estáveis com elementos presentes em proteínas e peptídeos. Por esta razão, radiomarcações de proteínas e peptídeos com metais radioativos são realizadas com o uso de quelantes bifuncionais, os quais formam compostos não covalentes com o radiometal ${ }^{53}$. Muito frequentemente estes quelantes se ligam ao AcM por meio de 
grupamentos amino localizados nos resíduos de lisina ou também por meio de ligação ao grupo tiol das cisteínas ${ }^{30,54}$.

O Ácido 1,4,7,10-tetraazaciclododecano-1,4,7,10-tetracético (DOTA) é um quelante macrocíclico que apresenta melhor estabilidade in vivo comparada ao ácido dietileno-triamino-pentacético (DTPA) (quelante acíclico). Quando o AcM é conjugado ao DTPA e posteriormente marcado com ${ }^{111} \mathrm{In}$, por exemplo, pode ocorrer reação de transquelação com a transferrina o que aumenta o acúmulo hepático e em outros órgãos do sistema reticuloendotelial ${ }^{55}$.

Para a conjugação do quelante à biomolécula é necessária a ativação do grupo carboxílico do quelante a partir de um éster ativo, e a reação com uma amina primária das biomoléculas. Desta forma se obtêm uma ligação peptídica altamente estável sob condições fisiológicas. Um exemplo comum da ativação do grupo carboxílico é a utilização do éster $N$ hidroxisuccinimida (NHS). Os ésteres do NHS ativados são seletivos para aminas primárias em solução aquosa e pH ligeiramente alcalino, como é o caso das condições da reação de imunoconjugação ${ }^{33}$.

Na FIGURA 1 está representada a estrutura do DOTA-NHS-éster e na FIGURA 2, há a representação esquemática da conjugação do AcM com o DOTA e posterior radiomarcação com o radionuclídeo.

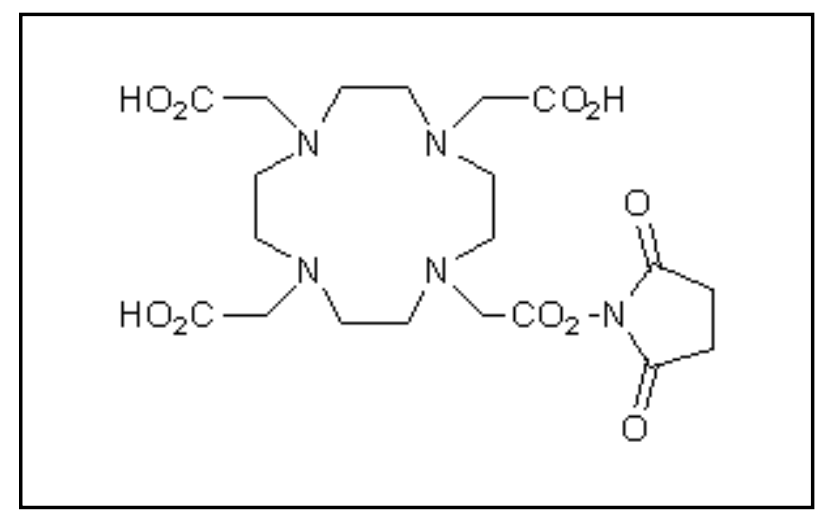

FIGURA 1 - Ácido 1,4,7,10-tetraazociclododecano N, N',N",N"N'-tetracético (DOTA-NHS-éster) 


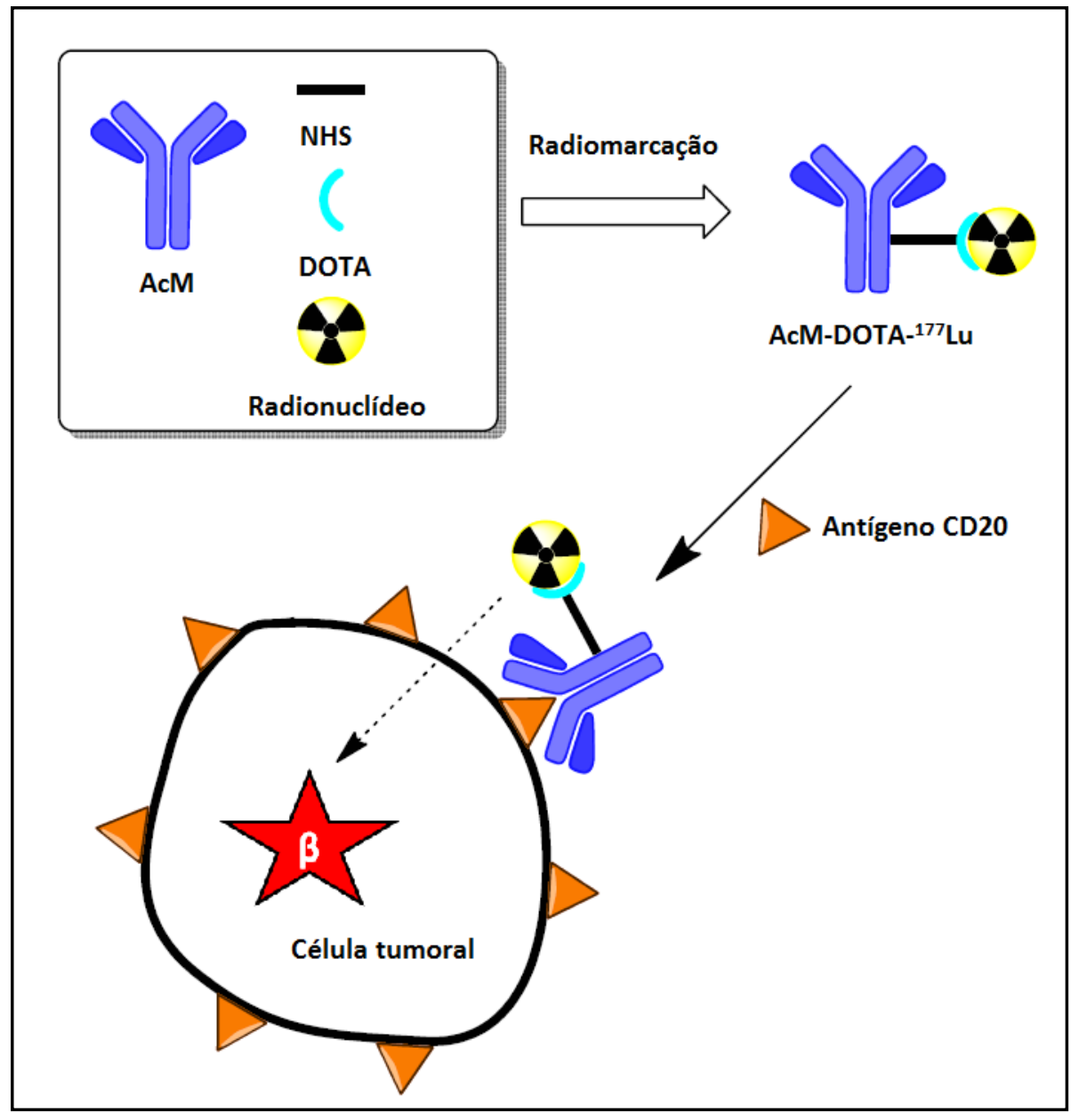

FIGURA 2 - Representação esquemática da conjugação do AcM ao DOTA e posterior radiomarcação com radionuclídeo $\beta$ emissor. Adaptado de Kitson e colaboradores (2013) ${ }^{34}$.

\subsection{RADIOIMUNOTERAPIA DO LNH}

A RIT é particularmente interessante para tumores hematológicos por várias razões, incluindo o fato de que muitos antígenos de superfície expressos nas linhagens celulares não são expressos em outros tecidos ${ }^{45}$.

A maioria dos estudos clínicos para tumores hematopoiéticos são focados na radiomarcação de anticorpos anti-CD20. Entes anticorpos quando conjugados ao ${ }^{131} \mathrm{I}$ e ${ }^{90} \mathrm{Y}$ produzem maiores taxas de resposta global (60 - 80\%) e de remissão completa (15 - 40\%) quando comparados aos AcM não radiomarcados. Em alguns casos a remissão dura 10 anos ou mais ${ }^{45}$.

Conforme citado anteriormente, existem dois radioimunocconjugados aprovados pelo FDA para tratamento de $\mathrm{LNH}$ : ibritumomabe-tiuxetan $-{ }^{90} \mathrm{Y}$ (Zevalin ${ }^{\circledR}$ ) e tositumomabe- 
${ }^{131}$ I $\left(\right.$ Bexxar $\left.^{\circledR}\right)$, contudo, ambos não são comercializados no Brasil.

\subsubsection{Ibritumomabe-tiuxetan- ${ }^{90} \mathrm{Y}\left(\right.$ Zevalin $\left.^{\circledR}\right)$}

Este foi o primeiro AcM radiomarcado aprovado pelo FDA para tratamento de LNH recidivos ou resistentes de baixo grau, folicular ou $\mathrm{LNH}$ transformado de células $B$, incluindo LNH rituximabe-resistente ${ }^{56}$.

O ibritumomabe é um AcM murínico que, assim como o rituximabe, se liga ao antígeno $\mathrm{CD} 20 . \mathrm{O}^{90} \mathrm{Y}$ é um radioisótopo com meia vida de 64 horas e emite apenas partículas beta com energia média de $2,3 \mathrm{MeV}$ e penetração no tecido mole de $5,3 \mathrm{~mm}{ }^{57}$. Para realizar a radiomarcação com o radioisótopo, primeiramente conjuga-se o AcM com o quelante tiuxetan.

Como o ${ }^{90} \mathrm{Y}$ é um emissor beta puro, a imagem para biodistribuição e dosimetria é realizada com ${ }^{111} \mathrm{In}$. Para realização do tratamento, o paciente recebe no dia 1 uma prédose de rituximabe $\left(250 \mathrm{mg} / \mathrm{m}^{2}\right)$, em seguida recebe uma dose de $5 \mathrm{mCi}$ de ${ }^{111} \mathrm{ln}$ ibritumomab-tiuxetan. Após 3 dias da administração, o paciente retorna ao centro de medicina nuclear para realizar um exame cintilográfico de corpo inteiro (scan) para determinar a biodistribuição do radiofármaco. O objetivo é assegurar que a captação em órgãos radiossensíveis, tais como pulmão, rins e intestino delgado, seja menor que a captação no fígado. Se a biodistribuição for favorável, o paciente retornava dentro de alguns dias para iniciar o tratamento com ibritumomabe-tiuxetan- $-{ }^{90} \mathrm{Y}^{58}$.

Em 1996 foi publicado o primeiro estudo clínico de fase I/II para o ibritumomabetiuxetan- ${ }^{90} \mathrm{Y}$ com o objetivo de determinar o efeito da pré-infusão de AcM não radiomarcado na biodistribuição do ibritumomabe-tiuxetan- ${ }^{111} \mathrm{In}$, determinar a dose máxima tolerada de ibritumomab-tiuxetan- ${ }^{90} Y$ que não requeresse transplante de medula e avaliar a segurança e efeito anti-tumoral do radiofármaco ${ }^{59}$.

Dezoito pacientes com LNH recidivos de grau baixou ou intermediário foram tratados com diferentes atividades de ibritumomabe-tiuxetan- $-{ }^{90} \mathrm{Y}$. O estudo demonstrou que a administração de AcM não radiomarcado antes da infusão de ibritumomab-tiuxetan- ${ }^{111}$ In afetou a biodistribuição favoravelmente e que doses $\leq 40 \mathrm{mCi}$ de ibritumomab-tiuxetan $-{ }^{90} \mathrm{Y}$ não são mielotóxicas. A taxa de resposta global, após dose única, foi de $72 \%$ incluindo 6 respostas completas e 7 respostas parciais ${ }^{59}$. 
Em novembro de 2011, o FDA retirou a obrigação da realização do exame com

${ }^{111}$ In, uma vez que cinco estudos clínicos demonstraram que alterações na biodistribuição ocorrem em apenas $1 \%$ dos pacientes, contudo a infusão prévia com rituximabe continua sendo obrigatória 1 dia antes do tratamento ${ }^{58,60}$.

Os principais efeitos adversos decorrentes do uso do radiofármaco incluem infecções (sobretudo bacterianas), reações alérgicas e trombocitopenia. Pode ocorrer anemia, mas é menos importante do que a toxicidade hematológica (neutropenia e trombocitopenia) que ocorre em $60 \%$ dos $\operatorname{casos}^{31}$.

No primeiro estudo clínico de fase III publicado em 2002, os pesquisadores demonstraram a superioridade do ibritumomabe-tiuxetan- ${ }^{90} \mathrm{Y}$ em relação ao rituximabe em pacientes com linfoma folicular ou LNH de células B transformado recidivos ou resistentes. Setenta e três pacientes receberam dose única de $0,4 \mathrm{mCi} / \mathrm{kg}$ de ibritumomabe-tiuxetan- ${ }^{90} \mathrm{Y}$ e 70 pacientes receberam tratamento com $375 \mathrm{mg} / \mathrm{m}^{2}$ de rituximabe semanalmente por 4 semanas. A taxa de resposta global e remissão completa para o grupo que recebeu ibritumomabe-tiuxetan- ${ }^{90} \mathrm{Y}$ foi $80 \%$ e $30 \%$ respectivamente contra $56 \%$ e $16 \%$ para o grupo que recebeu apenas rituximabe. Estimou-se uma resposta média de 14,2 meses para o grupo que recebeu RIT contra 12,1 meses para o grupo que recebeu imunoterapia ${ }^{61}$.

Este mesmo grupo publicou mais recentemente (2015) um estudo clínico de fase II com 53 pacientes portadores de linfoma difuso de células B grandes. Este linfoma é o LNH mais comum nos Estados Unidos e é potencialmente curável. Os pacientes receberam 4 a 6 ciclos de CHOP com rituximabe seguido de RIT $(0,4 \mathrm{mCi} / \mathrm{kg})$. Os pacientes que apresentaram nódulos positivos após exame com $\mathrm{FDG}-{ }^{18} \mathrm{~F}$ receberam radioterapia com $30 \mathrm{~Gy}{ }^{62}$.

A remissão completa foi de $89 \%$; destes pacientes, $89 \%$ alcançaram a remissão completa sem a necessidade de radioterapia. Após acompanhamento de 5,9 anos, 4 pacientes tiveram progressão da doença e morreram. Após cinco anos, $78 \%$ continuam em remissão e $94 \%$ continuam vivos ${ }^{62}$.

Em 2014, Illidge e colaboradores demonstraram que bons resultados também podem ser obtidos com doses fracionadas do radiofármaco. Setenta e quatro pacientes com linfoma folicular avançado, não tratado previamente, receberam 2 doses de 11,1 MBq/kg de ibritumomabe-tiuxetan- ${ }^{90} \mathrm{Y}$ e a reposta global foi de $95,8 \%$ com remissão completa de $69,4 \%$. A sobrevida livre de progressão foi de 40,2 meses ${ }^{63}$.

A eficiência do ibritumomabe-tiuxetan- ${ }^{90} Y$ também foi avaliada em LNH 
agressivos juntamente com a utilização de CHOP e radioterapia. Neste estudo, 46 pacientes com linfoma de Burkitt, linfoma difuso de células B grandes e linfoma de células do manto em estágio inicial receberam tratamento com $\mathrm{CHOP}$, seguido de radioterapia dos linfonodos acometidos e RIT $(0,4 \mathrm{mCi} / \mathrm{kg})$ para consolidação. Os pacientes foram acompanhados por 7,3 anos e a sobrevida livre de progressão e sobrevida global estimadas foram $75 \%$ e $82 \%$ respectivamente para 7 anos ${ }^{64}$.

Recentemente, Koechli e colaboradores (2015), relataram a primeira consolidação de remissão em pacientes com linfoma de Burkitt. Foram avaliados 27 pacientes (tratados anteriormente com rituximabe), 22 receberam terapia sem a utilização do ibritumomabe-tiuxetan $-{ }^{90} \mathrm{Y}$ e 5 receberam a RIT. Todos os pacientes foram acompanhados por pelo menos 50 meses e durante toda a avaliação, nenhum dos 5 pacientes tratados com RIT sofreram recidivas e não houve óbitos. Já no grupo sem RIT, 1 paciente apresentou recidiva e morreu após seis meses ${ }^{65}$.

\subsubsection{Tositumomabe- $^{131} \mathrm{I}\left(\right.$ (Bexxar $\left.^{\circledR}\right)$}

O tositumomabe é um AcM murínico que se liga ao antígeno CD20. O radioisótopo ${ }^{131} \mathrm{I}$ é ligado diretamente a ele, sem a necessidade de uso de quelantes bifuncionais. Por ser beta e gama emissor, o ${ }^{131}$ I pode ser usado para dosimetria e terapia. A dose de tositumomabe- ${ }^{131}$ I é calculada baseando-se no clareamento da radiação do corpo por intermédio de imagens de corpo inteiro feitas em gama - câmaras ou SPECT. No primeiro dia, os pacientes recebem pré-dose de tositumomabe não radiomarcado, em seguida, $5 \mathrm{mCi}$ do tositumomabe- ${ }^{131}$ I. Imediatamente após a infusão, realiza-se uma imagem de corpo inteiro para se obter a contagem de corpo inteiro do paciente. No segundo, quarto, sexto e sétimo dia, novas imagens são realizadas e baseando-se no clareamento da radiação, o médico calcula a dose terapêutica ${ }^{58}$.

Durante a infusão do tositumomabe- ${ }^{131}$ l, podem ocorrer reações adversas como calafrios, febre, hipotensão de leve a moderada. Sua principal toxicidade é hematológica, induzindo a anemia, neutropenia e trombocitopenia prolongada. Cerca de $8 \%$ dos pacientes podem desenvolver HAMA ${ }^{31}$.

O primeiro uso clínico do tositumomabe- ${ }^{131}$ I foi reportado em 1993 e ele foi aprovado para uso nos Estados Unidos em 2003. A indicação inclui o tratamento de 
pacientes com LNH folicular de baixo grau resistentes, LNH de células B transformadas e LNH rituximabe-resistentes. Vinte e quatro horas antes da administração de tositumomabe- ${ }^{131} \mathrm{I}$, é administrado ao paciente uma solução saturada de iodeto de potássio ou solução de Lugol com o intuito de bloquear a captação na tireoide e essa administração é continuada por 14 dias após a dose terapêutica ${ }^{56}$.

O regime de tratamento consiste em duas etapas. Primeira: o paciente recebe uma infusão de $450 \mathrm{mg}$ de tositumomabe frio seguido de $35 \mathrm{mg}$ de tositumomabe radiomarcado com $5 \mathrm{mCi}$ de $\mathrm{I}-131$. Nesta primeira etapa são realizados os estudos dosimétricos, para tanto, o paciente realiza três imagens de corpo inteiro distribuídas nos sete dias subsequentes à administração. Segunda: o paciente recebe uma infusão de $450 \mathrm{mg}$ de tositumomabe frio seguido de $35 \mathrm{mg}$ de tositumomabe radiomarcado com uma quantidade de $\mathrm{I}-131$ que forneça dose de radiação de corpo inteiro de $75 \mathrm{cGy}{ }^{66}$.

Em 2003, Press e colaboradores publicaram um estudo clínico de fase II com pacientes portadores de linfoma folicular avançado não tratado previamente ${ }^{67}$.

Noventa pacientes receberam seis ciclos de CHOP com intervalos de 3 semanas, em seguida, os pacientes receberam uma dose de tositumomabe- ${ }^{131} \mathrm{I}$. A taxa de resposta global foi de $90 \%$ e $67 \%$ dos pacientes apresentaram remissão completa e $23 \%$ apresentaram remissão parcial. Após um seguimento médio de 2,3 anos, a sobrevida global e a taxa de sobrevida livre de progressão foram de 2 anos. Estes dados permitiram concluir que o novo tratamento aparentemente era promissor ${ }^{67}$.

Fisher e colaboradores (2005) analisaram 5 ensaios clínicos realizados entre 1990 e 2011, totalizando 250 pacientes com linfoma folicular, LNH de baixo grau recidivo ou resistente e LNH de baixo grau transformado previamente tratados. Estes pacientes receberam uma única dose de tositumomabe- ${ }^{131} \mathrm{I}$ e foram acompanhados por uma média de 5,3 anos. Nestes estudos, a taxa de resposta global foi de 47 - $68 \%$ e a remissão completa de 20 - 38\%. No 5 o ano, a sobrevida livre de progressão foi de $17 \%{ }^{68}$.

No mesmo ano, Kaminski e colaboradores publicaram um estudo em que o uso de tositumomabe- ${ }^{131}$ I foi realizado em 76 pacientes com linfoma folicular não tratado (estágio III ou IV). Estes pacientes receberam dose única do radiofármaco de acordo com o regime de tratamento citado acima ${ }^{66}$.

A reposta global foi de 95\%; 75\% dos pacientes tiveram taxa de remissão completa e apenas 20\% (15 pacientes) tiveram resposta parcial. Estimou-se que $77 \%$ dos 
pacientes com remissão completa, permaneceram livres da doença por 5 anos. Somente 4 pacientes apresentaram recidiva de nódulos isolados após 5 anos e estes focos foram tratados com radioterapia. A resposta HAMA foi detectada em 48 pacientes e estes anticorpos foram detectados até 5,5 meses após a primeira dose diagnóstica. De todos os pacientes, 9 mortes ocorreram, mas sem associação com o tratamento e foi possível concluir que a terapia utilizando tositumomabe- ${ }^{131}$ I pode induzir uma remissão clínica e molecular prolongada. ${ }^{66}$.

Este mesmo grupo realizou outro estudo em que 32 pacientes recidivos que foram previamente tratados com tositumomabe- ${ }^{131}$ I foram retratados. Eles concluíram com o estudo, que o re-tratamento com tositumomabe- ${ }^{131}$ I pode ser uma escolha terapêutica potencialmente valiosa para pacientes que responderam previamente ao tratamento podendo resultar em respostas duradouras, além de ser seguro e efetivo ${ }^{69}$.

Um estudo clínico de fase II publicado em 2012 avaliou a eficiência do uso de tositumomabe- ${ }^{131}$ I associado à ablação de medula óssea seguida de transplante autólogo ${ }^{70}$.

Neste estudo, 40 pacientes com linfoma difuso de células B previamente tratados, receberam 75 cGy de tositumomabe- ${ }^{131}$ I e doses altas de carmistina, etoposide, citarabina e melfalano (BEAM) seguido de transplante. A toxicidade de longo prazo foi similar ao histórico de pacientes que receberam somente tratamento com BEAM. A taxa de resposta global foi de $80 \%$ (32 pacientes) e a remissão completa foi de $78 \%$ (31 pacientes). Os pacientes foram acompanhados por uma média de 6 anos; a sobrevida global foi de $72 \%$ e a taxa de sobrevida livre de progressão foi de $70 \%{ }^{70}$.

Com base nestes resultados, os autores planejaram um estudo clínico randomizado de fase III comparando as terapias utilizando tositumomabe- ${ }^{131}$ I + BEAM e rituximabe + BEAM $^{71}$.

Cento e treze pacientes, com linfoma difuso de células B previamente tratados, receberam terapia com rituximabe juntamente com ablação de medula por BEAM seguida de transplante e 111 pacientes receberam terapia com tositumomabe- ${ }^{131}$ I e BEAM seguida de transplante. Ambos os grupos apresentaram sobrevida global e taxa de sobrevida livre de progressão de 2 anos e os pesquisadores concluíram que o uso de tositumomabe- ${ }^{131}$ I não trouxe benefícios aos pacientes ${ }^{71}$.

Outro estudo clínico de fase III publicado em janeiro de 2013 comparou a eficiência do tratamento CHOP e rituximabe com CHOP e tositumomabe- ${ }^{131}$ I em pacientes 
com linfoma folicular avançado não tratado previamente ${ }^{72}$.

Um grupo recebeu seis ciclos de CHOP com intervalos de 3 semanas e seis doses de rituximabe (CHOP-R) enquanto outro grupo recebeu os mesmos seus ciclos de CHOP e um regime terapêutico de tositumomabe- ${ }^{131}$ I (CHOP-RIT). Após um acompanhamento médio de 4,9 anos, os pesquisadores encontraram uma sobrevida livre de doença de 2 anos para os dois grupos (76\% CHOP-R e 80\% CHOP-RIT) e taxa de sobrevida global também de 2 anos para os dois grupos (97\% CHOP-R e 93\% CHOP-RIT) ${ }^{72}$.

Em fevereiro 2014, após a publicação destes dois últimos estudos clínicos a Glaxo Smith Kline (GSK) suspendeu a produção e venda do Bexxar ${ }^{\circledR}$ nos Estados Unidos e Canadá ${ }^{73}$. Na realidade, a empresa já vinha discutindo a suspensão devido à queda nas vendas e os dois estudos apenas reforçaram a decisão. O pico de uso/vendas do Bexxar foi em 2006 e desde então as vendas vinham caindo $30 \%$ ao ano, tanto que somente 75 pacientes utilizaram o medicamento em $2012^{74}$.

Embora não existam estimativas publicadas para as vendas cumulativas da droga, estima-se que entre 2.000 e 3.000 pacientes fizeram uso dela e considerando que o produto era vendido a $\$ 32.400$, calcula-se que as vendas possam ter chegado a $\$ 100$ milhões $^{74}$.

\subsection{OUTROS RADIOIMUNOCONJUGADOS EM DESENVOLVIMENTO}

Como visto anteriormente, a RIT é uma alternativa terapêutica muito promissora e embora ela tenha sido primariamente empregada em tumores linfáticos, muitos avanços têm sido feitos na RIT de tumores sólidos. O avanço nesta área é tamanho, que Tomblyn e colaboradores (2013), chegaram a dizer que a RIT vive uma nova era de ouro ${ }^{58}$. Em relação aos tumores linfáticos, o avanço se dá no desenvolvimento de AcM contra novos alvos, além do CD20.

A seguir, destacam-se alguns dos novos radiofármacos para RIT e radioimunodiagnóstico (RID) em estudos pré-clínicos e/ou clínicos divididos por tipo de câncer. 


\subsubsection{Câncer de mama}

Pertuzumabe-DTPA- ${ }^{111}$ In

O pertuzumabe é um AcM humanizado que se liga aos receptores HER2 presentes no câncer de mama. Comercialmente ele é disponível para imunoterapia de câncer de mama HER2 positivo.

O radiofármaco está sendo desenvolvido para monitorar o decréscimo da expressão de HER2 em pacientes que estão fazendo tratamento com trastuzumabe, ou seja, acompanhar a eficácia do tratamento. Como ele se liga aos domínios II dos receptores HER2 e o trastuzumabe aos domínios IV, o trastuzumabe não interfere na ligação do pertuzumabe. Os estudos pré-clínicos foram concluídos com sucesso, e agora os autores iniciarão os estudos clínicos de fase $\mathrm{I} / \mathrm{II}^{75,76}$.

\section{Pertuzumabe-DFO- ${ }^{89} \mathrm{Zr}$}

Além da radiomarcação com ${ }^{111} \mathrm{In}$, o pertuzumabe vem sendo explorado como um radiotraçador para $\mathrm{PET}$ por meio da radiomarcação de emissores de pósitron, com o mesmo objetivo citado anteriormente.

Em um estudo realizado em 2014, Marquez e colaboradores, radiomarcaram o pertuzumabe com ${ }^{89} \mathrm{Zr}$ via quelante bifuncional DFO e realizaram estudos pré-clínicos em animais implantados com tumor xenográfico. O pertuzumabe-DFO- ${ }^{89} \mathrm{Zr}$ foi administrado aos animais e a imagem foi realizada 7 dias depois. O radiofármaco apresentou captação de 47,5 $\pm 32,9 \% \mathrm{Al} / \mathrm{g}$ nos tumores HER2+ comparada a 9,5 $\pm 1,7 \% \mathrm{Al} / \mathrm{g}$ de captação no tumor HER2 negativo. Além disso, eles observaram que a captação no tumor foi significativamente maior em presença de trastuzumabe não radiomarcado.

Eles concluíram que o radiofármaco é muito promissor para realizar o acompanhamento não invasivo da diminuição da expressão de HER2 em tumores tratados com trastuzumabe ${ }^{77}$.

Trastuzumabe-DOTA- ${ }^{177} \mathrm{Lu}$

O trastuzumabe é um AcM humanizado que se liga aos receptores HER2 presentes no câncer de mama. Comercialmente ele é disponível para imunoterapia de câncer de mama HER2 positivo. 
Os estudos pré-clinicos do trastuzumabe-DOTA- ${ }^{177} \mathrm{Lu}$, foram muito promissores e o radiofármaco apresentou alta pureza radioquímica, imunorreatividade e estabilidade apropriadas, alta toxicidade às células HER2 positivas (cinco vezes mais em relação ao AcM não radiomarcado com ${ }^{177} \mathrm{Lu}$ ) e alta captação no tumor (xenográfico) ${ }^{8,78,79}$. Contudo, até a presente data, não foram publicados estudos clínicos.

\subsubsection{Câncer de próstata}

huJ591-DOTA- ${ }^{177} \mathrm{Lu}$

O J591 é um AcM humanizado que se liga com alta afinidade ao antígeno da membrana específica de próstata (PSMA). O PSMA é uma glicoproteína expressa em todos os cânceres de próstata e sua densidade aumenta progressivamente em câncer de próstata de alto grau, metástases e cânceres hormônios-resistentes.

Bander e colaboradores (2005) realizaram estudos clínicos de fase I com 35 pacientes portadores de câncer de próstata andrógeno-independente. Dezesseis destes pacientes receberam 3 doses do radiofármaco. Quando os pacientes receberam 3 doses entre 45 e $60 \mathrm{mCi} / \mathrm{m}^{2}$ todos apresentaram mielotoxicidade, contudo, 3 doses consecutivas de $30 \mathrm{mCi} / \mathrm{m}^{2}$ mostraram-se segura. Nenhum paciente desenvolveu anticorpos anti-huJ591.

Mais de $50 \%$ dos pacientes apresentaram diminuição dos níveis séricos de PSA até 8 meses após o tratamento e 16 pacientes (46\%) tiveram índices de PSA estáveis por 60 dias em média.

O órgão crítico para dosimetria foi o fígado $(7,8 \pm 2,2 \mathrm{cGy} / \mathrm{mCi})$, seguido do baço e rins. A dose de radiação absorvida na medula óssea, com base na radioatividade presente no sangue, foi de $1,2 \pm 0,4 \mathrm{cGy} / \mathrm{mCi}$ de ${ }^{177} \mathrm{Lu}$ administrado.

Dos 35 pacientes, 30 (86\%) tinham metástases ósseas detectadas. Em todos eles, houve captação do huJ591-DOTA- ${ }^{177}$ Lu nas lesões metastáticas. Um paciente não possuía focos de metástases pré-conhecidos e teve focos identificados com o radiofármaco ${ }^{80}$.

\subsubsection{Câncer colorretal}

huA33-DTPA- ${ }^{177}$ Lu/ ${ }^{211}$ At e huA33- ${ }^{131}$ I

O A33 é um AcM humanizado (huA33) direcionado ao receptor A33 que é altamente expresso (>95\%) nas células de carcinoma colorretal, tanto no tumor primário 
quanto nas metástases. Nos estudos pré-clínicos, Almqvist e colaboradores (2006), concluíram que o huA33-DTPA- ${ }^{177}$ Lu apresentou uma biodistribuição favorável com captação no tumor (xenográfico) ${ }^{81}$.

Além de marcar o huA33 com ${ }^{177} \mathrm{Lu}$, os autores também realizaram estudo com o AcM marcado com ${ }^{211} \mathrm{At}$, um emissor alfa, demonstrando afinidade pelas células, taxa alta de internalização e citotoxidade dose dependente ${ }^{82}$. Contudo, desde 2006, não foram publicados novos pesquisas do huA33 radiomarcado com estes dois radioisótopos.

Outro grupo publicou recentemente (2014), um estudo clínico de fase I do huA33 radiomarcado com ${ }^{131} \mathrm{l}$. O estudo envolveu 19 pacientes com metástases de câncer colorretal mensuráveis (1 paciente retirou-se do estudo devido aos efeitos adversos). O radiofármaco apresentou excelente biodistribuição com ligação aos alvos já conhecidos de tumor (metástase), captação transitória já esperada nos intestinos e baixíssima (praticamente nula) captação nos tecidos sadios.

Dos 18 pacientes, 1 apresentou resposta parcial de 15,2 meses; 10 pacientes apresentaram estabilização da doença, destes, 4 apresentaram redução do tamanho das lesões e 7 tiveram progressão da doença. A média de sobrevida livre de progressão foi de 5 meses (variação de 1 a 48,6 meses).

Os autores concluíram que os resultados encontrados foram expressivos, com benefício clínico em 11 dos 18 pacientes (61\%), e também sugeriram novos estudos com radioisótopos terapêuticos diferentes como o ${ }^{177} \mathrm{Lu}^{83}$.

\subsubsection{Câncer de ovário}

muHMFG1-DTPA $-{ }^{90} \mathrm{Y}$

O HMFG1 é um AcM murínico direcionada ao epítopo MUC1, um gene expresso na superfície da maioria das células epiteliais secretoras. O MUC1 é um alvo atrativo, pois é superexpresso em 90\% dos adenocarcinomas incluindo câncer de ovário, mama e pâncreas.

Verheijen e colaboradores (2006) realizaram um estudo clínico randomizado de fase III com 447 pacientes com câncer ovariano epitelial ${ }^{84}$.

Os pacientes foram divididos em dois grupos. No primeiro grupo, 224 mulheres receberam intraperitoneamente dose única de muHMFG1-DTPA- ${ }^{90} \mathrm{Y}\left(666 \mathrm{MBq} / \mathrm{m}^{2}\right)$ 
associado ao tratamento convencional; no segundo grupo 223 mulheres receberam apenas o tratamento convencional.

Após um segmento de 3,5 anos, os autores concluíram que a RIT não estendeu significativamente o tempo de remissão ou de sobrevivência ${ }^{84}$.

\subsubsection{Linfoma não - Hodgkin}

Tetulomabe-DOTA- ${ }^{177} \mathrm{Lu}\left(\mathrm{HH} 1-{ }^{177} \mathrm{Lu}\right)$

O tetulomabe é um AcM anti-CD37. $O$ antígeno CD37 é expresso em células $B$, sobretudo em células B de LNH e leucemia linfocítica crônica. Este radiofármaco está sendo desenvolvido para tratamento de pacientes que fizeram uso de rituximabe e consequentemente desenvolveram resistência ou a expressão de CD20 nas células tumorais ficou comprometida. O estudo está em fase pré-clinica e mostrou bons resultados nos estudos in vitro e in vivo ${ }^{43,85}$.

Rituximabe-DOTA- ${ }^{64} \mathrm{Cu}$

Assim como o trastuzumabe e pertuzumabe, o uso de rituximabe também tem sido explorado para radioimunodiagnóstico com tecnologia PET.

Os primeiros estudos pré-clínicos realizados tiveram por objetivo determinar a dosimetria do radiofármaco e extrapolar os dados para humanos. Para tanto, foi utilizado camundongos transgênicos que expressam receptores CD20 humanos. O radiofármaco produzido apresentou pureza radioquímica e estabilidade altas e imunorreatividade acima de $75 \%$. A captação tumoral in vivo foi específica demonstrada pelo baixo acúmulo do radiofármaco no tumor após a administração prévia de rituximabe frio ${ }^{86}$.

A extrapolação da dosimetria para humanos indicou que quando uma pré-dose de AcM frio é administrada, os órgãos que recebem maior dose são as células osteogênicas, o fígado e a parede do coração respectivamente. Já quando a pré-dose de AcM não é administrada, os órgãos que recebem a maior dose são o baço, o fígado e a parede do coração respectivamente ${ }^{86}$.

Este mesmo grupo realizou a validação da produção do rituximabe $-{ }^{64} \mathrm{Cu}$ sob condições de Boas Práticas de Fabricação. Foram produzidos três lotes que atenderam aos parâmetros de qualidade química, radioquímica, microbiológica e biológica. A 
imunorreatividade do imunoconjugado foi de $73 \%$ e a alta especificidade da ligação in vivo foi confirmada pela captação alta (em torno de $99 \%$ da dose injetada) no baço de camundongos que expressam antígenos CD20 humanos ${ }^{87}$.

Rituximabe- ${ }^{131}$ I

O sucesso inicial do uso clínico do tositumomabe- ${ }^{131}$ I influenciou e intensificou as pesquisas pré-clínicas e clínicas do rituximabe- ${ }^{131} \mathrm{I}$, tanto que existem dezenas de estudos disponíveis. Nesta seção, estão descritos algumas dos estudos clínicos realizados com este radiofármaco que ainda não está aprovado pelo FDA para comercialização.

A eficácia e segurança da RIT com rituximabe- ${ }^{131}$ I foi avaliada em 24 pacientes com linfoma de células B de baixo grau ou linfoma difuso de grandes células B. Como critério de inclusão no estudo, todos os pacientes apresentaram pelo menos uma lesão detectável por meio de exame de PET com FDG $-{ }^{18} \mathrm{~F}$. Eles receberam dose única média de 7,3 GBq de rituximabe- ${ }^{131}$ I e a resposta ao tratamento foi avaliada 1 mês após com novo exame de PET com FDG- ${ }^{18} \mathrm{~F}^{88}$.

A taxa de resposta global foi de $29 \%$. Remissão parcial ou completa foi encontrada em $46 \%$ dos pacientes com linfoma de células $B$ de baixo grau ou linfoma difuso e 1 paciente com linfoma de grandes células B apresentou remissão parcial. Após 55 meses de avaliação, a sobrevida livre de progressão para todos os pacientes foi de 2,2 meses e a média de sobrevida global foi de 11,3 meses $^{88}$.

Um estudo clínico multicêntrico de fase II também demonstrou bons resultados em pacientes com LNH recidivos ou resistentes. Noventa e um pacientes receberam dose de $375 \mathrm{mg} / \mathrm{m}^{2}$ de rituximabe frio seguido de $200 \mathrm{MBq}$ de rituximabe- ${ }^{131} \mid$ para realização da dosimetria. A dose terapêutica foi calculada individualmente para cada paciente a partir dos dados da dosimetria; assim, cada paciente recebeu uma dose que fornecesse 0,75 Gy de radiação absorvida no corpo inteiro.

A taxa de resposta global foi de $76 \%$ com $53 \%$ de remissão completa ou remissão completa não confirmada e a duração da remissão foi de 20 meses em média. A sobrevida livre de progressão foi de 13 meses e após acompanhamento de 23 meses, a taxa de sobrevivência foi de 4 anos. A principal toxicidade observada foi hematológica, mas sem gravidade ${ }^{89}$. 
Para complementar os estudos clínicos, o mesmo grupo avaliou outros 76 pacientes, juntamente com 66 pacientes do estudo anterior, totalizando 142 pacientes. Os pacientes receberam o mesmo protocolo de tratamento e a resposta ao tratamento foi monitorada por PET com FDG- ${ }^{18} \mathrm{~F}$ três meses após o tratamento. A taxa de resposta global foi de $68 \%$ (97 pacientes) com remissão completa ou remissão completa não confirmada de $50 \%$ (61 pacientes) ${ }^{90}$. Estes resultados confirmaram a eficácia e segurança do uso de rituximabe- ${ }^{131}$ I reportada anteriormente pelo grupo.

A eficácia da administração fracionada do radiofármaco também foi avaliada em 18 pacientes. Estes pacientes foram divididos em quatro grupos, cada grupo recebeu duas doses de rituximabe- $-{ }^{131}$ I que variou de 15 a 60 cGy cada dose. Antes da RIT, todos os pacientes foram submetidos à imunoterapia com rituximabe frio por 4 semanas consecutivas. A resposta terapêutica foi avaliada por exame clínico e tomografia computadorizada por até 12 meses após a RIT ${ }^{91}$.

A pré-terapia com rituximabe frio aumentou significativamente a meia vida efetiva do radiofármaco em todos os grupos, mas não comprometeu a eficácia clínica ou aumentou a toxicidade da RIT. A taxa de resposta global foi de $94 \%$ com remissão completa de $50 \%$ e remissão parcial de $44 \%$. Todas as doses foram bem toleradas e toxicidade doselimitante não foi observada ${ }^{91}$.

Assim como realizado para o ibritumomabe-tiuxetan $-{ }^{90} \mathrm{Y}$, pesquisadores avaliaram um protocolo envolvendo mieloablação de medula óssea com rituximabe- ${ }^{131}$ I ou quimioterapia. A atividade administrada de rituximabe- ${ }^{131} \mid$ foi calculada individualmente para cada paciente para fornecer dose de corpo inteiro de $21-27 \mathrm{~Gy}^{92}$.

Vinte e três pacientes foram divididos em 3 grupos. Nove pacientes receberam apenas RIT seguido de transplante autólogo de medula óssea; seis pacientes receberam RIT associada com doses altas de quimioterapia, seguido de transplante de medula e oito pacientes receberam RIT sozinha ou RIT associada à quimioterapia seguido de transplante. Em seguida estes pacientes receberam uma segunda dose de quimioterapia mieloablasiva seguido de um segundo transplante ${ }^{92}$.

Após um segmento médio de 9,5 anos, a taxa de resposta global foi de $87 \%$ com $64 \%$ de remissão completa. A sobrevida livre de progressão e a sobrevida global foram de 47,5 meses e 101,5 meses respectivamente. Foi possível concluir que a mieloablação com RIT é factível, bem tolerada, pois não causou toxicidade hematológica severa, e produz 
remissão de longo prazo. Todavia, a associação de RIT com doses altas de quimioterapia aumenta significativamente a toxicidade hematológica ${ }^{92}$.

Rituximabe-DOTA $-{ }^{177} \mathrm{Lu}$

A superioridade do uso de Lu-177 na terapia de massas tumorais pequenas e médias, como o LNH, foi confirmada por Audicio e colaboradores (2011) por intermédio de simulação de Monte Carlo. Além disso, com nos estudos pré-clínicos, os autores obtiveram um radiofármaco com pureza radioquímica e afinidade altas pelo antígeno CD20. Os estudos de biodistribuição permitiram observar que a principal via de eliminação foi hepatobiliar e urinária ${ }^{93}$.

Em 2009, Forrer e colaboradores realizaram estudos pré-clínicos e dosimétricos com o rituximabe-DOTA $-{ }^{177} \mathrm{Lu}$. O radiofármaco apresentou bons resultados in vitro e considerável captação em focos tumorais de dois pacientes com LNH que foram utilizados para realizar os estudos dosimétricos ${ }^{51}$.

Mais recentemente, Kameswaran e colaboradores (2015), também obtiveram resultados animadores em seus estudos pré-clínicos. Foi possível obter um radiofármaco com pureza radioquímica e estabilidade altas. A captação tumoral em camundongos $S C I D$, implantados com células Raji, foi de $23,3 \% 72$ horas após a injeção ${ }^{94}$.

Os primeiros estudos clínicos de fase I e II foram publicados em 2012 e 2013 . O estudo foi realizado com 31 pacientes portadores de linfoma folicular e linfoma de células do manto resistentes ou recidivos que fossem CD20 positivos. Estes pacientes foram divididos em grupos que receberam doses diferentes do radiofármaco. A dose máxima tolerada encontrada foi de $45 \mathrm{mCi} / \mathrm{m}^{2}$ limitada mormente pelo desenvolvimento de trombocitopenia e leucopenia ${ }^{7,95}$

Surpreendentemente, conforme descrito pelos autores, respostas clínicas ocorreram em todas as doses estudadas tanto nos pacientes com linfoma folicular como nos pacientes com linfoma de células do manto. Um paciente com linfoma folicular e que recebeu a menor dose (36 $\mathrm{mCi}$ ), apresentou remissão completa nos nódulos envolvendo o intestino delgado e retroperitônio por até 105 meses. A taxa de resposta global foi de $82 \%$ para os pacientes com linfoma folicular e $21 \%$ para os demais. 
Após aproximadamente 9 anos, 11 dos 31 pacientes continuaram vivos e os autores estimaram um tempo de sobrevivência média após a RIT de 4 anos ${ }^{7}$. 
Neste capítulo apresenta-se o planejamento experimental deste trabalho.

\subsection{PLANEJAMENTO EXPERIMENTAL}

O presente trabalho foi dividido em quatro grandes etapas que são abordadas com detalhes nos capítulos 5, 6 e 7.

Cada etapa contou com vários estudos que visaram responder a uma questão investigativa. Ao final de cada etapa, chegaram-se às conclusões que permitiram seguir para as demais etapas.

Os estudos realizados, seus indicadores e as questões investigativas estão descritos nas TABELAS 3, 4, 5 e 6 .

Na primeira etapa do trabalho determinou-se o melhor método de conjugação e a razão molar ideal AcM:DOTA. Para tanto, conjugou-se o anticorpo em diferentes razões molares (1:10, 1:20, 1:50 e 1:100) radiomarcando-o posteriormente com ${ }^{177} \mathrm{Lu}$.

A razão molar escolhida foi aquela que promoveu a incorporação de certo número de grupamentos quelantes ao anticorpo, produzindo alta pureza radioquímica com preservação da imunorreatividade e da ligação específica às células Raji. 
TABELA 3 - Estudos realizados, indicadores e questões investigativas da primeira etapa do trabalho.

\begin{tabular}{|c|c|c|c|}
\hline ETAPA & ESTUDOS REALIZADOS & INDICADOR & $\begin{array}{c}\text { QUESTÃO } \\
\text { INVESTIGATIVA }\end{array}$ \\
\hline \multirow{5}{*}{ 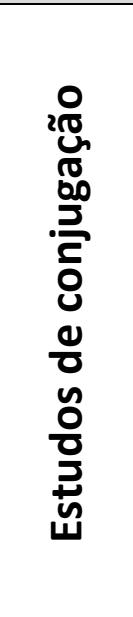 } & $\begin{array}{l}\text { Variação da razão molar de } \\
\text { conjugação (1:10, 1:20, 1:50 e } \\
\text { 1:100) }\end{array}$ & $\begin{array}{l}\text { Número de quelantes } \\
\text { acoplados ao AcM }\end{array}$ & \multirow{4}{*}{$\begin{array}{l}\text { Qual a condição de } \\
\text { conjugação que } \\
\text { promove a formação } \\
\text { de imunoconjugado } \\
\text { com } \\
\text { imunorreatividade } \\
\text { preservada e alta \% de } \\
\text { pureza radioquímica? }\end{array}$} \\
\hline & Ligação específica às células & \% Ligação específica & \\
\hline & Imunorreatividade & Fração imunorreativa & \\
\hline & $\begin{array}{l}\text { Radiomarcação do AcM } \\
\text { conjugado em diferentes razões } \\
\text { molares (1:10, 1:20, 1:50 e } 1: 100)\end{array}$ & $\begin{array}{l}\text { \% Pureza } \\
\text { radioquímica e } \\
\text { estabilidade da } \\
\text { radiomarcação }\end{array}$ & \\
\hline & Estabilidade do imunoconjugado & $\begin{array}{l}\text { \% de } \\
\text { imunoconjugado } \\
\text { íntegro }\end{array}$ & $\begin{array}{l}\text { Qual a validade do } \\
\text { imunoconjugado? }\end{array}$ \\
\hline
\end{tabular}

O objetivo da segunda etapa foi aperfeiçoar as condições de radiomarcação do anticorpo conjugado nas condições aperfeiçoadas na primeira etapa. Foram avaliadas diferentes atividades específicas utilizando atividade baixa de ${ }^{177} \mathrm{Lu}$. A melhor condição foi extrapolada para uma situação de radiomarcação para uso em terapia utilizando atividade alta de ${ }^{177} \mathrm{Lu}$.

Para as marcações realizadas com atividade alta, estudou-se a estabilidade do radiomarcado com e sem utilização de agentes estabilizantes e em diferentes condições de armazenamento, bem como a estabilidade em plasma in vitro.

Nesta etapa também foram realizados estudos in vitro, tais como, ligação às proteínas plasmáticas, imunorreatividade do radioimunoconjugado radiomarcado com alta atividade específica e a influência da atividade específica na ligação às células tumorais. 
TABELA 4 - Estudos realizados, indicadores e questões investigativas da segunda etapa do trabalho.

\begin{tabular}{|c|c|c|c|}
\hline ETAPA & ESTUDOS REALIZADOS & INDICADOR & $\begin{array}{c}\text { QUESTÃO } \\
\text { INVESTIGATIVA }\end{array}$ \\
\hline \multirow{6}{*}{ 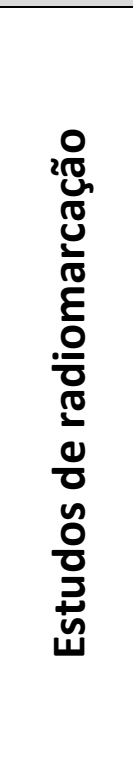 } & $\begin{array}{l}\text { Variação da massa de } \\
\text { imunoconjugado na } \\
\text { radiomarcação }\end{array}$ & $\begin{array}{l}\text { \% Pureza } \\
\text { radioquímica }\end{array}$ & \multirow{4}{*}{$\begin{array}{l}\text { Qual a máxima } \\
\text { atividade específica } \\
\text { que não compromete } \\
\text { a estabilidade e a } \\
\text { imunorreatividade do } \\
\text { radioimunoconjugado? }\end{array}$} \\
\hline & $\begin{array}{l}\text { Variação da atividade de }{ }^{177} \text { Lu na } \\
\text { radiomarcação }\end{array}$ & $\begin{array}{l}\text { \% Pureza } \\
\text { radioquímica }\end{array}$ & \\
\hline & Imunorreatividade & Fração imunorreativa & \\
\hline & $\begin{array}{l}\text { Ligação às células do } \\
\text { imunoconjugado radiomarcado } \\
\text { com diferentes atividades } \\
\text { específicas }\end{array}$ & \% Ligação específica & \\
\hline & $\begin{array}{l}\text { Radiomarcação em diferentes } \\
\text { condições }\end{array}$ & $\begin{array}{l}\text { \% Pureza } \\
\text { radioquímica }\end{array}$ & \multirow{2}{*}{$\begin{array}{l}\text { Qual a condição de } \\
\text { radiomarcação que } \\
\text { fornece maior pureza } \\
\text { radioquímica e maior } \\
\text { estabilidade? }\end{array}$} \\
\hline & $\begin{array}{l}\text { Estabilidade do } \\
\text { radioimunoconjugado com e sem } \\
\text { estabilizantes }\end{array}$ & $\begin{array}{l}\text { \% Pureza } \\
\text { radioquímica }\end{array}$ & \\
\hline
\end{tabular}

$\mathrm{Na}$ terceira etapa do trabalho realizaram-se os estudos in vivo a fim de caracterizar a farmacocinética do radiofármaco, sua estabilidade in vivo, biodistribuição em camundongos sadios e implantados com tumor. 
TABELA 5 - Estudos realizados, indicadores e questões investigativas da terceira etapa do trabalho.

\begin{tabular}{|c|c|c|c|}
\hline ETAPA & ESTUDOS REALIZADOS & INDICADOR & $\begin{array}{c}\text { QUESTÃO } \\
\text { INVESTIGATIVA }\end{array}$ \\
\hline \multirow{4}{*}{ 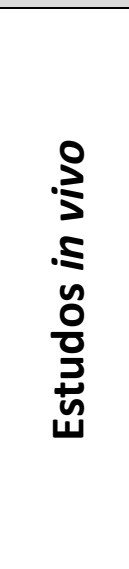 } & $\begin{array}{l}\text { Biodistribuição em } \\
\text { camundongos sadios }\end{array}$ & $\begin{array}{l}\text { \% de captação nos } \\
\text { órgãos }\end{array}$ & \multirow{3}{*}{$\begin{array}{l}\text { O imunoconjugado } \\
\text { radiomarcado com } \\
\text { alta atividade } \\
\text { específica preserva } \\
\text { suas características in } \\
\text { vivo e se liga o tumor? }\end{array}$} \\
\hline & $\begin{array}{l}\text { Farmacocinética em } \\
\text { camundongos sadios }\end{array}$ & $\begin{array}{l}\text { Parâmetros } \\
\text { farmacocinéticos }\end{array}$ & \\
\hline & $\begin{array}{l}\text { Biodistribuição em } \\
\text { camundongos implantados com } \\
\text { tumor }\end{array}$ & $\begin{array}{l}\text { \% de captação no } \\
\text { tumor }\end{array}$ & \\
\hline & Captação de corpo inteiro & $\begin{array}{l}\text { \% captação no corpo } \\
\text { inteiro }\end{array}$ & $\begin{array}{l}\text { Qual o tempo de } \\
\text { residência do } \\
\text { radioimunoconjugado } \\
\text { no organismo? }\end{array}$ \\
\hline
\end{tabular}

O objetivo da quarta etapa foi liofilizar o imunoconjugado, formulado nas condições estabelecidas como ideais para radiomarcação, buscando parâmetros de liofilização que preservassem a integridade estrutural, imunorreatividade do imunoconjugado e pureza radioquímica quando radiomarcado com alta atividade de ${ }^{177} \mathrm{Lu}$.

TABELA 6 - Estudos realizados, indicadores e questões investigativas da quarta etapa do trabalho.

\begin{tabular}{|c|c|c|c|}
\hline ETAPA & ESTUDOS REALIZADOS & INDICADOR & $\begin{array}{c}\text { QUESTÃO } \\
\text { INVESTIGATIVA }\end{array}$ \\
\hline \multirow{5}{*}{ 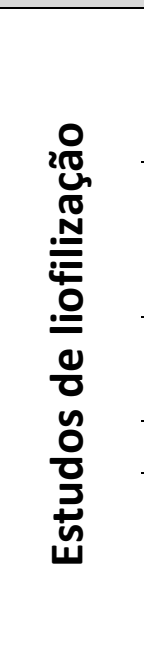 } & $\begin{array}{l}\text { Diferentes formulações do } \\
\text { imunoconjugado e diferentes } \\
\text { protocolos de liofilização }\end{array}$ & $\begin{array}{l}\text { \% de } \\
\text { imunoconjugado } \\
\text { íntegro }\end{array}$ & \multirow{5}{*}{$\begin{array}{l}\text { Qual o efeito da } \\
\text { liofilização sobre a } \\
\text { integridade estrutural, } \\
\text { imunorreatividade, } \\
\text { rendimento de } \\
\text { radiomarcação e } \\
\text { estabilidade do } \\
\text { imunoconjugado? }\end{array}$} \\
\hline & $\begin{array}{l}\text { Eletroforese em gel de } \\
\text { poliacrilamida }\end{array}$ & $\begin{array}{l}\text { \% de } \\
\text { imunoconjugado } \\
\text { íntegro }\end{array}$ & \\
\hline & $\begin{array}{l}\text { Eficiência de radiomarcação do } \\
\text { liofilizado }\end{array}$ & $\begin{array}{l}\text { \% Pureza } \\
\text { radioquímica }\end{array}$ & \\
\hline & Imunorreatividade & Fração imunorreativa & \\
\hline & Estabilidade do radiomarcado & $\begin{array}{l}\text { \% Pureza } \\
\text { radioquímica e } \\
\text { estabilidade da } \\
\text { radiomarcação }\end{array}$ & \\
\hline
\end{tabular}




\section{ESTUDOS DE CONJUGAÇÃO E RADIOMARCAÇÃO}

Neste capítulo apresentam-se os objetivos específicos, materiais, métodos, resultados, discussões e conclusões referentes aos estudos de conjugação e radiomarcação que constituíram a primeira e segunda etapa do trabalho.

\subsection{OBJETIVOS ESPECÍFICOS}

Os objetivos específicos desta etapa do trabalho foram:

$\checkmark$ Conjugar o rituximabe ao DOTA-NHS-éster utilizando diferentes razões molares AcM:DOTA e avaliar a influência na pureza radioquímica e imunorreatividade;

Analisar a estabilidade do imunoconjugado quando armazenado a 2 - $8{ }^{\circ} \mathrm{C}$;

$\checkmark$ Analisar a estabilidade do radioimunoconjugado em diferentes condições de armazenamento;

Analisar a estabilidade do radioimunoconjugado em soro humano;

$\checkmark$ Determinar a porcentagem de ligação do radioimunoconjugado às células do plasma.

\subsection{MATERIAIS}

\subsubsection{Infraestrutura}

Os ensaios foram realizados nos laboratórios de Pesquisa e Desenvolvimento do Centro de Radiofarmácia, no laboratório de Cultivo Celular do Centro de Biotecnologia e no Biotério, sendo todas as dependências sitiadas na área do IPEN. Esses laboratórios forneceram toda a infraestrutura necessária para a manipulação de materiais radioativos, células e animais, respectivamente. 


\section{Capítulo 5 \\ ESTUDOS DE CONJUGAÇÃO E RADIOMARCAÇÃO}

\subsubsection{Reagentes}

Os principais reagentes utilizados nesta etapa do trabalho foram:

Anticorpo monoclonal anti-CD20 - Rituximabe - (Mabthera ${ }^{\circledR}$ ) (Roche, Brasil);

$\checkmark$ DOTA-NHS-éster (ácido 1,4,7,10-tetraazociclododecano -1,4,7,10-ácido mono tetracetico-

N-hidroxilsuccinamida); (Macrocyclics, EUA);

$\checkmark$ Cloreto de lutécio-177 (IDB, Holanda);

$\checkmark$ Acetato de amônio (Merck, Alemanha);

$\checkmark$ Acetato de sódio trihidratado 99,5\% (Sigma Aldrich, EUA);

$\checkmark$ Ácido acético glacial 100\% (Merck, Alemanha);

$\checkmark$ Ácido L-ascórbico (Sigma Aldrich, EUA);

$\checkmark$ Ácido gentísico (Sigma Aldrich, EUA);

$\checkmark$ Acrilamida (Merck, Alemanha);

$\checkmark$ Água purificada - Purificador Milli-RX 45 (Millipore, EUA);

$\checkmark$ Arsenazo III (Sigma Aldrich, EUA);

$\checkmark$ Azida sódica (Merck, Alemanha);

$\checkmark$ Azul de bromofenol (Merck, Alemanha);

Bicarbonato de sódio (Merck, Alemanha);

Bisacrilamida (Merck, Alemanha);

$\checkmark$ Citrato de sódio (Merck, Alemanha);

$\checkmark$ Cloreto de sódio (Merck, Alemanha);

$\checkmark$ Corante Coomassie Brilliant Blue G-250 (Sigma Aldrich, EUA);

$\checkmark$ Dodecil sulfato de sódio (SDS) (GE Healthcare, Reino Unido);

$\checkmark$ EDTA (Merck, Alemanha);

$\checkmark$ Etanol (Merck, Alemanha);

$\checkmark$ Fosfato de sódio dibásico (Merck, Alemanha);

$\checkmark$ Fosfato de sódio monobásico hidratado (Merck, Alemanha);

$\checkmark$ Gentamicina para uso celular (Sigma Aldrich, EUA);

$\checkmark$ Glicina (Sigma Aldrich, EUA);

$\checkmark$ Glicerol (Merck, Alemanha);

$\checkmark$ Hidróxido de sódio lentilhas (Merck, Alemanha);

$\checkmark$ Manitol (Merck, Alemanha);

Meio de cultura RPMI 1640 (Cultilab, Brasil); 
Metanol (Merck, Alemanha);

Padrão de chumbo (Merck, Alemanha);

Padrão de peso molecular (Promega, EUA);

Penicilina: estreptomicina (Cultibab, Brasil);

Persulfato de amônio (Merck, Alemanha);

Resina Chelex 100 (BioRad, EUA);

Sacarose (Merck, Alemanha);

Soro fetal bovino (Cultilab, Brasil);

TEMED ( $\mathrm{N}, \mathrm{N}, \mathrm{N}, \mathrm{N}$-tetrametil etilenodiamina) (USB);

Tris base ((Sigma Aldrich, EUA);

Anestésico para uso animal cloridrato de quetamina - Dopalen ${ }^{\circledR}$ (Ceva, Brasil);

Relaxante muscular para uso animal cloridrato de xilasina - Ansedan ${ }^{\circledR}$ (Vetbrands, Brasil).

\subsubsection{Equipamentos, materiais e sistemas}

Os principais equipamentos, materiais e sistemas utilizados nesta etapa do trabalho foram:

Agitador/aquecedor Thermomixer Comfort 1,5 mL (Eppendorf, EUA);

Balança analítica (Mettler Toledo, EUA);

$\checkmark$ Calibrador de atividade CRM ${ }^{\mathrm{TM}}$ - 35R (Capintec, EUA);

$\checkmark$ Câmara hemocitométrica de Neubauer (HBG, Alemanha);

$\checkmark$ Centrífuga refrigerada Mikro 220 (Hettich, Alemanha);

$\checkmark$ Cartucho de pré-coluna SEC-S 3000 - 4 x 3,0 mm (Phenomenex, EUA);

$\checkmark$ Contador automático tipo poço com cristal Nal (TI) - D5002 cobra II (Packard-Camberra, EUA);

Coluna BioSep SEC-S 3000 para cromatografia líquida de alta eficiência - 300 x 7,8 mm, 5 $\mu \mathrm{m}$ (Phenomenex, EUA);

$\checkmark$ Coluna Protein-Pak ${ }^{\top M}$ 300SW para cromatografia líquida de alta eficiência - $300 \times 7,5 \mathrm{~mm}$, $5 \mu \mathrm{m}$ (Waters, Japão);

$\checkmark$ Coluna Sephadex G25 - PD-10 (GE Healthcare, Reino Unido);

$\checkmark$ Cromatógrafo líquido de alta eficiência, modelo 1260 Infinity, composto por sistema modulado constituído por bomba G1311B (1260 Quant Pump), injetor automático de 
amostras G1329B (1260 ALS), detector UV G4212B (1260 DAD) e forno G1316A (1260 TCC) (Agilent Technologies, EUA);

$\checkmark$ Detector radioativo (câmara de cintilação - Nal) do sistema CLAE (Agilent), modelo 2x2" Pinhole, acoplado à interface de processamento, modelo Gabi Star (Raytest, Alemanha);

$\checkmark$ Detector radioativo (câmara de cintilação - Nal) do sistema CLAE (Shimadzu) - Shell Jr. 1000/2000 (Shell, EUA);

$\checkmark$ Dispositivo de ultrafiltração (Amicon ${ }^{\circledR}$ Ultra) 10.000 MWCO (Millipore, EUA);

$\checkmark$ Espectrofotômetro Evolution 160 (Thermo Scientific, EUA);

$\checkmark$ Fonte de alta tensão para eletroforese EPS 600 (GE Healthcare, Reuni Unido);

$\checkmark$ GraphPad Prism 5.00 ${ }^{\circledR}$ (GraphPad Software, Inc., USA);

$\checkmark$ Medidor de $\mathrm{pH}$ (Mettler Toledo, EUA);

Suporte cromatográfico de sílica gel 60 em placa de alumina (TLC-SG) (Merck, Alemanha);

$\checkmark$ Material plástico descartável em geral, tais como ponteiras, seringas, tubos cônicos com tampa para reação tipo eppendorf, tubos cônicos tipo Falcon, criotubos e placas de cultura;

Pipetas automáticas (Brand, Alemanha; Socorex, Suíça e Eppendorf, EUA);

Vidraria em geral, tais como béqueres, erlemeyers, balões volumétricos e provetas.

\subsubsection{Células Raji de linfoma de Burkitt humano}

As células Raji, derivadas de linfoma de Burkitt humano, foram adquiridas do Banco de Células do Rio de Janeiro e cultivadas no Centro de Biotecnologia, a $37{ }^{\circ} \mathrm{C}$ e $5 \%$ de $\mathrm{CO}_{2}$ em meio de cultura RPMI 1640 enriquecido com $10 \%$ de soro fetal bovino (SFB) e contendo penicilina (100.000 unidades/L), estreptomicina (100 mg/L) e gentamicina (40 $\mathrm{mg} / \mathrm{L})$.

\subsection{MÉTODOS}

\subsubsection{Fluxograma da metodologia}

O desenvolvimento do radioimunoconjugado envolveu muitas etapas e contou com diversas metodologias. Com o intuito de fornecer ao leitor uma visão ampla das etapas que envolveram a primeira e segunda etapa deste trabalho, apresentam-se nas FIGURAS 3 e 4 os fluxogramas descrevendo a sequência lógica da obtenção do radioimunoconjugado. 


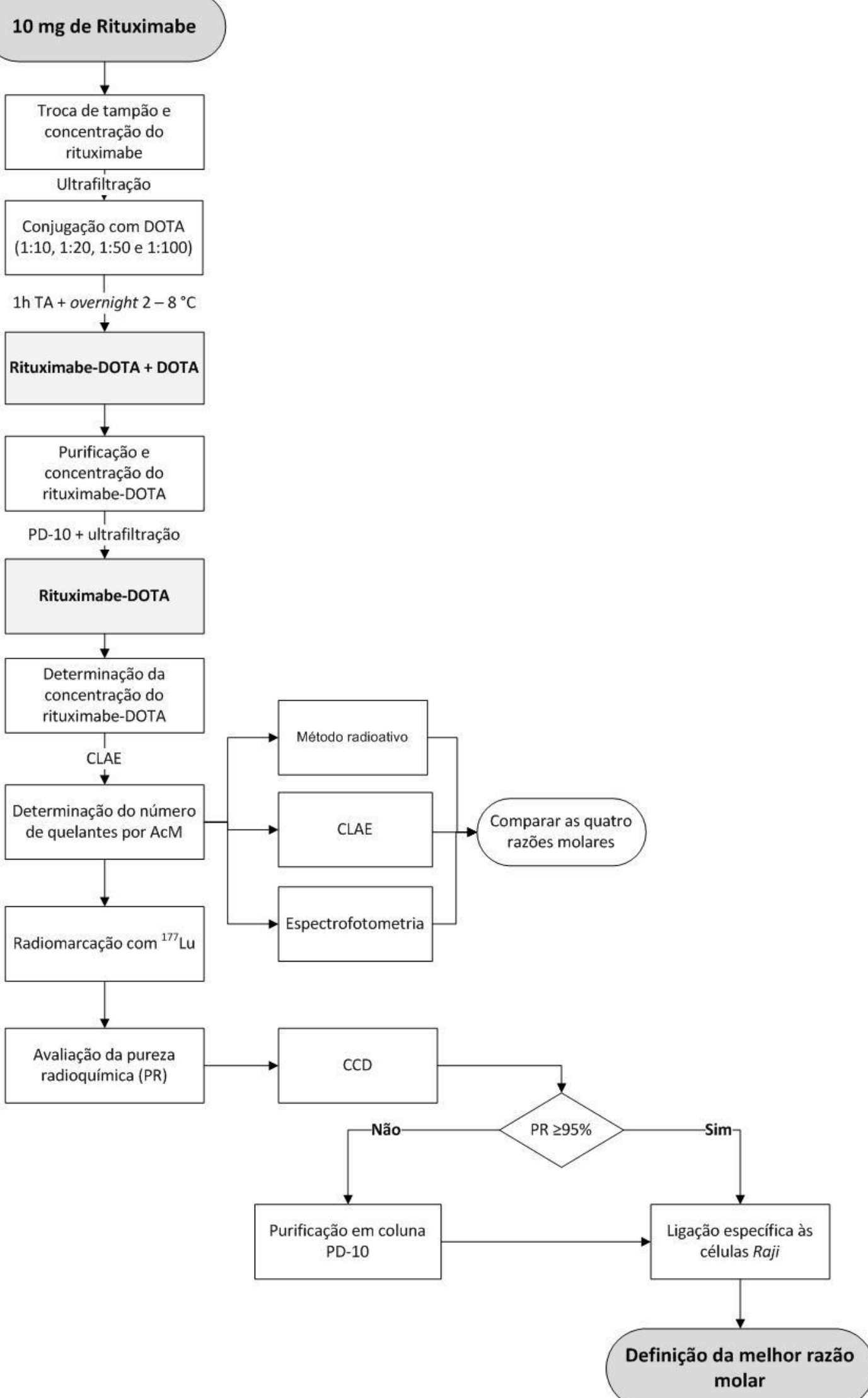

FIGURA 3 - Fluxograma dos métodos empregados no desenvolvimento do imunoconjugado. 


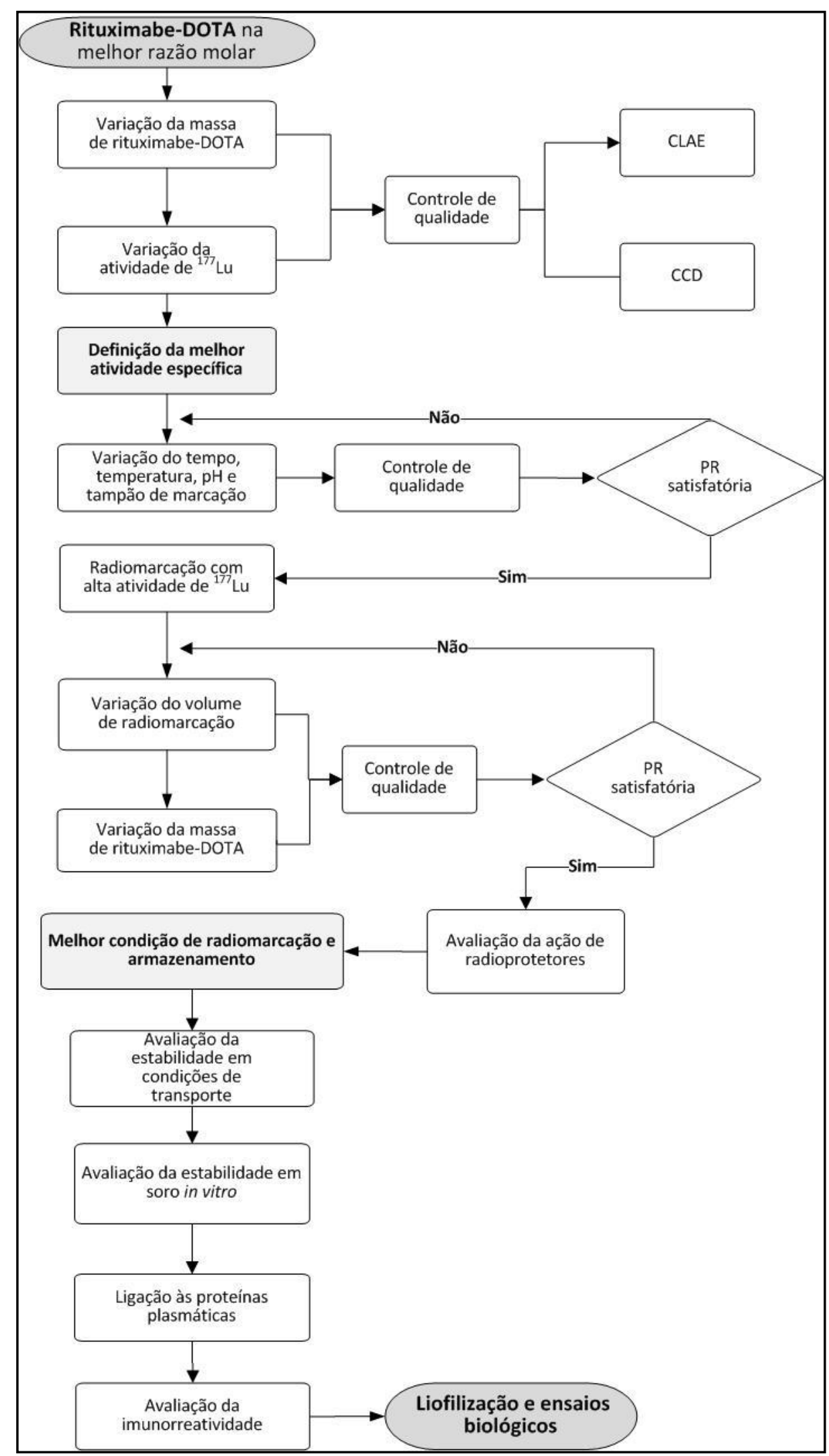

FIGURA 4 - Fluxograma dos métodos empregados no desenvolvimento do radioimunoconjugado. 


\section{Capítulo 5 \\ ESTUDOS DE CONJUGAÇÃO E RADIOMARCAÇÃO}

\subsubsection{Desenvolvimento do imunoconjugado}

\subsubsection{Troca de tampão do anti-CD20}

Antes de quaisquer ensaios, o anticorpo monoclonal (AcM) foi submetido à ultrafiltração para a retirada de estabilizantes e conservantes presentes na formulação do AcM (cloreto de sódio, citrato de sódio e polisorbato 80 ), além de promover a troca do tampão ${ }^{51}$.

Foi utilizado um dispositivo de ultrafiltração de proteínas (Amicon Ultra $15^{\circledR}$ Millipore) com especificação do poro da membrana de 10.000 Da.

Adicionou-se $10 \mathrm{mg}(1 \mathrm{~mL})$ de AcM na parte superior do tubo e o volume foi

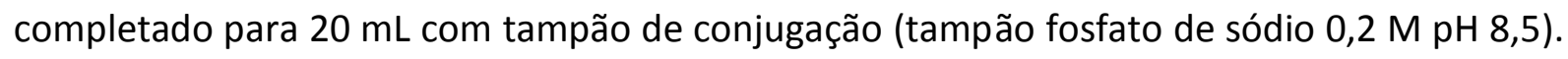
O tubo foi centrifugado a $3000 \mathrm{~g}$ por 30 minutos sob refrigeração $\left(7^{\circ} \mathrm{C}\right)$. Após a centrifugação, o volume foi novamente completado para $20 \mathrm{~mL}$ com o mesmo tampão e o tubo foi novamente centrifugado. Segundo o fabricante dos tubos, são necessárias três centrifugações para a troca total do tampão.

Em seguida, o AcM foi concentrado até aproximadamente $10 \mathrm{mg} / \mathrm{mL}$. Para isso, o tubo foi submetido à centrifugação sob as mesmas condições, sem adicionar tampão, pelo número de vezes necessário para se obter a concentração desejada (10 mg/mL). A amostra foi então retirada da parte superior do tubo e utilizada no processo de conjugação.

A concentração do anticorpo foi estimada analisando-se o anticorpo em espectrofotômetro a $280 \mathrm{~nm}$ e dividindo-se a absorbância pelo coeficiente de extinção $(1,49)$ 96

Todas as soluções utilizadas na purificação, conjugação e radiomarcação, foram preparadas com água purificada por equipamento de osmose reversa e tratada com resina trocadora de íons (Chelex 100) para remoção de íons metálicos.

\subsubsection{Conjugação do anti-CD20 ao DOTA}

\section{A) Método 1 (conjugação padrão)}

O método padrão de conjugação foi adaptado da literatura ${ }^{4,51,52,97-99}$. Assim, um volume equivalente a $10 \mathrm{mg}$ de AcM purificado, foi adicionado ao DOTA-NHS-éster em 
diferentes razões molares anticorpo : DOTA (1:10, 1:20, 1:50 e 1:100). Quando necessário, o $\mathrm{pH}$ da reação foi ajustado para 8,5 com auxílio de tampão fosfato de sódio $0,2 \mathrm{M} \mathrm{pH} \mathrm{8,5.} \mathrm{A}$ mistura permaneceu 1 hora sob agitação $(500 \mathrm{rpm})$ em temperatura ambiente e depois foi mantida durante toda a noite em geladeira $\left(2-8^{\circ} \mathrm{C}\right)$.

Ao longo do texto, caso não seja mencionada diferenciação entre o Método 1 e 2, deve-se considerar que a conjugação foi realizada pelo Método 1.

B) Método 2

Um volume equivalente a $10 \mathrm{mg}$ de AcM purificado, foi adicionado ao DOTANHS-éster na razão molar anticorpo : DOTA de 1:50. Quando necessário, o pH da reação foi ajustado para 8,5 com auxílio de tampão fosfato de sódio 0,2 M pH 8,5. A mistura permaneceu sob agitação (500 rpm) por 2 horas a $37^{\circ} \mathrm{C}$.

\subsubsection{Purificação do imunoconjugado}

O processo de conjugação é realizado com excesso molar de quelante e este precisa ser retirado para não interferir na radiomarcação. Decorrido o tempo de conjugação, o imunoconjugado (anti-CD20-DOTA) foi purificado por coluna de exclusão molecular (PD10).

A coluna foi equilibrada com $50 \mathrm{~mL}$ de tampão acetato de sódio $0,4 \mathrm{M} \mathrm{pH} \mathrm{7,0} \mathrm{ou}$ tampão acetato de amônio 0,25 M pH 6,5. O volume do imunoconjugado foi ajustado para $2,5 \mathrm{~mL}$, adicionado no topo da coluna e eluído com o mesmo tampão utilizado para equilibrar a coluna. Dez amostras de $1 \mathrm{~mL}$ foram coletadas e as absorbâncias das amostras foram analisadas em um espectrofotômetro em comprimento de onda de $280 \mathrm{~nm}$. Além deste controle em espectrofotômetro, as dez frações foram analisadas por cromatografia líquida de alta eficiência (CLAE) a fim de identificar quais frações continham o imunoconjugado. Para tanto, $20 \mu \mathrm{L}$ de cada fração foram analisadas em um sistema Agilent equipado com detector UV 190 - 300 nm e coluna de exclusão molecular Protein-Pak 300 SW (Waters, $300 \times 7,5,5 \mu \mathrm{m}$ ). O fluxo empregado foi de $1 \mathrm{~mL} / \mathrm{min}$ utilizando como fase móvel tampão fosfato de sódio 0,1 M pH 7,0 por 15 minutos.

As frações que continham o imunoconjugado foram misturadas e posteriormente concentradas (item 5.3.2.4). 


\subsubsection{Concentração do imunoconjugado}

O procedimento de concentração foi semelhante ao descrito no item 5.3.2.1, exceto que não foi adicionado tampão ao final de cada ciclo de centrifugação. 0 imunoconjugado foi concentrado até aproximadamente $10 \mathrm{mg} / \mathrm{mL}$ e utilizado para os demais experimentos ${ }^{98}$.

\subsubsection{Cálculo da concentração proteica do imunoconjugado}

Uma curva de calibração foi construída com o AcM não conjugado utilizando-se diluição seriada, obtendo-se concentrações entre 1 e $10 \mathrm{mg} / \mathrm{mL}$. Vinte microlitros de cada solução foram analisados por exclusão molecular utilizando-se a técnica de CLAE. Foi utilizado um sistema Agilent equipado com coluna de Protein-Pak 300 SW (Waters, $300 x$ 7,5, $5 \mu \mathrm{m}$ ). As absorbâncias das amostras foram analisadas em no comprimento de onda de $280 \mathrm{~nm}$. O fluxo empregado foi de $1 \mathrm{~mL} / \mathrm{min}$ utilizando como fase móvel tampão fosfato de sódio $0,1 \mathrm{M} \mathrm{pH} \mathrm{7,0} \mathrm{por} 15$ minutos.

A curva foi construída relacionando-se a concentração do anticorpo com a área sob a curva do pico correspondente. Com a curva calculou-se, a equação da reta e com ela a concentração do imunoconjugado, a partir da determinação da área sob a curva do pico da solução amostra.

\subsubsection{Determinação do número de quelantes por anticorpo}

A) Método de cromatografia líquida de alta eficiência

Uma curva de calibração foi construída com o DOTA-NHS-éster por meio de diluição seriada, obtendo-se concentrações entre 53,91 e $6.900 \mathrm{nmol} / \mathrm{mL}$.

As soluções foram analisadas por exclusão molecular utilizando-se a técnica de CLAE como descrito anteriormente no item 5.3.2.5.

A curva foi construída relacionando-se a concentração do anticorpo com a área sob a curva do pico correspondente. Com a curva calculou-se, a equação da reta e com ela a concentração do imunoconjugado, a partir da determinação da área sob a curva do pico da solução amostra. 
A concentração de DOTA foi determinada em dois momentos: (1) antes da conjugação, imediatamente após a mistura do DOTA com o AcM e (2) após a conjugação e antes da purificação. Desta forma, o número de quelantes por anticorpo foi calculado com o auxílio da seguinte equação:

$$
\text { DOTA inc. }=\text { DOTA a.conj. }- \text { DOTA d.conj. }
$$

Onde:

DOTA inc. = Quantidade de DOTA incorporado após a conjugação em nmol.

DOTA a. conj. = Quantidade de DOTA antes da conjugação em nmol.

DOTA d. conj. = Quantidade de DOTA depois da conjugação em nmol.

O valor encontrado foi então dividido por $69 \mathrm{nmol}$, que é a molaridade de AcM presente em cada conjugação de $10 \mathrm{mg}$. Desta forma, obteve-se o número de quelantes incorporados ao anticorpo.

\section{B) Método espectrofotométrico}

O método utilizado foi adaptado do método proposto por Dadachova e colaboradores (1999) ${ }^{100}$. Uma solução estoque de $\mathrm{Pb}(\mathrm{II})-\mathrm{AA}(\mathrm{III})$ (chumbo-arsenazo) em tampão acetato de amônio $0,15 \mathrm{M} \mathrm{pH} \mathrm{7,0} \mathrm{foi} \mathrm{preparada} \mathrm{contendo} 10 \mu \mathrm{M}$ de AAlll (Arsenazo) e $5 \mu \mathrm{M}$ de $\mathrm{Pb}(\mathrm{II})$, e mantida em frasco âmbar sob refrigeração.

Uma curva padrão foi construída a partir de uma solução de $2 \mathrm{mg} / \mathrm{mL}$ de DOTANHS-éster. Desta forma, 0 - $25 \mu \mathrm{L}$ de DOTA-NHS-éster foram adicionados a $850 \mu \mathrm{L}$ de solução de $\mathrm{Pb}(\mathrm{II})-\mathrm{AA}(\mathrm{III}), 125$ - $150 \mu \mathrm{L}$ de tampão acetato de amônio 0,15 M pH 7,0 e $50 \mu \mathrm{L}$ de solução de $\mathrm{NaCl} 1 \mathrm{mg} / \mathrm{mL}$, de forma a obter um volume final de $1.050 \mu \mathrm{L}$. Deixou-se reagir por 20 minutos à temperatura ambiente e ao abrigo da luz.

Após o tempo de reação, as amostras foram analisadas em um espectrofotômetro em comprimento de onda de $590 \mathrm{~nm}$. O mesmo procedimento foi realizado para as amostras do anticorpo conjugado: adicionando-se $50 \mu \mathrm{L}$ de cada amostra a $100 \mu \mathrm{L}$ de tampão acetato de amônio 0,15 M pH 7,0 seguido de $50 \mu \mathrm{L}$ de solução de $\mathrm{NaCl} 1$ $\mathrm{mg} / \mathrm{mL}$ e $850 \mu \mathrm{L}$ de solução de $\mathrm{Pb}(\mathrm{II})-\mathrm{AA}(\mathrm{III})$.

A concentração de quelante presente na amostra foi calculada mediante da equação da reta obtida por meio da curva de calibração. O valor encontrado foi dividido pela 
massa de AcM presente na amostra e desta forma obteve-se o número de quelantes por anticorpo.

\section{C) Método radioativo}

Ao término da imunoconjugação e antes da purificação, duas alíquotas de $10 \mu \mathrm{L}$ foram retiradas da mistura de reação. Adicionou-se a elas $1,85 \mathrm{MBq}(50 \mu \mathrm{Ci})$ de ${ }^{177} \mathrm{LuCl}_{3}$ e o volume foi completado para $200 \mu \mathrm{L}$ com tampão acetato de amônio $0,25 \mathrm{M} \mathrm{pH} 6,5$. A reação ocorreu sob agitação leve (350 rpm) por 1 hora a $43^{\circ} \mathrm{C}$.

As amostras foram analisadas por cromatografia em camada delgada (ITLC-SG), utilizando-se tampão acetato de sódio $0,1 \mathrm{M} \mathrm{pH} \mathrm{5,0} \mathrm{como} \mathrm{fase} \mathrm{móvel.} \mathrm{A} \mathrm{fração} \mathrm{de}$ radioatividade na origem da fita (anti-CD20-DOTA- ${ }^{177} \mathrm{Lu}$ ) foi multiplicada pela razão molar utilizada na conjugação para calcular o número de quelantes acoplados ao anticorpo.

\subsubsection{Análise da integridade estrutural do imunoconjugado por eletroforese em gel de poliacrilamida}

O anticorpo conjugado na razão molar 1:50 utilizando-se os dois métodos de conjugação, foi analisado por eletroforese de acordo com o método descrito por Laemmli $(1970)^{101}$. O gel de empilhamento foi preparado com $5 \%$ de acrilamida/bisacrilamida e o gel de resolução com $10 \%$ de acrilamida/bisacrilamida.

As amostras foram diluídas em tampão de amostra redutor (glicerol, SDS $10 \%$, Tris $1 \mathrm{M}, \mathrm{pH}$ 6,8, beta-mercaptoetanol e azul de bromofenol) (1:1 v/v) e aquecidos a $90^{\circ} \mathrm{C}$ por aproximadamente 5 segundos. Posteriormente, foram adicionadas $10 \mu \mathrm{g}$ destas soluções em cada poço do gel e o conjunto foi submetido à eletroforese sob voltagem de 35 V por 11 horas. O gel foi corado com Coomassie brilliant blue G 250. 


\subsubsection{Análise da estabilidade do imunoconjugado}

A estabilidade da conjugação (método 1 e 2 de conjugação) foi analisada armazenando-se o imunoconjugado, já purificado, por até 10 meses a $2-8{ }^{\circ} \mathrm{C}$. Ao final de cada tempo, as amostras de imunoconjugado foram analisadas por exclusão molecular utilizando-se a técnica de CLAE, a fim de se avaliar a integridade proteica, o possível desacoplamento do quelante e a formação de agregados. A metodologia de análise por CLAE está descrita no item 5.3.2.5.

Foram avaliados também o pH, a aparência (límpido e incolor) e a presença de partículas visíveis nos imunoconjugados em todos os tempos estudados.

\subsubsection{Desenvolvimento do radioimunoconjugado}

\subsubsection{Análise da pureza radioquímica}

A pureza radioquímica de um radiofármaco é definida como a porcentagem do total da radioatividade que se encontra na forma química desejada, ou seja, a porcentagem de anti-CD20-DOTA- ${ }^{177}$ Lu (radioimunoconjugado) ${ }^{15}$. Para determinar a pureza radioquímica do radioimunoconjugado, foram utilizados dois métodos, a saber:

\section{A) Cromatografia em camada delgada (CCD)}

A CCD foi realizada aplicando-se uma alíquota da mistura de radiomarcação sobre as fitas de sílica gel 60 (ITLC-SG ou TLC-SG) $(1,0 \times 10 \mathrm{~cm})$ e procedeu-se à cromatografia utilizando como fase móvel tampão citrato:ácido cítrico 0,1 M pH 5,0. Neste sistema, o anticorpo radiomarcado permanece na origem da fita $\left(R_{f} 0,0-0,1\right)$ ao passo que as impurezas $\left({ }^{177} \mathrm{Lu}^{3+}\right.$ e DOTA- $\left.{ }^{177} \mathrm{Lu}\right)$, migram com a frente do solvente $\left(R_{f} 0,7-1\right)^{76,102}$.

\section{B) Cromatografia líquida de alta eficiência (CLAE)}

A CLAE foi utilizada para determinar a pureza radioquímica do radioimunoconjugado e avaliar a estabilidade das marcações. Procederam-se as cromatografias por exclusão molecular em um sistema Agilent equipado com detector UV 190 - 300 nm, coluna de exclusão molecular Protein-Pak 300 SW (Waters, 300 x 7,5, 5 m) e detector de radiação gama (Raytest). O fluxo empregado foi de $1 \mathrm{~mL} / \mathrm{min}$ utilizando como 
fase móvel tampão fosfato de sódio $0,1 \mathrm{M} \mathrm{pH} \mathrm{7,0} \mathrm{por} 15$ minutos.

\subsubsection{Aperfeiçoamento do método de radiomarcação do imunoconjugado com lutécio-} 177

A condição padrão de radiomarcação foi adaptada de trabalhos anteriormente publicados ${ }^{12,103}$. Desta forma, a reação de radiomarcação ocorreu por 1 hora a $43{ }^{\circ} \mathrm{C}$ e agitação de 350 rpm em tampão acetato de sódio 0,4 M pH 5,5-6,0 e volume final de $200 \mu \mathrm{L}$.

A) Estudo da relação atividade de ${ }^{177}$ Lu / massa de imunoconjugado (atividade específica)

Este estudo foi realizado com baixa atividade de ${ }^{177}$ Lu com o intuito de, uma vez definida a melhor atividade específica, realizar a extrapolação para altas atividades.

Para tanto, adicionou-se 18,5 - $185 \mathrm{MBq}(0,5-5 \mathrm{mCi})$ de ${ }^{177} \mathrm{LuCl}_{3}$, diluído em $\mathrm{HCl}$ $0,05 \mathrm{M}$, a diferentes massas $(0,1-1 \mathrm{mg}$ ) de imunoconjugado (conjugado pelo método $1 \mathrm{na}$ razão molar 1:50). A reação de radiomarcação ocorreu na condição padrão anteriormente citada. A pureza radioquímica foi determinada por cromatografia em camada delgada. As marcações foram armazenadas sob refrigeração $\left(2-8^{\circ} \mathrm{C}\right)$, sem adição de conservantes, por até 72 horas. Ao fim de intervalos de tempo específicos, uma alíquota foi recolhida e submetida a controle de pureza radioquímica por CCD, como descrito no item 5.3.3.1 A. Os experimentos foram realizados em triplicata.

B) Estudo das condições de radiomarcação

Foram avaliados três diferentes parâmetros de radiomarcação: tempo, temperatura e $\mathrm{pH}$. Sempre quando um parâmetro de radiomarcação foi alterado, os demais permaneceram conforme descrito na condição padrão de radiomarcação.

Desta forma, adicionou-se $148 \mathrm{MBq}(4 \mathrm{mCi})$ de ${ }^{177} \mathrm{LuCl}_{3}$ diluído em $\mathrm{HCl}$ 0,05 M, a 0,2 mg de imunoconjugado (conjugado pelo método 1 na razão molar 1:50) e o volume foi ajustado para $200 \mu \mathrm{L}$ com tampão acetato de sódio $0,4 \mathrm{M} \mathrm{pH} \mathrm{5,5} \mathrm{ou} \mathrm{7,0.} \mathrm{Incubou-se} \mathrm{a}$ mistura por diferentes tempos (30 minutos a 2 horas) a $43{ }^{\circ} \mathrm{C}$ ou $50{ }^{\circ} \mathrm{C}$ e agitação de 350 rpm. A pureza radioquímica foi determinada por $C C D$, conforme descrito no item 5.3.3.1 A. Os experimentos foram realizados em triplicata. 


\subsubsection{Estudos de radiomarcação com alta atividade de lutécio-177}

A) Estudo da influência do volume de radiomarcação na pureza radioquímica

A melhor relação massa de imunoconjugado/ atividade de ${ }^{177}$ Lu encontrada nos estudos anteriores $(0,2 \mathrm{mg} / 4 \mathrm{mCi} ; 740 \mathrm{MBq} / \mathrm{mg})$ foi extrapolada a uma atividade ideal para tratamento proposta por Forrer e colaboradores ${ }^{7}$. Assim, 2 mg de imunoconjugado (conjugado pelo método 1 na razão molar 1:50), foram radiomarcados com $1.480 \mathrm{MBq}$ (40 $\mathrm{mCi}) \mathrm{de}{ }^{177} \mathrm{LuCl}_{3}(740 \mathrm{MBq} / \mathrm{mg})$. O volume final foi ajustado para $0,5 \mathrm{~mL}$ ou $1 \mathrm{~mL}$ com tampão acetato de sódio $0,4 \mathrm{M} \mathrm{pH} \mathrm{5,5}$ e a reação ocorreu por 1 hora a $43^{\circ} \mathrm{C}$ com agitação de 500 rpm. A pureza radioquímica foi determinada por CCD, como descrito no item 5.3.3.1 A. Os experimentos foram realizados, no mínimo, em triplicata.

\section{B) Estudo da influência da massa de imunoconjugado na pureza radioquímica}

Adicionou-se $1.480 \mathrm{MBq}(40 \mathrm{mCi})$ de ${ }^{177} \mathrm{LuCl}_{3}$ diluído em $\mathrm{HCl}$ 0,05 M, a 2 ou $5 \mathrm{mg}$ de imunoconjugado (conjugado pelo método 1 na razão molar 1:50) e o volume foi ajustado para $1 \mathrm{~mL}$ com tampão acetato de sódio $0,4 \mathrm{M} \mathrm{pH} \mathrm{5,5.} \mathrm{Incubou-se} \mathrm{a} \mathrm{mistura} \mathrm{por} 1$ hora a $43^{\circ} \mathrm{C}$ e agitação de $500 \mathrm{rpm}$. A pureza radioquímica foi determinada por CCD, como descrito no item 5.3.3.1 A. Os experimentos foram realizados, no mínimo, em triplicata.

\section{C) Estudo da influência do tampão e pH na radiomarcação na pureza radioquímica}

Adicionou-se $1.480 \mathrm{MBq}(40 \mathrm{mCi})$ de ${ }^{177} \mathrm{LuCl}_{3}$, diluído em $\mathrm{HCl}$ 0,05 M, a $2 \mathrm{mg}$ de imunoconjugado (conjugado pelo método 1 na razão molar 1:50). O volume foi ajustado para $1 \mathrm{~mL}$ com tampão acetato de sódio $0,4 \mathrm{M} \mathrm{pH} \mathrm{5,5,} \mathrm{ou} \mathrm{tampão} \mathrm{acetato} \mathrm{de} \mathrm{amônio} \mathrm{0,25} \mathrm{M}$ pH 5,5; 6,0 ou 6,5. Incubou-se a mistura por 1 hora a $43{ }^{\circ} \mathrm{C}$ e agitação de $500 \mathrm{rpm} A$ pureza radioquímica foi determinada por $\mathrm{CCD}$ e/ou CLAE como descrito no item 5.3.3.1 A. Os experimentos foram realizados em triplicata.

\subsubsection{Purificação do anti-CD20-DOTA- ${ }^{177}$ Lu em coluna PD-10}

Quando necessário, o anti-CD20-DOTA- ${ }^{177}$ Lu foi purificado em coluna de exclusão molecular (PD-10).

O produto foi adicionado no topo da coluna e eluído com solução de $\mathrm{NaCl} 0,9 \%$. Dez frações de $1 \mathrm{~mL}$ foram coletadas e analisadas em um calibrador de atividade ajustado 
para o radioisótopo ${ }^{177} \mathrm{Lu}$. Os tubos correspondentes ao anticorpo radiomarcado foram submetidos a controle de qualidade por CCD para verificar a pureza radioquímica

\subsubsection{Avaliação da estabilidade do anti-CD20-DOTA- ${ }^{177} \mathrm{Lu}$}

A) Estudo do efeito de agentes estabilizantes

Adicionou-se $1.480 \mathrm{MBq}(40 \mathrm{mCi})$ de ${ }^{177} \mathrm{LuCl}_{3}$, diluído em $\mathrm{HCl} 0,05 \mathrm{M}$, a $2 \mathrm{mg}$ de imunoconjugado (conjugado pelo método 1 na razão molar 1:50). O volume foi ajustado para $1 \mathrm{~mL}$ com tampão acetato de sódio $0,4 \mathrm{M} \mathrm{pH} \mathrm{5,5.} \mathrm{Incubou-se} \mathrm{a} \mathrm{mistura} \mathrm{por} 1$ hora a 43 ${ }^{\circ} \mathrm{C}$ e agitação de $500 \mathrm{rpm}$. Após a radiomarcação, o anticorpo foi diluído com $3 \mathrm{~mL}$ de solução de $\mathrm{NaCl}$ 0,9\% (volume final de $4 \mathrm{~mL}$ ) contendo como agente estabilizante ácido ascórbico $(10 \mathrm{mg} / \mathrm{mL})$ ou ácido gentísico $(10 \mathrm{mg} / \mathrm{mL})$ ou etanol $(10 \% \mathrm{v} / \mathrm{v})$. Após a avaliação da pureza radioquímica imediata, as soluções foram congeladas à $-20^{\circ} \mathrm{C}$ por 24 horas.

Decorrido este tempo, a pureza radioquímica foi determinada novamente por CCD e/ou CLAE (item 5.3.3.1 A e B). O anti-CD20-DOTA- ${ }^{177}$ Lu diluído e não acrescido de estabilizantes, também foi congelado e a sua estabilidade avaliada no mesmo tempo. Os experimentos foram realizados em triplicata.

B) Estudo da estabilidade em condições de transporte: regiões próximas ao centro produtor

O imunoconjugado radiomarcado e diluído como descrito no item anterior foi mantido à $-20{ }^{\circ} \mathrm{C}$ por 4 horas. Decorrido este tempo, o anticorpo foi descongelado (até temperatura ambiente) e mantido sob refrigeração $\left(2-8^{\circ} \mathrm{C}\right)$ por até 6 horas e a pureza radioquímica foi avaliada, por $\mathrm{CCD}$, em diferentes tempos. Os experimentos foram realizados em duplicata.

C) Estudo da estabilidade em condições de transporte: regiões distantes do centro produtor O imunoconjugado radiomarcado com atividade específica de 296, 740 e 925 $\mathrm{MBq} / \mathrm{mg}$ foi purificado em coluna de exclusão molecular (PD-10), as frações correspondentes ao anti-CD20- ${ }^{177} \mathrm{Lu}$ foram misturadas e o volume ajustado para $4 \mathrm{~mL}$. O anti-CD20- ${ }^{177} \mathrm{Lu}$ foi mantido à $-20{ }^{\circ} \mathrm{C}$ por 24 e 48 horas. Decorrido estes tempos, o anticorpo foi descongelado (até temperatura ambiente) e mantido sob refrigeração $\left(2-8^{\circ} \mathrm{C}\right)$ por até 6 horas e a pureza radioquímica foi avaliada, por CCD, em diferentes tempos. Os experimentos 


\section{Capítulo 5 \\ ESTUDOS DE CONJUGAÇÃO E RADIOMARCAÇÃO}

foram realizados em duplicata.

\section{D) Estabilidade em plasma in vitro}

Quinze mililitros de sangue humano foram coletados, com coagulante, de doador sadio e centrifugados a 3.000 rpm por 10 minutos para separação do plasma.

Decorrido o tempo, retirou-se uma alíquota das misturas (200 $\mu \mathrm{L})$; adicionou-se etanol $(1: 1 \mathrm{v} / \mathrm{v})$ para precipitação das proteínas plasmáticas e centrifugou-se a $9.720 \mathrm{~g}$ (10.000 rpm). Uma alíquota do sobrenadante foi submetida à CCD conforme descrito no item 5.3.3.1 A para avaliação da pureza radioquímica. Os ensaios foram realizados em duplicata com dois lotes diferentes de imunoconjugados.

\subsubsection{Estudos in vitro}

\subsubsection{Ensaio de ligação específica às células Raji}

Os ensaios de ligação específica do anti-CD20-DOTA- ${ }^{177}$ Lu foram realizados com células Raji e a metodologia foi adaptada da literatura ${ }^{81,104}$. O anticorpo marcado foi diluído em meio de cultura contendo $1 \%$ de soro fetal bovino (SFB) (v/v) a uma concentração radioativa de $400 \mathrm{cpm} / \mu \mathrm{L}$. O anticorpo não radiomarcado (4 $\mu \mathrm{M}$ em meio de cultura contendo $1 \%$ de SFB v/v) foi utilizado como competidor. O ensaio foi realizado por meio da adição de diferentes quantidades de células $\left(0,125,0,25,0,5\right.$ e 1,0 × $10^{6}$ células) em $0,5 \mathrm{~mL}$ de meio de cultura contendo $1 \% \mathrm{v} / \mathrm{v} \mathrm{SFB}$, a tubos cônicos de 1,5 mL, seguido da adição de $250 \mu \mathrm{L}$ de meio de cultura (1 \% SFB) (ligação total) ou $250 \mu \mathrm{L}$ da solução do competidor (ligação não-específica) e $250 \mu \mathrm{L}$ da solução contendo o marcador molecular diluído. As células foram incubadas a temperatura ambiente por $1 \mathrm{~h}$, centrifugadas a 3.000 rpm por 5 minutos, lavadas duas vezes com $1 \mathrm{~mL}$ de meio de cultura contendo $1 \% \mathrm{v} / \mathrm{v}$ SFB e contadas em contador gama, juntamente com um padrão da atividade total adicionada. As curvas de porcentagem de ligação total, ligação específica e não-específica em relação ao número de células foram construídas utilizando-se o programa estatístico GraphPad Prism $5.0^{\circledR}$. O experimento foi realizado em triplicata e com três lotes diferentes de imunoconjugados. 


\section{Capítulo 5 \\ ESTUDOS DE CONJUGAÇÃO E RADIOMARCAÇÃO}

\subsubsection{Análise da influência da atividade específica na ligação às células}

O imunoconjugado foi radiomarcado em quatro diferentes atividades específicas (296, 370, 740 e 925 MBq/mg) em seguida foi analisado quanto à capacidade de ligação específica às células.

Assim, procedeu-se o ensaio conforme descrito no item 5.3.4.1, contudo não se utilizou uma quantidade variada de células e apenas o ponto de $1,5 \times 10^{6}$ células foi avaliado para todas as atividades específicas consideradas. Os ensaios foram realizados com um único lote de imunoconjugado, mas com duplicata de tubos intraensaio.

\subsubsection{Avaliação da imunorreatividade}

O método utilizado para avaliar a imunorreatividade do anticorpo foi proposto por Lindmo e colaboradores (1984 e 1986). O radioimunoconjugado foi diluído em meio de cultura (1 \% SFB) a uma concentração de aproximadamente $40 \mathrm{ng} / \mathrm{mL}$. Como competidor, foi utilizado o próprio anticorpo não conjugado e não radiomarcado, diluído a uma concentração de $1 \mathrm{mg} / \mathrm{mL}$.

Realizaram-se diluições seriadas a fim de obter as seguintes quantidades de

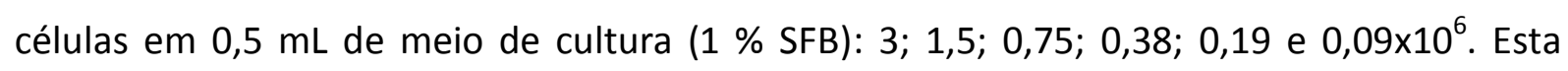
diluição foi realizada seis vezes, sendo um conjunto de 3 diluições utilizado para determinar a porcentagem de ligação específica (LE) e o outro conjunto de três diluições utilizado para determinar a porcentagem de ligação não específica (LNE), obtendo-se assim, triplicata de cada concentração celular para a LE e LNE. Posteriormente, adicionou-se $50 \mu \mathrm{L}$ (50 $\mu \mathrm{g}$ ) da solução de competidor ao conjunto de diluições referentes à ligação não-específica, seguido de incubação por 30 minutos a $4{ }^{\circ} \mathrm{C}$ sob agitação banda. Em seguida, adicionou-se $250 \mu \mathrm{L}$ da solução do anticorpo radiomarcado a todos os tubos (ligação específica e ligação não específica). As células foram homogeneizadas e incubadas por 1 hora a $4{ }^{\circ} \mathrm{C}$ sob agitação banda. Decorrido o tempo de incubação, as células foram centrifugadas a $3000 \mathrm{rpm}$ por 5 minutos, lavadas três vezes com meio de cultura (1\% SFB) e os precipitados de células foram contados em contador gama, juntamente com um padrão da atividade total adicionada.

As curvas de porcentagem de ligação total, ligação específica e não-específica em relação ao número de células foram construídas utilizando o programa estatístico GraphPad Prism $5.00^{\circ}$. O experimento foi realizado em triplicata. 


\section{Capítulo 5 \\ ESTUDOS DE CONJUGAÇÃO E RADIOMARCAÇÃO}

As porcentagens da ligação total, ligação não-específica, e ligação específica, foram calculadas e utilizando o programa estatístico GraphPad Prism 5.0 foram construídos gráficos relacionando a concentração de células ( $\mathrm{mL} / \mathrm{milhão}$ de células) versus a ligação total /ligação específica e os dados foram ajustados para uma curva de regressão linear. O valor de $Y$ quando $X$ foi igual a zero, corresponde à fração imunorreativa $(r$ ) expressa em $1 / r$.

O ensaio foi realizado em triplicata e com três lotes diferentes de imunoconjugados.

\subsubsection{Ligação do anti-CD20-DOTA- ${ }^{177}$ Lu às proteínas do plasma in vitro}

Quinze mililitros de sangue humano foram coletados, com coagulante, de doador sadio e centrifugados a $1400 \mathrm{~g}$ (1500 rpm) por 10 minutos para separação do plasma.

Adicionou-se, em duplicata, $37 \mathrm{MBq}(1 \mathrm{mCi})$ de anti-CD20-DOTA- ${ }^{177} \mathrm{Lu}$, radiomarcado com atividade específica de $740 \mathrm{MBq} / \mathrm{mg}$, a $1 \mathrm{~mL}$ de plasma humano e incubou-se a $37{ }^{\circ} \mathrm{C}$ sob agitação de $350 \mathrm{rpm}$ por 24, 48 e 72 horas. Decorrido o tempo, retirou-se uma alíquota das misturas (200 $\mu \mathrm{L})$; adicionou-se etanol (1:1 v/v) para precipitação das proteínas plasmáticas e centrifugou-se a $9.720 \mathrm{~g}$ (10.000 rpm). O sobrenadante foi coletado e a radioatividade nele e no precipitado foi determinada em um contador automático tipo poço devidamente calibrado para o radioisótopo. A porcentagem de anti-CD20-DOTA- ${ }^{177}$ Lu ligados às proteínas plasmáticas (LP) foi determinada pela equação:

$L P(\%)=\frac{\text { Atividade }(c p m) \text { no precipitado }}{\text { Atividade }(c p m) \text { no precipitado }+ \text { Atividade }(\text { cpm }) \text { no sobrenadante }} \times 100$

\subsubsection{Análise estatística}

A análise estatística foi realizada utilizando-se o programa estatístico GraphPad Prism $5.00^{\circledR}$ (GraphPad Software, Inc., San Diego, CA, EUA). Os resultados foram expressos como média \pm erro padrão da média (EPM) ou média \pm desvio padrão (DP).

Para comparar até dois grupos (amostras pareadas ou não), o teste t de Student foi utilizado com distribuição bicaudal. Para a comparação entre três ou mais grupos foi 
utilizado o teste de variância de um fator (one-way ANOVA) ou dois fatores (two-way ANOVA). Quando necessário, os dados foram submetidos a pós-teste (teste de Bonferroni ou de Newman-Keuls de comparações múltiplas). As diferenças foram consideradas significativas quando o valor de $\mathrm{P}$ foi menor do que 0,05 .

\subsection{RESULTADOS E DISCUSSÃO}

\subsubsection{Desenvolvimento do imunoconjugado: escolha da razão molar}

\section{A) Conjugação}

O agente quelante DOTA foi escolhido para conjugação com AcM anti-CD20, pois forma complexos estáveis com muitos metais e em comparação com outros agentes bifuncionais, tais como DTPA, o DOTA fornece complexos radiomarcados com ${ }^{177} \mathrm{Lu}$ mais estáveis in vivo e in vitro ${ }^{12,93,98}$, sendo esta uma importante característica do ponto de vista de desenvolvimento de radiofármacos. No entanto, a conjugação requer uma atenção especial no preparo dos tampões e soluções utilizados na síntese, pois até mesmo concentrações muito baixas de metais são capazes de interagir com o DOTA interferindo na posterior radiomarcação. Para minimizar a quantidade de metais, todos os tampões utilizados foram preparados com água purificada por osmose reversa e tratada com resina trocadora de íons (Chelex 100) ${ }^{52}$.

Ésteres reagem com aminas por reação de adição-eliminação nucleofílica, nos átomos de carbono acíclico, com aminas primárias e secundárias. $O$ esquema genérico desta reação está representado na FIGURA 5 A. A reação de conjugação ocorre em soluções com $\mathrm{pH}$ ligeiramente alcalino ( $\mathrm{pH} 8,0$ - 9,0), pois nestas condições, o grupamento éster sofre reação de hidrólise promovida pela hidroxila (reação de saponificação) e com isso o grupamento carboxílico do quelante se torna altamente seletivo por aminas alifáticas presentes no AcM ${ }^{105,106}$. O esquema da reação do grupamento carboxílico com o grupamento amina do AcM com a saída do grupamento NHS está apresentado na FIGURA 5 B. 

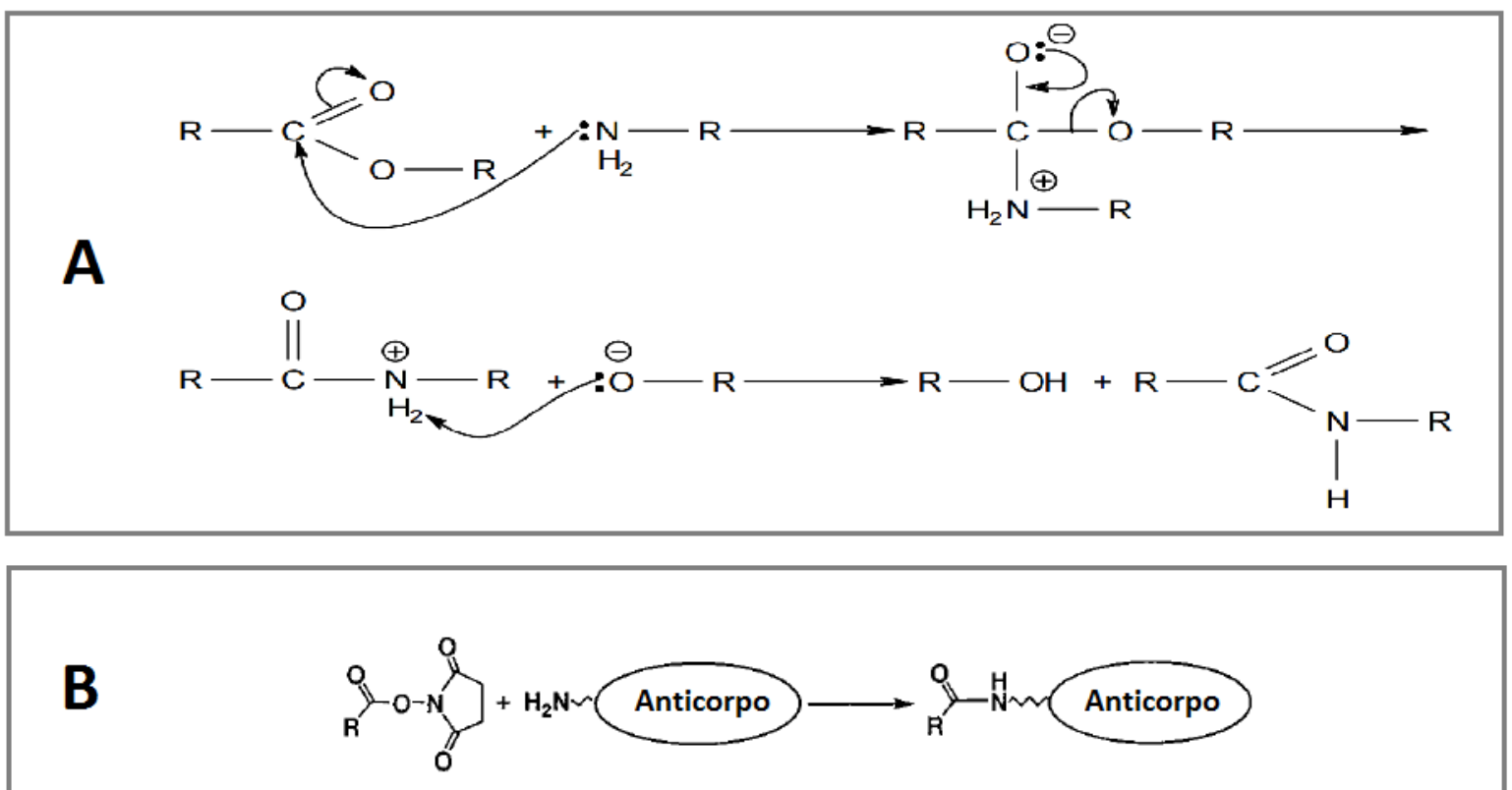

FIGURA 5 - Esquema da reação geral de ésteres com aminas primárias (A) e esquema geral da reação do grupamento NHS-éster do DOTA com grupamentos aminas presentes no AcM. Adaptado de Solomons et al., $2002{ }^{106}$ e Liu et al., $2001^{105}$.

A reação de mais de um grupo carboxílico do quelante pode levar à diminuição da estabilidade do complexo. Por este motivo, a reação de conjugação ocorre com excesso molar de quelante, em relação ao AcM, desta forma, é possível tornar a reação das aminas mais seletivas pelo grupamento éster poupando os outros grupamentos carboxílicos presentes no DOTA ${ }^{107}$.

Todavia, a identificação da melhor razão molar é uma etapa importante e deve ser estudada, uma vez que dependendo da razão molar empregada, pode haver uma incorporação baixa de quelantes resultando em eficiência baixa de radiomarcação e/ou estabilidade prejudicada do AcM radiomarcado. Por outro lado, um grande número de quelantes por anticorpo pode comprometer a imunorreatividade do AcM. Este aspecto será discutido mais adiante.

Neste estudo foram avaliadas quatro razões molares AcM:DOTA diferentes: 1:10, $1: 20,1: 50$ e $1: 100$.

Um controle em processo utilizado para a análise do anticorpo conjugado foi a cromatografia líquida de alta eficiência, utilizando uma coluna de exclusão molecular. Neste 


\section{Capítulo 5 \\ ESTUDOS DE CONJUGAÇÃO E RADIOMARCAÇÃO}

sistema, substâncias com maior peso molecular são eluídas primeiro ${ }^{108}$. Isso significa dizer que o anticorpo conjugado e, portanto, com maior peso molecular, possuirá um tempo de retenção (TR) menor comparado ao anticorpo não conjugado.

Esta mudança no TR foi observada para todas as razões molares estudadas (TABELA 7). No entanto, a diferença entre o TR do anticorpo não conjugado e do anticorpo conjugado pelo método 1 , só foi significativa para as razões $1: 20(P<0,0001), 1: 50$ ( $P$ $<0,0001)$ e 1:100 ( $P<0,0062)$, mostrando que a técnica não foi sensível em demonstrar o incremento de massa do AcM quando se utilizou razão molar 1:10.

Quando o anticorpo foi conjugado pelo método 2 (razão molar 1:50), também foi observada uma diferença significativa no tempo de retenção do AcM não conjugado para o AcM conjugado $(P=0,0003)$.

TABELA 7 - Tempo de retenção (TR) do anticorpo não conjugado e conjugado ao DOTA analisados por CLAE. Resultados expressos em média \pm DP $(n \geq 3)$.

\begin{tabular}{cccc}
\hline Razão & TR do anticorpo não & \multicolumn{2}{c}{ TR do anticorpo conjugado (minutos) } \\
\cline { 3 - 4 } molar & conjugado (minutos) & Método 1 & Método 2 \\
\hline $1: 10$ & $7,33 \pm 0,18$ & $7,20 \pm 0,02$ & nd \\
$1: 20$ & $7,47 \pm 0,01$ & $7,20 \pm 0,09$ & nd \\
$1: 50$ & $7,47 \pm 0,01$ & $7,08 \pm 0,02$ & $6,72 \pm 0,49$ \\
$1: 100$ & $7,33 \pm 0,18$ & $6,93 \pm 0,004$ & nd \\
\hline
\end{tabular}

nd: não determinado

Como já citado, a reação de conjugação ocorre com excesso molar de quelante e este, quando não acoplado à proteína, torna-se um contaminante, interferindo diretamente na eficiência de radiomarcação.

Portanto, após a conjugação e antes da radiomarcação, o imunoconjugado foi purificado em uma coluna de exclusão molecular (PD-10). O resultado da análise espectrofotométrica das frações coletadas está expresso na FIGURA 6.

O perfil sugere uma separação parcial com uma região de intersecção na sexta fração entre o primeiro pico (anticorpo conjugado) e o segundo pico (quelante DOTA). 


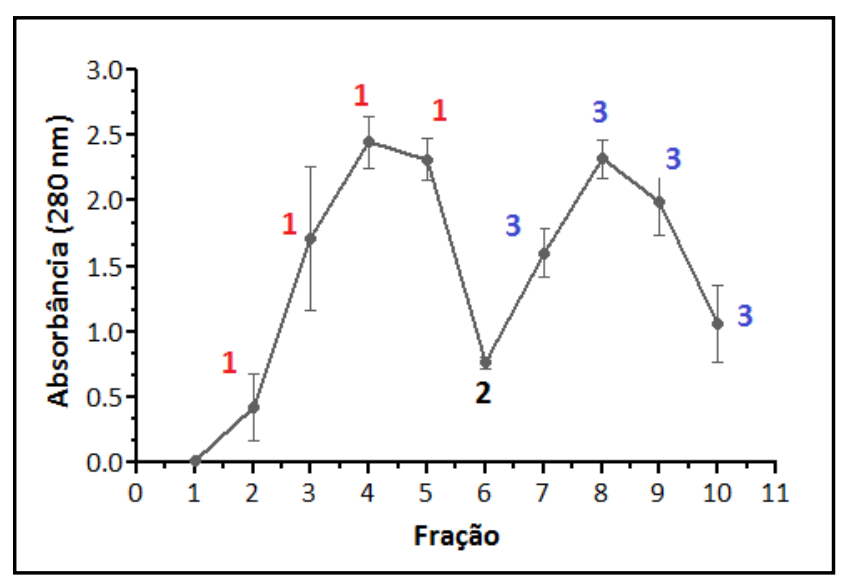

FIGURA 6 - Absorbância (UV, $280 \mathrm{~nm}$ ) das frações de purificação do imunoconjugado em coluna de exclusão molecular (PD-10), utilizando tampão acetato de sódio 0,4 M pH 7,0 como eluente ( $N=6)$. Em (1) frações correspondentes ao AcM; em (2) fração correspondente ao AcM-DOTA e em (3) frações correspondentes ao DOTA.

O princípio do método é o mesmo citado para a CLAE. Desta forma, o anticorpo quelado ou não ao DOTA é eluído primeiro, seguido do quelante livre (DOTA não acoplado à proteína). As frações eluídas na coluna PD-10 também foram analisadas por CLAE (FIGURA 7).

Foi observada predominância de anticorpo nas primeiras frações, correspondentes ao primeiro pico da curva da FIGURA 6. As últimas frações, representadas pelo segundo pico da FIGURA 6, indicaram a presença de DOTA. A fração 6, conforme esperado, indicou presença de anticorpo e DOTA, correspondendo este, ao ponto de intersecção entre as duas curvas da FIGURA 6. Esta sobreposição foi devida, provavelmente, ao tamanho pequeno da coluna PD-10 (10 cm de gel) que impossibilitou a perfeita separação das duas espécies. Colunas de tamanho maiores poderiam ser testadas para aumentar a eficiência do processo, porém demorariam mais tempo para completar a purificação.

Os cromatogramas apresentados na FIGURA 7 apresentaram picos com tempo de retenção diferentes dos informados na TABELA 7, pois, para esta análise, utilizou-se uma coluna cromatográfica diferente (BioSep SEC-S 3000 - Phenomenex). 


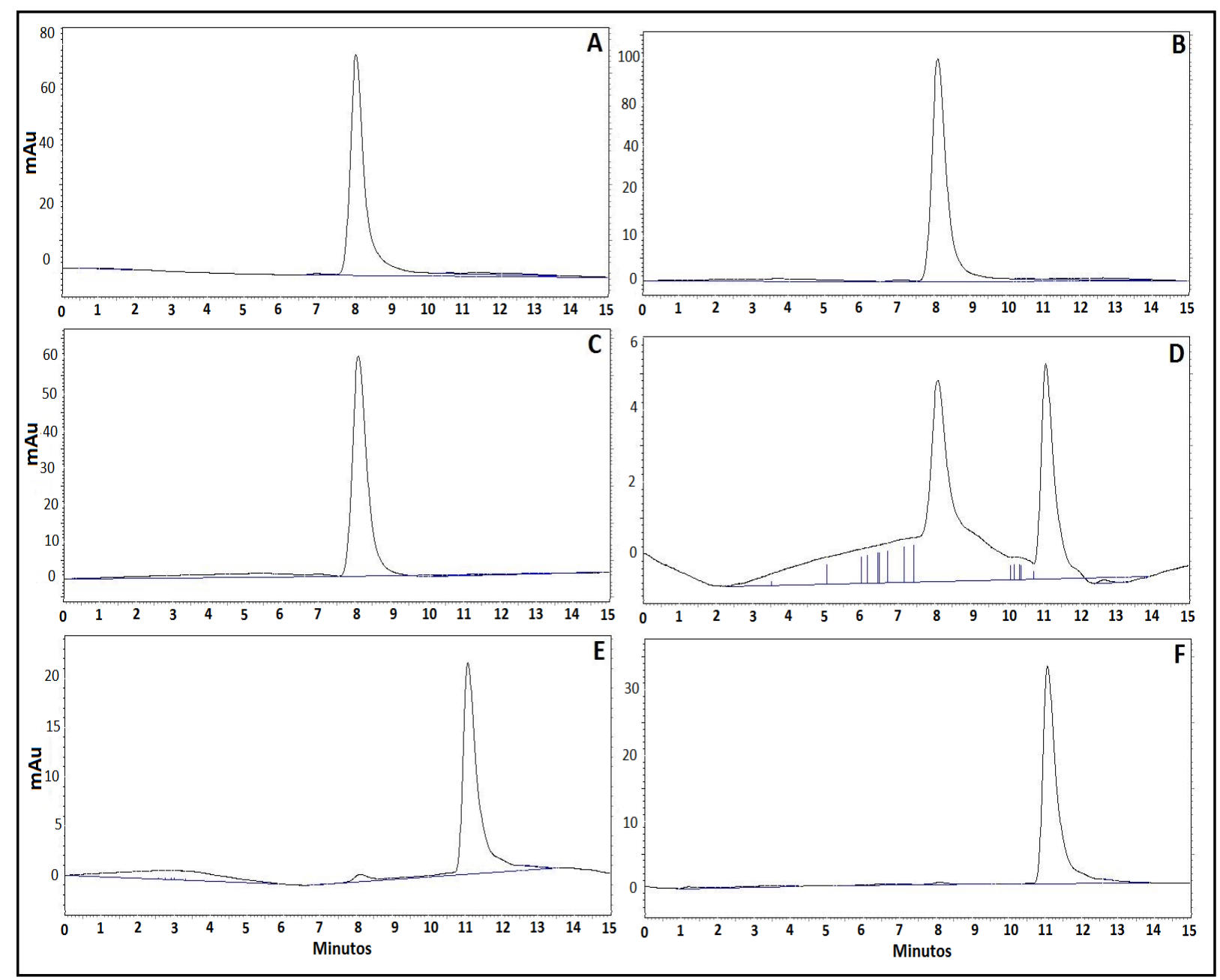

FIGURA 7 - Perfil cromatográfico (UV, $280 \mathrm{~nm}$ ) do imunoconjugado após purificação em coluna de exclusão molecular, utilizando tampão acetato de sódio $0,4 \mathrm{M} \mathrm{pH} \mathrm{7,0} \mathrm{como}$ eluente. Em (A), fração 3; (B) fração 4; (C) fração 5; (D) fração 6; (E) fração 7 e (F) fração

Após esse processo de purificação, as frações que correspondiam ao imunoconjugado, incluindo-se o ponto de intersecção com o DOTA, foram misturadas e concentradas, utilizando-se tubos de ultrafiltração $\left(\right.$ Amicon $\left.{ }^{\circledR}\right)$.

A principal vantagem deste método é que com a utilização de centrifugas refrigeradas, o anticorpo permanece o tempo todo sob uma temperatura ideal $\left(2-8^{\circ} \mathrm{C}\right)$. No entanto, a quantidade necessária de ciclos de centrifugação para se obter um imunoconjugado puro consiste na maior desvantagem. Quase sempre são necessários de 6 a 8 ciclos, cada ciclo com duração de 30 minutos em média.

Como mencionado anteriormente, o método utilizado neste trabalho utilizou uma purificação prévia em coluna PD-10 com posterior concentração em tubos de ultrafiltração. A combinação destes dois métodos reduziu em mais de $50 \%$ o tempo de 
purificação, uma vez que foram necessários apenas dois ciclos de centrifugação para concentrar o imunoconjugado. Além disso, este método forneceu um imunoconjugado puro sem qualquer vestígio de quelante livre, conforme análise por CLAE (FIGURA 8).

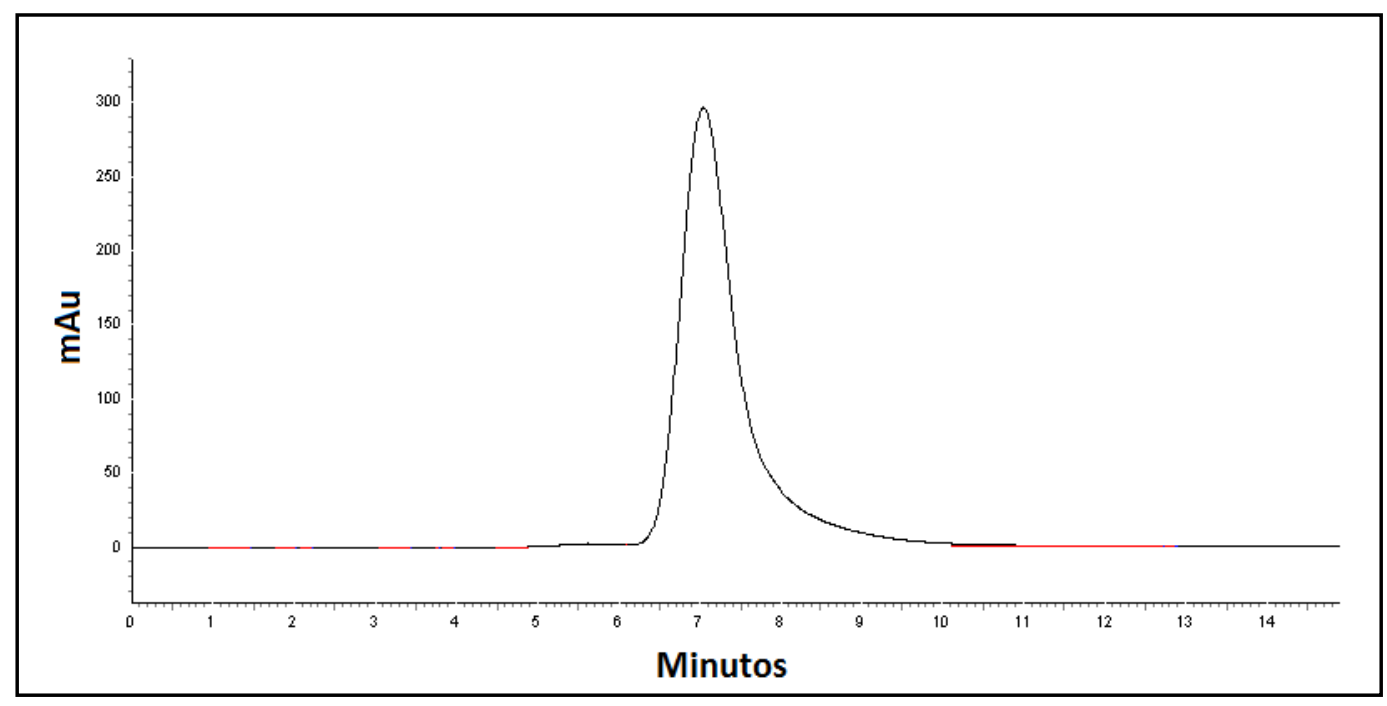

FIGURA 8 - Perfil de CLAE do imunoconjugado purificado e concentrado.

A recuperação proteica encontrada neste método foi alta, $(80,75 \pm 16 \% ; N=51)$ promovendo uma perda percentual média de $19,25 \%(\mathrm{~N}=51)$.

Wojdowska e colaboradores $(2015)^{109}$ compararam diferentes métodos de purificação do AcM antes da conjugação e do imunoconjugado com excesso de quelante. 0 método que resultou em melhor recuperação proteica, 77,2\%, foi o que utilizou ultrafiltração para a purificação do AcM e do imunoconjugado. Quando a diálise foi utilizada para purificar o AcM e a ultrafiltração foi empregada para a purificação do imunoconjugado, a recuperação foi de 50,5\%. O outro método avaliado se assemelha ao utilizado no presente trabalho: utilização de ultrafiltração para a purificação do AcM e colunas PD-10 para purificar o imunoconjugado. Com este método a recuperação proteica foi de apenas $34 \%$, ou seja, $46,75 \%$ a menos comparado ao obtido no presente trabalho.

Em outro estudo, foi relatada uma recuperação entre $46 \%$ a $60 \%$, quando o mesmo método de purificação (ultrafiltração e PD-10 + Ultrafiltração) foi empregado ${ }^{11}$. 
Estes trabalhos, citados acima, encontraram resultados compatíveis com Cooper e colaboradores $(2006)^{98}$ que relataram perda de 10 - 50\% quando apenas o método de purificação por ultrafiltração foi utilizado.

Estes trabalhos têm em comum o uso de tubos de ultrafiltração com tamanho de poro de $30 \mathrm{kDa}$. Aparentemente, quando se utiliza um dispositivo de ultrafiltração com o poro menor, como 10 kDa (utilizado neste trabalho), a recuperação é maior.

Apesar de relativamente pequena, a perda de anticorpo deve ser considerada e o conhecimento exato da concentração proteica, após a conjugação e purificação, é imprescindível para cálculo da atividade específica do radiofármaco e estabelecimento das condições de radiomarcação.

Portanto, uma curva de calibração foi construída por intermédio da análise da área sob a curva dos picos observados em CLAE para diferentes concentrações de anticorpo e a concentração do imunoconjugado determinada por meio da equação da reta (FIGURA 9).

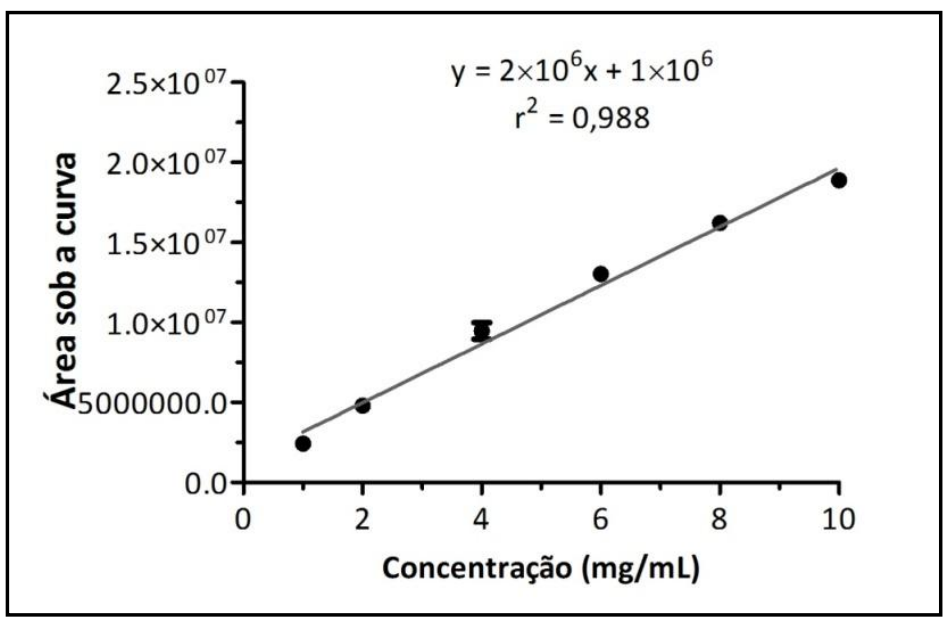

FIGURA 9 - Curva de calibração do anticorpo não conjugado. Resultados expressos em média $\pm \operatorname{EPM}(n=3)$.

A média da concentração do imunoconjugado encontrada, considerando todos os lotes produzidos para este estudo, foi $8,08 \pm 1,6 \mathrm{mg} / \mathrm{mL}(\mathrm{N}=51)$. 


\section{Capítulo 5 \\ ESTUDOS DE CONJUGAÇÃO E RADIOMARCAÇÃO}

\section{B) Cálculo do número de quelantes por anticorpo}

Como mencionado anteriormente, há um crescente esforço para desenvolver radioimunoconjugados para tratamento e diagnóstico de diversas doenças. Um ponto crítico para o sucesso destes radioimunoconjugados é a manutenção da imunorreatividade e das características de ligação destas proteínas após o procedimento de conjugação com o quelante bifuncional ${ }^{100}$. Portanto, para manter um comportamento ótimo e reprodutível do anticorpo radiomarcado nos estudos clínicos, é necessário estabelecer uma relação entre a eficiência de ligação do AcM (imunorreatividade) com o número de quelantes acoplados por molécula de AcM $^{110}$.

Em geral, o aumento do número de ligantes acoplados ao anticorpo, afeta diretamente a imunorreatividade do produto final ${ }^{100}$. Todavia, moléculas com maior quantidade de quelantes incorporados tendem a apresentar maior eficiência de radiomarcação.

Além disso, o objetivo de se acoplar um grande número de quelantes ao AcM é, teoricamente, utilizar quantidade menor, em $\mathrm{mg}$, do imunoconjugado para entregar uma determinada dose terapêutica do radiometal ao tumor. Contudo, na prática isto não ocorre. Foi relatado que a porcentagem de dose injetada no tumor, após 72 horas da administração, foi proporcionalmente menor conforme se aumentou o número de quelantes acoplados ao AcM, isso porque a imunorreatividade deste AcM também diminui com o aumento de quelantes acoplados ${ }^{111}$.

Sendo assim, a influência da razão molar quelante:AcM (Q:AcM), utilizada no processo de conjugação, sobre a imunorreatividade, deve ser estudada.

Existem diversos métodos desenvolvidos para determinar o número de quelantes acoplados ao AcM, sendo a espectrometria de massas (MALDI/TOF ou MALDI/MS) o método mais preciso ${ }^{12}$. No entanto, este método requer uma instrumentação de alto valor e um conhecimento não trivial na interpretação dos resultados ${ }^{100,112}$. Na ausência ou indisponibilidade do equipamento, é possível obter uma estimativa do número de quelantes por AcM utilizando-se métodos espectrofotométricos que se baseiam na formação de complexos coloridos por intermédio da reação do Arsenazo (AAIII) com metais como Y, Cu ou $\mathrm{Pb} 100,110,112$. Estes complexos reagem com o quelante bifuncional presente no imunoconjugado e fornecem uma coloração proporcional à quantidade de quelante na amostra. Por fim, outros métodos muito utilizados são os que utilizam radioisótopos ${ }^{75,97,99}$. 
Neste trabalho, foram utilizados três métodos para determinar o número de quelantes acoplados ao AcM: (1) o método espectrofotométrico utilizando-se um complexo de $\mathrm{Pb}$ (II)-AAIII; (2) o método radioativo, utilizando ${ }^{177} \mathrm{Lu}$ e (3) um método utilizando CLAE que foi desenvolvido especialmente para este trabalho.

Na TABELA 8 estão apresentados os resultados obtidos por estes três métodos.

TABELA 8 - Número de quelantes acoplados ao anticorpo. Resultados expressos em média \pm DP.

\begin{tabular}{ccccc} 
& \multicolumn{4}{c}{ Número de quelantes acoplados ao AcM } \\
\cline { 2 - 5 } $\begin{array}{c}\text { Razão molar } \\
\text { AcM:DOTA }\end{array}$ & \multicolumn{3}{c}{ Conjugação: Método 1} & $\begin{array}{c}\text { Conjugação: Método } \\
\text { Espectrofotometria }\end{array}$ \\
\hline & CLAE & Radioativo & Radioativo \\
$1: 10$ & $0,35 \pm 0,21^{*}$ & $1,73 \pm 0,88^{*}$ & $0,14 \pm 0,003^{*}$ & nd \\
$1: 20$ & $2,76 \pm 1,06^{* *}$ & $2,18 \pm 0,07^{*}$ & $0,24 \pm 0,003^{*}$ & nd \\
$1: 50$ & $3,02 \pm 1,89^{* *}$ & $4,89 \pm 1,54^{*}$ & $4,26 \pm 0,49^{*}$ & $5,50 \pm 2,84^{*}$ \\
$1: 100$ & $4,11 \pm 1,30^{*}$ & $8,67 \pm 0,83^{*}$ & $12,05 \pm 0,01^{*}$ & nd \\
\hline
\end{tabular}

${ }^{*} \mathrm{~N}=2 ;{ }^{* *} \mathrm{~N}>3$; nd: não determinado

Os três métodos permitiram observar um incremento no número de quelantes acoplados ao AcM, relacionado ao aumento da razão molar de conjugação (conjugação pelo método 1). As diferenças encontradas entre as razões molares foram significativas para os três métodos $(P=0,0419$ para espectrofotometria, $P=0,001$ para $C L A E$ e $P<0,001$ para radioativo). Quando as razões molares foram comparadas individualmente entre os três métodos, a diferença foi significativa apenas para as razões molares 1:20 $(P=0,0134)$ e 1:100 $(P=0,0008)$. Apesar destas diferenças, o estudo foi útil para correlacionar o aumento do número de quelantes por AcM ao aumento da razão molar AcM:DOTA utilizada na conjugação.

Em relação aos dois métodos de conjugação empregados (método 1 e 2), o aumento de temperatura utilizado no método 2, não promoveu maior incorporação de quelantes por anticorpo, uma vez que a diferença observada não foi significativa $(P=$ 0,4977). 
Dentre os trabalhos que utilizaram o quelante DOTA-NHS para conjugar AcMs, destacam-se cinco e a comparação da metodologia de conjugação destes trabalhos está apresentada na TABELA 9.

TABELA 9 - Comparação dos métodos de conjugação e número de quelantes por AcM obtidos para diferentes AcMs conjugado ao quelante DOTA-NHS.

\begin{tabular}{|c|c|c|c|c|c|c|}
\hline \multirow[b]{2}{*}{ Estudo } & \multirow[b]{2}{*}{ AcM } & \multicolumn{2}{|c|}{ Método de conjugação } & \multirow[b]{2}{*}{$\begin{array}{c}\text { Razão molar } \\
\text { AcM:DOTA }\end{array}$} & \multirow[b]{2}{*}{$\begin{array}{l}\text { Número de } \\
\text { Q:AcM }\end{array}$} & \multirow[b]{2}{*}{ Referência } \\
\hline & & $\begin{array}{c}\text { Tampão de } \\
\text { reação }\end{array}$ & $\begin{array}{c}\text { Tempo de } \\
\text { reação }\end{array}$ & & & \\
\hline 1 은 & Trastuzumabe & $\begin{array}{c}\mathrm{NaHCO}_{3} 0,2 \\
\mathrm{M} \mathrm{pH} \mathrm{9,2}\end{array}$ & $24 \mathrm{~h} / \mathrm{TA}$ & $1: 120$ & 5,8 & 113 \\
\hline 20 & Trastuzumabe & $\begin{array}{c}\mathrm{NaHCO}_{3} \mathrm{pH} \\
8,6\end{array}$ & $24 \mathrm{~h} / \mathrm{TA}$ & $1: 20$ & $2,1-2,7$ & 8,78 \\
\hline 30 & Conatumumabe & PBS pH 8,5 & $2 \mathrm{~h} / \mathrm{TA}$ & $1: 20$ & $3,9-4,9$ & 114 \\
\hline 40 & B72.3 & $\begin{array}{c}\mathrm{AcNH}_{4} 0,25 \mathrm{M} \\
\mathrm{pH} 7\end{array}$ & $\begin{array}{c}24 \text { a } 48 \mathrm{~h} / \\
\text { TA }\end{array}$ & $1: 40$ & 5 & 115 \\
\hline 50 & Rituximabe & $\begin{array}{l}\mathrm{NaHPO}_{4} \text { 0,1 } \\
\mathrm{M} \mathrm{pH} 7-7,5\end{array}$ & $1 \mathrm{~h} / 25^{\circ} \mathrm{C}$ & 1:15 - 1:30 & 4 & 87 \\
\hline
\end{tabular}

$\mathrm{TA}$ = temperatura ambiente; $\mathrm{NaHCO}_{3}=$ tampão bicarbonato de sódio; $\mathrm{PBS}$ = tampão fosfato salino; $\mathrm{AcNH}_{4}$ = tampão acetato de amônio; $\mathrm{NaHPO}_{4}$ = fosfato de sódio; $\mathrm{Q}: \mathrm{AcM}$ = quelantes por anticorpo.

Com exceção do 4 ㅇ e 5 을 estudos, todos os outros utilizaram pH alcalino para realizar a conjugação ao DOTA-NHS. No 10 estudo, a incorporação de apenas 5,8 quelantes ao anticorpo não é comparável com os valores encontrados no presente trabalho, pois a razão molar de 1:100 promoveu incorporação de 8,67 - 12,05 quelantes por AcM (método espectrofotométrico e radioativo) (TABELA 8).

A reação de conjugação ocorreu em temperatura ambiente por no mínimo 24 horas nos 1ํ, 2ㅇ e 4 ㅇ estudos. Realizar a conjugação em altas temperaturas por longo tempo favorece a cinética de reação, mas pode causar degradação do AcM.

No presente trabalho, o número de quelantes por AcM para a razão molar 1:20 foi de 2,18 - 2,76 (quando determinada por CLAE ou espectrofotometria) (TABELA 8). Estes valores são muito próximos dos encontrados no 2 o estudo $(2,1-2,7)$. Isto indica que 


\section{Capítulo 5 \\ ESTUDOS DE CONJUGAÇÃO E RADIOMARCAÇÃO}

diminuir a temperatura a $2-8^{\circ} \mathrm{C}$ (método 1 de conjugação) não interfere na quantidade de quelantes incorporados ao AcM e ainda mantém o AcM em uma temperatura ideal de conservação.

Quando o AcM foi conjugado na razão molar 1:50, o número de quelantes por AcM foi de 3,02 - 4,89 (método 1 de conjugação - TABELA 8), valores próximos ao encontrado por Mohsin e colaboradores (2007) para a razão molar 1:40 ${ }^{115}$ (40 estudo TABELA 9).

O número de quelantes por AcM encontrado para o método 2 e razão molar 1:50 (TABELA 8) foi maior comparado ao encontrado por Rossin e colaboradores (2011) (3을 estudo - TABELA 9) e esta diferença, embora não tão expressiva, pode ser atribuída ao emprego de uma temperatura maior $\left(37^{\circ} \mathrm{C}\right)$.

No 50 estudo, os autores utilizaram o mesmo AcM, quelante e tampão utilizados no presente trabalho. Apesar da razão molar e do $\mathrm{pH}$ de reação terem sido diferentes, o número de quelantes incoporados foi similar (TABELA 8).

De modo geral, os dois métodos de conjugação empregados neste trabalho corroboram com os dados encontrados na literatura. A principal vantagem observada com o uso destes dois métodos foi obter uma incorporação similar de quelantes por anticorpo, utilizando tanto temperatura de reação mais baixa, preservando assim o AcM (método 1), quanto empregando aquecimento e tempo de reação menor (método 2).

\section{C) Radiomarcação}

A radiomarcação de anticorpos conjugados com DOTA com metais trivalentes como ${ }^{177} \mathrm{Lu}$ e ${ }^{90} \mathrm{Y}$ pode ser obtida por incubação prolongada do imunoconjugado com uma solução de metal radioativo à temperatura ambiente. Entretanto, a exposição de um anticorpo a uma solução concentrada de radioisótopo emissor $\beta^{-}$, por um período de tempo prolongado, pode resultar em radiólise significativa da proteína. Portanto, uma incorporação rápida e eficaz do metal radioativo ao imunoconjugado é desejável ${ }^{12}$.

Pensando nisso, o método padrão usado para realizar a marcação foi adaptado a partir de um trabalho desenvolvido por Lewis e colaboradores ${ }^{12}$. Desta forma, a condição padrão de marcação foi 1 hora a $43{ }^{\circ} \mathrm{C}, \mathrm{pH} \mathrm{5,5}$, volume final de $200 \mu \mathrm{L}$ com agitação constante a $350 \mathrm{rpm}$. Esta condição padrão representou o ponto de partida para estudar a 


\section{Capítulo 5 \\ ESTUDOS DE CONJUGAÇÃO E RADIOMARCAÇÃO}

interferência à variação dos diversos parâmetros da radiomarcação, com o objetivo de obter um radioimunoconjugado com pureza radioquímica e estabilidade altas frente às condições de armazenamento.

Um miligrama de anticorpo conjugado pelo método 1, em diferentes razões molares (1:10; 1:20; 1:50 e 1:1000) foi radiomarcado com $37 \mathrm{MBq}(1 \mathrm{mCi})$ de ${ }^{177} \mathrm{Lu}$.

A maior pureza radioquímica foi encontrada para a razão molar 1:50 (FIGURA 10). Quando o anticorpo radiomarcado foi purificado em coluna PD-10, uma pureza radioquímica satisfatória (>90\%) foi encontrada nas razões molares 1:20, 1:50 e 1:100, por conseguinte, estas foram as razões molares escolhidas para realizar o ensaio de ligação específica em células Raji.

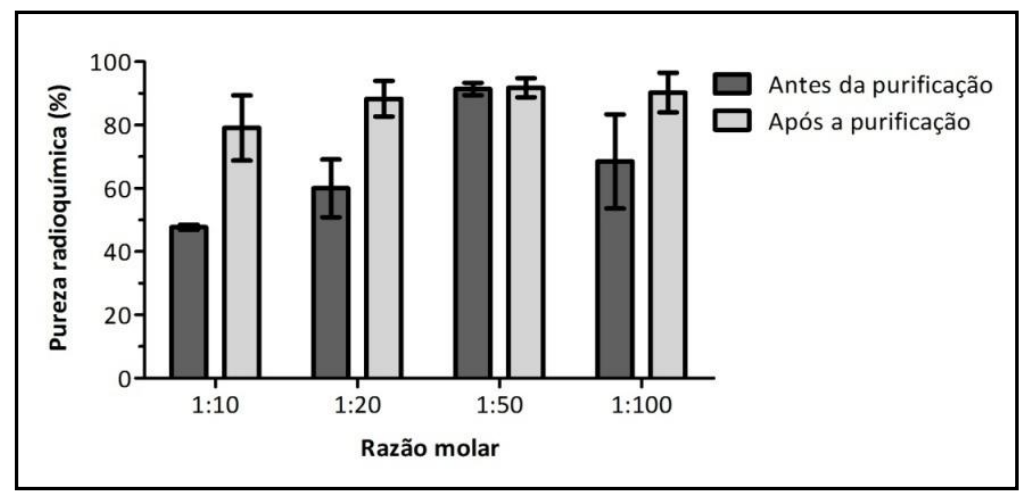

FIGURA 10 - Pureza radioquímica do anti-CD20-DOTA- ${ }^{177}$ Lu antes e após a purificação em coluna de exclusão molecular (PD-10). Condições de radiomarcação: $1 \mathrm{mg}$ de imunoconjugado; $37 \mathrm{MBq}(1 \mathrm{mCi})$ de ${ }^{177} \mathrm{Lu}$; 1 hora a $43{ }^{\circ} \mathrm{C}, \mathrm{pH}$ 5,5, $350 \mathrm{rpm}$. Resultados expressos em média \pm EPM $(n \geq 3)$.

D) Ligação específica às células Raji.

O estudo de ligação específica do anti-CD20-DOTA- ${ }^{177}$ Lu (radioimunoconjugado) em células Raji foi realizado com o AcM conjugado em diferentes razões DOTA:AcM e os resultados estão expressos na FIGURA 11. 


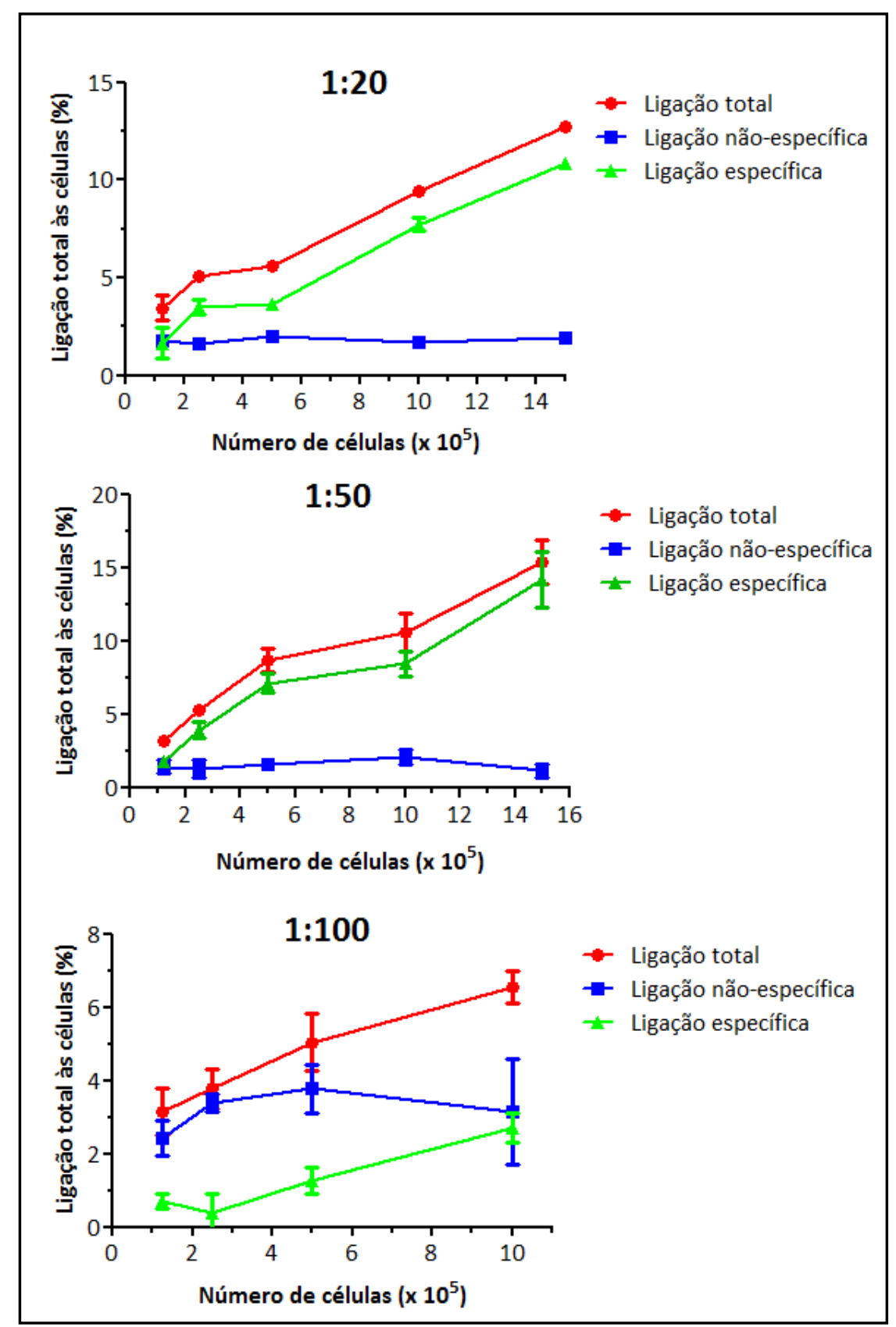

FIGURA 11 - Ligação específica do anti-CD20-DOTA- ${ }^{177}$ Lu às células Raji em diferentes razões molares de conjugação. Resultados expressos em média \pm EPM $(\mathrm{N} \geq 3)$.

As três razões molares consideradas produziram imunoconjugados com capacidade de ligação às células Raji e um aumento da ligação total às células foi observado conforme o número de células aumentou (FIGURA 11). No entanto, a razão molar de 1:100 mostrou ligação não específica maior que a ligação específica. A ligação específica para a quantidade de $1 \times 10^{6}$ células, foi diferente $(P<0,05)$ quando se compararam as razões molares 1:100 versus 1:20 e 1:100 versus 1:50 (FIGURA 12). 


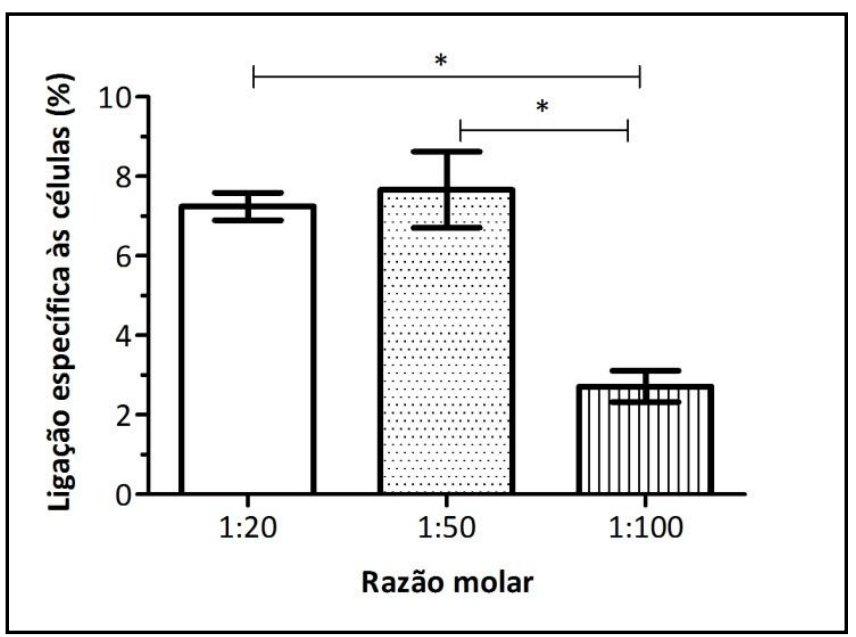

FIGURA 12 - Ligação específica do anti-CD20-DOTA- ${ }^{177}$ Lu à $1 \times 10^{6}$ células Raji em diferentes razões molares de conjugação. Resultados expressos em Média \pm EPM ( $N \geq 3$ ). Diferença estatística representado por *.

\section{E) Imunorreatividade}

Ainda que o efeito da imunorreatividade de AcMs radiomarcados na localização do tumor não seja aparente imediatamente após a administração, é prudente preservar a imunorreatividade o quanto possível, de modo a garantir a ligação especifica ao tumor ${ }^{116}$. A perda de imunorreatividade pode ser causada pelo processo de conjugação, radiomarcação e radiólise durante o armazenamento do anticorpo radiomarcado ${ }^{12}$.

A imunorreatividade pode ser medida de diferentes maneiras, mas os métodos comumente aceitos são a afinidade de ligação pelo antígeno, refletida pela constante de afinidade $\left(K_{\mathrm{a}}\right)$ e a fração imunorreativa $(\mathrm{FI})$. A $\mathrm{K}_{\mathrm{a}}$ descreve a força de ligação do anticorpo ao antígeno ao passo que a $\mathrm{Fl}$ descreve a proporção de moléculas de anticorpo que estão hábeis a se ligar a um excesso infinito de antígeno ${ }^{116}$.

Com os resultados obtidos nos ensaios de ligação específica (FIGURA 11), foi possível aplicar o cálculo proposto por Lindmo e colaboradores (1984 e 1986) ${ }^{117}$ e determinar a fração imunorreativa dos imunoconjugados (FIGURA 13). Considerando-se, teoricamente, que o anticorpo não conjugado possui imunorreatividade de $100 \%$, foi possível observar que a imunorreatividade foi maior para as razões de 1:20 e 1:50 (85,3\% e $89,8 \%$ respectivamente), enquanto que para razão molar de 1:100, a imunorreatividade foi de $24,4 \%$. Provavelmente, o decréscimo da imunorreatividade na razão 1:100, foi devido ao 
elevado número de quelantes incorporados por molécula de AcM (TABELA 8).

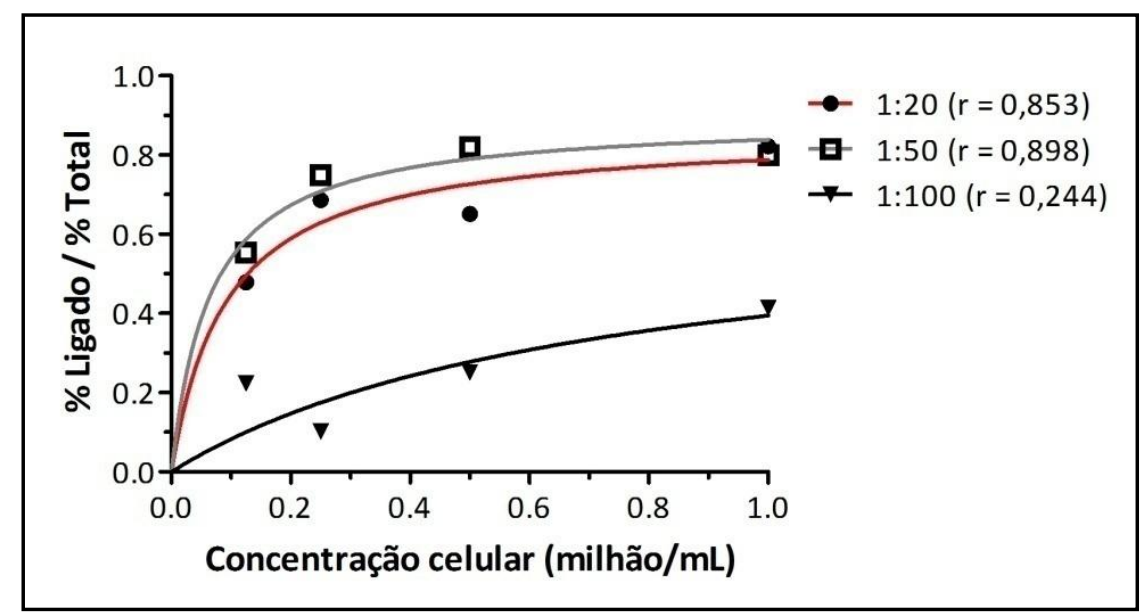

FIGURA 13 - Imunorreatividade do anti-CD20-DOTA- ${ }^{177}$ Lu conjugado em diferentes razões molares de conjugação (atividade específica de $37 \mathrm{MBq} / \mathrm{mg}$ ).

Na TABELA 10 estão relacionados os principais trabalhos de conjugação de AcMs encontrados na literatura, com o intuito de comparar a metodologia de conjugação, o número de quelantes por AcM e a imunorreatividade obtida. Ressalta-se que o critério de escolha destes trabalhos foi a metodologia de determinação da imunorreatividade. Em todos eles, a imunorreatividade foi determina pela fração imunorreativa calculada pelo método de Lindmo, o mesmo utilizado neste trabalho. Foram excluídos também os trabalhos que apresentavam metodologia detalhada com cálculo de número de quelantes por AcM, mas não a imunorreatividade. 


\section{Capítulo 5 \\ ESTUDOS DE CONJUGAÇÃO E RADIOMARCAÇÃO}

TABELA 10 - Comparação dos métodos de conjugação, número de quelantes por AcM e imunorreatividade obtidos para diferentes AcMs conjugados a diferentes quelantes.

\begin{tabular}{|c|c|c|c|c|c|c|c|c|}
\hline \multirow{2}{*}{ Estudo } & \multirow{2}{*}{ AcM } & \multirow{2}{*}{ Quelante } & \multicolumn{2}{|c|}{ Método de conjugação } & \multirow{2}{*}{$\begin{array}{l}\text { Razão molar } \\
\text { AcM:DOTA }\end{array}$} & \multirow{2}{*}{ № de Q:AcM } & \multirow{2}{*}{ Imunorreatividade } & \multirow{2}{*}{ Referência } \\
\hline & & & Tampão de reação & Tempo de reação & & & & \\
\hline \multirow{4}{*}{10} & \multirow{4}{*}{ Lym-1 } & \multirow{4}{*}{ TETA } & \multirow{4}{*}{$\begin{array}{l}\text { Fosfato de sódio 0,1 M } \\
\qquad \mathrm{pH} 8\end{array}$} & \multirow{4}{*}{30 minutos a $4{ }^{\circ} \mathrm{C}$} & \multirow{4}{*}{ - } & 2,1 & $82 \%$ & \multirow{4}{*}{111} \\
\hline & & & & & & 4,3 & $79 \%$ & \\
\hline & & & & & & 8,4 & $58 \%$ & \\
\hline & & & & & & 11,4 & $45 \%$ & \\
\hline 20 & Trastuzumabe & DOTAGA & PBS 0,1 M pH 7,4 & 30 minutos a $25^{\circ} \mathrm{C}$ & $1: 20$ & 2,6 & $65 \%$ & 118 \\
\hline \multirow{3}{*}{30} & \multirow{3}{*}{ Nimotuzumabe } & \multirow{3}{*}{ p-SCN-Bn-DOTA } & \multirow{3}{*}{ PBS 0,1 M pH 8,5 } & \multirow{3}{*}{ Uma noite a $2-8^{\circ} \mathrm{C}$} & $1: 50$ & 9 & \multirow{3}{*}{$91,4 \%$} & \multirow{3}{*}{11} \\
\hline & & & & & $1: 100$ & 13 & & \\
\hline & & & & & $1: 150$ & 15 & & \\
\hline \multirow{2}{*}{40} & Anti-mesotelina MB & \multirow{2}{*}{ p-SCN-Bn-DTPA } & Bicarbonato de sódio 0,1 & 21 horas à & \multirow{2}{*}{$1: 5$} & 2,4 & $78,5 \%$ & \multirow{2}{*}{104} \\
\hline & Anti-mesotelina K1 & & $\mathrm{M} \mathrm{pH} 8,5$ & temperatura ambiente & & 2,6 & $76,3 \%$ & \\
\hline 50 & Trastuzumabe & DOTA-NHS & $\begin{array}{c}\text { Acetato de amônio } 0,25 \\
\qquad \mathrm{M} \mathrm{pH} \mathrm{8,5}\end{array}$ & $\begin{array}{l}24 \text { horas à } \\
\text { temperatura ambiente }\end{array}$ & $1: 20$ & $2,1-2,7$ & $89 \%$ & 8 \\
\hline \multirow{5}{*}{60} & \multirow{5}{*}{ L8A4 } & 1B4M-DTPA & \multirow{5}{*}{$\begin{array}{l}\text { Carbonato de sódio } \mathrm{pH} \\
\qquad 8,6\end{array}$} & \multirow{5}{*}{$\begin{array}{l}24 \text { horas à } \\
\text { temperatura ambiente }\end{array}$} & & 1,1 & $76 \%$ & \multirow{5}{*}{52} \\
\hline & & CHX-DTPA & & & & 0,3 & $60 \%$ & \\
\hline & & p-SCN-Bz-DTPA & & & $1: 20$ & 0,9 & $68 \%$ & \\
\hline & & C-DOTA & & & & 3,1 & $63 \%$ & \\
\hline & & MeO-DOTA & & & & 2,7 & $70 \%$ & \\
\hline \multirow{2}{*}{$7 \stackrel{0}{0}$} & & & Carbonato de sódio 0,2 & & $1: 10$ & 4 & $84,7 \%$ & \\
\hline & Rituxımabe & P-SCN-BZ-DUIA & $\mathrm{M} \mathrm{pH} \mathrm{9,5}$ & I nora a $3 / \mathrm{C}$ & $1: 20$ & 8 & $50 \%$ & 51 \\
\hline & & p-SCN-Bz-DOTA & & & & 3 & $24 \%$ & \\
\hline 80 & AMB8LK & p-SCN-Bz-DTPA & HEPES $0,1 \mathrm{M} \mathrm{pH} \mathrm{8,5}$ & Uma noite a $37^{\circ} \mathrm{C}$ & $1: 50$ & 3 & $52 \%$ & 99 \\
\hline & & p-CHX-A"-DTPA & & & & 3 & $43 \%$ & \\
\hline $9 \circ$ & Rituximabe & $\begin{array}{c}\text { p-SCN-Bn-CHX- } \\
\text { A"-DTPA }\end{array}$ & $\begin{array}{l}\text { Bicarbonato de sódio 0,2 } \\
\qquad \mathrm{M} \mathrm{pH} \mathrm{9,0}\end{array}$ & $\begin{array}{c}2 \mathrm{~h} \text { à temperatura } \\
\text { ambiente }+ \text { uma noite a } \\
4^{\circ} \mathrm{C}\end{array}$ & 1:10 & 3 & $75 \%$ & 94 \\
\hline $10 \cong$ & Rituximabe & DOTA-NHS & $\begin{array}{l}\text { Fofato de sódio } 0,1 \mathrm{M} \mathrm{pH} \\
\qquad 9-10\end{array}$ & $2 \mathrm{~h}$ a $25^{\circ} \mathrm{C}$ & - & 1 & $>80 \%$ & 86 \\
\hline 110 & Rituximabe & DOTA-NHS & $\begin{array}{l}\text { Fofato de sódio } 0,1 \mathrm{M} \mathrm{pH} \\
\qquad 7-7,5\end{array}$ & $1 \mathrm{~h}$ a $25^{\circ} \mathrm{C}$ & $1: 15-1: 30$ & 4 & $>60 \%$ & 86,87 \\
\hline
\end{tabular}




\section{Capítulo 5 \\ ESTUDOS DE CONJUGAÇÃO E RADIOMARCAÇÃO}

De modo geral, a imunorreatividade do AcM diminui conforme aumenta a quantidade de quelantes acoplados a ele. Isto foi relatado por Kukis e colaboradores quando investigaram o efeito do número de substituições de grupamentos quelantes na imunorreatividade do AcM Lym-1 marcado com ${ }^{67} \mathrm{Cu}$ (10 estudo - TABELA 10). Eles observaram uma FI de 0,82 com 2,1 Q:AcM e houve um decréscimo da FI para 0,45 com 11,4 $\mathrm{Q}: A c M^{111}$. Forrer e colaboradores também relataram o decréscimo da imunorreatividade devido à alta incorporação de quelante. Quando apenas 4 resíduos de lisinas foram substituídos pelo DOTA, o AcM apresentou um FI de 0,85 que diminuiu para menos de 0,50 quando 8 quelantes se acoplaram ao $\operatorname{AcM}^{51}$ (70 estudo - TABELA 10).

Esta relação também foi observada neste trabalho, no qual a incorporação de 8 12 DOTA:ACM (conjugação 1:100, método de determinação por CLAE e radioativo - TABELA 8), resultou em uma FI de 0,24 (FIGURA 13).

A quantidade de quelantes incorporado está diretamente relacionada à razão $\mathrm{Q}: \mathrm{AcM}$, tipo de quelante, $\mathrm{pH}$, temperatura e tempo de reação e concentração do AcM no momento da reação ${ }^{51,111}$.

Empregar temperaturas mais elevadas é uma vantagem do ponto de vista da cinética química do DOTA, mas uma desvantagem quando se pensa na estabilidade do AcM. Talvez seja por este motivo que no 5 o estudo (TABELA 10) um menor número de quelantes incorporados, resultou em imunorreatividade igual a encontrada neste trabalho $(89,8 \%$ FIGURA 13) mesmo os autores utilizando uma razão molar Q:AcM menor. Provavelmente manter o AcM à temperatura ambiente por 24 horas tenha sido o motivo da diminuição da imunorreatividade.

A incorporação de um grande número de quelantes ao AcM não é o único fator causador do decréscimo da imunorreatividade, uma vez que existem AcM resistentes aos efeitos desta substituição ${ }^{116}$.

Outro fator essencial a ser considerado é o tipo de quelante utilizado. Essa diferença é claramente notada no 60 e 8을 estudo. No 6으, os autores utilizaram a mesma metodologia de conjugação, o mesmo AcM, e a mesma razão molar (1:20) para 5 tipos de quelantes diferentes. Eles obtiveram quantidades diferentes de quelantes por AcM para cada quelante e esta incorporação não teve relação direta com a perda da imunorreatividade.

Já para o 8o estudo, os autores utilizaram três quelantes diferentes e obtiveram a 
mesma quantidade de grupamentos incorporados por AcM (3) para valores de imunorreatividade muito diferentes.

Uma característica importante do quelante é o grupo químico que se ligará ao AcM. Os derivados de DOTA e DTPA mais utilizados para conjugação de proteínas são o NHSéster e o p-SCN-Bn, pois estes grupos podem ser ativados in situ no momento da reação e terão maior afinidade por aminas presente no AcM ${ }^{105,107}$. Mas, o NHS-éster apresenta a vantagem de ser menos imunogênico que o p-SCN-Bn. Já que a resposta imunogênica encontrada em pacientes tratados com cT84.66-DTPA- ${ }^{111}$ In pareceu estar relacionada ao grupamento tioureia aromático presente no p-SCN-Bn-DTPA. O uso de ésteres faz com que o quelante macrocíclico fique próximo a estrutura do AcM tornando-o pouco disponível para se apresentar ao sistema imunológico como um hapteno ${ }^{12}$. Hapteno é uma substância antigênica de baixo peso molecular que sozinha não é capaz de induzir resposta imunológica, a não ser quando ligada à outra substância de peso molecular alto, como uma proteína $^{119}$.

O 9o estudo utilizou uma metodologia de conjugação análoga à empregada no método 1 de conjugação do presente trabalho. Observa-se que apesar do AcM utilizado ser o mesmo (rituximabe) e a razão molar Q:AcM ser menor (1:10), a incorporação de apenas 3 quelantes por AcM produziu um imunoconjugado com $14 \%$ menos imunorreatividade quando comparado ao imunoconjugado produzido no presente trabalho. Isto é mais uma evidência de que o tipo de quelante é um fator muito importante na conjugação.

010 e e o 11 을 estudos foram realizados pelo mesmo grupo e se assemelham com o presente trabalho, pois utilizam o mesmo AcM, quelante e tampão. Contudo estes estudos apresentaram menor incorporação de quelante por AcM e menor imunorreatividade. Foi possível observar que a incorporação de apenas 3 quelantes a mais, diminuiu a imunorreativiade em aproximadamente $20 \%$.

Comparando os resultados deste trabalho com os onze estudos da TABELA 10, apenas o 3 o obteve número de quelantes acoplados ao AcM maior que 4 e imunorreatividade próxima a 90\%, muito embora os autores não tenham apresentados os resultados de imunorreatividade individualmente para cada condição, apenas uma média.

Com o levantamento bibliográfico realizado, fica evidente a importância de se estudar caso a caso, as condições de conjugação para um dado AcM e um quelante escolhido de modo a garantir a imunorreatividade do imunoconjugado resultante. 
Analisando os resultados obtidos e diante da discussão apresentada, a razão 1:50 foi escolhida para os demais experimentos, por apresentar preservação da imunorreatividade e maior pureza radioquímica determinada após a radiomarcação (FIGURA 10).

5.4.2 Análise da integridade estrutural do imunoconjugado por eletroforese em gel de poliacrilamida

Com o objetivo de demonstrar a integridade do AcM após a conjugação, a eletroforese com gel de poliacrilamida (SDS-Page) é comumente utilizada comparando-se as bandas do imunoconjugado com as bandas do AcM não conjugado 75, 113, 120, 121.

$\mathrm{O}$ AcM conjugado pelos dois métodos e o AcM não conjugado foram reduzidos com tampão redutor e analisados em gel de poliacrilamida e o resultado está representado na FIGURA 14.

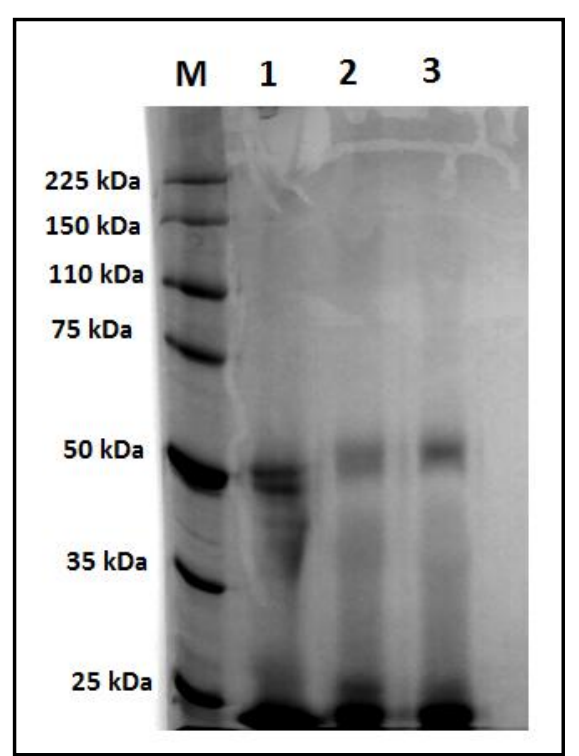

FIGURA 14 - Eletroforese em gel de poliacrilamida do (1) AcM não conjugado; (2) AcM conjugado pelo método 1 e (3) AcM conjugado pelo método 2 . $M=$ marcador de peso molecular.

Após a corrida no gel de poliacrilamida, ambos imunoconjugados apresentaram duas bandas com peso molecular de aproximadamente 50 kDa e 25 kDa (FIGURA 14 - 2 e 3). 
Estas bandas correspondem à cadeia pesada e à cadeia leve da molécula de IgG que foram separadas devido à quebra das pontes de dissulfeto.

As mesmas bandas com o mesmo padrão de peso molecular foram observadas para o AcM não conjugado, indicando que não houve degradação do AcM devido à conjugação (FIGURA 14 - 1).

\subsubsection{Estabilidade do imunoconjugado}

Para determinar o prazo de armazenamento do imunoconjugado, em outras palavras o prazo de validade, utilizou-se alguns dos parâmetros descritos por Lam e colaboradores $(2015)^{75}$ para avaliação da estabilidade do pertuzumabe-Bz-DTPA, tais como $\mathrm{pH}$, aparência e integridade por CLAE, além da porcentagem de DOTA e agregados.

Os parâmetros avaliados, as especificações e os resultados obtidos para o AcM conjugado pelo dois métodos, estão descritos na TABELA 11 (método 1) e TABELA 12 (método 2).

Logo após a conjugação observou-se, pelo perfil de CLAE, que para o método 2 houve uma maior formação de agregados (FIGURA 15), contudo esta quantidade não foi maior do que a encontrada no AcM conjugado pelo método $1(P=0,9943)$.

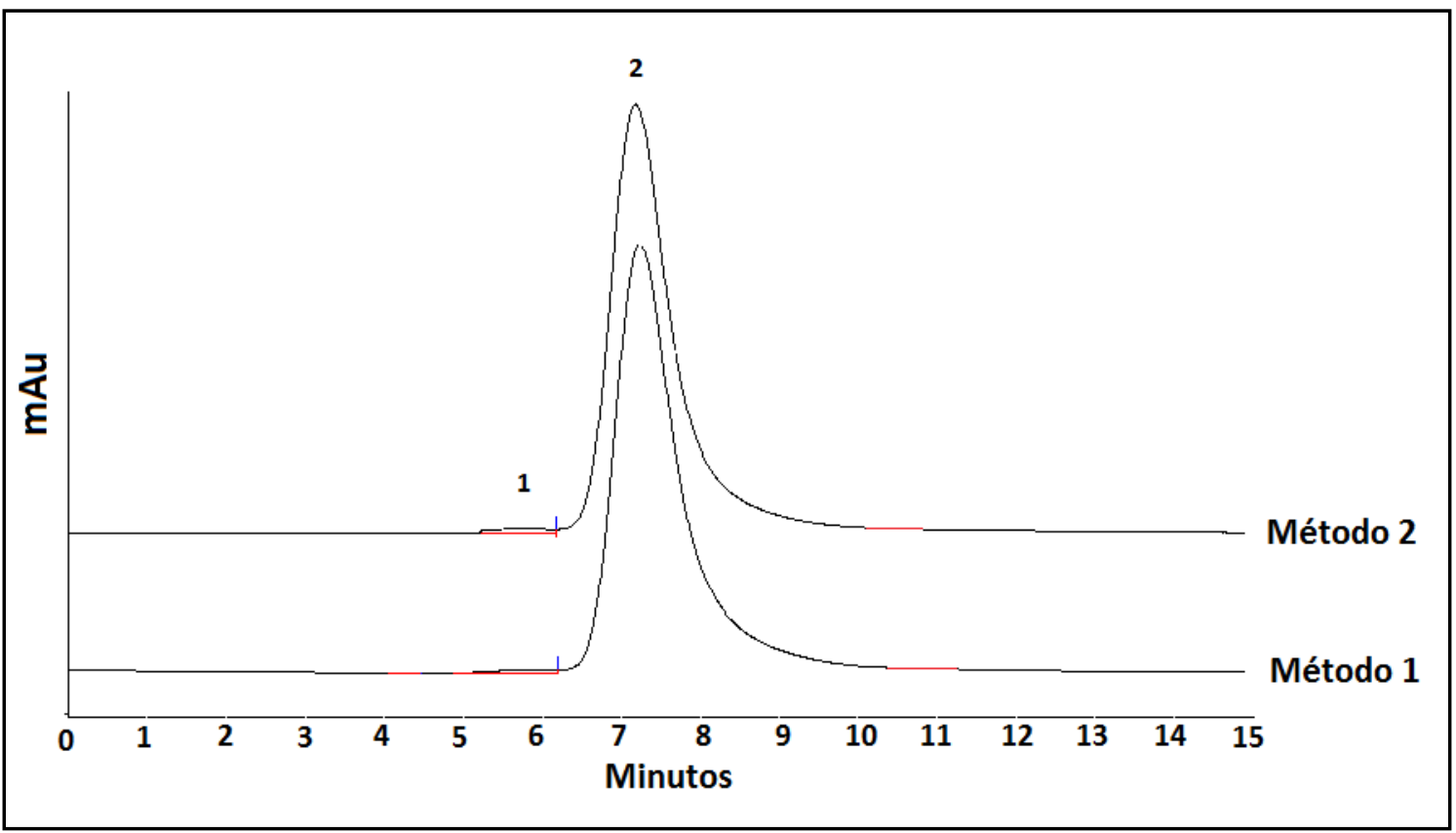

FIGURA 15 - Perfil de CLAE do ACM anti-CD20 conjugado ao DOTA pelos dos dois métodos. (1) = agregados; $(2)=$ anti-CD20-DOTA. 
TABELA 11 - Estabilidade do anti-CD20-DOTA (1:50), conjugado pelo método 1 e armazenado a 2-8 ${ }^{\circ} \mathrm{C}$. Resultados expressos em média \pm DP.

\begin{tabular}{|c|c|c|c|c|c|c|c|}
\hline \multirow{3}{*}{ Parâmetro } & \multirow{3}{*}{ Especificação } & \multicolumn{6}{|c|}{ Resultados } \\
\hline & & \multicolumn{6}{|c|}{ Tempo de armazenamento (meses) } \\
\hline & & 0 & 0,7 & 2 & 4 & 8 & 10 \\
\hline$\%$ Anti-CD20-DOTA (\%) & $\geq 99$ & $99,85 \pm 0,22$ & $99,72 \pm 0,06$ & $99,40 \pm 0,41$ & $99,19 \pm 0,06$ & $98,52 \pm 1,79$ & $97,24 \pm 0,01$ \\
\hline$\%$ Agregado (\%) & $\leq 1$ & $0,14 \pm 0,27$ & $0,26 \pm 0,06$ & $0,50 \pm 0,13$ & $0,57 \pm 0,03$ & $0,83 \pm 0,25$ & $1,44 \pm 0,06$ \\
\hline$\%$ DOTA (\%) & $\leq 0,5$ & $0,01 \pm 0,02$ & $0,02 \pm 0,01$ & $0,10 \pm 0,39$ & $0,24 \pm 0,09$ & $0,65 \pm 0,88$ & $1,32 \pm 0,02$ \\
\hline $\mathrm{pH}$ & $6,0-6,5$ & Passou & Passou & Passou & Passou & Passou & Passou \\
\hline Aparência & Límpido e incolor & Passou & Passou & Passou & Passou & Passou & Passou \\
\hline Partículas visíveis & Ausência & Passou & Passou & Passou & Passou & Passou & Passou \\
\hline
\end{tabular}

TABELA 12 - Análise dos parâmetros de qualidade do anti-CD20-DOTA (1:50), conjugado pelo método 2 e armazenado a $2-8{ }^{\circ} \mathrm{C}$. Resultados expressos em média \pm DP.

\begin{tabular}{llccccc}
\hline \multirow{2}{*}{\multicolumn{1}{c}{ Parâmetro }} & Especificação & \multicolumn{5}{c}{ Resultados } \\
\cline { 3 - 7 } & & $\mathbf{0}$ & $\mathbf{0 , 7}$ & $\mathbf{1 , 5}$ & $\mathbf{2}$ & $\mathbf{3}$ \\
\hline \% Anti-CD20-DOTA (\%) & $\geq 99$ & $99,54 \pm 0,02$ & $99,54 \pm 0,27$ & $99,54 \pm 0,06$ & $99,43 \pm 0,11$ & $99,22 \pm 0,09$ \\
$\%$ Agregado (\%) & $\leq 1$ & $0,44 \pm 0,03$ & $0,42 \pm 0,39$ & $0,41 \pm 0,03$ & $0,53 \pm 0,05$ & $0,61 \pm 0,03$ \\
$\%$ DOTA (\%) & $\leq 0,5$ & $0,01 \pm 0,02$ & $0,04 \pm 0,06$ & $0,05 \pm 0,09$ & $0,04 \pm 0,06$ & $0,17 \pm 0,11$ \\
pH & $6,0-6,5$ & Passou & Passou & Passou & Passou & Passou \\
Aparência & Límpido e incolor & Passou & Passou & Passou & Passou & Passou \\
Partículas visíveis & Ausência & Passou & Passou & Passou & Passou & Passou \\
\hline
\end{tabular}


A porcentagem de agregado e DOTA livre aumentam discretamente com o tempo de armazenamento, independente do método de conjugação.

Para o método 1 (TABELA 11), o aumento de agregados e DOTA é significante $(P<0,001)$ quando se compara o primeiro e último (10) mês, ao passo que o AcM conjugado pelo método 2 (TABELA 12), não apresentou aumentos expressivos de agregado e DOTA durante o período de armazenamento estudado ( 3 meses) $(P=0,1928$ para quantidade de agregados e $\mathrm{P}=0,9795$ para quantidade de DOTA).

Comparando-se os dois métodos nos tempos de 0, 0,7 e 2 meses, ambos não apresentaram diferenças na formação de agregados $(P>0,994)$ durante o armazenamento.

Embora o método 2 aparentou ser mais estável em relação ao desacoplamento de DOTA, a comparação da porcentagem de DOTA com o método 1, realizada até o segundo mês de armazenamento, indicou que ambos produzem conjugados estáveis $(P=0,4975)$.

Na FIGURA 16 estão apresentados os cromatogramas do anti-CD20-DOTA conjugado pelo método 1 e armazenado por até 10 meses sob refrigeração, na qual foi possível observar que a quantidade de agregados e DOTA livre aumentou discretamente em virtude do tempo de armazenamento. 


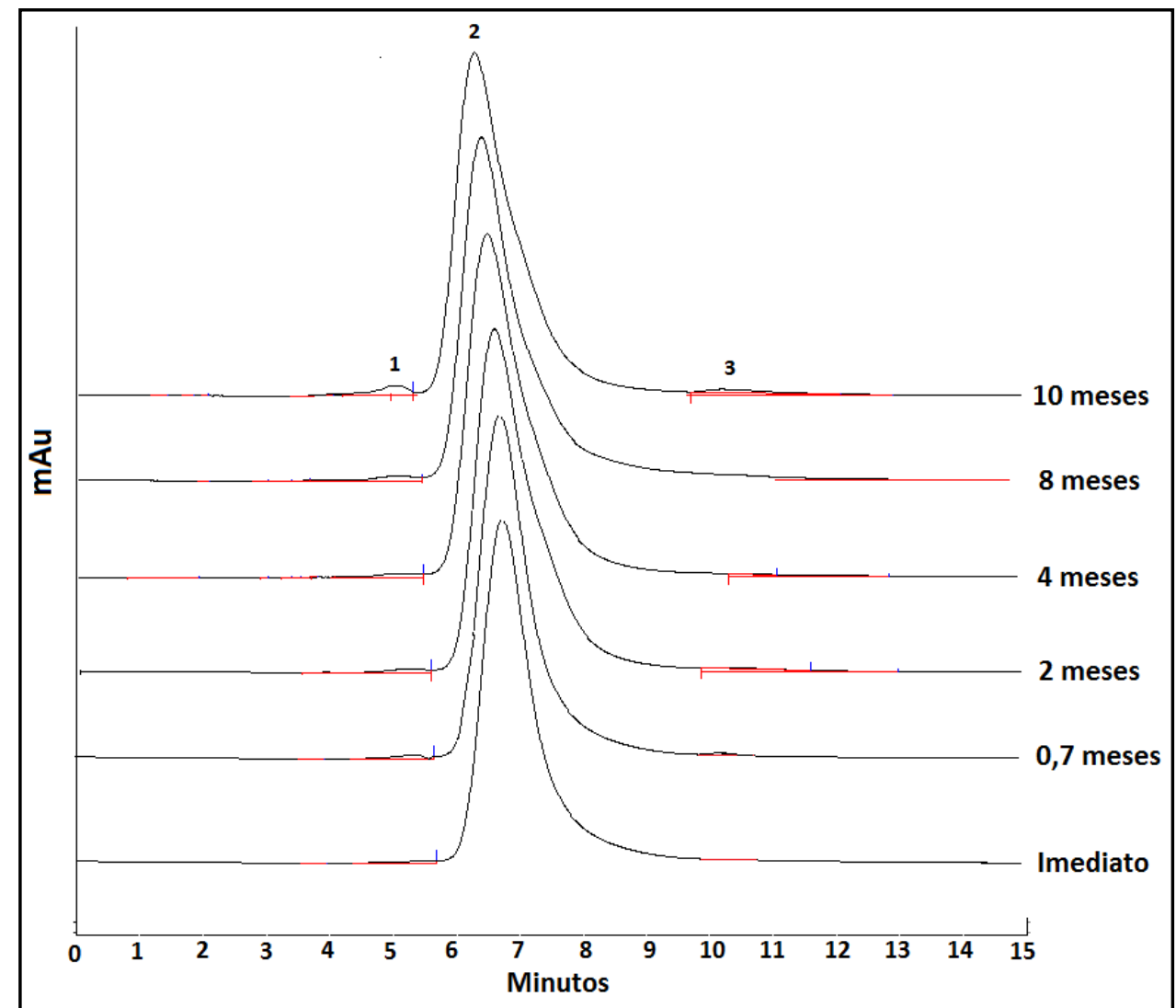

FIGURA 16 - Estudo de estabilidade por CLAE do AcM anti-CD20 (1:50) conjugado pelo método 1 e armazenado a $2-8^{\circ} \mathrm{C}$. (1) = agregado; (2) = anti-CD20-DOTA e (3) = DOTA livre.

Ambos os imunoconjugados apresentaram pH e aparência dentro das especificações e ausência de partículas visíveis durante todo o tempo estudado (TABELA 11 e TABELA 12).

Todavia, o AcM conjugado pelo método 1 atendeu as especificações de \% de agregado e \% DOTA somente até o 40 mês de armazenamento e este foi o prazo de validade estabelecido para este imunoconjugado (TABELA 11).

Diferentemente do imunoconjugado anterior, o AcM conjugado pelo método 2 apresentou resultados condizentes com as especificações durante todo o tempo estudado. Provavelmente esta tendência seria seguida, dado os resultados encontrados, contudo, devido à ausência de dados mais tardios, a validade deste imunoconjugado foi estabelecida como 3 meses (TABELA 12).

Os prazos de validade foram satisfatórios considerando os resultados encontrados por Lam e colaboradores ${ }^{75}$, que produziram um imunoconjugado de 
pertuzumabe-DTPA para marcação com ${ }^{111}$ In e este se mostrou estável por até 4 meses sob armazenamento a $2-8^{\circ} \mathrm{C}$.

\subsubsection{Desenvolvimento do radioimunoconjugado: estudo das condições de radiomarcação}

A) Definição da atividade específica

A atividade de ${ }^{177} \mathrm{LuCl}_{3}$ incorporada por $\mathrm{mg}$ do anticorpo, em outras palavras, a atividade específica do radiofármaco, é uma propriedade importante do ponto de vista do desenvolvimento de novos radiofármacos ${ }^{15}$. De forma geral, radiofármacos com baixa atividade específica têm baixo valor em termos de aplicação clínica, uma vez que as moléculas não radiomarcadas competem com as radiomarcadas pela ligação in vivo com o receptor, bem como aumenta a toxicidade devido aos efeitos fisiológicos desta ligação. Em contraste, a atividade específica muito elevada pode promover a desnaturação da proteína, em decorrência da radiólise ${ }^{15}$.

Para definir a melhor atividade específica do anti-CD20-DOTA- ${ }^{177} \mathrm{Lu}$, primeiramente estudou-se a influência da massa na radiomarcação e para tanto, diferentes massas do anti-CD20-DOTA, conjugado na razão 1:50, foram radiomarcadas com $37 \mathrm{MBq}$ (1 $\mathrm{mCi})$ de ${ }^{177} \mathrm{Lu}$. Além disto, a estabilidade do radioimunoconjugado foi avaliada após armazenamento a $2-8{ }^{\circ} \mathrm{C}$ por até 72 horas (FIGURA 17).

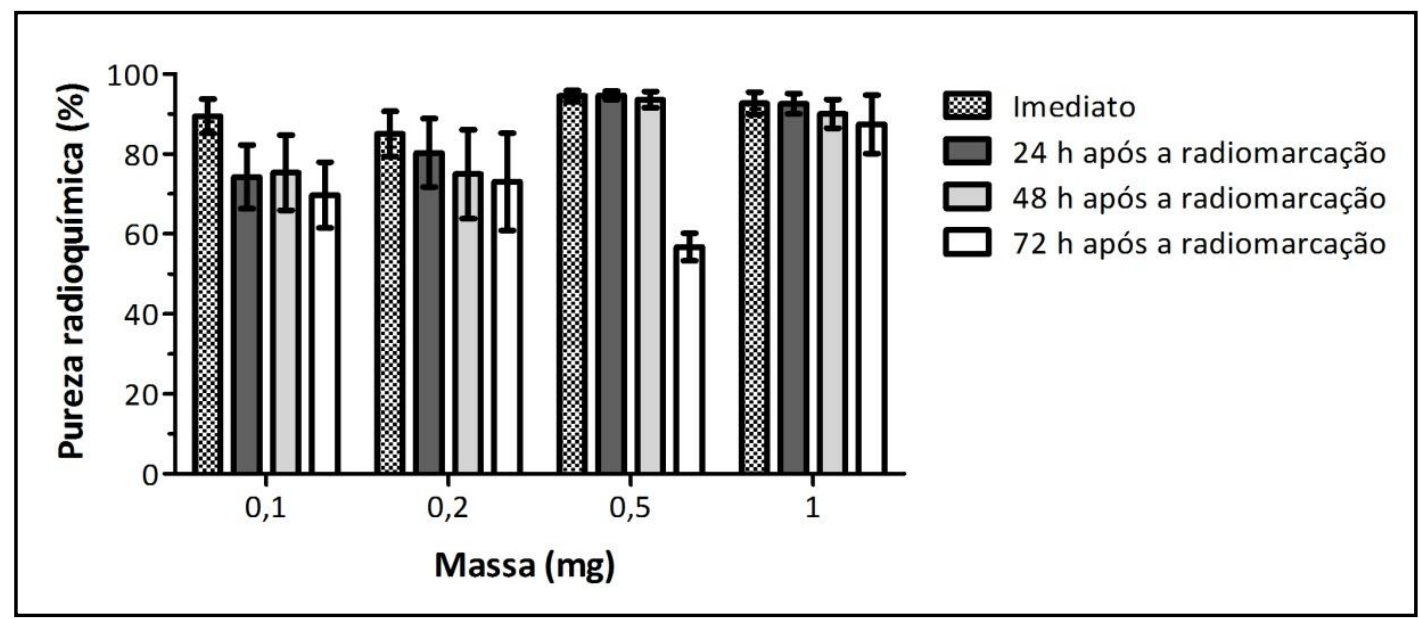

FIGURA 17 - Influência da massa de imunoconjugado na pureza radioquímica. Condições de radiomarcação: imunoconjugado 1:50, $37 \mathrm{MBq}(1 \mathrm{mCi})$ de ${ }^{177} \mathrm{LuCl}_{3}, 350 \mathrm{rpm}$. Resultados obtidos por CCD e expressos em média $\pm \operatorname{EPM}(n \geq 3)$. 


\section{Capítulo 5 \\ ESTUDOS DE CONJUGAÇÃO E RADIOMARCAÇÃO}

As condições que apresentaram melhores resultados foram $0,2 \mathrm{mg} / 37 \mathrm{MBq}, 0,5$ $\mathrm{mg} / 37 \mathrm{MBq}, 1 \mathrm{mg} / 37 \mathrm{MBq}$ e as massas de 0,2 e 0,5 mg foram radiomarcados com diferentes atividades (FIGURA 18 e FIGURA 19).

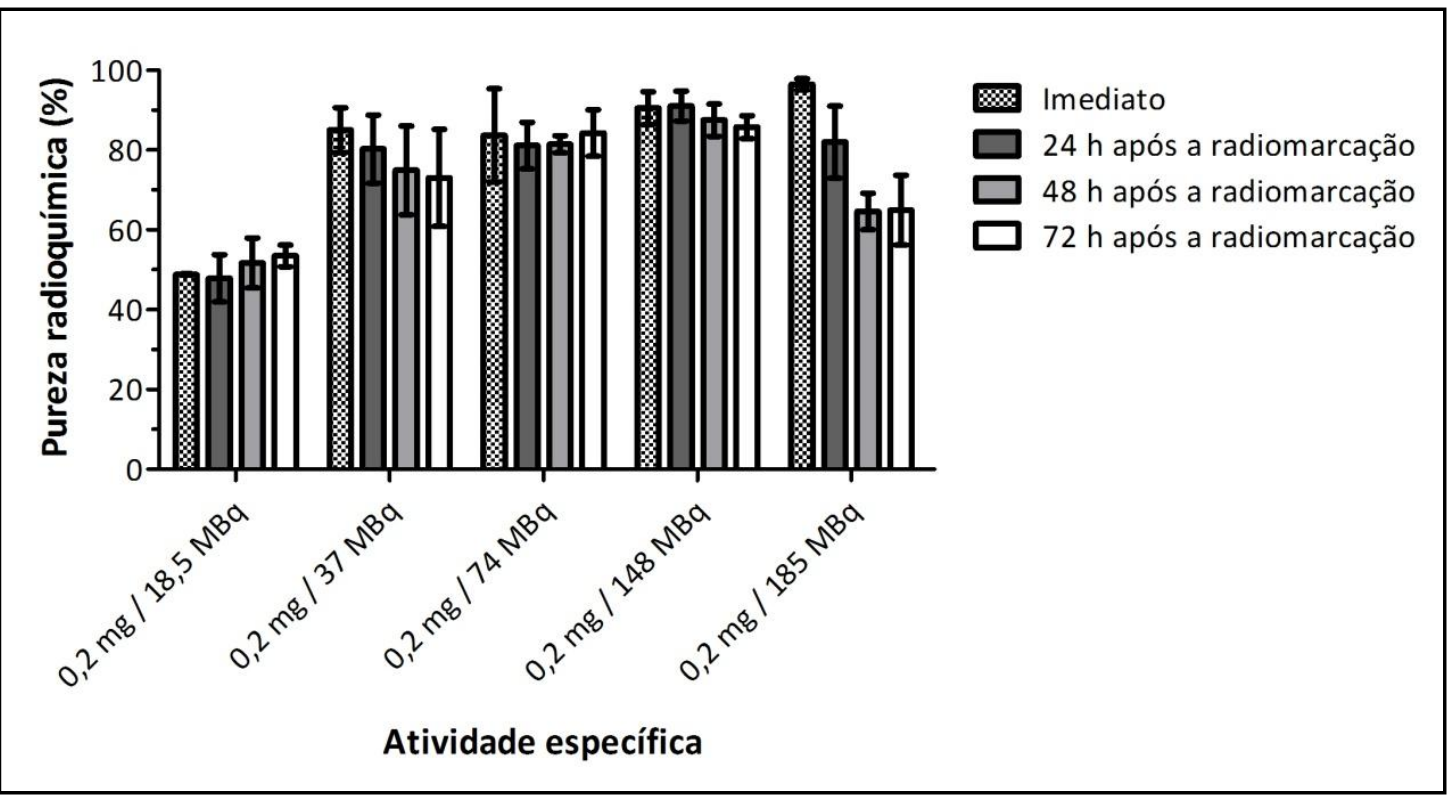

FIGURA 18 - Influência da atividade na pureza radioquímica da marcação de $\mathbf{0 , 2} \mathbf{~ m g}$ de imunoconjugado (1:50). Resultados obtidos por CCD e expressos em média \pm EPM $(n \geq 3)$.

Pureza radioquímica consideravelmente alta foi observada quando $0,2 \mathrm{mg}$ de imunoconjugado foi radiomarcado com 37, 74, 148 e 185 MBq de ${ }^{177}$ Lu (FIGURA 18). Quando a pureza radioquímica foi analisada como uma função de tempo (estabilidade), observou-se uma diferença significativa $(P<0,0001)$ entre os quatro grupos, sobretudo influenciado pela baixa pureza radioquímica observada no primeiro grupo $(0,2 \mathrm{mg} / 18,5 \mathrm{MBq})$ e pelo decréscimo na pureza radioquímica com o decorrer do tempo. 


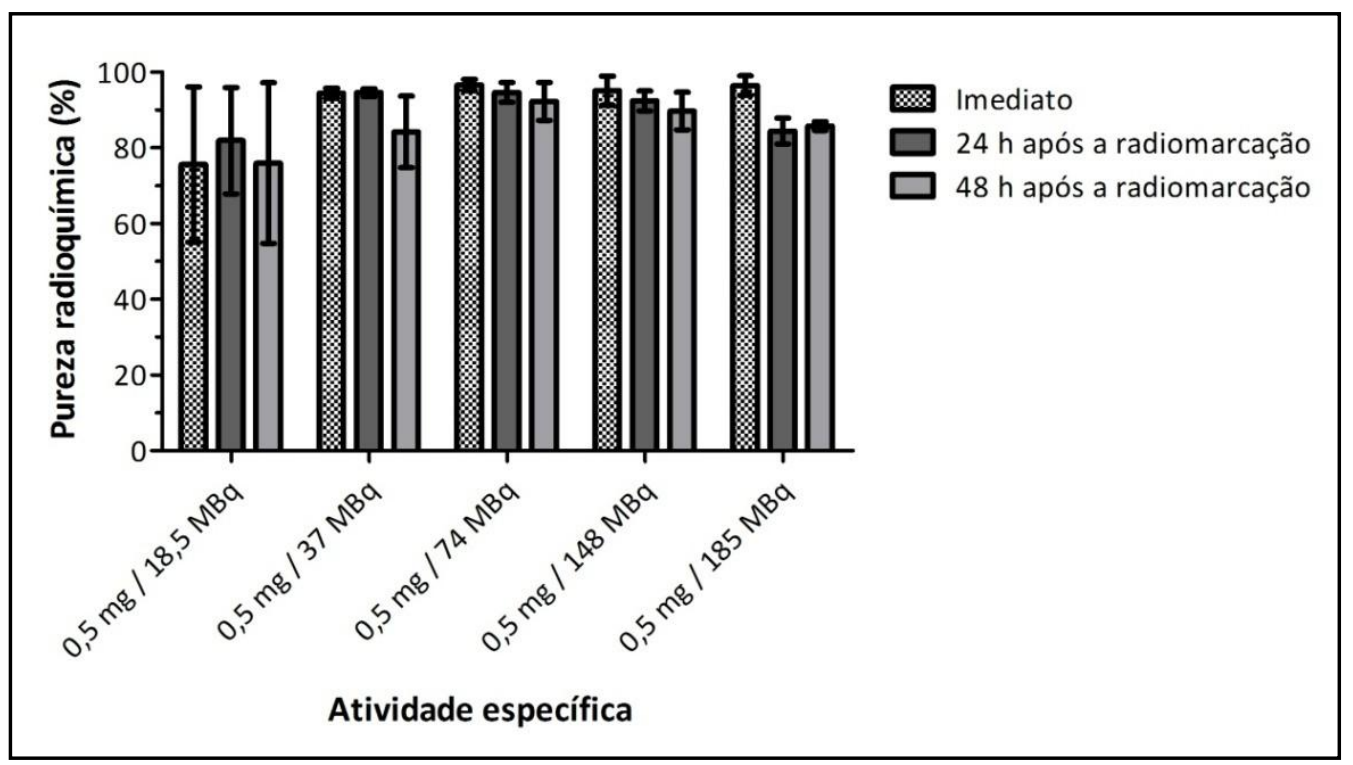

FIGURA 19 - Influência da atividade na pureza radioquímica da marcação de $\mathbf{0 , 5} \mathbf{~ m g}$ de imunoconjugado (1:50). Resultados obtidos por CCD e expressos em média \pm EPM $(n \geq 3)$.

Quando uma massa maior do anti-CD20-DOTA $(0,5 \mathrm{mg})$ foi radiomarcada (FIGURA 19), a pureza radioquímica aumentou no tempo imediato, contudo este aumento não foi significativo quando comparado com a massa de $0,2 \mathrm{mg}(P=0,1508)$. Observou-se também uma melhor estabilidade (armazenamento a $2-8^{\circ} \mathrm{C}$ ) para a maioria das atividades estudadas, mas os mesmos também não foram significativos, comparados à massa de 0,2 mg, tanto para o tempo de 24 horas, quanto para o tempo de 48 horas após a radiomarcação $(P>0,05)$.

O resumo das radiomarcações realizadas para definir a atividade específica está apresentado na TABELA 13. 
TABELA 13 - Estudo da influência da atividade específica na pureza radioquímica do AntiCD20-DOTA- ${ }^{177}$ Lu. Resultados expressos em média \pm DP $(n \geq 3)$.

\begin{tabular}{|c|c|c|c|}
\hline $\begin{array}{l}\text { Massa do Anti- } \\
\text { CD20-DOTA } \\
\text { (mg) }\end{array}$ & $\begin{array}{l}\text { Atividade de } \\
\qquad{ }^{177} \mathrm{LuCl}_{3} \\
\text { (MBq / mCi) }\end{array}$ & $\begin{array}{l}\text { \% Pureza radioquímica do } \\
\text { Anti-CD20-DOTA- }{ }^{177} \text { Lu (CCD) }\end{array}$ & $\begin{array}{l}\text { Atividade específica } \\
\text { do Anti-CD20-DOTA- } \\
{ }^{177} \mathrm{Lu}(\mathrm{MBq} / \mathrm{mg})\end{array}$ \\
\hline 0,1 & 37 / 1 & $89,73 \pm 9,60$ & 370 \\
\hline 0,2 & $18,5 / 0,5$ & $48,77 \pm 0,22$ & 92,5 \\
\hline 0,2 & $37 / 1$ & $85,00 \pm 12,55$ & 185 \\
\hline 0,2 & $74 / 2$ & $83,71 \pm 16,46$ & 370 \\
\hline 0,2 & $148 / 4$ & $90,52 \pm 7,12$ & 740 \\
\hline 0,2 & $185 / 5$ & $96,42 \pm 2,46$ & 925 \\
\hline 0,5 & $18,5 / 0,5$ & $75,63 \pm 29,01$ & 37 \\
\hline 0,5 & $37 / 1$ & $94,48 \pm 3,23$ & 74 \\
\hline 0,5 & $74 / 2$ & $96,64 \pm 2,12$ & 148 \\
\hline 0,5 & $148 / 4$ & $95,10 \pm 5,42$ & 296 \\
\hline 0,5 & $185 / 5$ & $96,47 \pm 3,68$ & 370 \\
\hline 1 & 37 / 1 & $92,60 \pm 5,60$ & 37 \\
\hline
\end{tabular}

O estudo da influência da atividade específica na pureza radioquímica foi realizado para diferentes massas de imunoconjugado e resultados de pureza radioquímica alta foram obtidos para radiomarcações utilizando-se $0,5 \mathrm{mg}$ do imunoconjugado, para atividade específica variando de 74 a $370 \mathrm{MBq} / \mathrm{mg}$. O mesmo pode-se dizer para a massa de 0,2 mg com a atividade específica de $740 \mathrm{MBq} / \mathrm{mg}$ e $925 \mathrm{MBq} / \mathrm{mg}$ (TABELA 13). 
Entretanto, quando a radiomarcação foi realizada com uma massa pequena de imunoconjugado e baixa atividade de ${ }^{177} \mathrm{Lu}$, a pureza radioquímica apresentou grande variabilidade entre as radiomarcações, resultando em uma pureza radioquímica média inferior a 90\%. Isto pode ser observado quando $0,1 \mathrm{mg}$ do imunoconjugado foi radiomarcado com $37 \mathrm{MBq}$; 0,2 $\mathrm{mg}$ com 18,5 MBq; 0,2 mg com $37 \mathrm{MBq}$ e 0,5 mg com 18,5 $\mathrm{MBq}$.

Aparentemente, o uso de uma massa muito pequena, especialmente quando combinado com baixa atividade de ${ }^{177} \mathrm{Lu}$, resulta na diminuição do rendimento de marcação, para uma mesma atividade específica (TABELA 13).

A melhor atividade específica, que resultou em rendimento radioquímica alto, foi $925 \mathrm{MBq} / \mathrm{mg}$, contudo, a atividade específica de $740 \mathrm{MBq} / \mathrm{mg}$ apresentou melhor estabilidade (FIGURA 18).

A atividade específica de $740 \mathrm{MBq} / \mathrm{mg}$ é maior do que a encontrada por Audicio e colaboradores $(300 \mathrm{MBq} / \mathrm{mg})^{93}$, Repetto-Llamazares e colaboradores (120 - $220 \mathrm{MBq} / \mathrm{mg}$ ) ${ }^{43}$ e Forrer e colaboradores $(296 \mathrm{MBq} / \mathrm{mg})^{51}$.

Em um estudo clínico realizado em 2013, 31 pacientes portadores de diferentes tipos de LNH refratários foram tratados com diferentes doses de anti-CD20-DOTA- ${ }^{177} \mathrm{Lu}$, radiomarcado com uma atividade específica de $296 \mathrm{MBq} / \mathrm{mg}$. A taxa de resposta global foi de $52 \%$ e muitos pacientes apresentaram remissão completa por vários meses. Ressalta-se, porém, que todos os pacientes receberam duas doses de $250 \mathrm{mg}$ de rituximabe não radioativo, por $\mathrm{m}^{2}$ de área de superfície corpórea antes da administração do radiofármaco ${ }^{7}$.

Este é um dos protocolos utilizados na radioimunoterapia, pois os receptores existentes em células de LNH (CD20, CD22, CD74, CD33 entre outros) estão também presentes em células B normais. Portanto, a administração prévia de rituximabe não radioativo bloqueia o receptor $\mathrm{CD} 20$ impedindo assim, a biodistribuição desfavorável especialmente no baço ${ }^{44,65}$.

Entende-se, portanto, que embora a atividade específica seja uma grandeza importante, no caso do anti-CD20-DOTA $-{ }^{177} \mathrm{Lu}$, ela teria uma menor importância, dado o protocolo de tratamento.

B) Definição do tempo, temperatura e $\mathrm{pH}$ de marcação

Como já mencionado, o protocolo padrão de radiomarcação foi baseado no 
estudo publicado por Lewis e colaboradores em 1994. Deste modo, a reação padrão de radiomarcação ocorreu a $43^{\circ} \mathrm{C}$ por 1 hora em pH de 5,5 -6,0.

Mas com o intuito de melhorar o rendimento radioquímico, a atividade específica anteriormente estuda (925 MBq/mg) que resultou em pureza radioquímica alta, equivalente à condição de radiomarcação de 0,2 mg / $185 \mathrm{MBq}$, foi submetida à radiomarcação em diferentes tempos, temperaturas e pHs.

Os dados estão expressos na FIGURA 20 e indicam uma diferença considerável entre os grupos estudados $(P=0,0080)$.

$\mathrm{O}$ aumento da temperatura da radiomarcação $\left(50^{\circ} \mathrm{C}\right)$, não promoveu aumento da pureza radioquímica em nenhum dos pHs estudados $(P>0,05)$. Embora muitos estudos tenham relatado bons rendimentos radioquímicos em $\mathrm{pH}$ neutro $4,11,51,78,79,93$, este resultado não foi observado em qualquer condição estudada para este tampão (acetato de sódio).

Usando um $\mathrm{pH}$ de 5,5 , os melhores resultados foram observados quando a marcação foi realizada a $43{ }^{\circ} \mathrm{C}(\mathrm{P}<0,05)$.

Embora o anti-CD20 seja um anticorpo robusto ${ }^{51}$, é conhecido que a exposição das proteínas às temperaturas elevadas, durante períodos de tempo prolongados, promove a sua desnaturação ${ }^{108}$. Isso pode explicar a queda acentuada na pureza radioquímica, quando o anticorpo foi radiomarcado a $50{ }^{\circ} \mathrm{C}$ por mais de $1 \mathrm{~h} 30$ minutos.

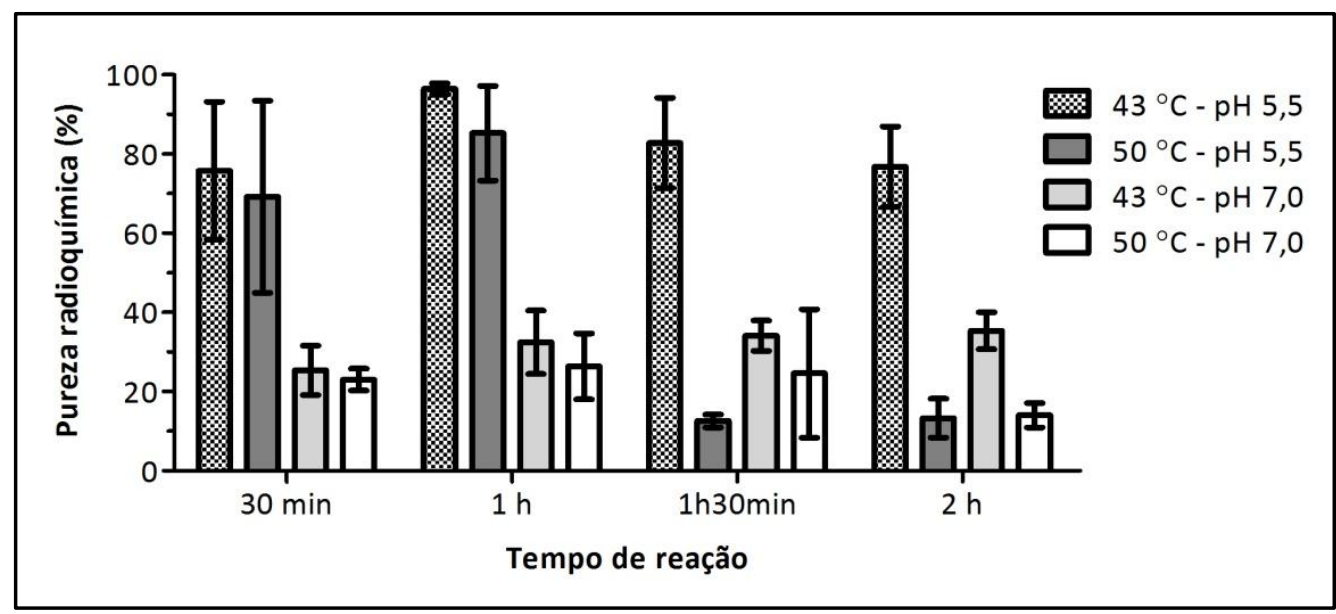

FIGURA 20 - Influência da temperatura, tempo e pH na radiomarcação. Condições de radiomarcação: $0,2 \mathrm{mg}$ do imunoconjugado, $185 \mathrm{MBq}(5 \mathrm{mCi})$ de ${ }^{177} \mathrm{LuCl}_{3}, 350 \mathrm{rpm}$. Resultados obtidos por CCD e expressos em média $\pm \operatorname{EPM}(n=3)$. 
Considerando a temperatura de $43{ }^{\circ} \mathrm{C}$ e pH 5,5, o aumento no tempo de reação de 30 minutos para 1 hora, promoveu um incremento na pureza radioquímica, embora esta diferença não tenha sido significativa $(P=0,2132)$. Entretanto, o aumento do tempo de reação para 1 h30 e $2 h$, não resultou em melhor pureza radioquímica $(P=0,208$ e 0,1289 respectivamente), provavelmente por promover maior efeito de radiólise sobre o imunoconjugado (FIGURA 20).

Este estudo confirmou a melhor condição encontrada por Lewis e colaboradores e a condição padrão de radiomarcação no presente trabalho foi mantida ( $43^{\circ} \mathrm{C}$ por 1 hora, $\mathrm{pH}$ ácido).

\subsubsection{Estudos com alta atividade de Lu-177}

A) Estudo da influência do volume de radiomarcação e massa do imunoconjugado

A atividade específica de $740 \mathrm{MBq} / \mathrm{mg}$ foi extrapolada para uma condição de aplicação clínica, ou seja, a atividade do radioisótopo foi ajustada para $1.480 \mathrm{MBq}(40 \mathrm{mCi})$, e a massa do imunoconjugado para $2 \mathrm{mg}$. A escolha desta atividade foi baseada na atividade terapêutica utilizada por Forrer e colaboradores ${ }^{7,51}$.

Inicialmente, foi avaliada a influência do volume final da reação (FIGURA 21) e quando a mesma foi realizada no volume de $1 \mathrm{~mL}$, a pureza radioquímica foi significativamente maior $(P=0,033)$ comparada a reação que ocorreu com volume de 0,5 $\mathrm{mL}$.

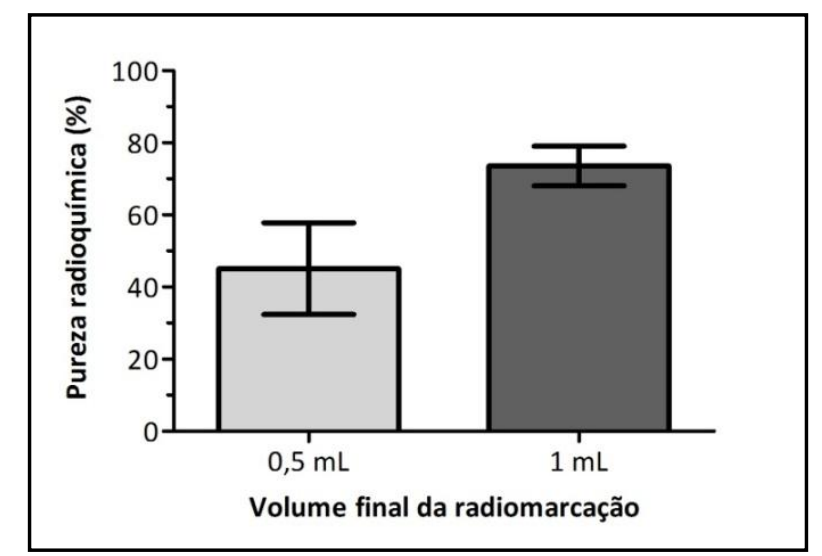

FIGURA 21 - Influência do volume de tampão na radiomarcação. Condições: 2 mg (1:50); $1.480 \mathrm{MBq}(40 \mathrm{mCi})$ de ${ }^{177} \mathrm{LuCl}_{3} ; 1$ hora a $43{ }^{\circ} \mathrm{C}$; tampão acetato de sódio $0,4 \mathrm{M} \mathrm{pH} \mathrm{5,5;}$ agitação de 500 rpm (imediato não purificado). Resultados obtidos por CCD e expressos em média $\pm \operatorname{EPM}(n \geq 4)$. 
Em seguida, foi avaliado o efeito da massa de imunoconjugado (FIGURA 22). A avaliação estatística revelou que não houve diferença significativa entre a pureza radioquímica encontrada para as massas de 2 e $5 \mathrm{mg}(P=0,524)$.

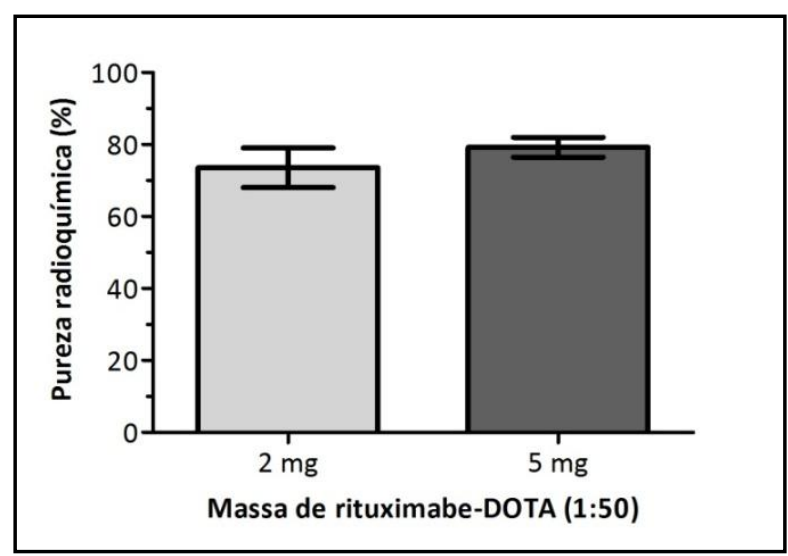

FIGURA 22 - Influência da massa de imunoconjugado na radiomarcação. Condições de radiomarcação: $1.480 \mathrm{MBq}(40 \mathrm{mCi})$ de ${ }^{177} \mathrm{LuCl}_{3}$; 1 hora a $43^{\circ} \mathrm{C}$; tampão acetato de sódio 0,4 $\mathrm{M} \mathrm{pH} \mathrm{5,5;} \mathrm{volume} \mathrm{final} \mathrm{de} 1 \mathrm{~mL}$ e agitação de $500 \mathrm{rpm}$ (Imediato não purificado). Resultados obtidos por CCD e expressos em média \pm EPM $(n \geq 4)$.

\section{B) Estudo da influência do tampão de radiomarcação na pureza radioquímica}

Com o intuito de aumentar a pureza radioquímica do radioimunoconjugado foi avaliado outro tampão de radiomarcação, acetato de amônio 0,25 M, e a sua influência na pureza radioquímica foi avaliada.

Quando 2 mg de imunoconjugado foram radiomarcados com $1.480 \mathrm{MBq}$ de ${ }^{177} \mathrm{Lu}$

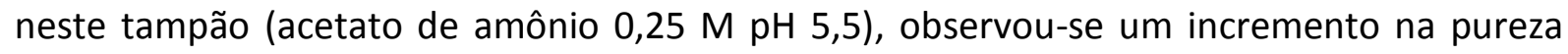
radioquímica de cerca de $14 \%$, quando comparado ao tampão acetato de sódio $0,4 \mathrm{M} \mathrm{pH}$ 5,5 , no entanto, este incremento não foi significativo $(P=0,0712)$ (FIGURA 23). $A$ comparação foi realizada com a pureza radioquímica obtida no tempo imediato sem purificação.

Os tampões acetato de amônio e citrato de amônio são preferíveis para a radiomarcação de metais como o Y-90 e Lu-177, pois assim evita-se a contaminação com outros metais, presentes na composição do tampão, e estabiliza o cation $\mathrm{Lu}^{3+}$ pela formação de um complexo fraco $\left[{ }^{177}\right.$ Lu]acetato ou [ ${ }^{177}$ Lu $]$ citrato ${ }^{105}$.

Além da troca do tampão, a partir deste momento a diluição do quelante passou 
a ser realizada em água e não mais em tampão fosfato $0,2 \mathrm{M} \mathrm{pH} \mathrm{8,5.} \mathrm{Com} \mathrm{isto,} \mathrm{esperava-se}$ diminuir a hidrólise da porção NHS-éster do quelante a qual pode ocorrer em pH alcalino, uma vez que o quelante hidrolisado interfere direta e negativamente na eficiência de conjugação ${ }^{122}$.

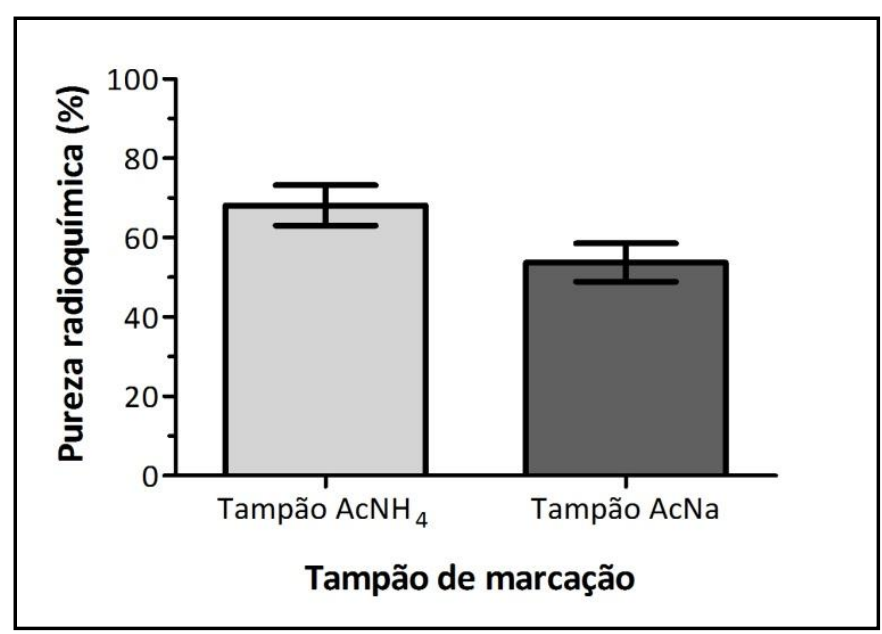

FIGURA 23 - Influência do tampão na radiomarcação. Condições: 2 mg (1:50); 1.480 MBq (40 $\mathrm{mCi})$ de ${ }^{177} \mathrm{LuCl}_{3} ; 1$ hora a $43{ }^{\circ} \mathrm{C} ; \mathrm{pH} 5$,5. Pureza radioquímica determinada por CLAE. Resultados expressos em média \pm EPM $(n \geq 3)$.

A variação do $\mathrm{pH}$ do tampão acetato de amônio $0,25 \mathrm{M}$ não promoveu melhora significativa $(P=0,719)$ na pureza radioquímica (FIGURA 24). Mas devido ao $\mathrm{pH} 6,5$ ter promovido uma pureza radioquímica discretamente maior e este $\mathrm{pH}$ ser comumente utilizado para este tampão ${ }^{12,78}$, o tampão acetato de amônio $0,25 \mathrm{M} \mathrm{pH} \mathrm{6,5,} \mathrm{foi} \mathrm{escolhido}$ para os demais estudos. 


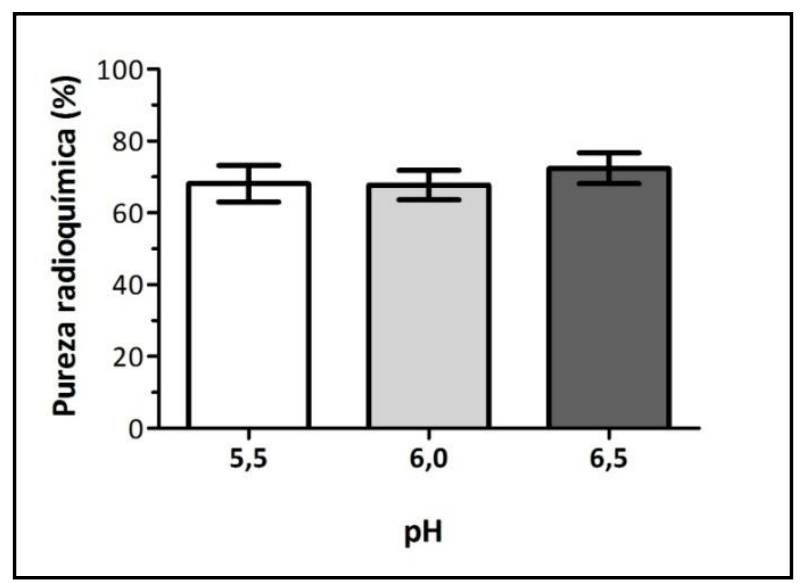

FIGURA 24 - Influência do pH na radiomarcação utilizando-se tampão acetato de amônio 0,25 M. Condições: $2 \mathrm{mg}(1: 50) ; 1.480 \mathrm{MBq}(40 \mathrm{mCi})$ de ${ }^{177} \mathrm{LuCl}_{3} ; 1$ hora a $43{ }^{\circ} \mathrm{C}$. Pureza radioquímica determinada por CLAE. Resultados expressos em média \pm EPM $(n=3)$.

\subsubsection{Avaliação da estabilidade do anti-CD20-DOTA- ${ }^{177} \mathrm{Lu}$}

A) Estudo do efeito de agentes estabilizantes

Como mencionado no item 5.4.2 B, radiofármacos emissores $\alpha^{2+}$ ou $\beta^{-}$ frequentemente sofrem radiólise durante a preparação e armazenamento. O AcM afetado pela radiólise não se liga preferencialmente no tumor, e portanto, a radiação pode contribuir para a toxicidade. Por este motivo, muitas vezes torna-se necessário a adição de estabilizantes em preparações radiofarmacêuticas obtidas com alta atividade.

O anti-CD20-DOTA $-{ }^{177}$ Lu radiomarcado com atividade alta foi diluído em $\mathrm{NaCl}$ 0,9 \% e sua estabilidade analisada por CCD após armazenamento à $-20{ }^{\circ} \mathrm{C}$ por 24 horas na ausência e presença de agentes estabilizantes. Estes resultados estão expressos na TABELA 14. 
TABELA 14 - Estabilidade do anti-CD20-DOTA- ${ }^{177} \mathrm{Lu}(2 \mathrm{mg} / 1.480 \mathrm{MBq}$ ), purificado em PD-10, após armazenamento sob congelamento $\left(-20^{\circ} \mathrm{C}\right)$ Pureza radioquímica determinada por CCD (Média \pm DP) $(n=3)$.

\begin{tabular}{|c|c|c|c|c|c|c|}
\hline \multicolumn{7}{|c|}{ Quantidade das espécies (\%) } \\
\hline \multirow{2}{*}{ Estabilizante } & \multicolumn{2}{|c|}{ Anti-CD20-DOTA- ${ }^{177} \mathrm{Lu}$} & \multicolumn{2}{|c|}{ DOTA ${ }^{177} \mathrm{Lu}$} & \multicolumn{2}{|c|}{${ }^{177} \mathrm{Lu}$} \\
\hline & Imediato & 24 horas & Imediato & 24 horas & Imediato & 24 horas \\
\hline$D+C$ & $90,7 \pm 0,5$ & $84,3 \pm 0,9$ & $4,3 \pm 0,5$ & $10,4 \pm 4,3$ & $9,9 \pm 0,3$ & $3,0 \pm 4,2$ \\
\hline $\begin{array}{l}D+A A(10 \\
m g / m L)+C\end{array}$ & $90,4 \pm 4,8$ & $74,0 \pm 18,0$ & $3,7 \pm 3,3$ & $25,7 \pm 17,7$ & $5,9 \pm 1,5$ & $0,3 \pm 0,4$ \\
\hline $\begin{array}{l}D+A G(10 \\
m g / m L)+C\end{array}$ & $91,9 \pm 4,5$ & $78,3 \pm 11,8$ & $4,1 \pm 1,4$ & $13,8 \pm 6,8$ & $9,1 \pm 4,7$ & $7,9 \pm 6,4$ \\
\hline $\begin{array}{l}D+E(10 \% v / v) \\
+C\end{array}$ & $90,3 \pm 7,8$ & $66,8 \pm 7,0$ & $8,0 \pm 0,03$ & $18,08 \pm 10,6$ & $7,8 \pm 2,6$ & $15,0 \pm 3,6$ \\
\hline
\end{tabular}

A adição de agentes estabilizantes antioxidantes como o ácido gentísico e ácido ascórbico é uma prática usual para estabilizar o radiofármaco. Além destes agentes, a diluição da amostra final também é uma estratégia para diminuir os efeitos da radiólise.

O congelamento foi empregado em todas as condições, pois se sabe que quando empregado logo após a radiomarcação, a interação dos radicais livres (formados com a radiólise indireta), com o AcM é diminuída ${ }^{123}$.

Chakrabarti e colaboradores (1996) ${ }^{123}$ relataram que o uso de ácido ascórbico na concentração de $11 \mathrm{mg} / \mathrm{mL}$, foi capaz de preservar 81\% da imunorreatividade do AcM T-101 radiomarcado com $\mathrm{Y}-90$ na atividade específica de $1.258 \mathrm{MBq} / \mathrm{mg}$ e portanto seu uso foi encorajado neste trabalho.

Entretanto, o uso de ácido ascórbico não impediu que a pureza radioquímica do anti-CD20-DOTA- ${ }^{177}$ Lu diminuísse $16 \%$ em 24 horas. Na realidade, a adição de conservantes não promoveu incremento significativo na estabilidade ( $P>0,2$ para todas as condições).

A melhor condição foi encontrada quando o radioimunoconjugado foi diluído em solução de cloreto de sódio $0,9 \%$ (salina) e congelado. 
B) Estabilidade em condições de transporte

O estudo da estabilidade do anti-CD20-DOTA- ${ }^{177}$ Lu pretendeu avaliar uma condição final que pudesse ser utilizada para o transporte do produto para diferentes localidades do país. O Centro de Radiofarmácia utiliza uma embalagem para transporte de moléculas marcadas que dispõe de um reservatório interno para acondicionar o radiofármaco congelado em gelo seco. Por este motivo, avaliou-se a estabilidade do antiCD20-DOTA- ${ }^{177} \mathrm{Lu}$ à $-20{ }^{\circ} \mathrm{C}$, por um tempo suficiente que fosse possível viabilizar a distribuição aos centros clínicos.

Além disso, este estudo simulou uma eventual situação na clínica médica em que após o recebimento e descongelamento do radiofármaco, o mesmo seria armazenado sob refrigeração até a administração ao paciente.

Assim, o anticorpo radiomarcado foi diluído e mantido à $-20{ }^{\circ} \mathrm{C}$ por 4 horas (FIGURA 25 A), este tempo simulou o tempo médio de transporte do radiofármaco, para regiões próximas ao centro produtor (IPEN). Após 4 horas, a amostra foi descongelada e mantida sob refrigeração $\left(2-8^{\circ} \mathrm{C}\right)$ por até 6 horas.

O congelamento por 24 horas e 48 horas (FIGURA 25 B e C) simulou o transporte para regiões mais distantes. Assim como na condição anterior, o anti-CD20-DOTA- ${ }^{177}$ Lu foi mantido à $-20^{\circ} \mathrm{C}$ por 24 ou 48 horas, transcorrido este tempo, foi descongelado e mantido sob refrigeração por 6 horas. Os perfis cromatográficos obtidos por CLAE para o tempo de até 24 horas estão apresentados na FIGURA 26.

Os perfis de CLAE indicaram que a quantidade de ${ }^{177}$ Lu-DOTA $/{ }^{177}$ Lu aumentam conforme o tempo de armazenamento e após 24 horas de armazenamento a $-20{ }^{\circ} \mathrm{C}$, há formação de uma espécie com tempo de retenção menor do que o pico principal do radioimunoconjugado. Esta espécie corresponde a agregados proteicos que são formados devido à radiólise do AcM (FIGURA 26).

O imunoconjugado radiomarcado na atividade específica de $740 \mathrm{MBq} / \mathrm{mg}$ apresentou estabilidade alta em todas as condições de armazenamento estudadas. 


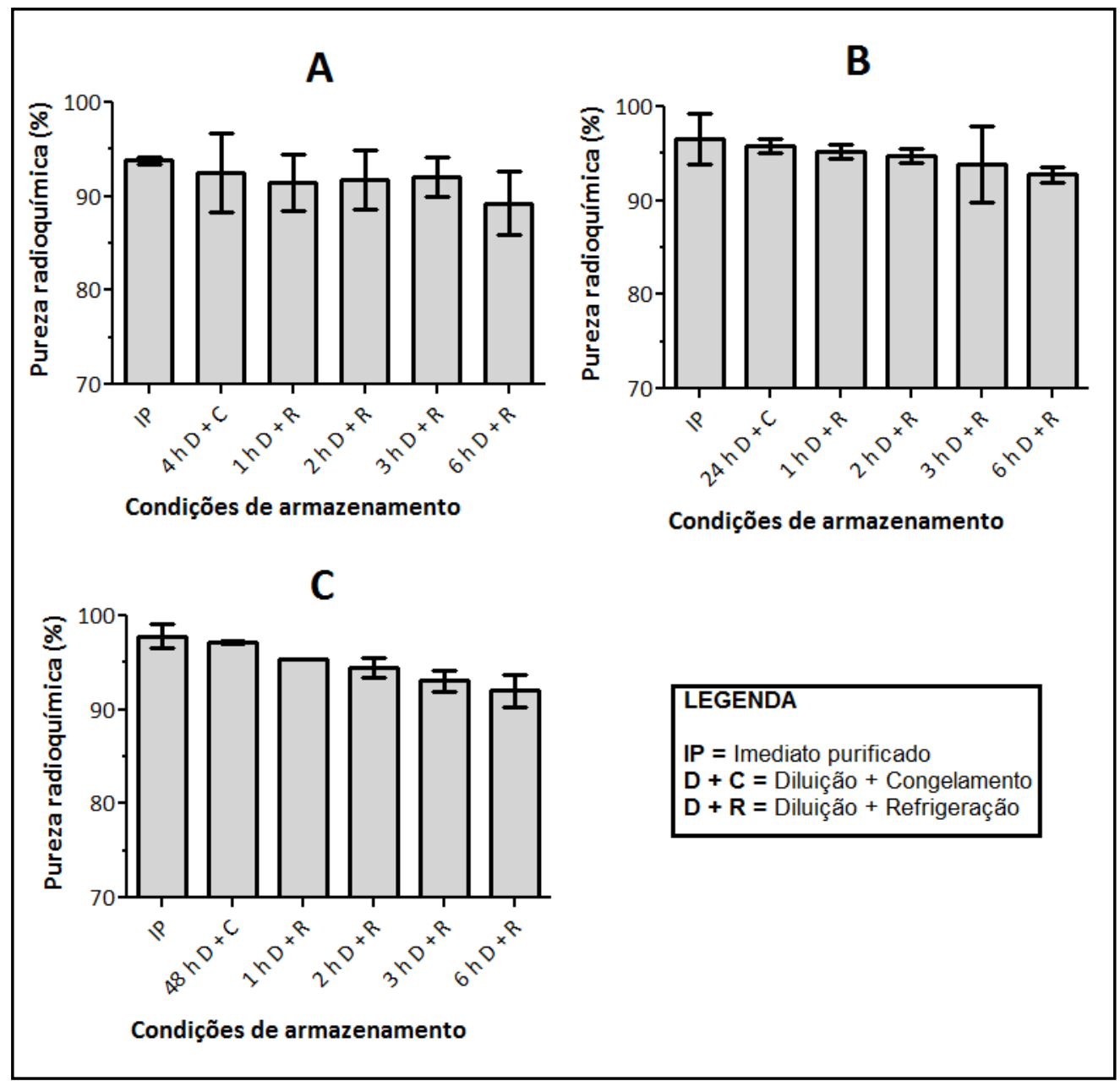

FIGURA 25 - Estabilidade do anti-CD20-DOTA radiomarcado com alta atividade de Lu-177 (2 $\mathrm{mg} / 1.400 \mathrm{MBq} ; \mathbf{7 4 0} \mathrm{MBq} / \mathrm{mg}$ ). Em (A), resultados da estabilidade após armazenamento por 4 horas à $-20{ }^{\circ} \mathrm{C}$; em (B), após armazenamento por 24 horas à $-20{ }^{\circ} \mathrm{C}$, seguido de armazenamento por 6 horas a $2-8^{\circ} \mathrm{C}$ e em (C), após armazenamento por 48 horas à $-20^{\circ} \mathrm{C}$, seguido de armazenamento por 6 horas a $2-8{ }^{\circ} \mathrm{C}$. Resultados obtidos por CCD e expressos em média \pm DP $(N=2)$. 


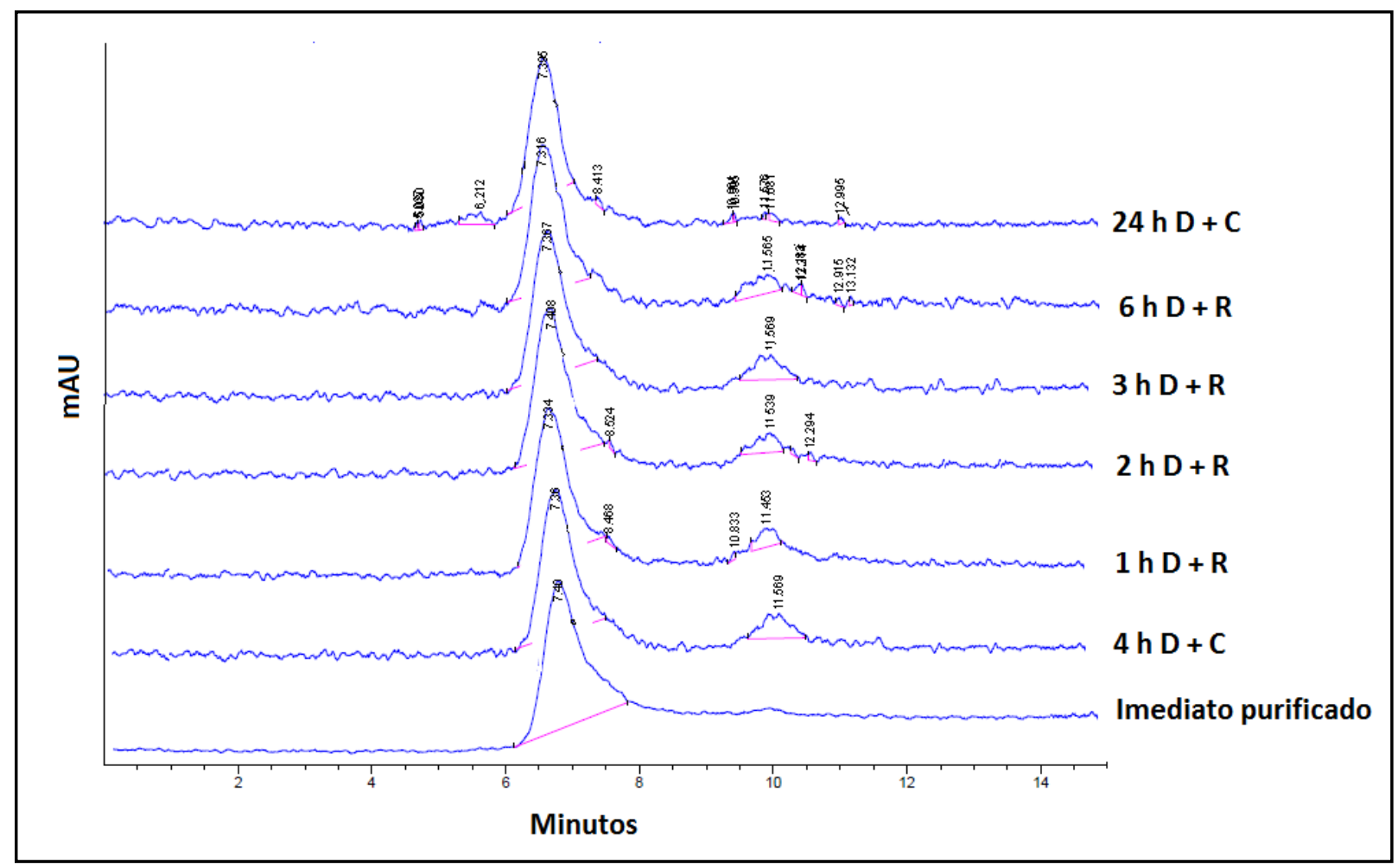

FIGURA 26 - Perfis cromatográficos (CLAE) do radioimunoconjugado (740 MBq/mg) armazenado em diferentes condições. $\mathrm{D}=$ Diluição; $\mathrm{C}=$ Congelamento e $\mathrm{R}=$ refrigeração.

O imunoconjugado radiomarcado em outras atividades específicas (296 e 925 $\mathrm{MBq} / \mathrm{mg}$ ) também tiveram suas estabilidades analisadas (FIGURA 27 e FIGURA 28).

Não foram encontradas diferenças significativas na estabilidade entre as atividades específicas de $740 \mathrm{MBq} / \mathrm{mg}$ e $296 \mathrm{MBq} / \mathrm{mg}$ para o tempo de 24 horas $(P=0,7280)$ e para o tempo de 48 horas ( $P=0,6126)$ (FIGURA 25 e FIGURA 26).

A atividade específica de $925 \mathrm{MBq} / \mathrm{mg}$ não foi submetida à análise estatística pois possui um $\mathrm{N}=1$, impossibilitando a análise. Contudo, foi possível observar que a pureza radioquímica diminui após 6 horas de descongelamento do radioimunoconjugado tanto para o tempo de 24 horas (FIGURA 28 A), quanto para o tempo de 48 horas (FIGURA 28 B) após a radiomarcação. Isto indica que quando radiomarcado com atividade específica mais alta, o AcM sofre acentuada radiólise após 3 horas de armazenamento a 2 - $8^{\circ} \mathrm{C}$. 


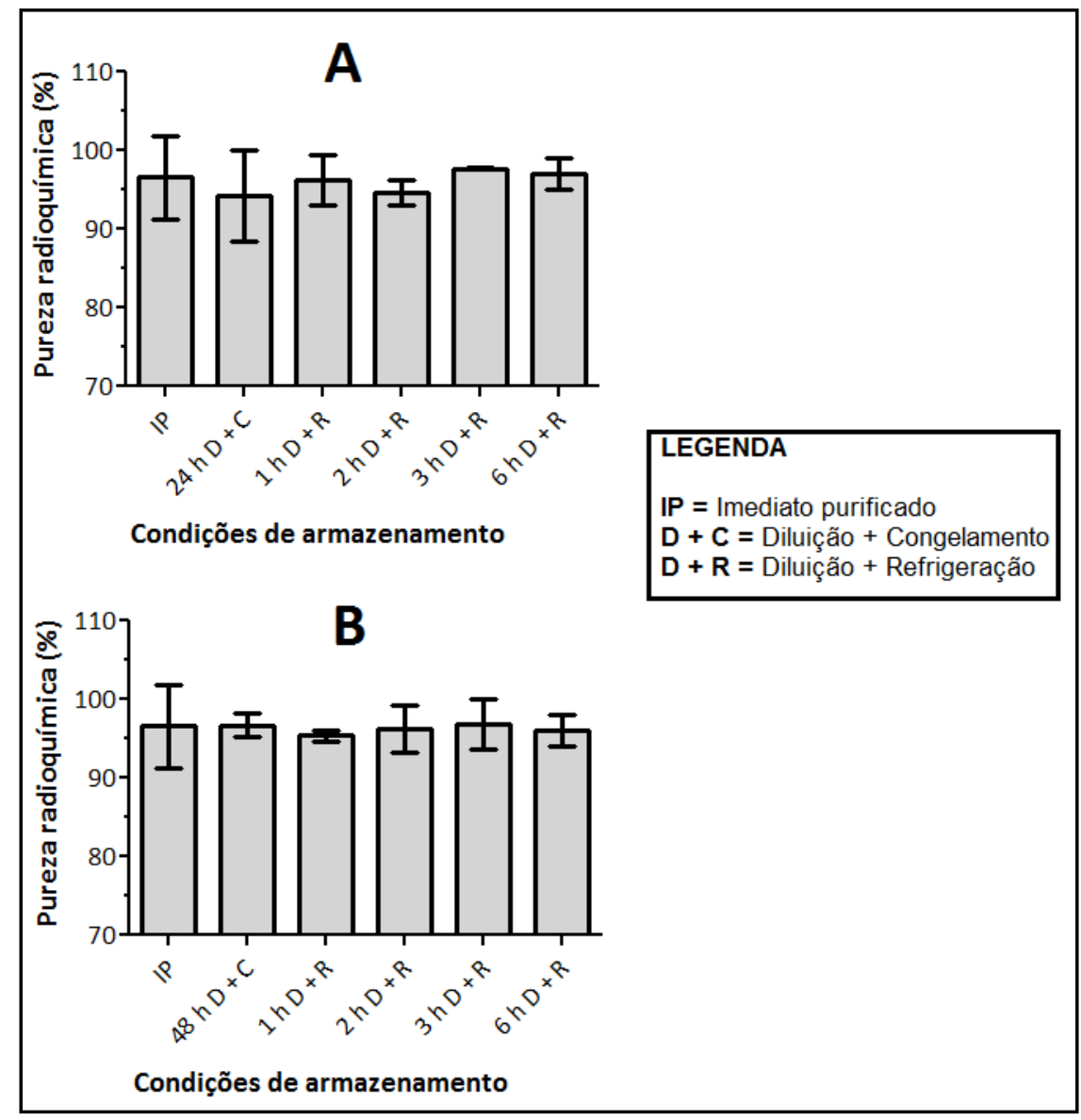

FIGURA 27 - Estabilidade do anti-CD20-DOTA radiomarcado com alta atividade de Lu-177 (2 $\mathrm{mg} / 1.400 \mathrm{MBq} ; 296 \mathrm{MBq} / \mathrm{mg}$ ). Em (A), resultados da estabilidade após armazenamento por 24 horas à $-20{ }^{\circ} \mathrm{C}$, seguido de armazenamento por 6 horas a $2-8{ }^{\circ} \mathrm{C}$ e em (B), após armazenamento por 48 horas à $-20^{\circ} \mathrm{C}$, seguido de armazenamento por 6 horas a $2-8{ }^{\circ} \mathrm{C}$. Resultados obtidos por CCD e expressos em média $\pm \mathrm{DP}(\mathrm{N}=2)$. 


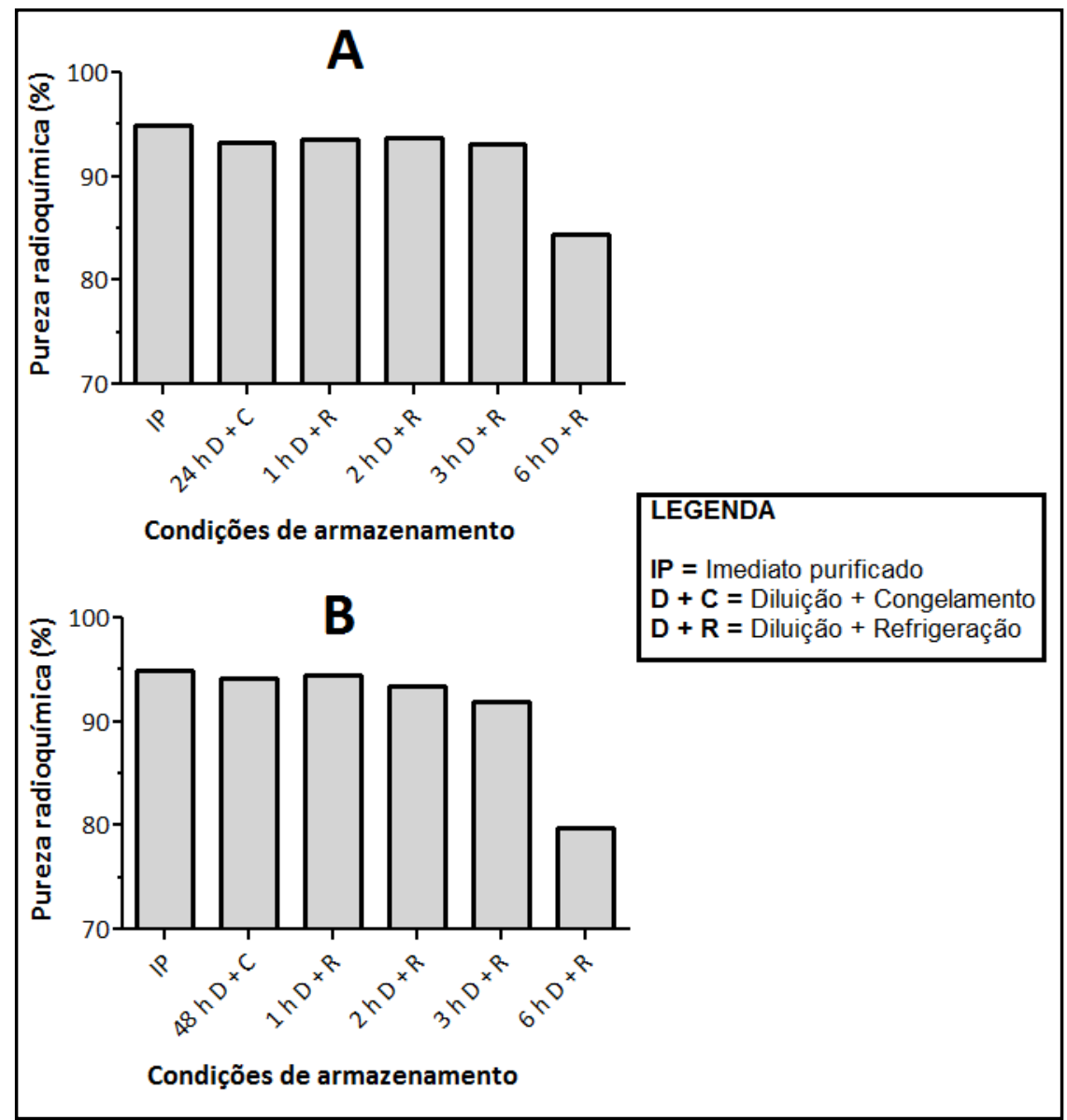

FIGURA 28 - Estabilidade do anti-CD20-DOTA radiomarcado com alta atividade de Lu-177 (2 $\mathrm{mg} / 1.850 \mathrm{MBq} ; 925 \mathrm{MBq} / \mathrm{mg}$ ). Em (A), resultados da estabilidade após armazenamento por 24 horas à $-20{ }^{\circ} \mathrm{C}$, seguido de armazenamento por 6 horas a $2-8{ }^{\circ} \mathrm{C}$ e em (B), após armazenamento por 48 horas à $-20^{\circ} \mathrm{C}$, seguido de armazenamento por 6 horas a $2-8^{\circ} \mathrm{C}$. Resultados obtidos por CCD e expressos em média $\pm \mathrm{DP}(\mathrm{N}=2)$.

Com o intuito de comparar os resultados obtidos com outros trabalhos, a base de dados PubMed foi consultada. Foram realizadas três buscas com palavras chaves diferentes, a saber: (1) in vitro stability and radiopharmaceutical and ${ }^{177} \mathrm{Lu}$, (2) stability and antibody and ${ }^{177} \mathrm{Lu}$ e (3) in vitro stability and antibody and ${ }^{177} \mathrm{Lu}$. As pesquisas recuperaram 23, 16 e 12 trabalhos respectivamente (consulta realizada em 09 de dezembro de 2015).

A seção de métodos de todos os trabalhos foi analisada e não foi encontrado nenhum estudo que se assemelhasse ao realizado no presente trabalho. Os estudos comumente encontrados utilizaram incubação do AcM ou peptídeo em temperatura ambiente ou $37^{\circ} \mathrm{C}$. 
Conclui-se, portanto, que o imunoconjugado radiomarcado com atividade específica de 296 e $740 \mathrm{MBq} / \mathrm{mg}$, pode ser diluído em solução salina e imediatamente congelado por até 48 horas possibilitando o seu transporte. Decorrido este tempo, o radioimunoconjugado pode ser descongelado e armazenado sob refrigeração por até 6 horas antes de ser administrado ao paciente com garantia de pureza radioquímica superior a $91 \%$.

Já para a atividade específica de $925 \mathrm{MBq} / \mathrm{mg}$, o radioimunoconjugado pode ser administrado até 3 horas após seu descongelamento, independente do tempo que ele ficou congelado (24 ou 48 horas), também com garantia de pureza radioquímica superior a 91\%. Ressalta-se que para esta atividade específica, o resultado é preliminar, pois o estudo foi realizado com número de amostra igual a 1.

\section{C) Estabilidade em plasma}

O estudo de estabilidade do radioimunoconjugado em plasma humano (TABELA 15), indicou que o anti-CD20-DOTA- ${ }^{177}$ Lu não ligado às proteínas sofre metabolismo lento pelas enzimas do plasma e cerca de $73 \%$ do complexo AcM-DOTA- ${ }^{177}$ Lu continua intacto após 72 horas de incubação.

TABELA 15 - Estabilidade in vitro do anti-CD20-DOTA- ${ }^{177} \mathrm{Lu}(740 \mathrm{MBq} / \mathrm{mg})$ diluído em plasma humano (proteínas precipitadas). Resultados expressos em média $\pm \mathrm{DP}(\mathrm{N}=2)$.

\begin{tabular}{cc}
\hline Tempo de incubação & Pureza radioquímica (\%) \\
\hline Imediato purificado & $99,36 \pm 0,31$ \\
$\mathbf{2 4} \mathbf{h}$ & $84,45 \pm 4,96$ \\
$\mathbf{4 8} \mathbf{h}$ & $78,50 \pm 8,27$ \\
$\mathbf{7 2} \mathbf{h}$ & $73,88 \pm 1,41$ \\
\hline
\end{tabular}

A estabilidade em plasma do radioimunoconjugado foi muito menor quando comparada com trabalhos já publicados $4,8,75,113,121$. Essa diferença pode ser explicada em parte, pelo método utilizado pelos outros autores. Enquanto que para este estudo, foi realizada a análise da pureza radioquímica após a precipitação das proteínas plasmáticas, os 
demais estudos citados utilizaram colunas de exclusão molecular (para análise em CLAE ou contador gama/calibrador de dose) ou CCD sem a precipitação prévia das proteínas. A precipitação destas proteínas é importante, pois, como será discutido mais à frente, AcMs se ligam em grande proporção a elas.

Este último caso representa os estudos realizados por Rasaneh e colaboradores (2009) que avaliaram a estabilidade em soro humano do trastuzumabe-DOTA- ${ }^{177}$ Lu por até 96 horas de incubação. Eles relataram pureza radioquímica de $85 \%$ após o período estudado 8

\subsubsection{Radiomarcação com alta atividade específica do AcM conjugado pelos métodos 1 e 2}

As comparações entre os dois métodos de conjugação no que diz respeito ao número de quelantes por anticorpo e a estabilidade do imunoconjugado a 2 - $8{ }^{\circ} \mathrm{C}$ foram realizadas oportunamente nos item 5.4.1 B e 5.4.3, respectivamente. Neste item avalia-se de forma comparativa a radiomarcação realizada com estes dois imunoconjugados.

$\mathrm{Na}$ FIGURA 29 relaciona-se a pureza radioquímica encontrada após a radiomarcação de 0,2 $\mathrm{mg}$ dos imunoconjugados com $148 \mathrm{MBq}(4 \mathrm{mCi})$ de ${ }^{177} \mathrm{Lu}$, antes e após a purificação em coluna de exclusão molecular (PD-10).

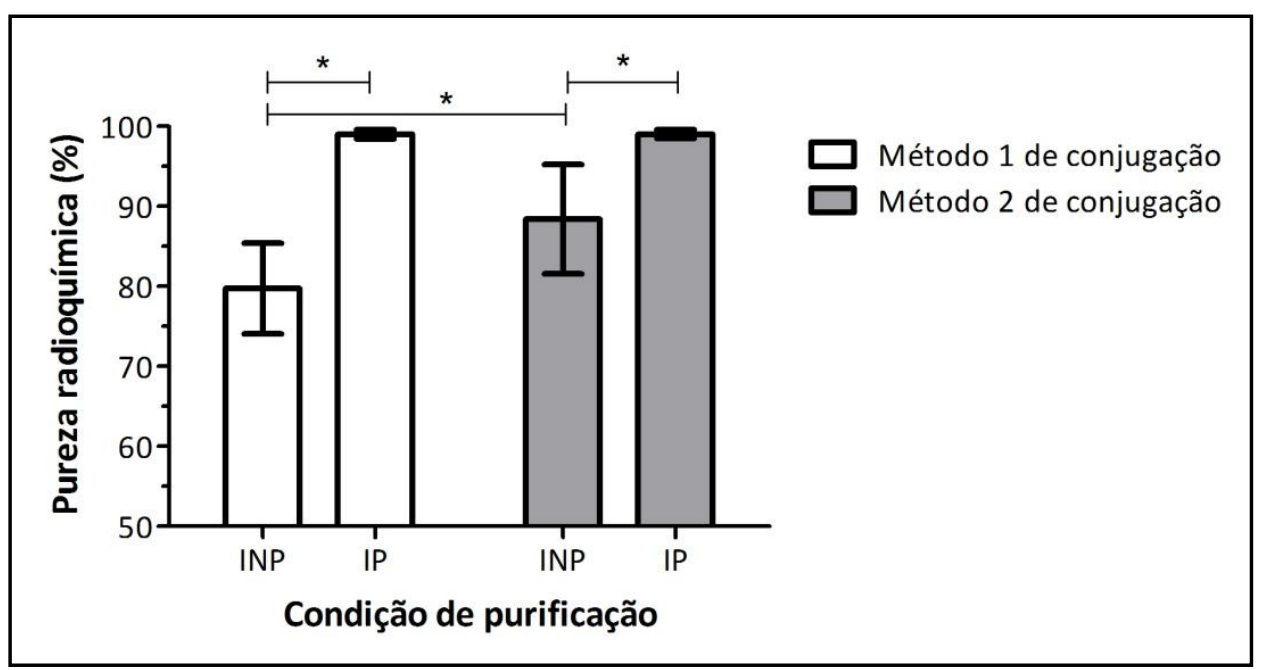

FIGURA 29 - Pureza radioquímica do AcM conjugado pelos dos dois métodos e radiomarcado com Lu-177 (740 MBq/mg). INP = Imediato não purificado e IP = Imediato purificado em coluna de exclusão molecular. Resultados expressos em média \pm DP $(N>4)$. 
O método 2 de conjugação resultou em um discreto aumento do número de quelantes acoplados ao AcM (TABELA 8) e consequentemente uma pureza radioquímica maior, porém sutil, quando comparado ao método $1(P=0,0489)$. Para ambos os métodos, a pureza radioquímica após a purificação foi significativamente maior $(P<0,001$ para método 1 e $\mathrm{P}=0,021$ para método 1). Contudo, a pureza radioquímica obtida após a purificação para os dois métodos, foi igualmente alta $(P=0,9810)$.

Isto indica que ao se empregar uma etapa de purificação após a marcação, qualquer método de conjugação pode ser utilizado.

$\mathrm{O}$ método 2 apresenta a vantagem de ser rápido $\left(2 \mathrm{~h} / 37^{\circ} \mathrm{C}\right)$ e em menos de 5 horas é possível obter o imunoconjugado purificado pronto para a radiomarcação. No entanto, a alta incorporação de quelantes por AcM encontrada neste método, pode interferir na estabilidade pós radiomarcação.

Este estudo de estabilidade, portanto, é importante para definir o melhor método de conjugação a ser empregado.

\subsubsection{Estudos in vitro}

A) Ligação in vitro do anti-CD20-DOTA- ${ }^{177}$ Lu às proteínas do plasma

O sangue contém $93 \%$ de água e os $7 \%$ restantes é composto por diferentes compostos dissolvidos, especialmente proteínas, sendo a albumina a principal proteína, correspodendo a $5 \%$ do total do plasma ${ }^{124}$.

Essas proteínas exercem a função de transportar diferentes substâncias, como fármacos, pela corrente sanguínea, e para tanto é necessário que estas substâncias se liguem às proteínas plasmáticas. Esta ligação é um fenômeno reversível e não específico dependendo de muitos fatores, tais como $\mathrm{pH}$ e carga da droga, afinidade pelas proteínas plasmáticas, tamanho da droga, entre outros ${ }^{124}$.

Assim como os fármacos não radioativos, os radiofármacos podem se ligar às proteínas plasmáticas e aqueles que possuem isótopos metálicos podem sofrer um processo chamado de transquelação. Isso ocorre quando há a troca de íons metálicos, que estão acoplados ao quelante, com as proteínas plasmáticas. Os anticorpos monoclonais radiomarcados com DOTA, apresentam maior estabilidade in vivo com pouca, ou nenhuma, 
transquelação ${ }^{15}$.

A ligação às proteínas do plasma afeta diretamente a biodistribuição do radiofármaco aos tecidos de interesse. Portanto, é necessário determinar a extensão dessa ligação em qualquer radiofármaco novo, antes da sua utilização ${ }^{15}$.

Os resultados de ligação do anti-CD20-DOTA- ${ }^{177}$ Lu às proteínas do plasma estão representados na FIGURA 30.

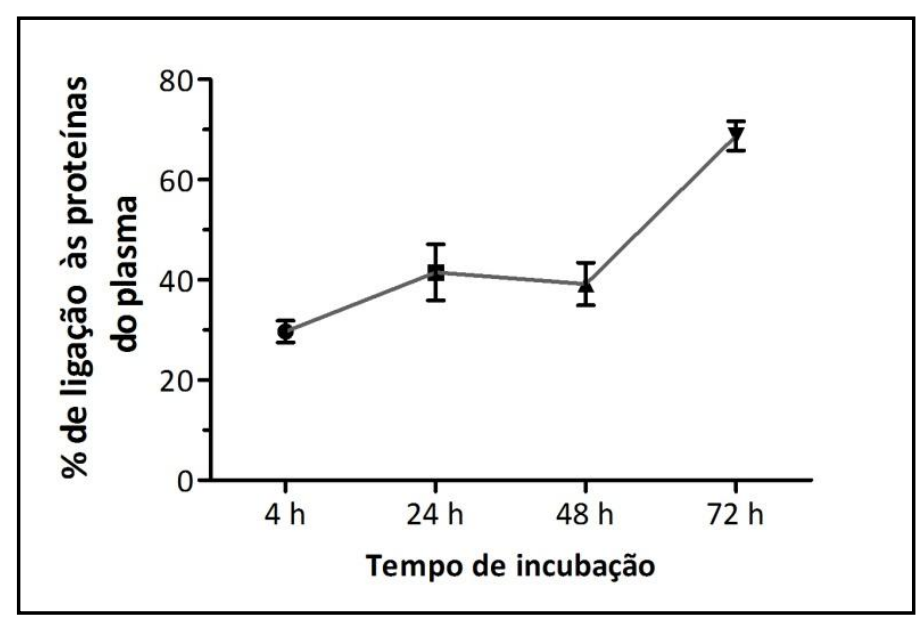

FIGURA 30 - Ligação in vitro do anti-CD20-DOTA- ${ }^{177} \mathrm{Lu}(740 \mathrm{MBq} / \mathrm{mg})$ às proteínas do plasma. Resultados expressos em média $\pm \mathrm{DP}(\mathrm{N}=2)$.

A quantidade de anti-CD20-DOTA $-{ }^{177}$ Lu ligado às proteínas séricas aumentou significativamente $(P=0,024)$ com o tempo de incubação variando de $29,68 \% \pm 2,16$ após 4 horas de incubação a $68,75 \% \pm 2,89 \%$ após 72 horas de incubação.

Drogas que possuem taxa alta de ligação às proteínas sérica apresentam baixo volume de distribuição, cinética de eliminação lenta e meia vida plasmática longa ${ }^{124}$. Todas estas características também são próprias de moléculas de peso molecular alto como IgG e $\operatorname{AcM}^{125}$.

A maior ligação às proteínas plasmáticas provavelmente deixa o anti-CD20- ${ }^{177} \mathrm{Lu}$ menos disponível para sofrer ação da atividade das enzimas séricas, o que faz com que sua degradação seja mais lenta, conforme evidenciado no estudo de estabilidade em plasma $\left(\right.$ TABELA 15) ${ }^{126}$. 
B) Influência da atividade específica na ligação às células

A influência da atividade específica do anti-CD20- ${ }^{177}$ Lu sobre a ligação específica às células foi avaliada com $1,5 \times 10^{6}$ células Raji e os resultados estão expressos na FIGURA 31.

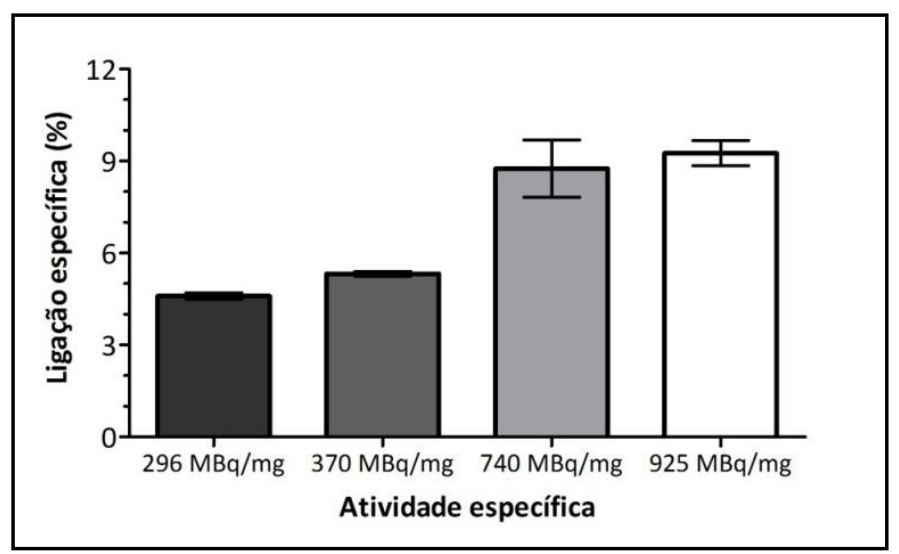

FIGURA 31 - Influência da atividade específica do anti-CD20-DOTA- ${ }^{177}$ Lu na ligação às células Raji. Estudo realizado com $1,5 \times 10^{6}$ células por atividade específica. Resultados expressos em média $\pm \operatorname{EPM}(\mathrm{N}=1)$.

Observou-se que a ligação específica às células aumentou conforme aumentou a atividade específica. Isso é esperado, pois quanto maior a atividade específica, menor a quantidade de moléculas não radiomarcadas que podem competir pelos receptores celulares.

Devido ao número de replicatas $(\mathrm{N}=1)$ não foi possível realizar análise estatística. Sugere-se, portanto, a realização de novos estudos.

C) Imunorreatividade do imunoconjugado radiomarcado com alta atividade específica

Como já discutido, a imunorreatividade é um controle de qualidade importante para AcMs radiomarcados e pode ser afetada por diversos fatores. Um destes fatores é a atividade específica do radioimunoconjugado, pois o AcM pode sofrer maior radiólise na presença de atividades mais altas de ${ }^{177} \mathrm{Lu}$.

A imunorreatividade do AcM conjugado pelo método 1 e 2 e radiomarcado com atividade específica de $740 \mathrm{MBq} / \mathrm{mg}$ está representada na FIGURA 32. 


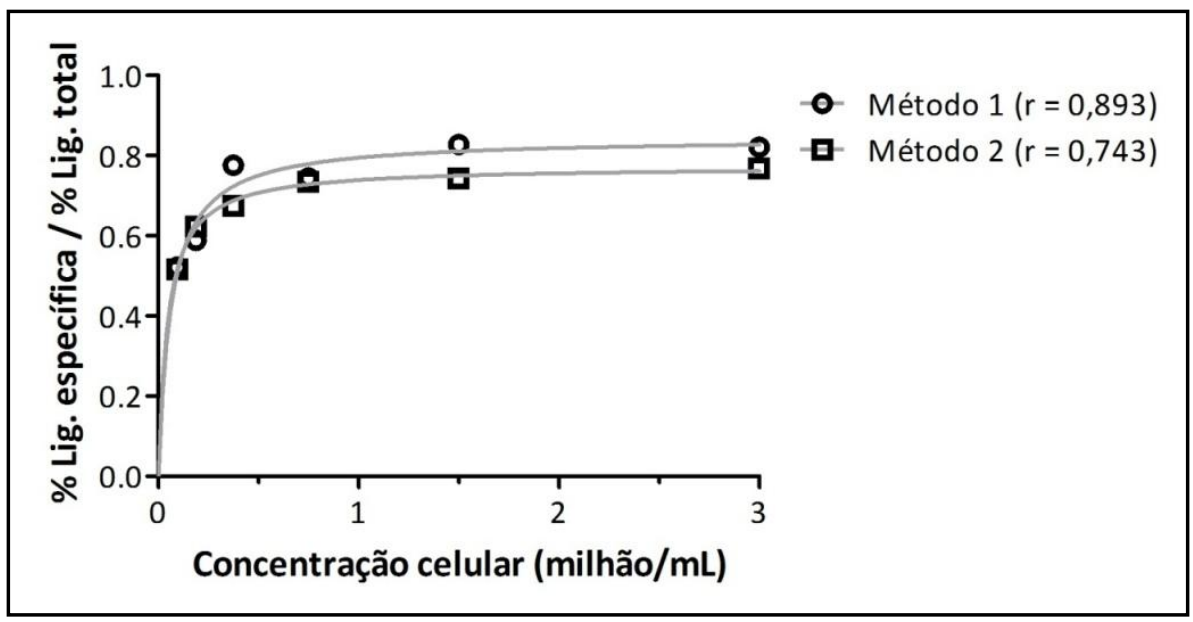

FIGURA 32 - Imunorreatividade do AcM conjugado pelos dois métodos de conjugação e radiomarcado com atividade específica de $740 \mathrm{MBq} / \mathrm{mg}(\mathrm{N}=3)$.

Foi possível observar que o AcM conjugado pelo método 1 teve sua imunorreatividade preservada $(r=0,893)$ mesmo quando radiomarcado com alta atividade específica e não houve diferença quando comparado ao imunoconjugado radiomarcado com atividade específica de $37 \mathrm{MBq} / \mathrm{mg}(r=0,898$ - FIGURA 13 - item 5.4.1 E).

O AcM conjugado pelo método 2 apresentou imunorreatividade $15 \%$ menor $(r=$ $0,743)$, no entanto, este valor não foi significativo $(P=0,597$ - teste $t)$.

É importante ressaltar, que apesar da análise estatística não ter apresentado diferença, a diminuição de $15 \%$ da imunorreatividade é relevante, ainda mais considerando que esta diferença se deu pela incorporação de apenas 1,24 quelantes por AcM a mais do que para o método 1 (TABELA 8).

Mesmo assim, a imunorreatividade encontrada foi maior do que os estudos apresentados na TABELA 10, considerando a razão molar empregada, o método e o número de quelantes por AcM. 


\section{Capítulo 5 \\ ESTUDOS DE CONJUGAÇÃO E RADIOMARCAÇÃO}

\subsection{CONCLUSÕES}

Os resultados encontrados nesta etapa do estudo permitiram concluir que:

$\checkmark$ a melhor razão molar AcM:DOTA encontrada foi 1:50, pois apresentou melhor resultado de pureza radioquímica e imunorreatividade satisfatória;

$\checkmark$ ambos os métodos de conjugação estudados não causaram danos estruturais na molécula do AcM;

$\checkmark$ o método 2 de conjugação conferiu maior pureza radioquímica (não purificado) do que o método 1 e preservação da imunorreatividade;

$\checkmark$ a melhor metodologia de radiomarcação foi quando a reação ocorreu em um volume final de $1 \mathrm{~mL}$ de tampão acetato de amônio $0,25 \mathrm{M} \mathrm{pH} \mathrm{6,5,} \mathrm{sob} \mathrm{agitação} \mathrm{de} 500$ rpm, e temperatura de $43^{\circ} \mathrm{C}$ durante 1 hora;

$\checkmark$ a adição de agentes estabilizantes não melhorou a estabilidade do radioimunoconjugado, sendo necessário apenas diluição e congelamento para preservação da pureza radioquímica;

$\checkmark$ para se obter pureza radioquímica superior a 95\%, o radioimunoconjugado necessita de purificação após a radiomarcação;

$\checkmark$ o radioimunoconjugado apresentou estabilidade alta em plasma humano in vitro e ligação alta às proteínas do plasma;

$\checkmark$ a melhor atividade específica encontrada foi $740 \mathrm{MBq} / \mathrm{mg}$, pois apresentou estabilidade relevante por mais de 48 horas após a radiomarcação, sendo possível a logística para lugares distantes do centro produtor (IPEN);

$\checkmark$ a atividade específica de $925 \mathrm{MBq} / \mathrm{mg}$ mostrou-se promissora, pois apresentou porcentagem de ligação às células, pureza radioquímica após purificação e estabilidade à $-20^{\circ} \mathrm{C}$. Contudo, a estabilidadeapós o descongelamento é menor. 


\section{ESTUDOS IN VIVO}

Neste capítulo apresentam-se os objetivos específicos, métodos, resultados, discussão e conclusões referentes aos estudos in vivo que constituíram a terceira etapa do trabalho.

\subsection{OBJETIVOS ESPECÍFICOS}

Os objetivos específicos desta etapa do trabalho foram:

$\checkmark$ Desenvolver um modelo tumoral de linfoma não - Hodgkin a partir de células de linfoma de Burkitt (Raji);

$\checkmark$ Caracterizar o perfil farmacocinético e de biodistribuição do anti-CD20-DOTA- ${ }^{177}$ Lu em camundongos sadios;

$\checkmark$ Avaliar a biodistribuição do anti-CD20-DOTA- ${ }^{177}$ Lu em camundongos com tumor;

$\checkmark$ Avaliar a estabilidade do anti-CD20-DOTA- ${ }^{177}$ Lu em soro in vivo em camundongos sadios;

$\checkmark$ Determinar o tempo de residência no organismo do Anti-CD20-DOTA- ${ }^{177}$ Lu por meio de estudos de corpo inteiro.

\subsection{MATERIAIS}

\subsubsection{Infraestrutura}

Os ensaios foram realizados nos laboratórios de Pesquisa e Desenvolvimento do Centro de Radiofarmácia (CR), no laboratório de Cultivo Celular do Centro de Biotecnologia (CB) e no Biotério, sendo todas as dependências sitiadas na área do IPEN. Esses laboratórios forneceram toda a infraestrutura necessária para a manipulação de materiais radioativos, células e animais, respectivamente. 


\subsubsection{Reagentes}

Os principais reagentes utilizados nesta etapa do trabalho foram:

$\checkmark$ anti-CD20-DOTA- ${ }^{177}$ Lu com pureza radioquímica superior a 95\%;

$\checkmark$ Água purificada - Purificador Milli-RX 45 (Millipore, EUA);

$\checkmark$ Cloreto de sódio (Merck, Alemanha);

$\checkmark$ Etanol (Merck, Alemanha);

$\checkmark$ Gentamicina para uso celular (Sigma Aldrich, EUA);

$\checkmark$ Meio de cultura RPMI 1640 (Cultilab, Brasil);

Penicilina: estreptomicina (Cultibab, Brasil);

Soro fetal bovino (Cultilab, Brasil).

Anestésico para uso animal cloridrato de quetamina - Dopalen (Ceva, Brasil);

Relaxante muscular para uso animal cloridrato de xilasina - Ansedan (Vetbrands, Brasil).

\subsubsection{Equipamentos e demais materiais}

Os principais equipamentos e materiais utilizados neste trabalho foram:

Balança analítica M220 (Denver Instrument, EUA);

$\checkmark$ Calibrador de atividade $\mathrm{CRM}^{\mathrm{TM}}$ - 35R (Capintec, EUA);

$\checkmark$ Centrífuga refrigerada Mikro 220 (Hettich, Alemanha);

$\checkmark$ Contador automático tipo poço com cristal Nal (TI) - D5002 cobra II (Packard-Camberra, EUA);

$\checkmark$ GraphPad Prism 5.00 ${ }^{\circledR}$ (GraphPad Software, Inc., USA);

$\checkmark$ Seringa de insulina com agulha de $12,7 \times 0,33 \mathrm{~mm}(B D, E U A) ;$

$\checkmark$ Material plástico descartável em geral, tais como ponteiras, pipetas, tubos cônicos tipo Falcon e placas de cultura;

Pipetas automáticas (Brand, Alemanha; Socorex, Suíça e Eppendorf, EUA).

\subsubsection{Células Raji de linfoma de Burkitt humano}

As células Raji, derivadas de linfoma de Burkitt humano foram cultivadas no Centro de Biotecnologia conforme descrito no item 5.2.4. 


\subsubsection{Camundongos Swiss e SCID}

Os camundongos das raças Swiss e SCID utilizados neste trabalho foram fornecidos pelo biotério do IPEN - CNEN/SP (São Paulo, SP, Brasil). Todos os experimentos foram previamente aprovados pelo Comitê de Ética em Pesquisa do IPEN (Projeto $n^{\circ}$ 97/12/CEUA-IPEN/SP) como consta no Anexo A, e realizados de acordo com as normas estabelecidas pela Sociedade Brasileira de Ciência em Animais de Laboratório (SBCAL).

A escolha por se utilizar fêmeas foi devido a maior disponibilidade deste sexo no biotério.

Os animais foram mantidos no biotério nas seguintes condições de criação e estas condições foram reproduzidas quando os animais estiveram em experimentação:

$\checkmark$ Temperatura ambiente: $22 \pm 2^{\circ} \mathrm{C}$;

$\checkmark$ Iluminação artificial com ciclo de 12 horas de luz / 12 horas de escuridão;

$\checkmark$ Ração e água ad libitum.

\subsection{MÉTODOS}

\subsubsection{Estudos de biodistribuição em camundongos Swiss sadios}

O método invasivo foi utilizado nos estudos de biodistribuição. Injetou-se por via endovenosa caudal 2,22 MBq $(60 \mu \mathrm{Ci})$ do anticorpo radiomarcado diluído em $100 \mu \mathrm{L}$ de solução salina $0,9 \%$. Após $1,24,48,72,96,168,232$ horas os animais foram anestesiados (com solução de quetamina e xilasina) e eutanasiados por deslocamento cervical, em seguida os principais órgãos foram retirados e pesados. Por fim, foi avaliada a radioatividade de cada órgão em um contador gama tipo poço. Foram calculadas as porcentagens da atividade injetada por órgão (\% $\mathrm{Al}, \mathrm{EQ} .6 .1$ ) e por grama de órgão (\% $\mathrm{Al} / \mathrm{g}, \mathrm{EQ}$. 6.2) por intermédio da média das contagens da quintuplicata de um padrão da atividade administrada. Os ensaios foram realizados em quadriplicata.

$$
\begin{gathered}
\% \mathrm{AI}=\frac{\mathrm{cpm} \text { órgão }}{\mathrm{cpm} \text { padrão }} \times 100 \\
\% \mathrm{AI} / \mathrm{g}=\frac{\mathrm{cpm} \text { órg ão }}{\text { peso órgão }(\mathrm{g}) \times \mathrm{cpm} \text { padr ão }} \times 100
\end{gathered}
$$


Para calcular a porcentagem de atividade injetada presente nos músculos, \% $\mathrm{Al}$ (músculo), e nos ossos, \% Al (ossos), dos animais, retirou-se o músculo da coxa e o fêmur dos camundongos e calculou-se a porcentagem de atividade por grama. O peso dos músculos foi assumido como $40 \%$ (EQ. 6.3) e dos ossos como $12 \%$ (EQ. 6.4) do peso total do camundongo 126

$$
\begin{aligned}
\% \mathrm{AI}(\text { osso }) & =\frac{\text { cpm músculo } \times 40 \times \text { peso do animal }(\mathrm{g})}{\text { peso músculo }(\mathrm{g}) \times \mathrm{cpm} \text { padrão }} \text { EQ. } 6.3 \\
\mathrm{AI}(\mathrm{osso}) & =\frac{\mathrm{cpm} \text { fêmur } \times 12 \times \text { peso do animal }(\mathrm{g})}{\text { peso osso }(\mathrm{g}) \times \text { cpm padrão }} \quad \text { EQ. } 6.4
\end{aligned}
$$

\subsubsection{Estabilidade do anti-CD20-DOTA- ${ }^{177}$ Lu em plasma in vivo}

Injetou-se por via endovenosa caudal 2,22 $\mathrm{MBq}(60 \mu \mathrm{Ci})$ do anticorpo radiomarcado diluído em $100 \mu \mathrm{L}$ de solução salina 0,9\%. Após 1, 24, 48, 72, 96, 168, 232 horas os animais foram anestesiados (com solução de quetamina e xilasina) e eutanasiados por deslocamento cervical. Após a abertura da cavidade torácica, o sangue foi coletado por punção cardíaca com auxílio de uma seringa.

Em seguida, o sangue foi centrifugados a $3.000 \mathrm{rpm}$ por 5 minutos para a obtenção do plasma. Uma alíquota do plasma foi analisada por cromatografia em camada delgada, utilizando como fase estacionária placas de ITLC-SG e fase móvel tampão citrato de sódio $0,1 \mathrm{M}$ pH 5,0 e $\mathrm{NaOH} 10 \mathrm{mM}$ em $\mathrm{NaCl}$ 0,9\%. . Os ensaios foram realizados em quadruplicata.

\subsubsection{Identificação das principais espécies presentes na urina}

Os mesmos animais utilizados nos estudos de biodistribuição foram utilizados para este estudo. Desta forma, injetou-se por via endovenosa caudal 2,22 MBq (60 $\mu \mathrm{Ci})$ do anticorpo radiomarcado diluído em $100 \mu \mathrm{L}$ de solução salina 0,9\%. Após $1,24,48,72,96$, 168, 232 horas os animais foram anestesiados (com solução de quetamina e xilasina) e 
eutanasiados por deslocamento cervical. Após a retirada dos órgãos para a realização dos estudos de bidistribuição, a urina acumulada na bexiga foi retirada com auxílio de uma seringa. Estas amostras foram analisadas por cromatografia em camada delgada, utilizando como fase estacionária placas de ITLC-SG e fase móvel tampão citrato de sódio 0,1 M pH 5,0.

Após a cromatografia, os $\mathrm{R}_{\mathrm{f}}$ das principais espécies radioativas presentes na urina foram identificados e inseridos em um gráfico correlacionando a presença destas espécies com o tempo após a administração endovenosa do radioimunoconjugado. Os resultados foram expressos como a média das espécies.

\subsubsection{Estudos farmacocinéticos em camundongos Swiss sadios}

Injetou-se por via endovenosa caudal $0,222 \mathrm{MBq}(60 \mu \mathrm{Ci})$ do anticorpo radiomarcado diluído em $100 \mu \mathrm{L}$ de solução salina 0,9\%. Após 1, 24, 48, 72, 96, 168, 232 horas, os animais foram anestesiados (com solução de quetamina e xilasina) e coletou-se 60 $\mu \mathrm{L}$ de sangue pelo plexo orbital dos camundongos utilizando um tubo capilar heparinizado. A radioatividade do sangue foi analisada em um contador gama tipo poço e os dados foram ajustados no programa GraphPad Prism $5.00^{\circledR}$, após o ajuste para um modelo de distribuição em dois compartimentos, caracterizado por duas exponenciais, uma de decaimento rápido e outra de decaimento lento. Os parâmetros farmacocinéticos meia-vida de distribuição $\left(t_{1 / 2} \alpha\right)$, meia-vida de eliminação $\left(t_{1 / 2} \beta\right)$, constante de distribuição $(\alpha)$ e constante de eliminação $(\beta)$, bem como a área sob a curva de concentração plasmática versus tempo, foram calculados utilizando o mesmo programa. A depuração $(\mathrm{CL})$ foi calculada pela equação:

$$
\mathrm{Cl}=\frac{\text { Dose injetada }(\mathrm{cpm})}{\text { Área sob a curva }}
$$

O volume de distribuição $(V d)$ foi calculado pela equação:

$$
\mathrm{Vd}=\frac{\mathrm{CL}}{\beta} \times \text { peso do animal }(\mathrm{kg})
$$


Por fim, a meia vida efetiva foi calculada mediante a seguinte equação:

$$
\mathrm{t}^{1} 1 / 2=\frac{\mathrm{t}^{1} / 2 \text { biol ógica } \times \mathrm{t}^{1 / 2} \text { física }}{\mathrm{t} 1 / 2 \text { biológica }+\mathrm{t}^{1} 1 / 2 \text { física }}
$$

\subsubsection{Estudos de captação de corpo inteiro em camundongos Swiss sadios}

Com o objetivo de avaliar a excreção e o tempo de residência no organismo do radiofármaco, foram realizados estudos de corpo inteiro em camundongos Swiss sadios. Injetou-se, por via endovenosa caudal, $11 \mathrm{MBq}(300 \mu \mathrm{Ci})$ do anti-CD20-DOTA- ${ }^{177}$ Lu diluídos em $100 \mu \mathrm{L}$ de solução salina 0,9\%. Decorridas 1 a 720 horas após administração, os animais foram confortavelmente imobilizados e posicionados sob o colimador da gama câmara para determinação das contagens acumuladas durante três minutos. Os resultados foram expressos em porcentagem da atividade injetada presente no organismo em razão do tempo, considerando-se como $100 \%$ a média das contagens imediatamente após a administração. Os ensaios foram realizados em quadruplicata.

\subsubsection{Desenvolvimento de modelo tumoral em camundongos $S C I D$}

Foram utilizados 6 (seis) camundongos SCID (fêmeas) de quatro a oito semanas de idade e 15 a 30 gramas de peso.

Inicialmente foram inoculados, via subcutânea no dorso dos animais, três diferentes números de células (1, 2 e $5 \times 10^{6}$ células), utilizando-se um animal para cada quantidade de célula. Estes animais foram observados semanalmente a fim de constatar crescimento tumoral.

O animal em que foi observado crescimento de massa sólida, foi eutanasiado e esta massa sólida foi retirada e encaminhada para análise histopatológica.

Em posse de um resultado positivo para linfoma, este mesmo número de células foi inoculado em mais três camundongos que foram observados semanalmente, com o objetivo de confirmar o modelo tumoral. 


\subsubsection{Estudos de biodistribuição em animais com tumor}

O método invasivo foi utilizado nos estudos de biodistribuição. Injetou-se por via endovenosa caudal 3,7 MBq $(100 \mu \mathrm{Ci})$ do anticorpo radiomarcado diluído em $100 \mu \mathrm{L}$ de solução salina 0,9 \%. Após 1 e 4 horas da injeção, os animais foram eutanasiados, e seus principais órgãos e o tumor foram retirados e pesados. Por fim, foi avaliada a radioatividade de cada órgão em um contador gama tipo poço. O cálculo da porcentagem da atividade injetada por órgão (\% $\mathrm{Al}$ ) e por grama de órgão (\% $\mathrm{Al} / \mathrm{g})$, \% $\mathrm{Al}$ nos músculos e \% $\mathrm{Al}$ nos ossos, foram realizados conforme citado no item 6.3.1. Os ensaios foram realizados em triplicata.

\subsection{RESULTADOS E DISCUSSÃO}

\subsubsection{Estudos farmacocinéticos}

O estudo farmacocinético é uma ferramenta que fornece uma descrição quantitativa da distribuição do composto no organismo. Processos como a absorção, distribuição, metabolismo e excreção são descritos pelos parâmetros farmacocinéticos ${ }^{127}$.

Para se obter estes parâmetros farmacocinéticos, é necessário construir uma curva de concentração plasmática versus tempo e aplicar a esta curva certos modelos matemáticos. Estes modelos podem ser não compartimentais ou compartimentais e permitem a simulação dos processos de absorção, distribuição e eliminação de um fármaco 128.

A curva de clareamento sanguíneo do imunoconjugado radiomarcado pode ser observada na FIGURA 33. 


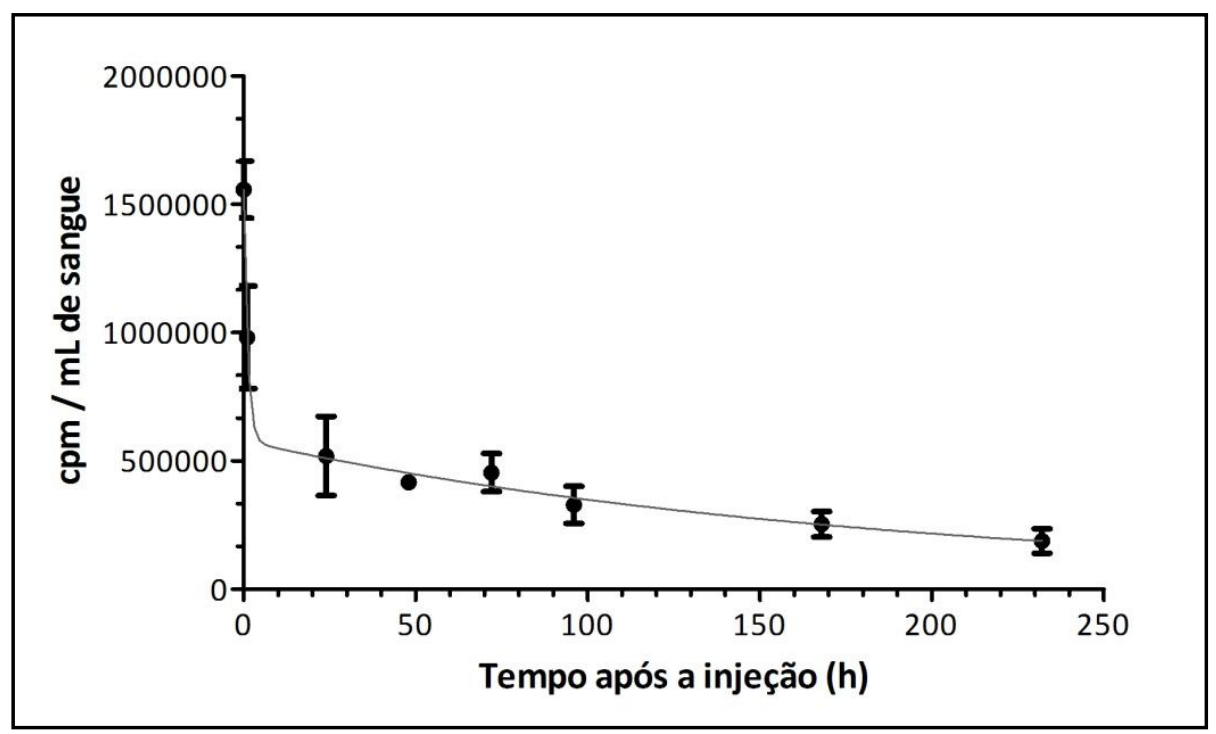

FIGURA 33 - Curva de clareamento sanguíneo do anti-CD20-DOTA- ${ }^{177}$ Lu em camundongos Swiss fêmeas sadias $(\mathrm{N}=4)$.

Esta curva de clareamento sanguíneo foi utilizada para cálculo dos parâmetros farmacocinéticos do anti-CD20-DOTA- ${ }^{177} \mathrm{Lu}$, os quais são apresentados na TABELA 16 . Os parâmetros foram calculados após ajuste dos dados para um modelo de decaimento em duas exponenciais ou modelo bicompartimental. 
TABELA 16 - Parâmetros farmacocinéticos do anti-CD20-DOTA- ${ }^{177}$ Lu determinados em camundongos Swiss fêmeas sadias $(\mathrm{N}=4)$.

\begin{tabular}{ccc}
\hline $\begin{array}{c}\text { Parâmetro } \\
\text { Farmacocinético }\end{array}$ & Símbolo & Valor \\
\hline $\begin{array}{c}\text { Tempo de meia-vida da } \\
\text { fase rápida ou distributiva }\end{array}$ & $\mathrm{t}_{1 / 2} \alpha$ & $0,79 \mathrm{~h}$ \\
$\begin{array}{c}\text { Tempo de meia-vida da } \\
\text { fase lenta ou de eliminação }\end{array}$ & $\mathrm{t}_{1 / 2} \beta$ & $127,1 \mathrm{~h}$ \\
Constante de distribuição & $\alpha$ & $0,88 \mathrm{~h}^{-1}$ \\
Constante de eliminação & $\beta$ & $0,005 \mathrm{~h}^{-1}$ \\
Depuração & $\mathrm{CL}$ & $0,04 \mathrm{~mL}^{-1} \mathrm{~h}^{-1}$ \\
Volume de distribuição & $\mathrm{Vd}$ & $0,007 \mathrm{~L}$ \\
Tempo de meia vida & & $71,76 \mathrm{~h}$ \\
efetiva & $\mathrm{t}_{1 / 2} \mathrm{E}$ & \\
\hline
\end{tabular}

O anti-CD20-DOTA- ${ }^{177}$ Lu apresentou meia-vida de distribuição $\left(t_{1 / 2} \alpha\right)$ de 0,79 horas e meia vida de eliminação $\left(t_{1 / 2} \beta\right)$ de 127,1 horas (TABELA 16).

A depuração $(\mathrm{CL})$ de um fármaco do organismo descreve a eficiência do processo de eliminação, que é irreversível, e pode ser considerado como o parâmetro que relaciona sua velocidade de eliminação com a concentração plasmática ${ }^{128}$. O anti-CD20-DOTA- ${ }^{177}$ Lu apresentou uma depuração lenta, o que influencia diretamente na $t_{1 / 2} \beta$.

Outro parâmetro a ser avaliado é o volume de distribuição ( $V d)$, que não é um volume real, e sim um volume hipotético de fluido corporal que seria necessário para dissolver a quantidade total de droga na mesma concentração em que é encontrada no sangue. É uma constante que relaciona a concentração plasmática e a quantidade de fármaco no organismo em um dado tempo. O volume de distribuição reflete, portanto, a extensão em que o fármaco está presente nos tecidos extravasculares ${ }^{129}{ }^{128}$. O anti-CD20DOTA- ${ }^{177} \mathrm{Lu}$ apresentou baixo volume de distribuição $(0,007 \mathrm{~L})$, indicando que ele permanece 
por mais tempo no espaço vascular e se distribui lentamente para os tecidos ${ }^{128}$.

Em um sistema biológico, a eliminação de um fármaco do organismo é dependente da meia vida física do radionuclídeo, que decai independentemente de qualquer processo, e da meia vida biológica, que é ditada pelo perfil farmacocinético e farmacodinâmico da molécula carreadora. A associação destes dois processos fornece a meia vida efetiva de um radiofármaco. Ela deve ser adequada para o estudo que se propõe. Para radiofármacos utilizados em diagnóstico, ela deve ser longa o suficiente para permitir a realização do exame e curta o suficiente para não fornecer uma dose desnecessária ao paciente. Já para radiofármacos utilizados em terapia, ela deve ser longa o suficiente para permitir o tratamento da doença ${ }^{15}$, especialmente quando concentradas nos tecidos alvos, neste caso os tumores.

Por fim, o anti-CD20-DOTA- ${ }^{177}$ Lu apresentou meia vida efetiva de aproximadamente 72 horas (TABELA 16), adequada para a utilização em radioimunoterapia.

\subsubsection{Biodistribuição, metabolismo e estabilidade em plasma do anti-CD20-DOTA- ${ }^{177}$ Lu}

Os AcMs são substâncias grandes e apolares e a sua biodistribuição apresenta mecanismos diferentes comparados às moléculas menores. A difusão através das células do endotélio vascular, mecanismo muito usado por moléculas pequenas, é muito lenta e a acredita-se que a convecção, ou dragagem pelo solvente, é o mecanismo primário responsável pelo transporte dos AcMs dos sangue para o tecido ${ }^{125}$.

Os mecanismos de eliminação de fármacos mais comuns são: (1) filtração, eliminando o fármaco pela urina; (2) secreção, eliminando o fármaco pela bile e consequentemente pelas fezes e (3) biotransformação por meio de metabolismo ou catabolismo. A eliminação renal, que é primariamente a via de eliminação de pequenas moléculas, é relativamente sem importância para IgG intactas, já que seu tamanho impede uma filtração eficiente pelos glomérulos ${ }^{125}$. Desta forma, se moléculas maiores que 60.000 $\mathrm{g} / \mathrm{mol}$ não são filtradas pelos glomérulos ${ }^{15}$, a captação renal encontrada, associada com a captação alta no fígado (FIGURA 34) indicam que o radiofármaco sofre acentuado metabolismo hepático e posterior eliminação dos metabólitos pela urina. 


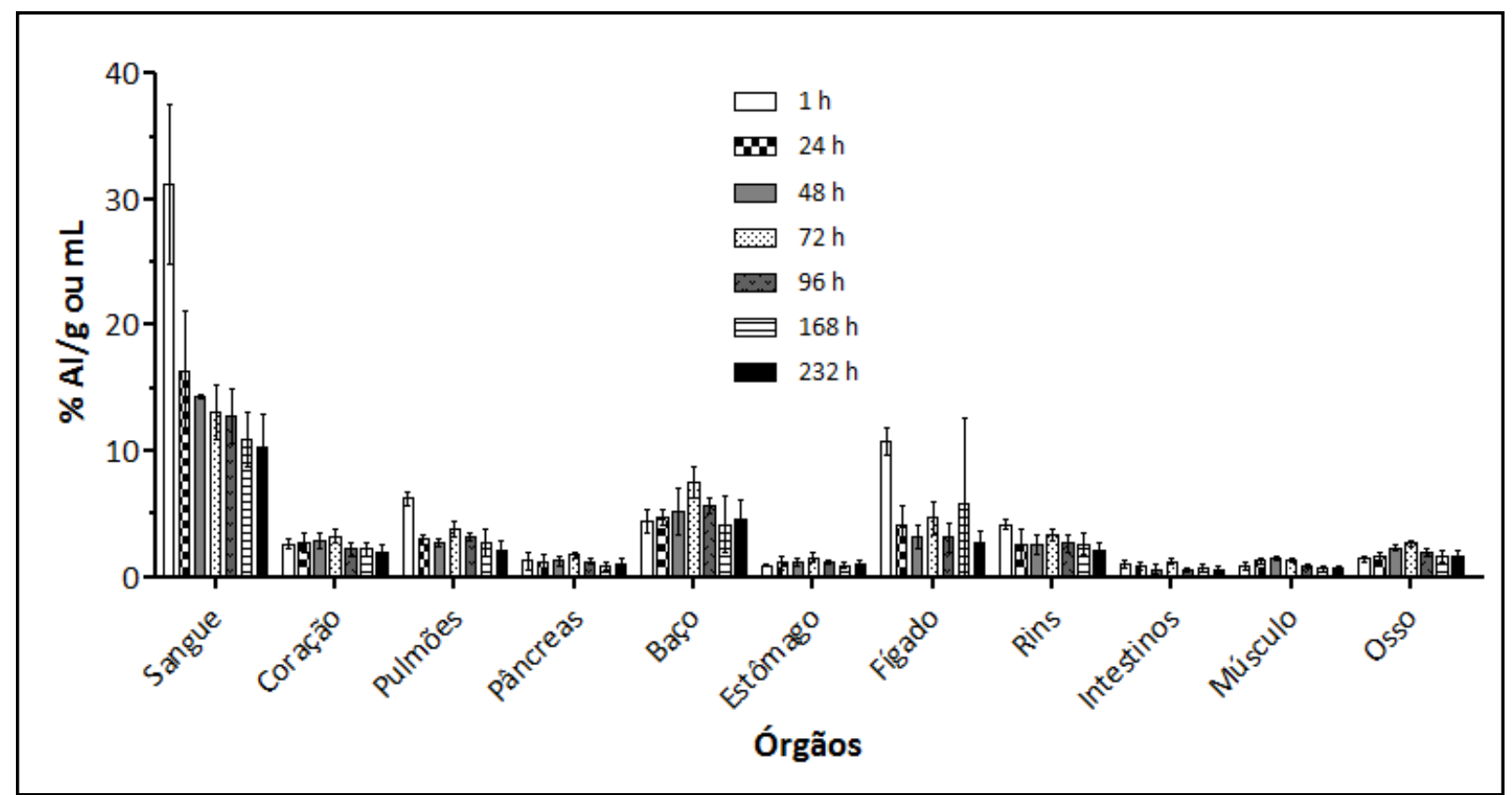

FIGURA 34 - Biodistribuição do anti-CD20-DOTA- ${ }^{177} \mathrm{Lu}(2,22 \mathrm{MBq}, 60 \mu \mathrm{Ci})$ em camundongos Swiss fêmeas sadios ( $\mathrm{N}=4)$.

A secreção pela bile é uma importante via de eliminação de $\lg A$, mas não significante para $\operatorname{lgG}{ }^{125}$, explicando assim a baixa captação do anti-CD20-DOTA- ${ }^{177}$ Lu nos intestinos (FIGURA 34).

A considerável atividade captada no baço é devida ao acúmulo de linfócitos $B$ neste órgão ${ }^{4}$. Esta captação pode ser útil, em parte, como uma medida indireta da imunorreatividade in vivo, sobretudo nos tempos iniciais do estudo.

A eliminação do IgG ocorre, especialmente, por catabolismo intracelular seguido de endocitose mediada por receptor. Este tipo de mecanismo pode ocorrer após a interação dos domínios Fab do anticorpo com os epítopos encontrados nas superfícies das células ${ }^{125}$. Este mecanismo também explica a alta captação esplênica, pois como o baço possui muitos linfócitos B, estes seriam responsáveis, em partes, pelo catabolismo do AcM.

Ao avaliar os perfis cromatográficos da urina (FIGURA 35) dos camundongos que receberam o anti-CD20-DOTA- ${ }^{177} \mathrm{Lu}$, observou-se nos tempos mais tardios uma maior porcentagem da espécie com perfil cromatográfico compatível com DOTA- ${ }^{177}$ Lu $\left(R_{f}=0,6\right.$ a 0,8). Isto indica, provável metabolismo do AcM, com quebra de ligação AcM-DOTA. Deve-se ressaltar que a técnica empregada neste estudo possibilita determinação apenas dos produtos de metabolismo que carregam o elemento radioativo, não sendo possível avaliar 
metabólitos da estrutura proteica não radioativos.

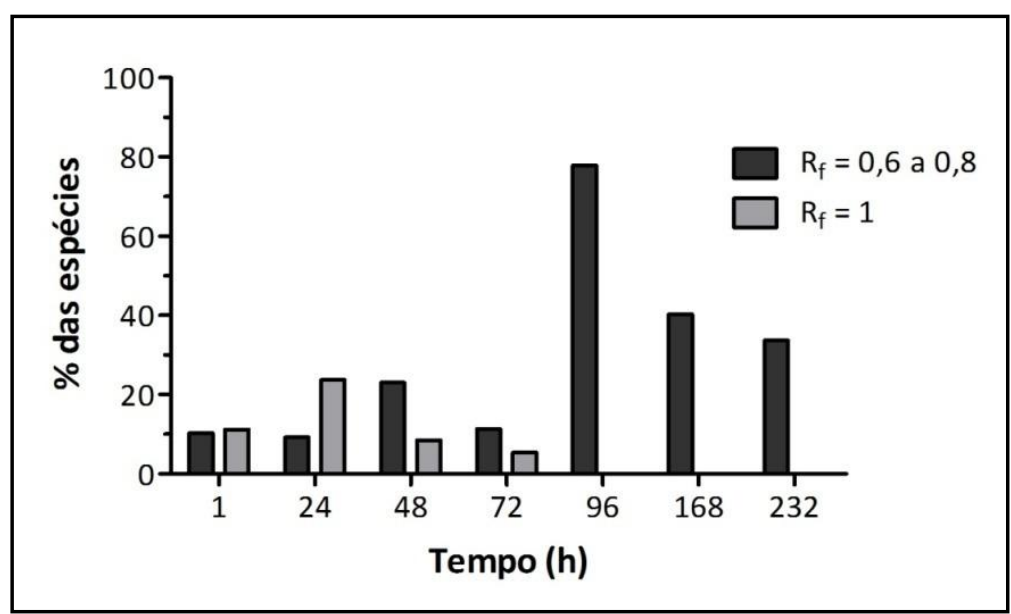

FIGURA 35 - Perfil cromatográfico (CCD) da urina coletada em diferentes tempos de camundongos sadios após a administração endovenosa do anti-CD20-DOTA- ${ }^{177} \mathrm{Lu}$. Resultados expressos em média ( $\mathrm{N}=4)$.

A captação óssea é comumente assumida como um controle da estabilidade in vivo de moléculas radiomarcadas com lutécio ${ }^{81,93}$. Esse tecido capta ativamente o lutécio não ligado, sendo um bom indicador da pureza radioquímica das marcações e de estabilidade in vivo perante descomplexação, especialmente nos tempos iniciais. A captação óssea do anti-CD20-DOTA- ${ }^{177}$ Lu foi insignificante (FIGURA 34) se comparada à do ${ }^{177}$ Lu livre, a qual atinge níveis de $10 \%$ e $26 \%$ da atividade injetada, no fêmur e crânio respectivamente, 24 horas após a administração ${ }^{43}$. Estes resultados confirmam a estabilidade alta complexo DOTA- ${ }^{177}$ Lu in vivo.

O estudo de estabilidade do anti-CD20-DOTA- ${ }^{177} \mathrm{Lu}$ em plasma de camundongo in vivo também evidencia a estabilidade do complexo (TABELA 17). Conforme o anticorpo foi metabolizado houve uma maior liberação de DOTA- ${ }^{177}$ Lu quando compado ao lutécio livre. A espécie DOTA $-{ }^{177}$ Lu é provavelmente a principal espécie encontrada no perfil cromatográfico da urina dos camundongos (FIGURA 35). Esta baixa liberação de ${ }^{177}$ Lu contribui para a baixa captação óssea encontrada nos estudos de biodistribuição (FIGURA 34). 
TABELA 17 - Estabilidade do anti-CD20-DOTA- ${ }^{177}$ Lu in vivo em plasma de camundongos Swiss fêmeas sadias. Pureza radioquímica determinada por CCD e resultados expressos em média $\pm \mathrm{DP}(\mathrm{n}=4)$.

\begin{tabular}{|c|c|c|c|}
\hline $\begin{array}{c}\text { Tempo após } \\
\text { i.e. }\end{array}$ & Anti-CD20-DOTA- ${ }^{177} \mathrm{Lu}(\%)$ & ${ }^{177} \mathrm{Lu}(\%)$ & $\begin{array}{c}\text { DOTA }{ }^{-177} \text { Lu } \\
\text { (\%) }\end{array}$ \\
\hline Imediato & $95,66 \pm 0,01$ & $1,85 \pm 0,00$ & $2,49 \pm 0,22$ \\
\hline $1 \mathrm{~h}$ & $92,72 \pm 0,02$ & $3,48 \pm 0,03$ & $3,80 \pm 0,01$ \\
\hline $24 \mathrm{~h}$ & $90,72 \pm 0,03$ & $2,22 \pm 0,03$ & $6,99 \pm 0,04$ \\
\hline $48 h$ & $88,78 \pm 0,03$ & $5,85 \pm 0,06$ & $5,37 \pm 0,02$ \\
\hline $72 \mathrm{~h}$ & $87,49 \pm 0,05$ & $5,32 \pm 0,06$ & $7,19 \pm 0,04$ \\
\hline $96 h$ & $87,67 \pm 0,12$ & $4,58 \pm 0,02$ & $7,75 \pm 0,04$ \\
\hline $168 \mathrm{~h}$ & $89,45 \pm 0,10$ & $3,23 \pm 0,09$ & $7,32 \pm 0,06$ \\
\hline $232 \mathrm{~h}$ & $77,58 \pm 0,06$ & $8,94 \pm 0,07$ & $13,48 \pm 0,06$ \\
\hline
\end{tabular}

i.e. injeção endovenosa

\subsubsection{Estudo de captação de corpo inteiro}

O estudo de captação de corpo inteiro foi realizado com o objetivo de determinar o tempo de residência no organismo e estimar a excreção do anti-CD20-DOTA${ }^{177} \mathrm{Lu}$. Os resultados foram expressos em porcentagem da atividade injetada retida no organismo em razão do tempo após a administração endovenosa e são mostrados na FIGURA 36. Pode-se observar que o perfil de eliminação do anticorpo radiomarcado é lento, e que após 720 horas da injeção endovenosa, cerca de $36 \%$ da atividade injetada permaneceu no organismo. 


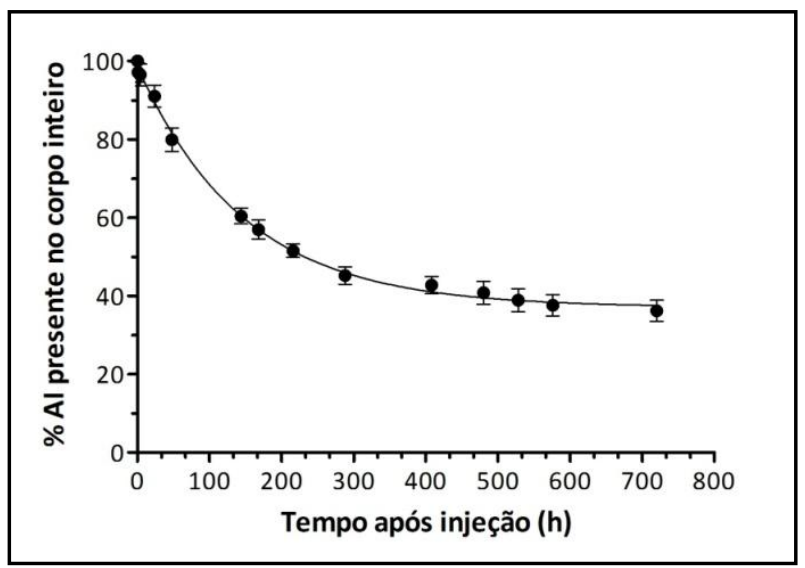

FIGURA 36 - Cinética de corpo inteiro do anti-CD20-DOTA- ${ }^{177} \mathrm{Lu}$ em camundongos Swiss fêmeas sadias $(\mathrm{N}=4)$.

Os dados utilizados para construir a curva da FIGURA 36 foram ajustados para um modelo de decaimento de uma exponencial (monocompartimental) utilizando o programa estatístico GraphPad Prism ${ }^{\circledR} 5.00$ para cálculo da meia-vida biológica $\left(\mathrm{t}_{1 / 2}\right)$ e da constante de eliminação do organismo $\left(K_{\text {el }}\right)$. O anti-CD20-DOTA- ${ }^{177}$ Lu apresentou $t_{1 / 2}$ de 102,8 $\mathrm{h}$ e $\mathrm{K}_{\mathrm{el}}$ de $0,007 \mathrm{~h}^{-1}$, compatíveis com o clareamento sanguíneo lento do radioimunoconjugado.

Como já discutido no item 6.4.2, a eliminação de uma droga do corpo depende de diversos fatores, mormente se tratando de anticorpos ${ }^{125}$.

\subsubsection{Desenvolvimento do modelo tumoral}

Para este trabalho utilizou-se camundongos $S C I D$, uma vez que camundongos Nude foram utilizados anteriormente em uma tentativa de desenvolvimento tumoral, mas não houve sucesso ${ }^{102}$.

O camundongo SCID apresenta um gene mutante autossômico, situado no cromossomo 16. A maioria dos homozigotos não possuem imunoglobulinas dos tipos IgA, IgM ou IgG, mas alguns animais têm baixíssimos níveis de alguma ou das três. Os órgãos linfóides desses animais se apresentam com um décimo do seu tamanho normal. Timo, linfonodos e o baço estão completamente destituídos de linfócitos. Os animais homozigotos são totalmente deficientes de linfócitos $T$ e $B$ e suas células esplênicas não respondem a estímulos de mitose para células $\mathrm{B}$ ou $\mathrm{T}$; por esta razão, não rejeitam transplantes $\mathrm{e}$ 
provavelmente tumores xenográficos ${ }^{130}$.

Esses animais, portanto, apresentam uma imunodeficiência severa (SCID - severe combined immunodeficient).

Das três concentrações de células testas (1, 2 e $5 \times 10^{6}$ células em $100 \mu \mathrm{L}$ de PBS), apenas a concentração de $2 \times 10^{6}$ células em $100 \mu \mathrm{L}$ apresentou crescimento tumoral após 5 semanas da inoculação subcutânea.

A massa tumoral foi retirada e encaminhada para análise histopatológica no Centro Veterinário de Anatomia Patológica. Segundo o laudo "o quadro morfológico foi compatível com Linfoma."

A foto do corte histológico está representada na FIGURA 37 e o laudo anatomopatológico está anexo a este trabalho (ANEXO B).

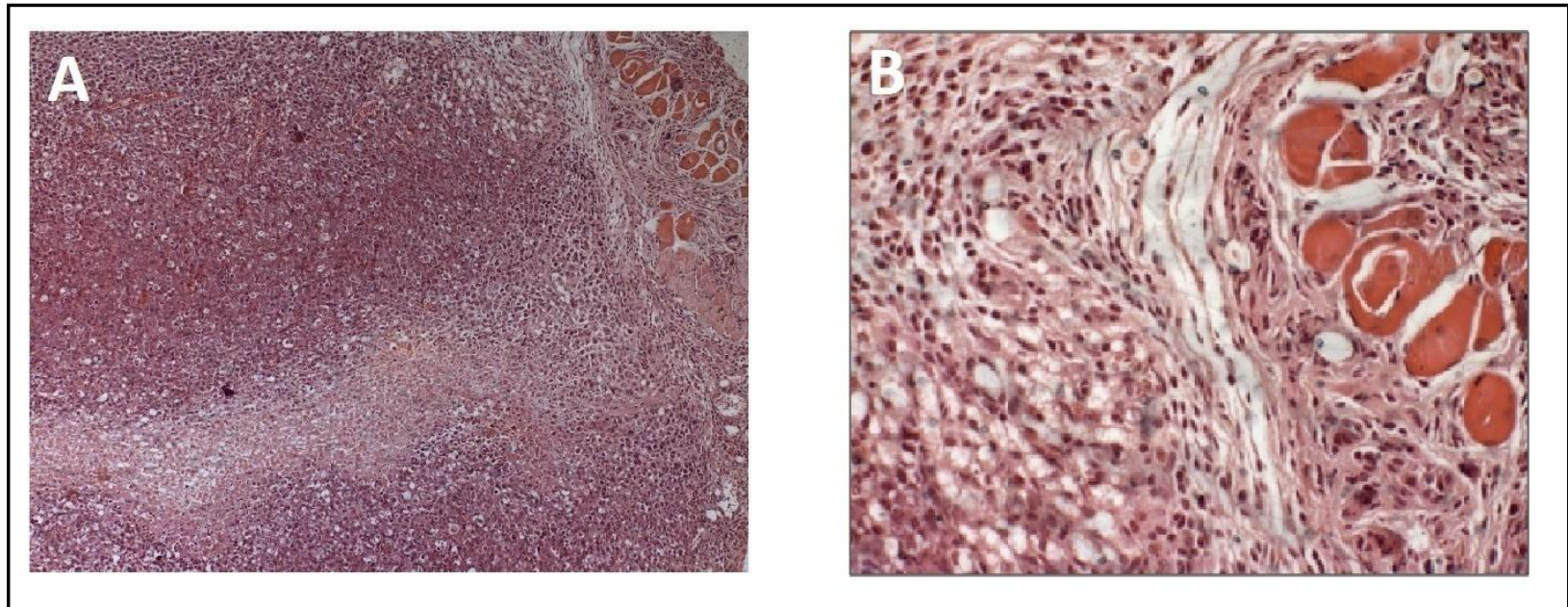

FIGURA 37 - Corte histológico do tumor desenvolvido em camundongos SCID. Em (A), aumento de $100 \mathrm{X}$; em (B), aumento de $400 \mathrm{X}$.

\subsubsection{Biodistribuição em camundongos com tumor}

Na FIGURA 38 apresentam-se os resultados do estudo de biodistribuição do antiCD20-DOTA- ${ }^{177}$ Lu em camundongos implantados com tumor. 


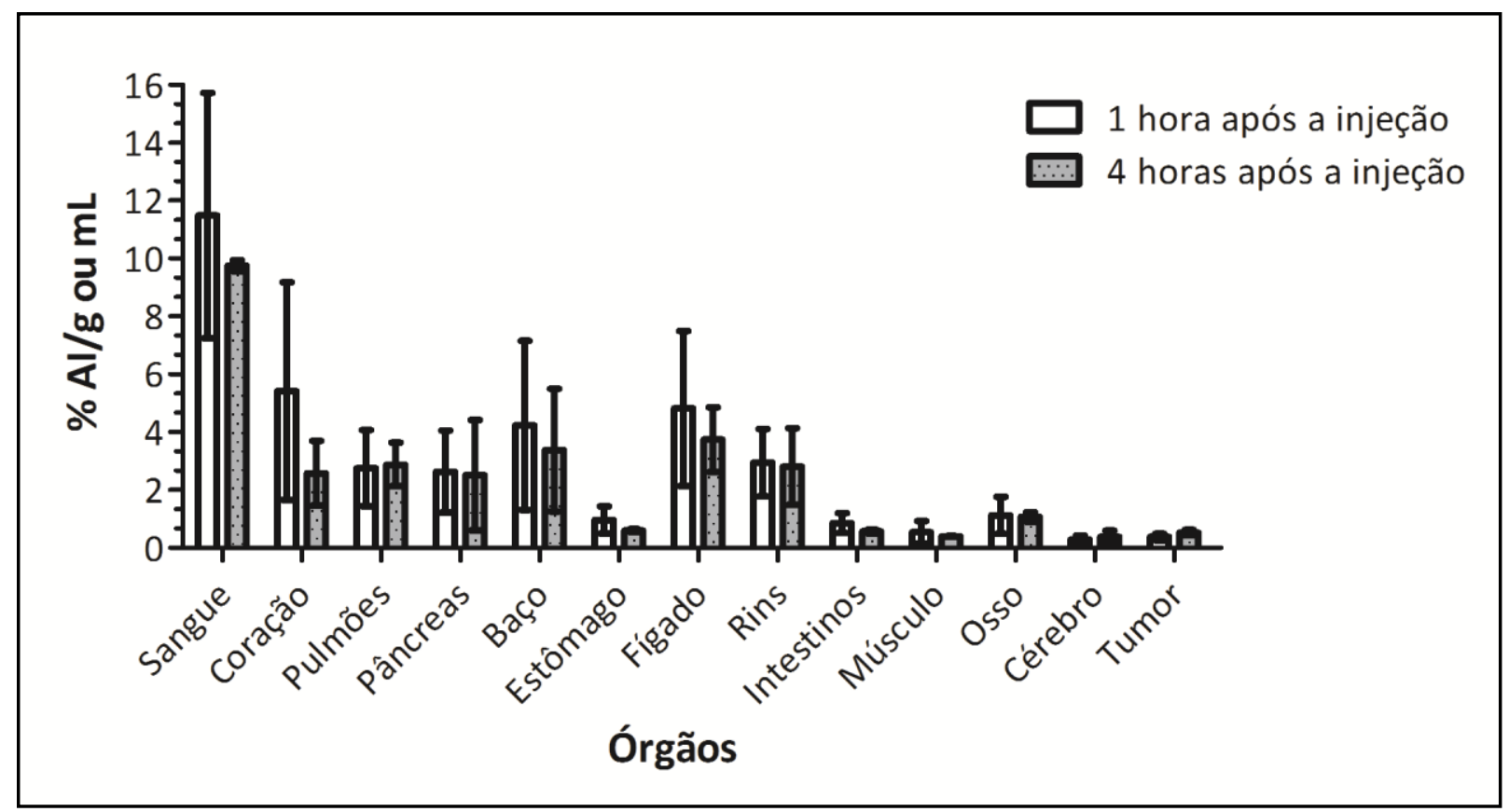

FIGURA 38 - Biodistribuição do anti-CD20-DOTA- ${ }^{177}$ Lu em camundongos SCID fêmeas (N=3).

De forma geral, a biodistribuição em camundongos com tumor apresentou o mesmo perfil da biodistribuição em animais sadios. Também neste caso, a baixa captação óssea confirma a alta estabilidade in vivo ${ }^{81,93}$.

A alta captação no fígado indica que o anti-CD20-DOTA- ${ }^{177}$ Lu sofre intenso metabolismo hepático e consequente eliminação urinária.

A captação no tumor foi significativa $(0,37 \pm 0,2 \%$ e $0,53 \pm 0,13 \%$, para os tempos de $1 \mathrm{~h}$ e $4 \mathrm{~h}$ respectivamente), e se manteve constante $(P>0,05)$ em virtude do tempo, 0 que indica a especificidade da ligação, já que não houve decréscimo dessa ligação apesar do clareamento sanguíneo. Outro dado que corrobora com esta especificidade, é o aumento no valor da razão tumor:sangue no decorrer do tempo, que sugere que a captação tumoral não se deve ao aporte sanguíneo do tumor, mas sim à sua ligação aos receptores (TABELA 18).

Já no caso do fígado, a razão de 1 e 4 horas refletiu o clareamento sanguíneo do composto no órgão. A razão tumor:rins praticamente constante, confirma que via renal é uma das vias de excreção do anticorpo. 
TABELA 18 - Razões tumor:tecido calculadas para o anti-CD20-DOTA- ${ }^{177}$ Lu. Os dados utilizados para o cálculo foram os \%Al/g ou $\mathrm{mL}$ obtidos por meio da biodistribuição do antiCD20-DOTA- ${ }^{177}$ Lu em camundongos SCID implantados com Raji.

\begin{tabular}{ccc}
\hline Tumor:tecido & 1 hora & $\mathbf{4}$ horas \\
\hline Tumor:sangue & 0,03 & 0,05 \\
Tumor:rins & 0,20 & 0,22 \\
Tumor:fígado & 0,20 & 0,15 \\
\hline
\end{tabular}

Considera-se esta captação tumoral como significativa, sobretudo porque o estudo foi realizado para intervalos relativamente curtos após a injeção intravenosa. A maioria dos estudos publicados avalia a captação tumoral após 48 horas, no mínimo, da injeção intravenosa 94, 99, 131, sendo que alguns estudos pré-clínicos e clínicos realizam imagem após 5 a 7 dias após a injeção do anticorpo radiomarcado $29,77,89,132$. Isso porque, a captação tumoral de anticorpos monoclonais aumenta em virtude do tempo, e este incremento é mais evidenciado devido ao clareamento sanguíneo e dos órgãos ${ }^{43,81}$.

Para o presente trabalho, os estudos em tempos mais tardios não foram realizados, pois devido a problemas na linhagem celular, não foi possível reproduzir o modelo tumoral.

\subsection{CONCLUSÕES}

Os resultados encontrados nesta etapa do estudo permitiram concluir que o antiCD20-DOTA- ${ }^{177}$ Lu:

$\checkmark$ apresentou perfil farmacocinético compatível com anticorpos radiomarcados;

$\checkmark$ apresentou meia-vida efetiva ideal para uso em radioimunoterapia;

$\checkmark$ possui estabilidade alta in vivo, evidenciada especialmente pela baixa captação óssea;

$\checkmark$ apresentou captação tumoral considerável mesmo em tempos mais curtos de estudo e razão tumor:tecidos não alvo que corroboram com a especificidade da ligação. 


\section{7 \\ ESTUDOS DE LIOFILIZAÇÃO}

Neste capítulo apresentam-se os objetivos específicos, revisão bibliográfica, materiais, métodos, resultados, discussões e conclusões referentes aos estudos de liofilização que constituíram a quarta e última etapa do trabalho.

\subsection{OBJETIVOS ESPECÍFICOS}

Os objetivos específicos desta etapa do trabalho foram:

Estudar as condições de liofilização do anti-CD20-DOTA de forma a preservar a estrutura do anticorpo;

$\checkmark$ Avaliar a influência da liofilização do anti-CD20-DOTA sobre a eficiência de radiomarcação;

Avaliar a influência da liofilização do anti-CD20-DOTA sobre a imunorreatividade.

\subsection{REVISÃO BIBLIOGRÁFICA ESPECÍFICA}

\subsubsection{Breve histórico}

A liofilização pode ser definida como o processo de secagem de um produto previamente congelado em que a maior parte da água é removida por sublimação (secagem primária) e então por dessorção (secagem secundária) ${ }^{133,134}$. É conhecida como o melhor método para obtenção de produtos desidratados de alta qualidade e é muito utilizado em materiais em que se pretenda manter a viabilidade ou atividade biológica no estado desidratado ${ }^{133}$. A liofilização é largamente utilizada em medicamentos para aumentar a estabilidade e o tempo de armazenamento para drogas termolábeis, especialmente 
proteínas ${ }^{135,136}$.

A primeira aplicação da liofilização para preservar preparações biológicas ocorreu por volta de 1930, com um interesse em preservar o plasma humano, devido à alta demanda deste material durante a Segunda Guerra Mundial ${ }^{137}$.

A origem do termo liofilização é atribuída por causa dos poros naturais do produto seco e sua característica "liofílica" para reabsorver rapidamente o solvente e restaurar a substância em seu estado original ${ }^{134,138}$.

\subsubsection{Vantagens e desvantagens da liofilização}

A liofilização é uma técnica que oferece muitas vantagens para o processo de produção de fármacos, ${ }^{138}$ descritos a seguir:

\section{A) Preservação da atividade}

A liofilização é conhecida como o mais suave de todos os métodos de congelamento e é frequentemente usada para preservação de moléculas que exibem atividade biológica ou outra atividade. Em alguns casos, por exemplo proteínas, é possível preservar não somente a estrutura ou outras moléculas complementares para atividade. Outro exemplo, é que bactérias apresentam retenção da viabilidade após a liofilização ${ }^{138}$.

Dentre as muitas razões, inerentes ao processo de liofilização, que contribuem para a conservação de estruturas e viabilidade de produtos biológicos, podem-se citar:

- O processo opera a baixas temperaturas, protegendo espécies termolábeis. Mesmo quando o calor é aplicado para prover a energia de sublimação da umidade durante secagem primária, a porção "molhada" da amostra permanece congelada e somente o gelo evapora;

- A imobilização associada com o congelamento impede o contato entre as moléculas quimicamente reativas;

- Enzimas degradantes ou bactérias não podem atuar em temperaturas tão baixas;

- A liofilização é um processo a vácuo e a ausência de oxigênio impede reações de oxidação. 
B) Retenção da forma

A imobilização que ocorre como consequência do congelamento impede a migração de moléculas não-covalentes para a fronteira de secagem, resultando na retenção da forma ${ }^{138}$.

\section{C) Facilidade de reconstituição}

Quando uma solução aquosa é congelada, sob as condições corretas, água pura é congelada em uma estrutura ramificada que também é chamada de gelo dendrítico. A solução concentrada então congela intersticialmente entre sua matriz. O material liofilizado estruturalmente consiste em lacunas formadas pela remoção do gelo dendrítico do seu redor. Esta estrutura possui uma grande área de superfície e é, portanto, facilmente dissolvida ${ }^{138}$.

D) Tempo longo de prateleira

A baixa concentração de umidade, geralmente abaixo de $2 \%$, resulta em uma boa estabilidade de armazenamento. Este longo tempo de prateleira facilita a produção, a distribuição e o armazenamento, reduzindo assim o custo do produto final ${ }^{138}$.

\section{E) Dosagem precisa}

Fármacos devem possuir doses precisas e reprodutíveis. O material a ser liofilizado será introduzido na sua embalagem final como um líquido e pode, portanto, ser dosado com mais precisão do que na forma de pó ${ }^{138}$.

\section{F) Produto estéril}

Embora a esterilidade não seja inerente ao processo de liofilização, o produto a ser liofilizado pode ser esterilizado e o processo de produção pode ser feito sob condições assépticas $^{138}$.

A liofilização também apresenta desvantagens e dentre elas, destaca-se o tempo e custo.

A liofilização não é um processo rápido. Os tempos dos ciclos são raramente menores que 24 horas. Com os processos extras como descongelamento, limpeza e esterilização, é raro que o liofilizador produza mais que três lotes por semana ${ }^{138}$. 
Assim como muitos equipamentos sob medida, um liofilizador representa um significante investimento de capital. No caso do liofilizador, há a restrição adicional da produção limitada. No ambiente de produção, é necessário uma razoável amortização, consequentemente, a técnica é geralmente restrita a baixos volumes, aumentando o valor dos produtos ${ }^{138}$.

Por fim, os custos de operação são altos, notadamente porque o liofilizador é extremamente ineficiente no seu uso de energia. Muita energia é necessária para aquecer poucos quilogramas de água ${ }^{138}$.

\subsubsection{Etapas da liofilização e do desenvolvimento de uma proteína liofilizada}

\section{A) Identificação das propriedades térmicas da formulação antes da liofilização}

O desenvolvimento de um ciclo robusto de liofilização necessita da determinação de alguns parâmetros críticos, que impactam diretamente na qualidade do produto. Uma técnica utilizada para investigar o comportamento de soluções congeladas é a calorimetria explanatória diferencial (Differential Scanning Calorimetry - DSC). Com esta técnica, a diferença no fluxo de calor entre a amostra e uma fase inerte (referência), é medida como uma função do tempo e temperatura. Ambas, a amostra e a referência são submetidas a uma condição controlada de tempo, temperatura e pressão. Este método pode medir reações endotérmicas e exotérmicas durante o experimento. Usando-o, é possível determinar diferentes fases de transições térmicas, tais como temperatura de transição vítrea $\left(T_{g}\right)$, temperatura de fusão $\left(T_{m}\right)$, temperatura de cristalização e a temperatura eutética $\left(T_{e}\right)^{139}$.

Outro ponto crítico e que deve ser conhecido é a temperatura de colapso $\left(T_{c}\right)$ da matriz liofilizada. $A T_{c}$ é a temperatura na qual a água intersticial em uma matriz congelada começa a se tornar significantemente móvel, ou seja, o produto liofilizado perde sua estrutura macroscópica e colapsa ${ }^{139}$. A $\mathrm{T}_{\mathrm{c}}$ é geralmente $2-5^{\circ} \mathrm{C}$ acima da $\mathrm{T}_{\mathrm{g}}{ }^{135}$.

Para determinar a temperatura de colapso utiliza-se um microscópico óptico acoplado a uma câmara de liofilização. Durante esta análise, a amostra é congelada sob pressão atmosférica, em seguida é aplicado um vácuo predeterminado e uma taxa de 
aquecimento para permitir a sublimação do gelo. Esta condição é mantida até que se alcance uma temperatura em que é possível visualizar o colapso da estrutura. Neste ponto, ocorre uma mudança morfológica (degeneração) na camada de sublimação da amostra e como resultado, bolsas de ar na frente de sublimação ou até mesmo buracos enormes podem ser visto ao microscópio ${ }^{139}$.

Conhecidos estes parâmetros, passa-se ao processo de estudo das etapas de liofilização e como elas podem interferir na qualidade final do produto liofilizado.

O processo de liofilização é divido em três etapas principais: congelamento, secagem primária e secagem secundária. Na FIGURA 39 está esquematizado o processo geral de liofilização e cada etapa será abordada com mais detalhes a seguir.

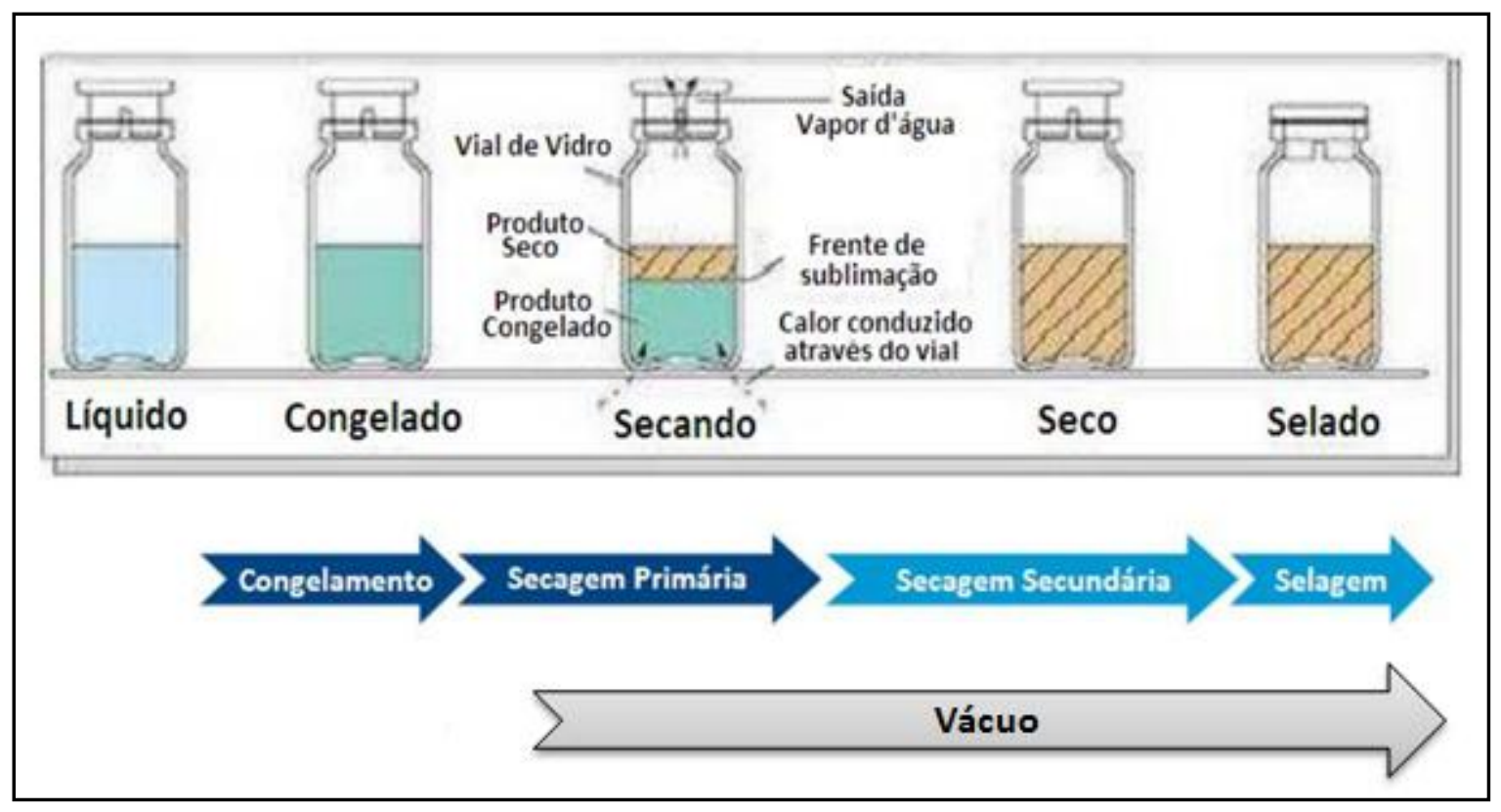

FIGURA 39 - Etapas da liofilização ${ }^{140}$.

\section{B) Congelamento}

A principal função do processo de congelamento é separar o solvente dos solutos. Para um sistema aquoso, a água formará cristais de gelo e os solutos serão confinados na região intersticial entre os cristais de gelo. A temperatura necessária para alcançar o completo congelamento da formulação dependerá da natureza do solvente e outros constituintes que compreendem a formulação ${ }^{134}$. 
Durante o congelamento da solução todos os solutos ficam altamente concentrados, ou seja, o processo de congelamento é também um processo desidratante ${ }^{136}$. Essa concentração dos solutos eventualmente modifica a solução de um líquido viscoso para um vidro frágil, o qual contem cerca de $20-50 \%$ de água ${ }^{136}$. A temperatura em que ocorre esta transição é denominada temperatura de transição vítrea $\left(T_{\mathrm{g}}\right)$. Ou seja, é a temperatura em que o material se apresenta em um estado vítreo, e ao mesmo tempo como uma solução viscosa. Nesta temperatura, o estado do material assemelha-se a uma borracha ${ }^{136,139}$.

Nesta etapa podem ocorrer além da alteração de viscosidade, mudanças nos valores de $\mathrm{pH}$ decorrentes da cristalização dos sais, redução das interações hidrofóbicas causadas pelo efeito desidratante da formação do gelo que remove a água da proteína, força iônica, ponto de congelamento, tensão superficial, entre outras ${ }^{133}$.

A escolha do tampão utilizado na formulação é muito importante, pois ele pode sofrer alterações bruscas de $\mathrm{pH}$. Em pHs extremos, aumenta a repulsão eletrostática entre as cargas iguais na proteína e isso tende a causar desdobramento e desnaturação proteica. Deste modo a agregação proteica é fortemente afetada pelo $\mathrm{pH}^{136}$. Um exemplo clássico de tampão que causa esse tipo de deslocamento de $\mathrm{pH}$, e portanto tem seu uso desaconselhado na formulação de proteínas liofilizadas, é o tampão fosfato ${ }^{135}$.

A taxa de congelamento é extremamente importante, pois quando se utiliza uma taxa de congelamento rápido, formam-se cristais de gelo menores, fazendo com que a área de superfície do gelo seja maior, portanto, a interface gelo:água também é maior e consequentemente, maior a degradação da proteína ${ }^{136,139,141 .}$

A utilização de taxa de congelamento lenta favorece a formação de cristais de gelo maiores que quando são sublimados, deixam espaços vazios grandes, pelos quais a água restante evapora mais facilmente ${ }^{141}$.

No congelamento tanto a desidratação quanto o congelamento podem induzir desnaturação da proteína e alguns excipientes podem ser utilizados para minimizar estes danos. Para proteger contra o congelamento, utilizam-se crioprotetores e para proteger contra a desidratação, lioprotetores ${ }^{136}$. Os crio e lioprotetores podem ser chamados de excipientes.

Dentre os vários excipientes utilizados, é possível citar os açúcares/poliois (sacarose, glicose, trealose, manitol), polímeros (dextran), solventes não aquosos (etilenoglicol, glicerol, dimetilsulfóxido), aminoácidos (glicina, prolina) e até mesmo a própria 
proteína, quando em altas concentrações, age como protetor ${ }^{136}$.

Os açúcares e os aminoácidos são bons crio e lioprotetores ${ }^{136}$. Dentre os açúcares, os monossacarídeos como a glicose, lactose, maltose e maltodextrina, são bons estabilizantes durante a liofilização, impedindo o desdobramento da proteína. Todavia, durante a estocagem eles são propensos a degradar a proteína via reação de Maillard. 0 resultado é a formação de uma pastilha marrom contendo a proteína degradada ao contrário de uma pastilha branca contendo a proteína ativa ${ }^{141}$.

Para evitar a reação de Maillard, as proteínas liofilizadas devem ser estocadas às temperaturas abaixo de $0{ }^{\circ} \mathrm{C}$, o que contradiz a propósito de um produto liofilizado ${ }^{141}$.

\section{C) Annealling}

Depois do congelamento, o produto congelado pode ser termicamente tratado para permitir a cristalização eficiente de alguns excipientes, como o manitol e a glicina e/ou aumentar o tamanho dos cristais de gelo ${ }^{142}$. O processo de annealing nada mais é que manter o produto congelado abaixo da $T_{g}$ por um período de tempo definido e depois continuar o congelamento até a temperatura desejada ${ }^{135,139}$.

Como os excipientes são eficientemente cristalizados, a $T_{g}$ da formulação aumenta permitindo a realização da secagem primária em uma temperatura mais alta ou simplesmente aumentando a faixa de segurança para se evitar o colapso; além disso, este proccesso melhora a homogeneidade da pastilha e aparência do produto final ${ }^{142}$.

O processo de annealing abaixo da $\mathrm{T}_{\mathrm{g}}$ causa crescimento dos cristais de gelo, $\mathrm{o}$ qual diminui a resistência do fluxo de vapor de água e resulta em tempo menor de secagem primária. Por outro lado, o annealing reduz a superfície da área do produto e isto pode levar ao aumento na umidade residual do produto final ou demandar tempo maior de secagem secundária ${ }^{135}$. Proteínas liofilizadas com umidade residual alta estão propensas à agregação 143.

\section{D) Secagem primária}

Esta é a segunda etapa da liofilização e seu principal objetivo é retirar a água por intermédio da sublimação do gelo ${ }^{138,139}$. Portanto, após o congelamento completo da formulação, a pressão no liofilizador é reduzida e calor é aplicado à formulação para iniciar a sublimação dos cristais de gelo ${ }^{134}$. 
O aquecimento da amostra é realizado mediante o aumento da temperatura da prateleira e o calor é conduzido pelo gelo, ou seja, pela amostra, por condução. Quando o calor percorre todo o gelo e chega à superfície, ocorre a sublimação do gelo. A este ponto, dá-se o nome de frente de sublimação ou interface gelo-água.

Nesta interface as moléculas de água podem colidir com moléculas de gás residuais como oxigênio e nitrogênio e retornar à superfície do gelo. Por este motivo, a taxa de sublimação depende diretamente da pressão do sistema, pois quando vácuo é aplicado, haverá poucas moléculas de oxigênio e nitrogênio.

A formação do vapor de água pode aumentar a pressão do sistema, por este motivo é necessário retirá-lo da câmara de liofilização. Para tanto, acopla-se à câmara um condensador e uma bomba de vácuo (FIGURA 40).

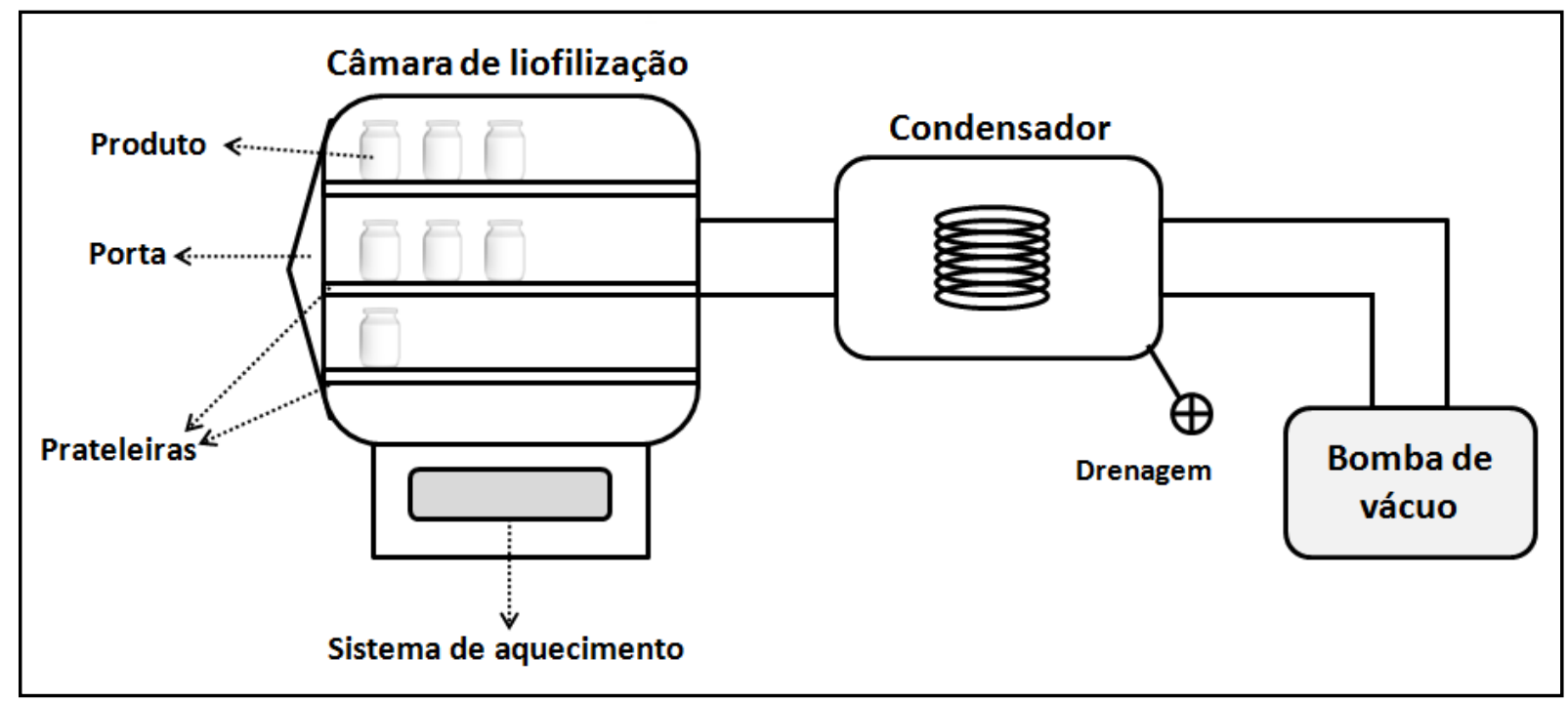

FIGURA 40 - Esquema dos principais componentes de um liofilizador.

A temperatura do condensador deve estar a uma temperatura muito menor em relação a da câmara, para que a pressão dentro dele seja menor e com isso seja facilitada a migração do vapor de água formado dentro da câmara.

Durante toda a secagem primária, deve-se controlar a temperatura da prateleira e pressão da câmara, pois elas afetam diretamente a taxa de sublimação da amostra. Se a temperatura da prateleira for muito baixa, então não haverá sublimação suficiente devido à diferença mínima entre a pressão do vapor de gelo e a pressão da câmara. Por outro lado, se a temperatura da prateleira for muito alta, o condensador pode não ser capaz de retirar 
todo o vapor de água sublimado ${ }^{134,138,142}$.

Esta etapa normalmente consome o maior tempo de todo o processo de liofilização e aprimorá-la significa economia de tempo e custo ${ }^{135,142}$.

O término desta etapa pode ser detectado por muitos métodos diferentes. Como no final da secagem primária não há mais gelo a ser sublimado, a temperatura do produto aumenta e se iguala a temperatura da prateleira, atingindo um platô logo em seguida, além disso o vapor de água reduz de forma significativa. Estes são os principais indicadores ${ }^{135,136}$. Um ciclo ótimo de liofilização fornecerá um produto com umidade residual em torno de $10 \%$ 139.

Se durante a secagem primária a temperatura exceder a $T_{c}$, pode ocorrer 0 colapso da matriz, colocando em risco não somente a estrutura da pastilha, mas também outros atributos de qualidade. Quando a estabilidade da proteína não é um problema, uma pastilha colapsada resultará na perda da elegância do produto final ${ }^{135}$.

Como visto, a secagem primária envolve conceitos puramente físicos, tais como pressão e temperatura, mas a escolha deste parâmetros dependem da amostra a ser liofilizada.

\section{E) Secagem secundária}

O último estágio da liofilização é a secagem secundária que tem por objetivo retirar, por dessorção, a água que não foi congelada. Esta umidade residual pode constituir, dependendo da temperatura e da natureza dos constituintes da massa, 5 - 20\% do produto seco e deseja-se que a umidade final do produto liofilizado seja entre 0,5 a $3 \%$, sendo este uma faixa ótima para a estabilidade ${ }^{135,138}$.

Para tanto, o produto deve ser mantido a temperaturas mais altas, em relação ao congelamento e secagem primária, por um período que permita a dessorção da água. Usualmente, é melhor realizar uma secagem secundária por um tempo menor empregandose temperaturas maiores, do que por um tempo maior com temperaturas menores. A razão é que a taxa de dessorção da água diminui drasticamente com o tempo a uma dada temperatura e tempos muito maiores que 6 horas não incrementam muito a perda da umidade ${ }^{135}$.

O incremento na temperatura da prateleira deve ser lento, tipicamente 0,1 - 0,15 
${ }^{\circ} \mathrm{C} /$ minuto, caso contrário, pode ocorrer o colapso do produto ${ }^{139}$.

Embora se deseje alcançar um produto com menor umidade residual possível, a secagem secundária pode retirar a água de hidratação da proteína. As moléculas de água presentes na camada de hidratação são partes integrais dos sítios ativos da proteína e retirálas pode desfazer a conformação nativa da proteína e causar desnaturação. Uma proteína hidratada quando exposta a um ambiente desidratante, tende a transferir prótons para ionizar os grupamentos carboxílicos e portanto anula quantas cargas for possível na proteína. A diminuição da densidade de cargas facilita a interação proteína-proteína, causando agregação ${ }^{136,141}$.

Para prevenir ou minimizar os danos à proteína, deve-se selecionar lioprotetores efetivos tais como a sacarose e trealose, entre outros, que são ótimos para prevenir o desdobramento da proteína durante a desidratação ${ }^{141}$. No entanto, a escolha e a quantidade a ser usada destes estabilizantes deve ser racionalmente avaliada, pois o mesmo excipiente que protege a proteína, pode, em grandes quantidades, promover sua desnaturação ${ }^{136}$.

Conclui-se, portanto, que o desenvolvimento de uma proteína liofilizada é uma ciência complexa e que envolve conceitos de diversas áreas do conhecimento, mas apesar de desafiador, o produto final apresenta muitas vantagens que justificam 0 desenvolvimento.

Em radiofarmácia, os radiofármacos/reagentes liofilizados, kits, prontos para a radiomarcação apresentam uma vantagem enorme, pois eles podem ser estocados por um longo período de tempo, são de fácil radiomarcação (em muitos deles a reação de radiomarcação ocorre em temperatura ambiente) e produzem um radiofármaco com pureza radioquímica adequada para uso em humanos.

Para este trabalho, o desenvolvimento de um produto para pronta marcação buscou agregar valor ao produto, aumentando o tempo de prateleira do imunoconjugado e facilitando a rotina de produção deste radiofármaco. 


\subsection{MATERIAIS}

\subsubsection{Infraestrutura}

Os estudos por calorimetria diferencial esplanatória foram realizados no laboratório de Biomateriais Poliméricos localizado no Centro de Química e Meio Ambiente (CQMA-IPEN) e sob a responsabilidade da Dra. Duclerc Parra.

Os estudos utilizando o liofilizador óptico (Lyostat) foram realizados no laboratório de Imunobiológicos e Biofármacos localizado na Faculdade de Ciências Farmacêuticas da Universidade de São Paulo (FCFUSP) que está sob responsabilidade do Dr. Marco Antônio Stephano.

Nas dependências do Centro de Biotecnologia (CB-IPEN) foram realizados os estudos de liofilização e cultivo celular, sendo estas dependências coordenadas pelo Dr. Carlos Roberto Jorge Soares.

\subsubsection{Reagentes}

Os principais reagentes utilizados neste trabalho foram:

$\checkmark$ AcM anti-CD20 conjugado ao DOTA na razão molar 1:50 e armazenado em tampão acetato de amônio $0,25 \mathrm{M} \mathrm{pH} \mathrm{6,5;}$

$\checkmark$ Cloreto de lutécio-177 (IDB, Holanda);

$\checkmark$ Acrilamida (Merck, Alemanha);

$\checkmark$ Água purificada - Purificador Milli-RX 45 (Millipore, EUA);

Azul de bromofenol (Merck, Alemanha);

Bisacrilamida (Merck, Alemanha);

$\checkmark$ Cloreto de sódio (Merck, Alemanha);

$\checkmark$ Corante Coomassie Brilliant Blue G-250 (GE Healthcare, Reino Unido);

$\checkmark$ Dodecil sulfato de sódio (GE Healthcare, Reino Unido);

$\checkmark$ Glicerol (Merck, Alemanha);

$\checkmark$ Glicina (Sigma Aldrich, EUA);

$\checkmark$ Manitol (Merck, Alemanha);

Padrão de peso molecular (Promega, EUA)

$\checkmark$ Persulfato de amônio (Merck, Alemanha); 
Resina Chelex 100 (BioRad, EUA);

Sacarose (Merck, Alemanha);

Soro fetal bovino (Cultilab, Brasil);

TEMED (N,N,N,N-tetrametil etilenodiamina) (USB);

$\checkmark$ Tris base (Sigma Aldrich, EUA).

\subsubsection{Equipamentos, sistemas e materiais}

Os principais equipamentos e materiais utilizados neste trabalho foram:

Agitador/aquecedor Thermomixer Comfort 1,5 mL (Eppendorf, EUA);

$\checkmark$ Analisador térmico diferencial - DSC - modelo 822 (Mettler Toledo, EUA);

Balança analítica (Mettler Toledo, EUA);

$\checkmark$ Cadinhos para calorimetria diferencial explanatória (Mettler Toledo, EUA);

$\checkmark$ Centrífuga refrigerada Mikro 220 (Hettich, Alemanha);

$\checkmark$ Contador automático tipo poço com cristal Nal (TI) - D5002 cobra II (Packard-Camberra, EUA);

$\checkmark$ Cromatógrafo líquido de alta eficiência composto por sistema modulado constituído por bomba LC-10 ATvp, controlador automático de gradiente FCV-10 AL, degaseificador DGU$20 A_{5}$, injetor automático de amostras SIL-10ADvp, detector UV SPD-10A e forno CTO-10 Avp (Shimadzu, Japão);

Cartucho de pré-coluna SEC-S 3000 - 4 x 3,0 mm (Phenomenex, EUA);

$\checkmark$ Coluna Protein-Pak ${ }^{\mathrm{TM}} 300 \mathrm{SW}$ para cromatografia líquida de alta eficiência - $300 \times 7,5 \mathrm{~mm}$, $5 \mu \mathrm{m}$ (Waters, Japão);

$\checkmark$ Coluna Sephadex G25 - PD-10 (GE Healthcare);

$\checkmark$ GraphPad Prism 5.00 ${ }^{\circledR}$ (GraphPad Software, Inc., EUA);

$\checkmark$ Fonte de alta tensão para eletroforese EPS 600 (GE Healthcare, Reino Unido);

$\checkmark$ Frascos de vidro tipo 1 com tampa de silicone;

$\checkmark$ Liofilizador Dura-Stop (FTS Systems, EUA);

$\checkmark$ Medidor de $\mathrm{pH}$ (Mettler Toledo, EUA);

$\checkmark$ Medidor de umidade Karl Fischer (Photovolt, EUA);

$\checkmark$ Microscópio de liofilização Lyostat 2 - modelo LINKAM (Biopharma Technology, Reino Unido); 
Suporte cromatográfico para cromatografia em camada delgada ITLC-SG (Merck, Alemanha);

$\checkmark$ Material plástico descartável em geral, tais como ponteiras e tubos cônicos com tampa para reação tipo eppendorf;

$\checkmark$ Pipetas automáticas (Brand, Alemanha; Socorex, Suíça e Eppendorf, EUA).

\subsubsection{Células Raji de linfoma de Burkitt humano}

As células Raji, derivadas de linfoma de Burkitt humano foram cultivadas no Centro de Biotecnologia conforme descrito no item 5.2.4.

\subsection{MÉTODOS}

\subsubsection{Fluxograma da metodologia}

O desenvolvimento do imunoconjugado liofilizado envolveu algumas etapas constituídas de diferentes metodologias. Com o intuito de fornecer uma visão ampla das etapas que envolveram esta parte trabalho, apresenta-se na FIGURA 41 um fluxograma descrevendo a sequência lógica da obtenção do imunoconjugado liofilizado. 


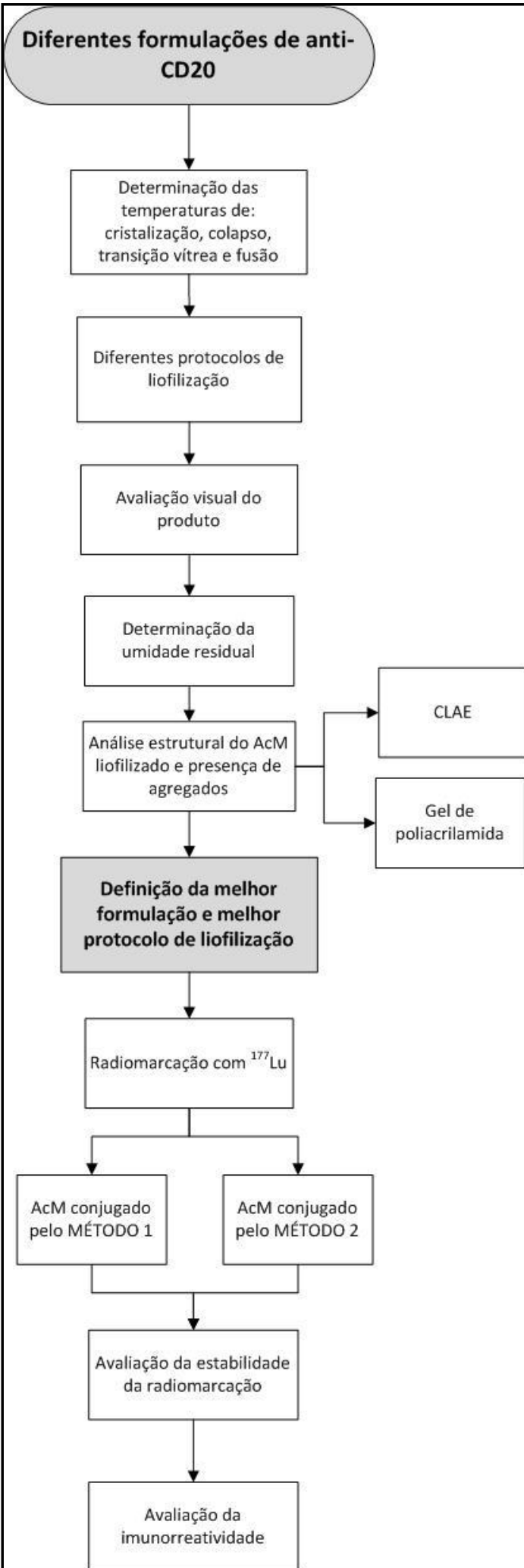

FIGURA 41 - Fluxograma do desenvolvimento do imunoconjugado liofilizado. 


\subsubsection{Estudo de diferentes formulações de imunoconjugado}

O AcM conjugado ao DOTA na razão molar 1:50 e diluído em tampão acetato de amônio 0,25 M pH 6,5, foi acrescido ou não de um ou mais agentes crioprotetores e /ou lioprotetores. Ao longo do texto, estes agentes foram abordados/nomeados apenas como excipientes.

Ao todo, foram estudadas 23 formulações que estão descritas em detalhes na TABELA 19.

As formulações 1 a 20 foram elaboradas com o AcM conjugado ao DOTA, já as formulações 21, 22 e 23 foram elaboradas com o AcM não conjugado ao DOTA e não acrescido de excipientes, apenas com o intuito de comparação.

Apenas para a formulação número 16, que foi proposta por Wojdowska e colaboradores (2015) ${ }^{109}$, foram avaliados lotes de imunoconjugado obtidos utilizando-se as metodologias 1 e 2 de conjugação (item 5.3.2.2 A e B). Para os demais, apenas o AcM conjugado pelo método 1 foi avaliado.

É importante ressaltar que todas as formulações possuíram uma massa final de imunoconjugado ou AcM de $2 \mathrm{mg}$. Para obter-se diferentes concentrações final, tais como 4 $\mathrm{mg} / \mathrm{mL}$ e $5 \mathrm{mg} / \mathrm{mL}$, foram alterados o volume final da formulação. 
TABELA 19 - Formulações estudadas do imunoconjugado diluído em acetato de amônio 0,25 $\mathrm{M} \mathrm{pH} \mathrm{6,5} \mathrm{acrescido} \mathrm{ou} \mathrm{não} \mathrm{de} \mathrm{excipientes.}$

\begin{tabular}{|c|c|c|c|c|c|c|}
\hline \multirow{2}{*}{$\begin{array}{l}\text { Formulação/Amostra } \\
\text { No }\end{array}$} & \multirow{2}{*}{$\begin{array}{l}\text { Imunoconjugado } \\
\qquad(\mathrm{mg} / \mathrm{mL})\end{array}$} & \multirow[b]{2}{*}{$\begin{array}{c}\text { AcM } \\
(\mathrm{mg} / \mathrm{mL})\end{array}$} & \multicolumn{4}{|c|}{ Massa de excipiente (mg) } \\
\hline & & & Manitol & Sacarose & Glicina & $\mathrm{NaCl}$ \\
\hline 1 & 2 & - & - & - & - & - \\
\hline 2 & 2 & - & 0,9 & - & - & - \\
\hline 3 & 2 & - & 2,5 & - & - & - \\
\hline 4 & 2 & - & 5 & - & - & - \\
\hline 5 & 2 & - & 10 & - & - & - \\
\hline 6 & 2 & - & - & 1,7 & - & - \\
\hline 7 & 2 & - & - & - & 0,4 & - \\
\hline 8 & 2 & - & 0,9 & 1,7 & - & - \\
\hline 9 & 2 & - & 0,9 & - & 0,4 & - \\
\hline 10 & 2 & - & 0,9 & 1,7 & 0,4 & - \\
\hline 11 & 2 & - & - & 1,7 & 0,4 & - \\
\hline 12 & 4 & - & - & - & - & - \\
\hline 13 & 4 & - & 2,5 & - & - & - \\
\hline 14 & 4 & - & 5 & - & - & - \\
\hline 15 & 4 & - & 10 & - & - & - \\
\hline 16 & 4 & - & 5 & - & - & 9 \\
\hline 17 & 5 & - & - & - & - & - \\
\hline 18 & 5 & - & 2,5 & - & - & - \\
\hline 19 & 5 & - & 5 & - & - & - \\
\hline 20 & 5 & - & 10 & - & - & - \\
\hline 21 & - & 2 & - & - & - & \\
\hline 22 & - & 4 & - & - & - & \\
\hline 23 & - & 5 & - & - & - & \\
\hline
\end{tabular}




\subsubsection{Determinação da temperatura de transição vítrea e temperatura de fusão}

Todas as formulações estudadas foram submetidas a teste de calorimetria explanatória (Differential Scanning Calorimetry - DSC) para determinar a temperatura de transição vítrea $\left(T_{g}\right)$ e temperatura de fusão $\left(T_{m}\right)$ destas amostras. Para tanto, alíquotas de $30 \mu \mathrm{L}$ de cada solução foram pipetadas em recipientes de alumínio ("cadinhos") e resfriados a $-60{ }^{\circ} \mathrm{C}$. Após o congelamento, as amostras foram aquecidas até $30{ }^{\circ} \mathrm{C}$ utilizando-se uma taxa de aquecimento de $2,5{ }^{\circ} \mathrm{C} /$ minuto e uma vazão de nitrogênio de $50 \mathrm{~mL} /$ minuto. As amostras foram analisadas em triplicata.

As formulações 21, 22 e 23 que foram realizadas com o AcM não conjugado ao DOTA, não foram analisadas por DSC.

\subsubsection{Determinação da temperatura de cristalização e temperatura de colapso}

A temperatura de colapso do imunoconjugado acrescido ou não de excipientes foi determinada por meio de microscopia óptica acoplada à liofilização (Lyostat ${ }^{\circledR}$ ). Este equipamento possui uma câmara de vídeo acoplado a um computador para captura das imagens. O equipamento consiste em uma pequena câmara de liofilização contendo um controlador de temperatura, uma bomba de vácuo para garantir a redução de pressão atmosférica durante as análises e uma janela óptica na qual a amostra pode ser observada microscopicamente durante a análise. Dez microlitros das amostras foram congelados à -40 ${ }^{\circ} \mathrm{C}$ em uma taxa de congelamento de $10{ }^{\circ} \mathrm{C} /$ minuto. Após 5 minutos, aplicou-se uma pressão de 100 mTorr e a amostra foi aquecida até $25{ }^{\circ} \mathrm{C}$ a uma taxa de aquecimento de 2,5 ${ }^{\circ} \mathrm{C} /$ minuto.

A temperatura de colapso foi determinada visualmente por meio da identificação de bolhas da frente de sublimação ou de ruptura na matriz liofilizada. As amostras foram analisadas em triplicata.

As formulações 21, 22 e 23 que foram realizadas com o AcM não conjugado ao DOTA, não foram analisadas por microscopia óptica acoplada à liofilização. 


\subsubsection{Estudo de diferentes protocolos de liofilização}

Para o desenvolvimento do imunoconjugado liofilizado, foram estudados quatro protocolos de liofilização diferentes e estes estão descritos detalhadamente na TABELA 20.

TABELA 20 - Protocolos estudados para a liofilização do imunoconjugado.

\begin{tabular}{|c|c|c|c|c|c|c|c|c|}
\hline \multirow[b]{2}{*}{$\begin{array}{c}\text { PROTOCOLO } \\
\text { № }\end{array}$} & \multicolumn{2}{|c|}{ CONGELAMENTO } & \multicolumn{3}{|c|}{ SECAGEM PRIMÁRIA } & \multicolumn{3}{|c|}{ SECAGEM SECUNDÁRIA } \\
\hline & $\begin{array}{c}\text { Temperatura } \\
\left({ }^{\circ} \mathrm{C}\right)\end{array}$ & $\begin{array}{l}\text { Tempo } \\
\text { (h) }\end{array}$ & $\begin{array}{c}\text { Temperatura } \\
\left({ }^{\circ} \mathrm{C}\right)\end{array}$ & $\begin{array}{c}\text { Tempo } \\
\text { (h) }\end{array}$ & $\begin{array}{l}\text { Pressão } \\
\text { (mTorr) }\end{array}$ & $\begin{array}{c}\text { Temperatura } \\
\left({ }^{\circ} \mathrm{C}\right)\end{array}$ & $\begin{array}{l}\text { Tempo } \\
\text { (h) }\end{array}$ & $\begin{array}{l}\text { Pressão } \\
\text { (mTorr) }\end{array}$ \\
\hline 1 & -40 & 4 & -35 & 12 & 200 & $\begin{array}{c}-20 \\
-10 \\
5 \\
10\end{array}$ & $\begin{array}{l}3 \\
3 \\
3 \\
3\end{array}$ & 100 \\
\hline 2 & -40 & 4 & -35 & 12 & 250 & $\begin{array}{c}-20 \\
-10 \\
5 \\
10\end{array}$ & $\begin{array}{l}3 \\
3 \\
3 \\
3\end{array}$ & 100 \\
\hline 3 & -45 & 4 & -40 & 24 & 100 & $\begin{array}{c}-20 \\
-10 \\
5 \\
10\end{array}$ & $\begin{array}{l}3 \\
3 \\
3 \\
3\end{array}$ & 100 \\
\hline 4 & -40 & 4 & -35 & 24 & 100 & $\begin{array}{c}-20 \\
-10 \\
5 \\
10\end{array}$ & $\begin{array}{l}2 \\
2 \\
2 \\
2\end{array}$ & 100 \\
\hline
\end{tabular}

Os estudos de liofilização foram conduzidos de maneira a aperfeiçoar cada etapa, portanto, nem todas as formulações foram liofilizadas utilizando todos os protocolos.

Para ilustrar e facilitar o entendimento, a TABELA 21 foi construída relacionandose as formulações estudadas com os protocolos de liofilização empregados. 
TABELA 21 - Tabela de correlação entre as formulações estudadas e o protocolo empregado na liofilização.

\begin{tabular}{|c|c|c|c|c|c|}
\hline & \multicolumn{4}{|c|}{ PROTOCOLO DE LIOFILIZAÇÃO } \\
\hline & & 1 & 2 & 3 & 4 \\
\hline \multirow{23}{*}{ 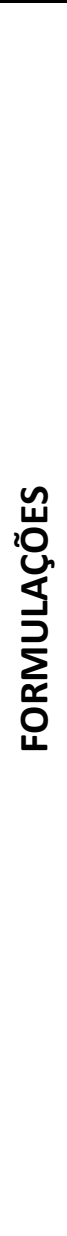 } & 1 & & & & \\
\hline & 2 & & & & \\
\hline & 3 & & & & \\
\hline & 4 & & & & \\
\hline & 5 & & & & \\
\hline & 6 & & & & \\
\hline & 7 & & & & \\
\hline & 8 & & & & \\
\hline & 9 & & & & \\
\hline & 10 & & & & \\
\hline & 11 & & & & \\
\hline & 12 & & & & \\
\hline & 13 & & & & \\
\hline & 14 & & & & \\
\hline & 15 & & & & \\
\hline & 16 & & & & \\
\hline & 17 & & & & \\
\hline & 18 & & & & \\
\hline & 19 & & & & \\
\hline & 20 & & & & \\
\hline & 21 & & & & \\
\hline & 22 & & & & \\
\hline & 23 & & & & \\
\hline
\end{tabular}

\subsubsection{Análise do produto liofilizado antes da reconstituição}

Antes da reconstituição com tampão acetato de amônio $0,25 \mathrm{M} \mathrm{pH} \mathrm{6,5,} \mathrm{o}$ imunoconjugado liofilizado teve as seguintes características avaliadas:

A) $\mathrm{Cor}$

A cor da pastilha/pó do imunoconjugado liofilizado foi analisada a olho nu e classificada como:

- B: Branco 
- I: Incolor, quando não houve formação de pastilha/pó e sim de uma massa com aparência gelificada.

B) Aparência da pastilha

O imunoconjugado liofilizado foi analisado a olho nu e o aspecto final do produto liofilizado foi classificado como:

- Pó: quando não houve formação de pastilha e sim de um pó liofilizado;

- Pastilha: quando houve a formação de pastilha; e

- Gel: quando não houve formação de pastilha ou pó, gerando uma massa com aparência gelificada.

C) Colapso macroscópico

Definiu-se como colapso macroscópico a formação de micro bolhas na pastilha visíveis a olho nu.

D) Teor de umidade residual

A umidade residual do pó liofilizado foi determinada por aquametria com reagente de Karl Fischer, utilizando-se o protocolo rotineiramente utilizado no Centro de Radiofarmácia para avaliação dos reagentes liofilizados produzidos.

\subsubsection{Análise do produto liofilizado após reconstituição}

O imunoconjugado liofilizado foi reconstituído com $1 \mathrm{~mL}$ de tampão acetato de amônio 0,25 M pH 6,5 e avaliou-se os parâmetros descritos a seguir:

A) Presença de partículas visíveis

Após a reconstituição e homogeneização, o frasco contendo o produto reconstituído foi avaliado visualmente quanto à obtenção de uma solução límpida, sem presença de partículas em suspensão ou turvação. 
B) Avaliação do $\mathrm{pH}$

Após a reconstituição com o tampão, o pH foi determinado por equipamento medidor de $\mathrm{pH}$.

C) Análise da integridade estrutural do anticorpo e da formação de agregados solúveis por CLAE

Vinte microlitros dos liofilizados reconstituídos foram analisados exclusão molecular utilizando a técnica de CLAE. As corridas foram realizadas em um sistema Shimadzu equipado com uma coluna de exclusão molecular (Protein-Pak 300 SW, Waters). 0 fluxo utilizado foi de $1 \mathrm{~mL} / \mathrm{min}$ utilizando como fase móvel tampão fosfato de sódio $0,1 \mathrm{M}$ pH 7,0 por 15 minutos. A absorbância das amostras foi analisada no comprimento de onda de $280 \mathrm{~nm}$.

Com esta metodologia foi possível observar a integridade do imunoconjugado, um possível desacoplamento do quelante e a presença de agregados.

D) Análise da integridade estrutural por eletroforese de poliacrilamida

O lote produzido utilizando o protocolo de liofilização número 4 e a formulação número 16 foi reconstituído com $1 \mathrm{~mL}$ de tampão acetato de amônio $0,25 \mathrm{M} \mathrm{pH} \mathrm{6,5}$ submetido à eletroforese de acordo com o procedimento descrito no item 5.3.2.7.

Os ensaios foram realizados em triplicata com três frascos diferentes de imunoconjugados.

\subsubsection{Estudos de radiomarcação do imunoconjugado liofilizado com Lu-177}

A) Marcação com baixa atividade de Lu-177

O lote produzido utilizando o protocolo de liofilização número 4 e a formulação número 16 foi reconstituído com $1 \mathrm{~mL}$ de tampão acetato de amônio $0,25 \mathrm{M} \mathrm{pH} \mathrm{6,5.} \mathrm{Um}$ volume equivalente a $0,2 \mathrm{mg}$ de imunoconjugado (100 $\mu \mathrm{L})$ foi radiomarcado com $148 \mathrm{MBq}(4$ $\mathrm{mCi}$ ) de Lu-177 (atividade específica de $740 \mathrm{MBq} / \mathrm{mg}$ ). A reação de radiomarcação ocorreu por 1 hora a $43^{\circ} \mathrm{C}$ e agitação de $350 \mathrm{rpm}$ e volume final de $200 \mu \mathrm{L}$. A pureza radioquímica 
foi determinada por CCD, conforme descrito no item 5.3.3.1 A. Os ensaios foram realizados em quintuplicata para três lotes de imunoconjugado.

\section{B) Marcação com alta atividade de Lu-177}

O lote produzido utilizando o protocolo de liofilização número 4 e a formulação número 16 foi reconstituído com $1 \mathrm{~mL}$ de tampão acetato de amônio 0,25 M pH 6,5 e radiomarcado com 1.480 MBq (40 mCi) de Lu-177 (atividade específica de $740 \mathrm{MBq} / \mathrm{mg}$ ). A reação de radiomarcação ocorreu por 1 hora a $43{ }^{\circ} \mathrm{C}$ e agitação de $500 \mathrm{rpm}$. A pureza radioquímica foi determinada por $\mathrm{CCD}$, conforme descrito no item 5.3.3.1 A. Os ensaios foram realizados em duplicata com dois lotes diferentes de imunoconjugados.

C) Estudo da estabilidade do rituximabe-DOTA- ${ }^{177}$ Lu em condições de transporte

O lote produzido utilizando o protocolo de liofilização número 4 e a formulação número 16 foi reconstituído com $1 \mathrm{~mL}$ de tampão acetato de amônio 0,25 M pH 6,5 e radiomarcado com 1.480 MBq (40 mCi) de Lu-177 (atividade específica de $740 \mathrm{MBq} / \mathrm{mg}$ ). 0 radioimunoconjugado foi purificado em coluna de exclusão molecular (PD-10), e as frações correspondentes ao anti-CD20- ${ }^{177}$ Lu foram misturadas e o volume final ajustado para $4 \mathrm{~mL}$.

O anti-CD20- ${ }^{177} \mathrm{Lu}$ foi mantido à $-20{ }^{\circ} \mathrm{C}$ por 24 e 48 horas. Decorrido estes tempos, o anticorpo foi descongelado (à temperatura ambiente) e mantido sob refrigeração $\left(2-8{ }^{\circ} \mathrm{C}\right)$ por até 6 horas. A pureza radioquímica foi avaliada, por CCD, em diferentes tempos. Os ensaios foram realizados em duplicata com dois lotes diferentes de imunoconjugados.

\subsubsection{Avaliação da Imunorreatividade}

O lote produzido utilizando o protocolo de liofilização número 4 e a formulação número 16 foi reconstituído com $1 \mathrm{~mL}$ de tampão acetato de amônio $0,25 \mathrm{M} \mathrm{pH} \mathrm{6,5.} \mathrm{Um}$ volume equivalente a $0,2 \mathrm{mg}$ de imunoconjugado $(100 \mu \mathrm{L})$ foi radiomarcado com $148 \mathrm{MBq}(4$ mCi) de Lu-177 (atividade específica de $740 \mathrm{MBq} / \mathrm{mg}$ ) e submetido a ensaio de imunorreatividade conforme descrito no item 5.3.2.8. Os ensaios foram realizados em duplicata para dois lotes de imunoconjugado. 


\subsubsection{Análise estatística}

A análise estatística foi realizada utilizando-se o programa estatístico GraphPad Prism $5.00^{\circledR}$. Os resultados foram expressos como média \pm erro padrão da média (EPM) ou média \pm desvio padrão (DP).

Para comparar até dois grupos (amostras pareadas ou não), o teste t de Student foi utilizado com distribuição bicaudal. Para a comparação entre três ou mais grupos foi utilizado o teste de variância de dois fatores (two-way ANOVA). Quando necessário, os dados foram submetidos a pós-teste (teste de Bonferroni ou de Newman-Keuls de comparações múltiplas). As diferenças foram consideradas significativas quando o valor de $p$ foi menor do que 0,05 .

\subsection{RESULTADOS E DISCUSSÃO}

Na primeira etapa deste trabalho (capítulo 5) foram estudados diversos aspectos de conjugação e radiomarcação que levaram à definição da massa de imunoconjugado a ser utilizada para produzir um radioimunoconjugado com eficiência de radiomarcação alta e estabilidade quando se utiliza atividade alta de Lu-177. Na presente etapa, estudou-se a liofilização da massa definida como ideal $(2 \mathrm{mg})$, com o objetivo de desenvolver um produto liofilizado.

\subsubsection{Determinação das temperaturas de cristalização, transição vítrea, fusão e colapso}

Com o intuito de direcionar os protocolos de liofilização, vinte formulações de imunoconjugado foram analisadas por calorimetria diferencial explanatória (DSC) e liofilizador óptico, a fim de determinar as temperaturas de transição vítrea $\left(T_{g}\right)$, ponto de fusão $\left(T_{m}\right)$, temperatura de cristalização $\left(T_{\text {cris }}\right)$ e temperatura de colapso $\left(T_{c}\right)$ das formulações estudadas.

As formulações 21, 22 e 23 que foram elaboradas com o AcM não conjugado ao DOTA, não foram analisadas por DSC nem por microscopia óptica acoplada à liofilização. 
A análise por DSC permite detectar as transições térmicas de uma amostra. A $T_{g}$ é visualizada na curva de DSC por uma mudança na linha de base. Esta técnica é muito aplicada para a determinação de $\mathrm{T}_{\mathrm{g}}$ de polímeros, no entanto, quando é empregada para análise de amostras biológicas, deve ser aplicada com cautela, uma vez que ao se observar as curvas provenientes da análise por DSC, os declives não são expressivos como os observados em polímeros. Além disso, deve-se utilizar um equipamento que possua um número maior de termopares para que a $\mathrm{T}_{\mathrm{g}}$ seja detectada ${ }^{144}$. Para análise das formulações elaboradas neste trabalho, utilizou-se um equipamento com 56 termopares.

Analisando-se as curvas obtidas por DSC de todas as formulações, observou-se um discreto declive referente a uma transição de segunda ordem na faixa de $-26,52{ }^{\circ} \mathrm{C}$ a $-21,19{ }^{\circ} \mathrm{C}$ correspondendo à temperatura de transição vítrea $\left(\mathrm{T}_{\mathrm{g}}\right)$. À temperatura de $-0,39{ }^{\circ} \mathrm{C}$ a $1,78{ }^{\circ} \mathrm{C}$ observou-se um pico endotérmico, atribuído à temperatura de fusão $\left(T_{m}\right)$ das amostras. Na FIGURA 42, está apresentado um exemplo de curva (perfil) obtido após análise por DSC do imunoconjugado sem adição de excipientes (formulação 1).

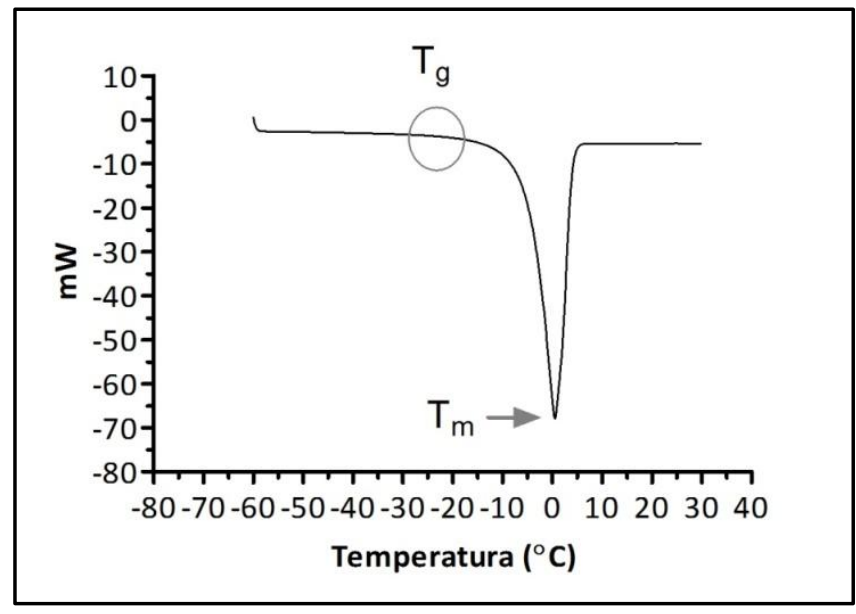

FIGURA 42 - Exemplo de curva (perfil) obtido após análise por DSC do imunoconjugado sem adição de excipientes (formulação 1).

Outro ponto crítico que deve ser conhecido é a temperatura de colapso $\left(T_{c}\right)$ da matriz liofilizada. $A T_{C}$ pode ser realizada utilizando-se uma câmara de liofilização acoplada a um microscópio, assim, a $\mathrm{T}_{\mathrm{c}}$ é determinada visualmente.

Na FIGURA 43, apresenta-se uma sequência de imagens obtidas durante o processo de congelamento e liofilização do imunoconjugado não acrescido de excipientes 
(formulação 1).

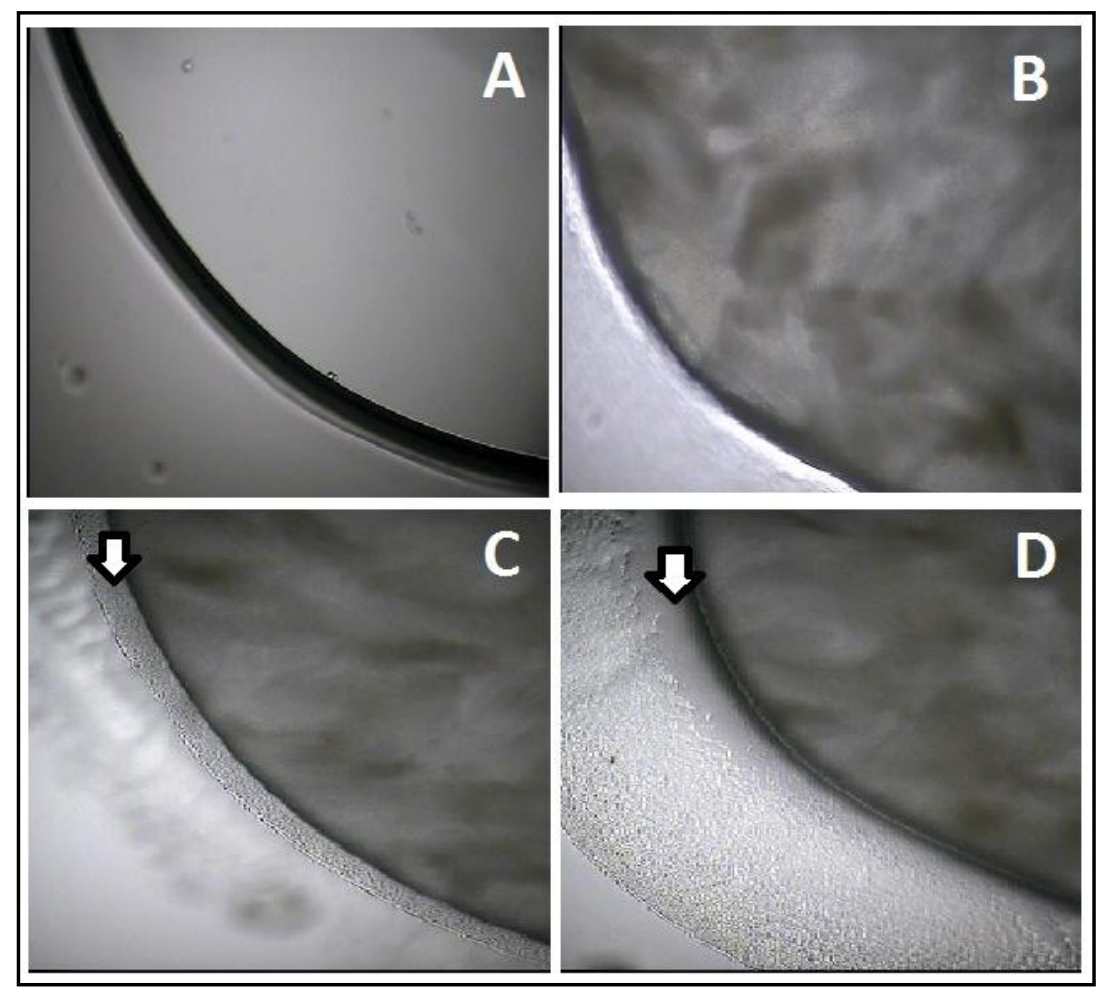

FIGURA 43 - Análise do imunoconjugado não acrescido de excipientes (formulação 1) por liofilizador óptico. Em (A), visualiza-se a borda da gota da amostra analisada; em (B), amostra cristalizada; em (C), início da liofilização da amostra, a seta indica a frente de sublimação e em (D), identificação visual do colapso da matriz liofilizada (seta).

Inicialmente, se visualiza a borda da gota da amostra ao microscópio (FIGURA 43 A), em seguida, conforme a temperatura da câmara diminui, observa-se o congelamento (cristalização) da amostra (FIGURA 43 B). Esta é a temperatura de cristalização da amostra $\left(T_{\text {cris }}\right)$. Quando vácuo é aplicado e inicia-se o aquecimento da câmara, ou seja, quando se inicia o processo de liofilização, é possível visualizar a frente de sublimação da amostra. Neste ponto a amostra antes congelada, começa a ser liofilizada (FIGURA 43 C).

A uma temperatura específica de cada amostra, observa-se a formação de bolsas de ar ou bolhas de água na frente de sublimação. Em alguns casos é possível observar a formação de buracos no material já liofilizado (FIGURA 43 D). Todos estes sinais são característicos de colapso da matriz e quando um destes aspectos é visualizado, determinase a temperatura de colapso $\left(T_{c}\right)$ da matriz liofilizada. 
Na TABELA 22, estão descritos os valores de $T_{g}, T_{m}, T_{\text {cris, }}$ e $T_{c}$ das formulações estudadas.

TABELA 22 - Transição vítrea $\left(T_{g}\right)$, ponto de fusão $\left(T_{m}\right)$, temperatura de cristalização $\left(T_{\text {cris }}\right)$ e temperatura de colapso $\left(T_{c}\right)$ das formulações estudadas. Valores expressos em média $\pm D P$ $(\mathrm{N}=3)$.

\begin{tabular}{|c|c|c|c|c|c|c|}
\hline FM & $\begin{array}{l}\text { AcM- } \\
\text { DOTA }\end{array}$ & EXCIPIENTES & $\mathrm{T}_{\mathrm{g}}\left({ }^{\circ} \mathrm{C}\right)$ & $\mathrm{T}_{\mathrm{m}}\left({ }^{\circ} \mathrm{C}\right)$ & $\mathrm{T}_{\text {cris }}\left({ }^{\circ} \mathrm{C}\right)$ & $\mathrm{T}_{\mathrm{c}}\left({ }^{\circ} \mathrm{C}\right)$ \\
\hline 1 & $2 \mathrm{mg} / \mathrm{mL}$ & - & $-26,52 \pm 2,44$ & $0,60 \pm 0,08$ & $-26,75 \pm 0,78$ & $-31,25 \pm 1,63$ \\
\hline 2 & $2 \mathrm{mg} / \mathrm{mL}$ & 0,9 mg Ma & $-25,95 \pm 2,12$ & $1,02 \pm 3,01$ & $-27,85 \pm 0,64$ & $-33,45 \pm 1,91$ \\
\hline 3 & $2 \mathrm{mg} / \mathrm{mL}$ & 2,5 mg Ma & $-26,03 \pm 1,67$ & $0,39 \pm 0,26$ & $-27,25 \pm 0,35$ & $-27,80 \pm 1,13$ \\
\hline 4 & $2 \mathrm{mg} / \mathrm{mL}$ & $5 \mathrm{mg} \mathrm{Ma}$ & $-23,54 \pm 0,58$ & $0,35 \pm 0,18$ & $-19,13 \pm 0,38$ & $-27,47 \pm 0,29$ \\
\hline 5 & $2 \mathrm{mg} / \mathrm{mL}$ & $10 \mathrm{mg} \mathrm{Ma}$ & $-25,59 \pm 1,28$ & $0,39 \pm 0,74$ & $-24,70 \pm 0,28$ & $-29,42 \pm 0,46$ \\
\hline 6 & $2 \mathrm{mg} / \mathrm{mL}$ & $1,7 \mathrm{mg} \mathrm{Sa}$ & $-25,95 \pm 0,78$ & $0,74 \pm 2,01$ & $-27,35 \pm 0,78$ & $-34,35 \pm 1,34$ \\
\hline 7 & $2 \mathrm{mg} / \mathrm{mL}$ & 0,4 mg Gly & $-23,21 \pm 1,63$ & $1,27 \pm 1,37$ & $-24,20 \pm 0,28$ & $-33,50 \pm 0,85$ \\
\hline 8 & $2 \mathrm{mg} / \mathrm{mL}$ & $\begin{array}{c}0,9 \mathrm{mg} \mathrm{Ma}+1,7 \mathrm{mg} \\
\mathrm{Sa}\end{array}$ & $-26,07 \pm 0,85$ & $0,99 \pm 0,15$ & $-23,95 \pm 3,61$ & $-33,70 \pm 0,71$ \\
\hline 9 & $2 \mathrm{mg} / \mathrm{mL}$ & $\begin{array}{c}0,9 \mathrm{mg} \mathrm{Ma}+0,4 \mathrm{mg} \\
\text { Gly }\end{array}$ & $-23,77 \pm 1,72$ & $1,78 \pm 0,99$ & $-23,05 \pm 1,48$ & $-34,80 \pm 0,57$ \\
\hline 10 & $2 \mathrm{mg} / \mathrm{mL}$ & $\begin{array}{c}0,9 \mathrm{mg} \mathrm{Ma}+0,4 \mathrm{mg} \\
\text { Gly + 1,7 mg de Sa }\end{array}$ & $-24,50 \pm 0,71$ & $1,50 \pm 0,50$ & $-25,10 \pm 1,27$ & $-32,70 \pm 0,85$ \\
\hline 11 & $2 \mathrm{mg} / \mathrm{mL}$ & $\begin{array}{c}0,4 \mathrm{mg} \mathrm{Gly}+1,7 \mathrm{mg} \\
\text { Sa }\end{array}$ & $-22,11 \pm 2,45$ & $1,30 \pm 1,13$ & $-26,50 \pm 2,12$ & $-28,35 \pm 2,76$ \\
\hline 12 & $4 \mathrm{mg} / \mathrm{mL}$ & - & $-24,00 \pm 0,40$ & $1,25 \pm 0,08$ & $-25,87 \pm 2,15$ & $-29,50 \pm 0,71$ \\
\hline 13 & $4 \mathrm{mg} / \mathrm{mL}$ & 2,5 mg Ma & $-25,52 \pm 0,57$ & $1,26 \pm 0,32$ & $-20,94 \pm 1,28$ & $-30,14 \pm 1,15$ \\
\hline 14 & $4 \mathrm{mg} / \mathrm{mL}$ & $5 \mathrm{mg} \mathrm{Ma}$ & $-21,80 \pm 0,09$ & $1,14 \pm 0,12$ & $-21,12 \pm 0,11$ & $-29,72 \pm 1,57$ \\
\hline 15 & $4 \mathrm{mg} / \mathrm{mL}$ & $10 \mathrm{mg} \mathrm{Ma}$ & $-21,26 \pm 1,92$ & $1,37 \pm 0,47$ & $-19,98 \pm 1,38$ & $-28,67 \pm 1,48$ \\
\hline 16 & $4 \mathrm{mg} / \mathrm{mL}$ & $\begin{array}{c}5 \mathrm{mg} \mathrm{Ma}+9 \mathrm{mg} \\
\mathrm{NaCl}\end{array}$ & $-22,28 \pm 1,41$ & $0,26 \pm 0,06$ & $-24,76 \pm 1,72$ & $-33,58 \pm 3,47$ \\
\hline 17 & $5 \mathrm{mg} / \mathrm{mL}$ & - & $-21,71 \pm 1,14$ & $1,19 \pm 0,04$ & $-24,35 \pm 0,40$ & $-29,60 \pm 2,05$ \\
\hline 18 & $5 \mathrm{mg} / \mathrm{mL}$ & $2,5 \mathrm{mg} \mathrm{Ma}$ & $-24,99 \pm 0,59$ & $1,00 \pm 0,19$ & $-18,75 \pm 0,77$ & $-33,92 \pm 0,93$ \\
\hline 19 & $5 \mathrm{mg} / \mathrm{mL}$ & $5 \mathrm{mg} \mathrm{Ma}$ & $-23,36 \pm 0,87$ & $0,99 \pm 0,22$ & $-17,67 \pm 1,46$ & $-31,41 \pm 1,12$ \\
\hline 20 & $5 \mathrm{mg} / \mathrm{mL}$ & $10 \mathrm{mg} \mathrm{Ma}$ & $-21,19 \pm 1,71$ & $0,67 \pm 0,91$ & $-15,99 \pm 1,20$ & $-25,93 \pm 1,56$ \\
\hline
\end{tabular}


Ao analisar o menor $\left(-26,52{ }^{\circ} \mathrm{C} \pm 2,44{ }^{\circ} \mathrm{C}\right)$ e o maior $\left(-21,19{ }^{\circ} \mathrm{C} \pm 0,02{ }^{\circ} \mathrm{C}\right)$ valor de $\mathrm{T}_{\mathrm{g}}$ obtidos para as formulações 1 e 20, respectivamente, observou-se que a adição de excipientes e o aumento da concentração do imunoconjugado não promoveram mudanças consideráveis na $T_{g}(P=0,0786)$ (TABELA 22).

O mesmo ocorreu com a $\mathrm{T}_{\mathrm{m}}$ ao analisar a menor $\left(0,26{ }^{\circ} \mathrm{C} \pm 0,06{ }^{\circ} \mathrm{C}\right)$ e a maior $\left(1,78{ }^{\circ} \mathrm{C} \pm 0,28{ }^{\circ} \mathrm{C}\right)$ temperatura de fusão obtidas para as formulações 16 e 9 , respectivamente $(P=0,0624)$.

Todavia, a maior concentração do imunoconjugado associada a uma maior quantidade de manitol diminui significativamente a $T_{\text {cris }}(P=0,0065$; comparando-se o maior valor e o menor valor: $-27,85{ }^{\circ} \mathrm{C} \pm 0,64{ }^{\circ} \mathrm{C}$ e $-15,99{ }^{\circ} \mathrm{C} \pm 1,20{ }^{\circ} \mathrm{C}$ respectivamente) e a $T_{C}(P=$ 0,0286; comparando-se o maior valor e o menor valor: $-34,35{ }^{\circ} \mathrm{C} \pm 1,34{ }^{\circ} \mathrm{C}$ e $-25,93{ }^{\circ} \mathrm{C} \pm 1,56$ ${ }^{\circ} \mathrm{C}$ respectivamente).

$A T_{c}$ é a temperatura em que a água presente na matriz congelada começa a se tornar significantemente móvel ${ }^{136}$, em outras palavras, a água que antes estava congelada começa a descongelar e não é sublimada na secagem primária. Esta água impede a sublimação do gelo e como consequência, a matriz perde sua estrutura e colapsa, formando um produto com aspecto farmacotecnicamente inaceitável e com reconstituição lenta devido à perda de porosidade ${ }^{142}$.

Além do aspecto, a sublimação ineficiente da água resulta em um produto com umidade residual mais alta quando comparado a um produto não colapsado. Esta água pode se distribuir de forma irregular no produto, interferindo na estabilidade ${ }^{142}$.

$A T_{c}$ e a $T_{g}$ são os parâmetros mais críticos durante a liofilização e para evitar o colapso da matriz, o produto deve ser congelado e sublimado abaixo da $T_{g}$ e da $T_{c}$. Caso não seja possível determinar a $T_{c}$, é possível considerá-la como igual ou muito próxima à $T_{g}{ }^{142}$.

Assim, com os valores encontrados na TABELA 22, foi possível concluir que um bom ciclo de liofilização congelaria as amostras abaixo de $-38^{\circ} \mathrm{C}$ e a secagem primária seria realizada a uma temperatura entre $-40{ }^{\circ} \mathrm{C}$ e $-35{ }^{\circ} \mathrm{C}$. Estes valores foram considerados na definição dos protocolos de liofilização. 


\subsubsection{Análise do imunoconjugado liofilizado antes e após a reconstituição}

A princípio, liofilizou-se $2 \mathrm{mg}$ do imunoconjugado diluído em tampão acetato de amônio 0,25 M pH 6,5 sem a adição de excipientes (formulação 1) pelos protocolos 1, 2, 3 e 4. Os resultados das análises realizadas antes e após a reconstituição do produto liofilizado estão descritos na TABELA 23.

TABELA 23 - Avaliação do imunoconjugado $(2 \mathrm{mg} / \mathrm{mL}$ ) liofilizado sem adição de excipientes (formulação 1). Resultados expressos em média $\pm \mathrm{DP}(\mathrm{N}=3)$.

\begin{tabular}{|c|c|c|c|c|c|c|c|c|c|c|}
\hline \multirow[b]{2}{*}{ 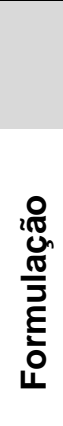 } & \multirow{2}{*}{ 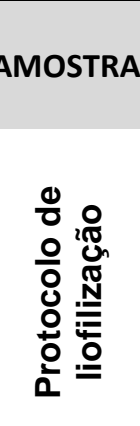 } & \multirow[b]{2}{*}{ 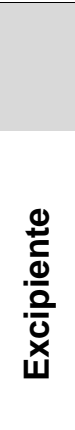 } & \multicolumn{4}{|c|}{$\begin{array}{l}\text { AVALIAÇÃO ANTES DA } \\
\text { RECONSTITUIÇÃO }\end{array}$} & \multicolumn{2}{|c|}{$\begin{array}{c}\text { AVALIAÇÃO } \\
\text { APÓS A } \\
\text { RECONSTITUIÇÃo }\end{array}$} & \multicolumn{2}{|c|}{ ANÁLISE POR CLAE } \\
\hline & & & 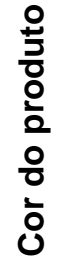 & 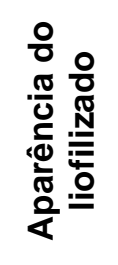 & 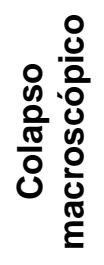 & 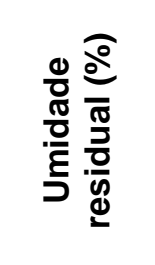 & 工 & 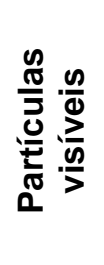 & 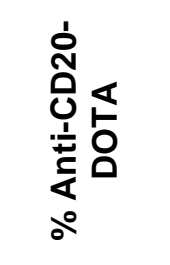 & 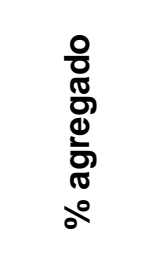 \\
\hline 1 & 1 & - & B & Pó & S & $2,40 \pm 1,47$ & $6,45 \pm 0,22$ & S & $95,63 \pm 0,13$ & $4,37 \pm 0,13$ \\
\hline 1 & 2 & - & B & Pó & $S$ & $3,95 \pm 1,00$ & $6,74 \pm 0,32$ & s & $93,32 \pm 0,82$ & $6,89 \pm 0,78$ \\
\hline 1 & 3 & - & B & Pó & S & $9,36 \pm 6,33$ & $6,49 \pm 0,11$ & S & $94,54 \pm 2,80$ & $5,46 \pm 2,14$ \\
\hline 1 & 4 & - & 1 & Gel & $\mathrm{s}$ & $6,10 \pm 2,11$ & $6,48 \pm 0,17$ & $\mathrm{~s}$ & $99,62 \pm 0,25$ & $0,38 \pm 0,25$ \\
\hline
\end{tabular}

$\mathrm{B}=$ Branco; I = Incolor; S = Sim

Na FIGURA 44 estão exemplificados os diferentes aspectos/aparência do produto liofilizado que permitiu classificá-los como pó (FIGURA 44 A e B), presença de colapso (FIGURA 44 C e D) e gel (FIGURA 44 E e F). 


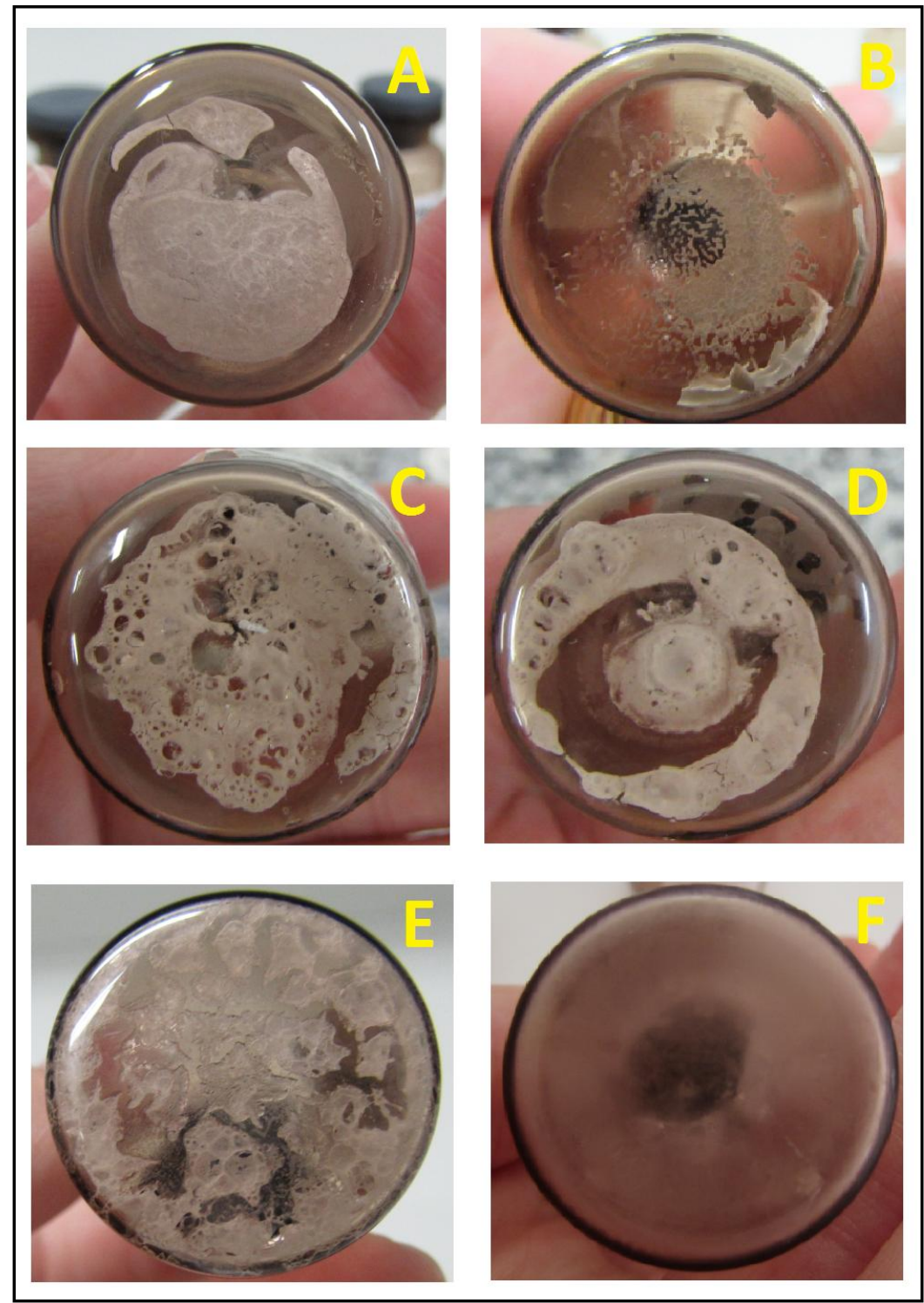

FIGURA 44 - Aparência do produto liofilizado classificado como: pó (A e B), colapsado (C e D) e gelificado (E e F).

O imunoconjugado não acrescido de excipientes apresentou colapso macroscópico (pastilha com bolhas visíveis a olho nú) quando liofilizado pelos 4 protocolos de liofilização (FIGURA 44 C e D).

Este colapso não foi evitado com o aumento da pressão na secagem primária (de 200 para 250 mTorr) no protocolo 2, tão pouco com o aumento do ciclo de secagem primária (de 12 horas para 24 horas - protocolo 3), ou com a diminuição da temperatura da secagem primária (de $-35{ }^{\circ} \mathrm{C}$ para $-40{ }^{\circ} \mathrm{C}$ - protocolo 3). Isto pode ser explicado, em parte, pela ausência de excipientes formadores de massa. 
A mudança nos parâmetros da secagem primária promoveu sublimação incompleta da água e consequentemente umidade residual maior quando comparada ao protocolo 1 (TABELA 23). No entanto, este aumento não foi significativo para nenhum imunoconjugado liofilizado avaliado $(P>0,05)$.

A via mais comum de degradação de proteínas liofilizadas é por agregação nãocovalente. O estresse físico da liofilização pode causar desnaturação parcial ou total da proteína. As porções desnaturadas, que estavam anteriormente escondidas no interior da molécula, se expõem. Estas superfícies expostas geralmente são hidrofóbicas e, portanto, disponíveis para interagir com outras moléculas de proteínas, formando dímeros nãocovalentes ou outras estruturas de alto peso molecular. Este tipo de agregação pode ocorrer na proteína liofilizada (sólida) ou após a reconstituição ${ }^{145}$.

Todos os frascos apresentaram formação de agregados solúveis identificados por CLAE (FIGURA 45) e agregados insolúveis identificados a olho nu (partículas visíveis). A quantidade de agregados solúveis não se mostrou proporcional à formação de partículas visíveis, visto que o imunoconjugado liofilizado pelo protocolo 4 apresentou a menor quantidade de agregados solúveis ( $\mathrm{P}<0,05$ para todas as comparações) e ainda assim, houve presença de partículas visíveis. 


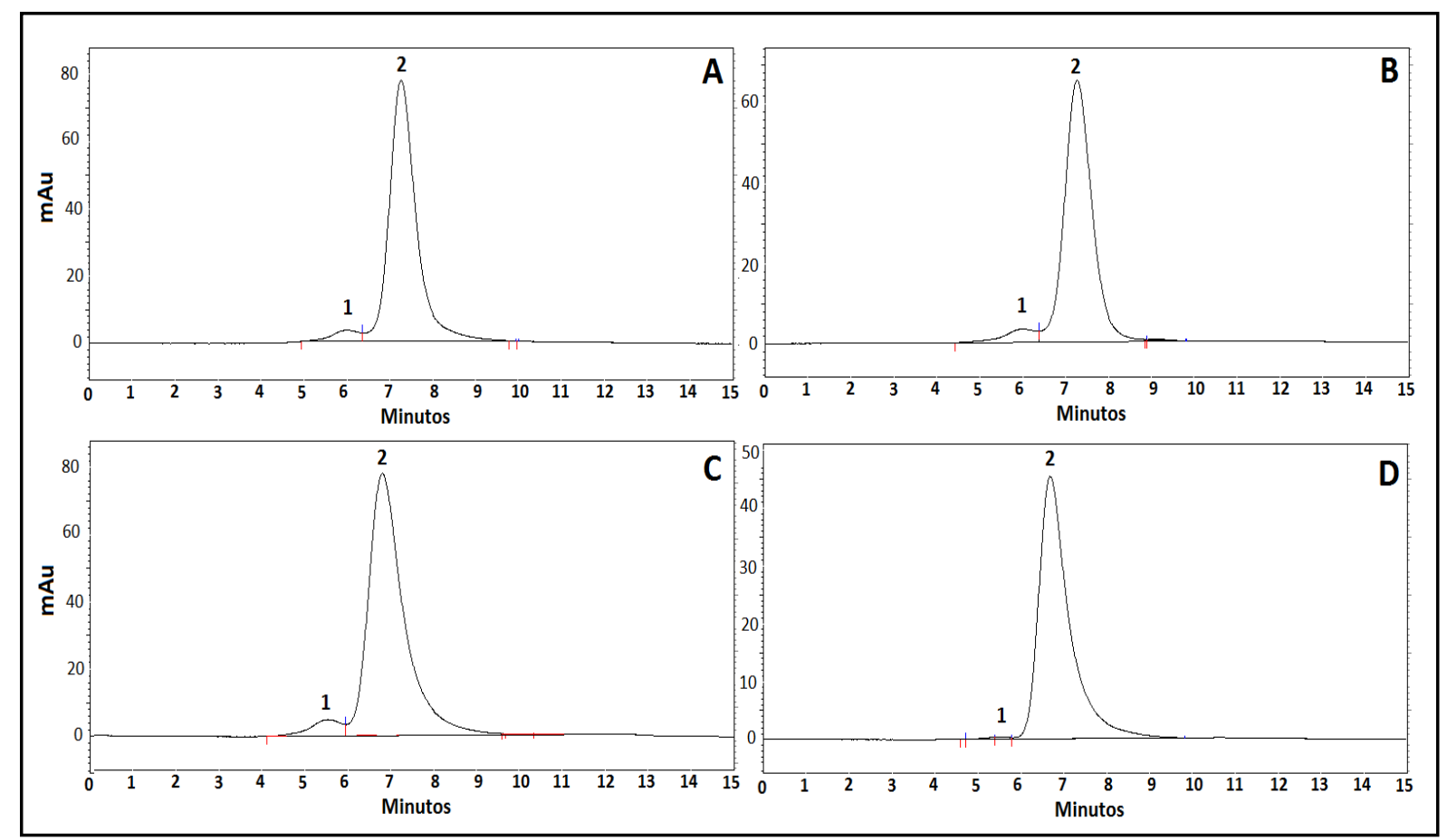

FIGURA 45 - Perfis cromatográficos por CLAE do imunoconjugado liofilizado pelos protocolos 1 (A), 2 (B), 3 (C) e 4 (D) não acrescido de quaisquer excipientes (formulação 1). (1) = agregado; $(2)=$ anti-CD20-DOTA.

Soluções injetáveis não podem apresentar partículas em suspensão. No caso específico de proteínas, a agregação proteica é indesejável porque a atividade biológica pode ser comprometida e a imunogenicidade da proteína pode aumentar ${ }^{145}$. Portanto, de acordo com os resultados encontrados, o imunoconjugado não poderia ser administrado endovenosamente.

O imunoconjugado liofilizado pelo protocolo 4 não apresentou formação de pó ou pastilha. Nestas amostras, foi observada a formação de um gel incolor não característico de um produto liofilizado (FIGURA $44 \mathrm{E}$ e F).

Agentes de massa são excipientes que são adicionados à formulação para preservar a estrutura da pastilha durante o processo de liofilização, conferindo um aspecto elegante a ela e consequentemente prevenindo o colapso ${ }^{139}$.

Estes agentes de massa são necessários, especialmente quando se deseja liofilizar proteínas com concentrações inferiores a $50 \mathrm{mg} / \mathrm{mL}$, já que formulações contendo concentrações de proteína $\geq 50 \mathrm{mg} / \mathrm{mL}$ não necessitam de agentes de massa, porque a concentração alta de proteína funciona como autoprotetor ${ }^{136,139}$.

Com o intuito de diminuir a formação de agregados solúveis e insolúveis, bem 
como melhorar o aspecto da pastilha, foram adicionados excipientes (manitol, sacarose ou glicina) ao imunoconjugado e as amostras foram liofilizadas pelo protocolo 2 . Os resultados da análise do imunoconjugado liofilizado estão apresentados na TABELA 24 e os cromatogramas na FIGURA 46.

TABELA 24 - Avaliação do imunoconjugado $(2 \mathrm{mg} / \mathrm{mL}$ ) liofilizado com adição de excipientes e liofilizado pelo protocolo 2. Resultados expressos em média $\pm \mathrm{DP}(\mathrm{N}=3)$.

\begin{tabular}{|c|c|c|c|c|c|c|c|c|c|c|}
\hline \multirow[b]{2}{*}{ 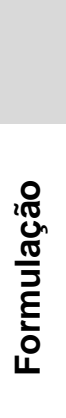 } & \multicolumn{2}{|c|}{ AMOSTRA } & \multicolumn{4}{|c|}{$\begin{array}{l}\text { AVALIAÇÃO ANTES DA } \\
\text { RECONSTITUIÇÃO }\end{array}$} & \multicolumn{2}{|c|}{$\begin{array}{c}\text { AVALIAÇÃO } \\
\text { APÓS A } \\
\text { RECONSTITUIÇÃO }\end{array}$} & \multicolumn{2}{|c|}{ ANÁLISE POR CLAE } \\
\hline & 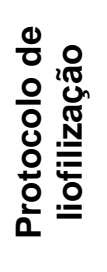 & 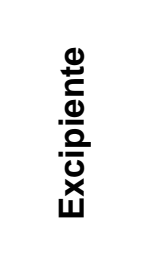 & 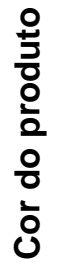 & 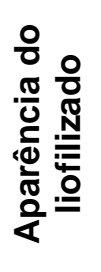 & 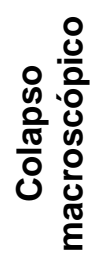 & 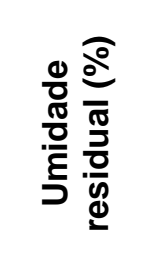 & I & 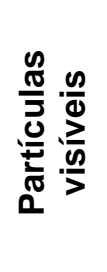 & 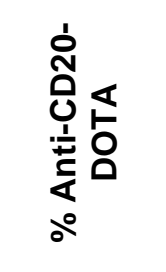 & 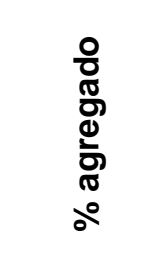 \\
\hline 2 & 2 & $\begin{array}{c}0,9 \mathrm{mg} \\
\mathrm{Ma}\end{array}$ & B & Pó & $S$ & $4,57 \pm 5,07$ & $6,46 \pm 0,25$ & $S$ & $90,38 \pm 2,10$ & $9,59 \pm 2,10$ \\
\hline 6 & 2 & $1,7 \mathrm{mg} \mathrm{Sa}$ & B & Pó & S & $5,01 \pm 4,06$ & $6,37 \pm 0,25$ & S & $92,33 \pm 1,28$ & $7,49 \pm 1,03$ \\
\hline 7 & 2 & $\begin{array}{l}0,4 \mathrm{mg} \\
\text { Gly }\end{array}$ & B & Pó & $S$ & $6,62 \pm 6,00$ & $6,54 \pm 0,01$ & $S$ & $90,59 \pm 2,76$ & $9,41 \pm 2,76$ \\
\hline 8 & 2 & $\begin{array}{c}0,9 \mathrm{mg} \\
\mathrm{Ma}+1,7 \\
\mathrm{mg} \mathrm{Sa}\end{array}$ & B & Pó & S & $1,89 \pm 4,83$ & $6,43 \pm 0,15$ & S & $91,24 \pm 2,60$ & $8,76 \pm 2,61$ \\
\hline 9 & 2 & $\begin{array}{c}0,9 \mathrm{mg} \\
\mathrm{Ma}+0,4 \\
\mathrm{mg} \mathrm{G}\end{array}$ & B & Pó & S & $7,5 \pm 2,56$ & $6,72 \pm 0,21$ & S & $90,86 \pm 1,40$ & $9,14 \pm 1,39$ \\
\hline 10 & 2 & $\begin{array}{c}0,4 \mathrm{mg} \\
\text { Gly }+1,7 \\
\mathrm{mg} \mathrm{Sa}\end{array}$ & B & Pó & $\mathrm{S}$ & $3,63 \pm 2,74$ & $6,71 \pm 0,08$ & S & $93,84 \pm 3,90$ & $6,16 \pm 3,90$ \\
\hline 11 & 2 & $\begin{array}{c}0,9 \mathrm{mg} \\
\mathrm{Ma}+1,7 \\
\mathrm{mg} \mathrm{Sa}+ \\
0,4 \mathrm{mg} \\
\text { Gly }\end{array}$ & B & Pó & S & $7,02 \pm 1,08$ & $5,85 \pm 0,14$ & S & $86,50 \pm 5,10$ & $13,50 \pm 5,11$ \\
\hline
\end{tabular}

Cleland e colaboradores $(2000)^{146}$ relataram que uma razão molar proteína:açúcar de 360:1 foi suficiente para inibir agregação do anticorpo monoclonal rhuMAb HER2 durante a liofilização e armazenamento a $40{ }^{\circ} \mathrm{C}$ por três meses. No entanto, no presente trabalho, não foi observada diminuição da agregação proteica quando esta 
relação molar foi utilizada (formulações 2,6 , e 7). Na realidade, a adição de glicina e manitol promoveu aumento significativo $(P<0,05)$ na formação de agregado quando comparado ao imunoconjugado liofilizado sem adição de excipientes pelo mesmo protocolo (TABELA 23 formulação 1). Além da formação de agregados solúveis, houve também presença de partículas visíveis (agregados insolúveis) em todos os lotes produzidos.

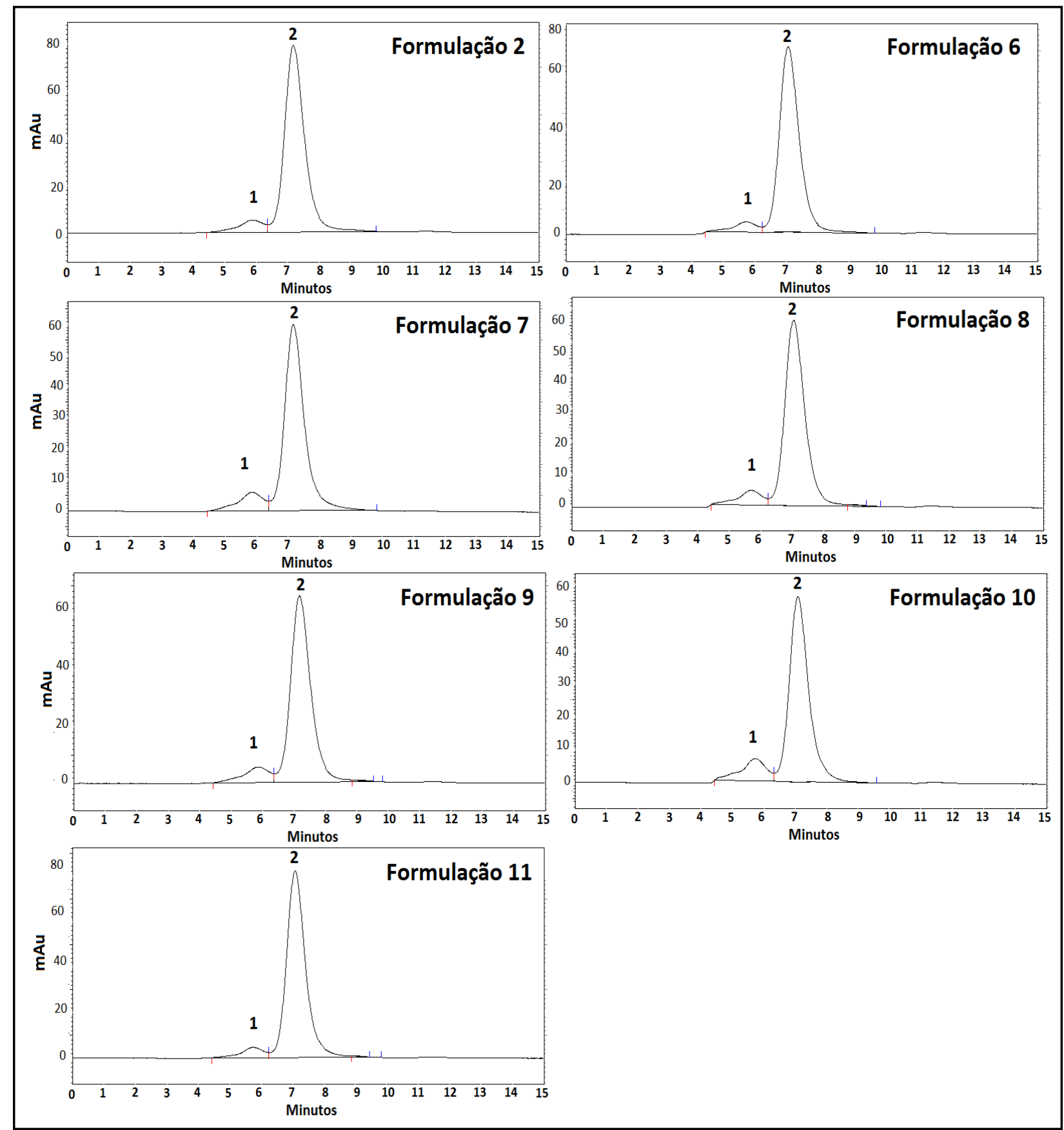

FIGURA 46 - Perfis cromatográficos por CLAE do imunoconjugado acrescido de diferentes excipientes e liofilizado pelo protocolo 2 . (1) = agregado; (2) = anti-CD20-DOTA. 
Durante a liofilização, as proteínas sofrem estresses diferentes derivados do congelamento e da desidratação (secagem primária e secundária). Por este motivo, muitos crioprotetores efetivos para estabilizar proteínas em solução, não apresentam a mesma eficiência durante a secagem. Portanto, em muitos casos o uso de dois ou mais excipientes é empregado para proteger a proteína contra a desnaturação ${ }^{136}$.

Assim, também foi avaliada a combinação de manitol, glicina e sacarose (formulações 8, 9, 10 e 11) para este mesmo protocolo de liofilização (2). Os resultados encontrados das análises antes e após a reconstituição dos liofilizados estão expressos na TABELA 24.

A combinação destes excipientes não promoveu melhora no aspecto da pastilha e não preveniu a formação de partículas visíveis (TABELA 24). Além disso, a formação de agregados solúveis foi significativamente maior $(P<0,04)$ para 3 das 4 combinações estudadas, quando comparadas com a formulação 1 liofilizada com o mesmo protocolo (TABELA 23). Quando sacarose e manitol foram empregados juntamente na concentração molar de 360:1, a formação de agregados solúveis foi ligeiramente maior do que na ausência do uso (TABELA 23 - formulação 1), contudo, estes dois excipientes não preveniram a formação de partículas visíveis.

Uma alternativa para diminuir a agregação proteica durante a liofilização é o aumento do tempo da secagem primária. Por este motivo foi avaliado um novo protocolo de liofilização (protocolo 3) com tempo de secagem primária de 24 horas à $-40^{\circ} \mathrm{C}$.

Foram liofilizados por este protocolo o imunoconjugado e o AcM não conjugado não acrescidos de excipientes e em três concentrações diferentes (2, 4 e $5 \mathrm{mg} / \mathrm{mL})$. Os resultados estão expressos na TABELA 25. 
TABELA 25 - Avaliação do imunoconjugado e do ACM não conjugado, ambos não acrescidos de excipientes e liofilizados pelo protocolo 3 . Resultados expressos em média $\pm D P(N=3)$.

\begin{tabular}{|c|c|c|c|c|c|c|c|c|c|c|c|}
\hline \multirow[b]{2}{*}{ 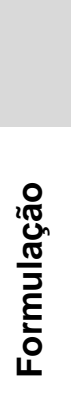 } & \multicolumn{2}{|c|}{ AMOSTRA } & \multirow[b]{2}{*}{ 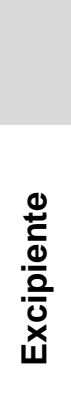 } & \multicolumn{4}{|c|}{$\begin{array}{l}\text { AVALIAÇÃO ANTES DA } \\
\text { RECONSTITUIÇÃO }\end{array}$} & \multicolumn{2}{|c|}{$\begin{array}{l}\text { AVALIAÇÃO APÓS } \\
\text { A } \\
\text { RECONSTITUIÇÃO }\end{array}$} & \multicolumn{2}{|c|}{ ANÁLISE POR CLAE } \\
\hline & 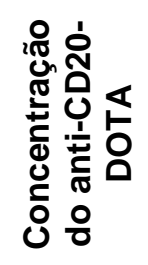 & 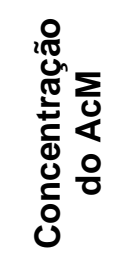 & & 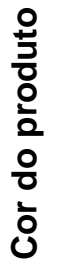 & 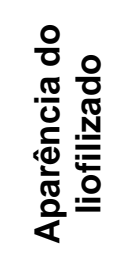 & 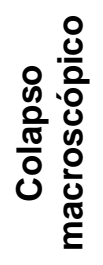 & 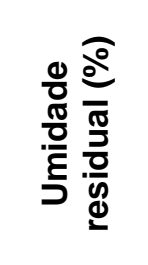 & I & 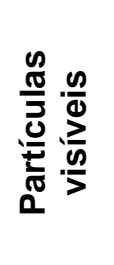 & 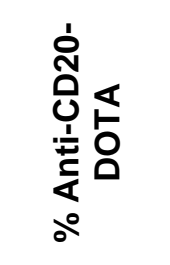 & 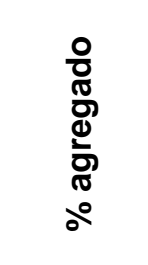 \\
\hline$*_{1}$ & $2 \mathrm{mg} / \mathrm{mL}$ & - & - & B & Pó & $\mathrm{s}$ & $9,36 \pm 6,33$ & $6,49 \pm 0,11$ & s & $94,54 \pm 2,80$ & $5,46 \pm 2,14$ \\
\hline 12 & $4 \mathrm{mg} / \mathrm{mL}$ & - & - & B & Pó & S & $8,32 \pm 4,02$ & $6,52 \pm 0,17$ & S & $95,73 \pm 0,02$ & $4,27 \pm 0,07$ \\
\hline 17 & $5 \mathrm{mg} / \mathrm{mL}$ & - & - & B & Pó & $S$ & $9,22 \pm 3,06$ & $6,47 \pm 0,07$ & $S$ & $93,70 \pm 2,21$ & $6,30 \pm 1,93$ \\
\hline 21 & - & $2 \mathrm{mg} / \mathrm{mL}$ & - & I & Gel & S & $4,04 \pm 0,41$ & $6,51 \pm 0,02$ & $\mathrm{~N}$ & $99,15 \pm 0,38$ & $0,75 \pm 0,39$ \\
\hline 22 & - & $4 \mathrm{mg} / \mathrm{mL}$ & - & B & Pastilha & $\mathrm{s}$ & $7,90 \pm 2,87$ & $6,46 \pm 0,27$ & $\mathrm{~N}$ & $99,84 \pm 0,04$ & $0,16 \pm 0,10$ \\
\hline 23 & - & $5 \mathrm{mg} / \mathrm{mL}$ & - & B & Pastilha & $\mathrm{s}$ & $9,34 \pm 0,39$ & $6,55 \pm 0,13$ & $\mathrm{~N}$ & $99,86 \pm 0,01$ & $0,14 \pm 0,07$ \\
\hline
\end{tabular}
a comparação entre as formulações.

Foi observado que o aumento do tempo de secagem primária não impediu a formação de partículas visíveis utilizando-se qualquer concentração final de imunoconjugado (formulações 1, 12 e 17).

O mesmo não aconteceu quando apenas o AcM não conjugado foi liofilizado. $\mathrm{Na}$ realidade, não apenas constatou-se ausência de partículas visíveis, como também a formação de agregados solúveis foi significativamente menor $(P<0,05)$ para todas as concentrações estudadas (TABELA 25). A diferença na quantidade de agregados solúveis pode ser visualizada nos cromatogramas por CLAE que estão demonstrados na FIGURA 47. 


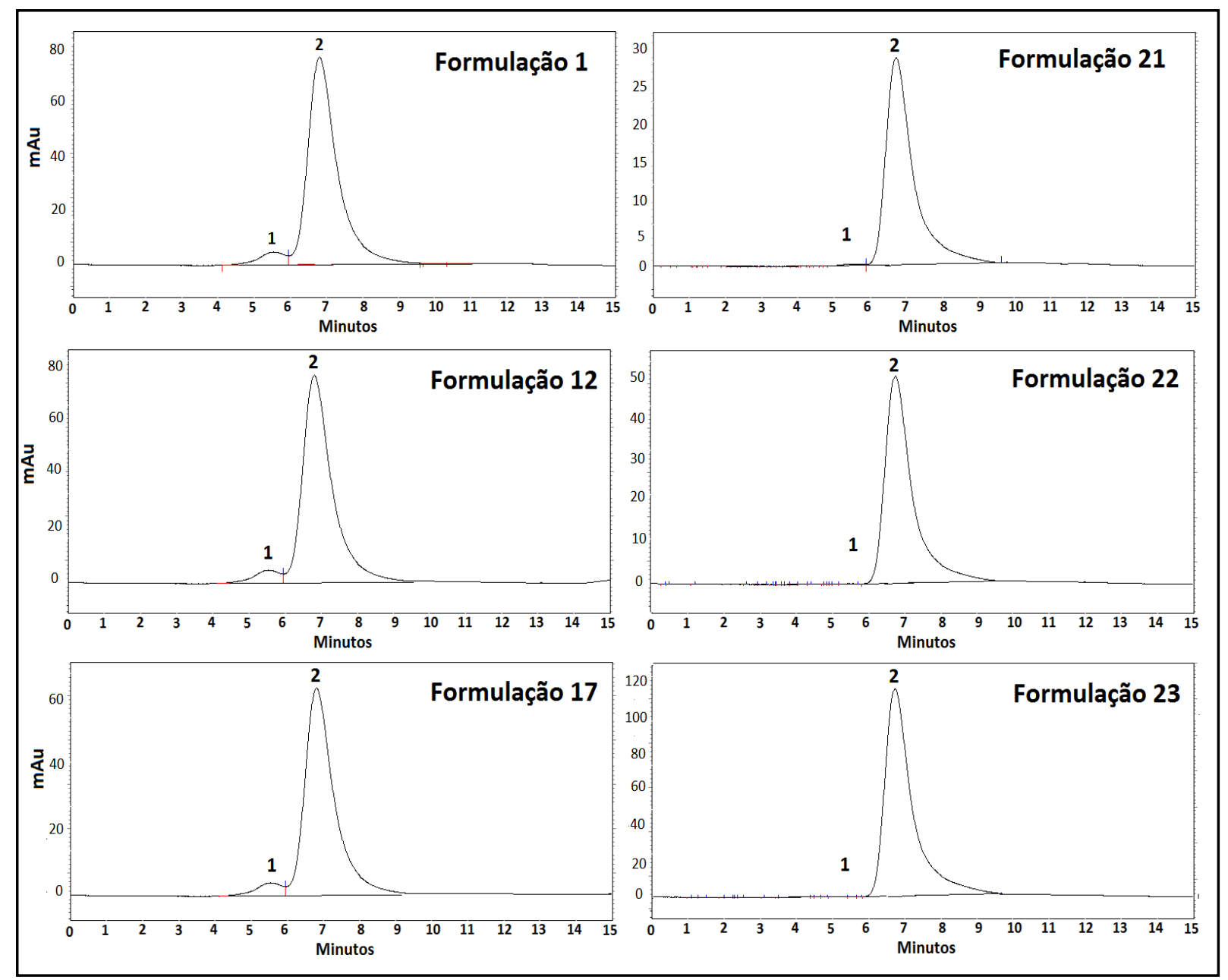

FIGURA 47 - Perfis cromatográficos por CLAE do imunoconjugado (formulações 1, 12 e 17) e do AcM não conjugado (formulações 21, 22 e 23) não acrescidos de quaisquer excipientes e liofilizados pelo protocolo 2. (1) = agregado; (2) = anti-CD20-DOTA.

Ademais, observou-se a formação de uma pequena pastilha (FIGURA 48) com pouco sinal de colapso macroscópico quando o AcM não conjugado foi liofilizado em uma concentração de 4 e $5 \mathrm{mg} / \mathrm{mL}$ (formulação 22 e 23). 


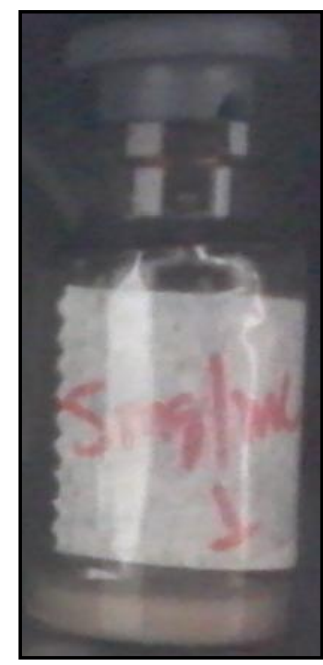

FIGURA 48 - Exemplo de formação de pastilha para o imunoconjugado liofilizado na concentração final de $5 \mathrm{mg} / \mathrm{mL}$.

Aparentemente, o fato de o AcM estar conjugado ao DOTA, interfere negativamente na obtenção de uma pastilha elegante, do mesmo modo que promove maior formação de agregados solúveis e insolúveis.

Isto é explicado em partes devido à composição original do MabThera ${ }^{\circledR}$ conter polissorbato 80 que por ser retirado antes do processo de conjugação, como citado no item 5.3.2.1, não está presente no imunoconjugado.

A formação da interface água:gelo durante o congelamento pode causar uma superfície hidrofóbica e provocar a desnaturação e/ou agregação de proteínas. Sulfactantes não-iônicos como o polissorbato 80 podem ser empregados para diminuir a superfície de tensão de proteínas em solução e estabilizá-las por se ligarem parcialmente às partes "desdobradas" da proteína de tal maneira que facilite o redobramento. Além disso, o uso de sulfactantes também pode ser útil para diminuir a agregação proteica ${ }^{136,141,147}$, e talvez por isso não foram encontrados agregados insolúveis bem como uma pequena quantidade de agregados solúveis nas formulações 21, 22 e 23 (TABELA 25).

Outro fator que poderia explicar a maior formação de agregados é a formação de bases de Schiff entre o quelante e a molécula de AcM. Estas bases são formadas geralmente quando o açúcar, utilizado como crioprotetor/lioprotetor, é reduzido e o grupo carbonil livre reage com um grupamento amino presente na proteína (geralmente resíduos de lisina e arginina). Esta reação é conhecida como reação de Maillard ${ }^{145}$. 
A reação de Maillard ocorre em especial quando açúcares como a glicose, lactose, maltose e maltodextrina são utilizados ${ }^{141}$. Mesmo que não ocorra reação de Maillard com o uso de manitol, é importante considerar que cada molécula de DOTA possui três grupos carboxílicos livres que podem formar bases de Schiff com os grupos amina presente nas porções desnaturadas do AcM que, como discutido anteriormente, ficaram expostas depois do processo de liofilização.

Como a diminuição da temperatura de congelamento e secagem primária não impediu a formação de partículas visíveis, avaliou-se um novo protocolo de liofilização (protocolo 4) com congelamento à $-40{ }^{\circ} \mathrm{C}$ e secagem primária à $-35^{\circ} \mathrm{C}$ por 24 horas.

Para este protocolo foram avaliadas diferentes concentrações finais do imunoconjugado $(2,4$ e $5 \mathrm{mg} / \mathrm{mL})$ com e sem adição de 2,5, 5 ou $10 \mathrm{mg}$ de manitol. Os resultados das análises antes e após a reconstituição estão apresentados na TABELA 26. 
TABELA 26 - Avaliação do imunoconjugado liofilizado em diferentes concentrações e acrescido de diferentes massas de manitol. As amostras foram liofilizadas pelo protocolo 4. Resultados expressos em média $\pm \mathrm{DP}(\mathrm{N}=3)$.

\begin{tabular}{|c|c|c|c|c|c|c|c|c|c|c|}
\hline \multirow[b]{2}{*}{ 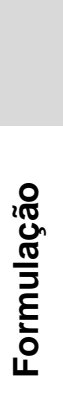 } & \multicolumn{2}{|c|}{ AMOSTRA } & \multirow[b]{2}{*}{ 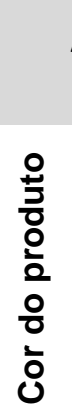 } & \multicolumn{3}{|c|}{$\begin{array}{l}\text { AVALIAÇÃO ANTES DA } \\
\text { RECONSTITUIÇÃO }\end{array}$} & \multicolumn{2}{|c|}{$\begin{array}{c}\text { AVALIAÇÃO } \\
\text { APÓS A } \\
\text { RECONSTITUIÇÃo }\end{array}$} & \multicolumn{2}{|c|}{ ANÁLISE POR CLAE } \\
\hline & 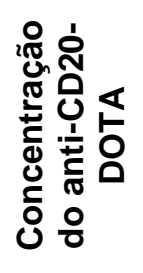 & \begin{tabular}{l}
$\stackrel{0}{ \pm}$ \\
$\frac{0}{0}$ \\
\hdashline$\frac{0}{0}$ \\
$x$ \\
ய
\end{tabular} & & $\begin{array}{l}\frac{0}{0} \\
\frac{\pi}{0} \\
\frac{0}{0} \\
\frac{1}{\pi} \\
\frac{1}{0} \\
\frac{10}{\pi} \\
\frac{0}{4}\end{array}$ & 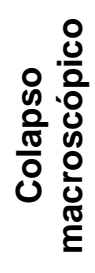 & 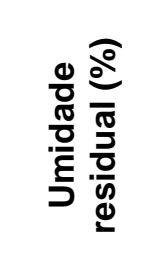 & $\frac{1}{2}$ & 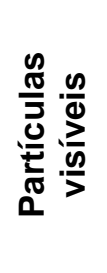 & 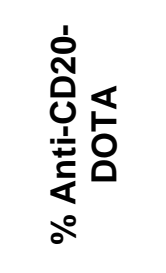 & $\begin{array}{l}\frac{0}{0} \\
\mathbb{0} \\
\frac{0}{1} \\
\frac{0}{0} \\
\circ \\
\circ\end{array}$ \\
\hline 3 & $2 \mathrm{mg} / \mathrm{mL}$ & $\begin{array}{c}2,5 \mathrm{mg} \\
\mathrm{Ma}\end{array}$ & 1 & Gel & S & $5,57 \pm 2,56$ & $6,50 \pm 0,04$ & $S$ & $99,74 \pm 0,02$ & $0,26 \pm 0,07$ \\
\hline 4 & $2 \mathrm{mg} / \mathrm{mL}$ & $5 \mathrm{mg} \mathrm{Ma}$ & 1 & Gel & S & $5,66 \pm 1,68$ & $6,55 \pm 0,07$ & $S$ & $99,91 \pm 0,09$ & $0,10 \pm 0,09$ \\
\hline 5 & $2 \mathrm{mg} / \mathrm{mL}$ & $\begin{array}{c}10 \mathrm{mg} \\
\mathrm{Ma}\end{array}$ & 1 & Gel & $S$ & $10,23 \pm 7,79$ & $6,47 \pm 0,09$ & $S$ & $99,93 \pm 0,09$ & $0,07 \pm 0,60$ \\
\hline 12 & $4 \mathrm{mg} / \mathrm{mL}$ & - & B & Pó & S & $12,94 \pm 1,30$ & $6,54 \pm 0,27$ & $\mathrm{~S}$ & $99,30 \pm 0,47$ & $0,70 \pm 0,47$ \\
\hline 13 & $4 \mathrm{mg} / \mathrm{mL}$ & $\begin{array}{c}2,5 \mathrm{mg} \\
\mathrm{Ma}\end{array}$ & B & Pó & $S$ & $12,79 \pm 4,83$ & $6,39 \pm 0,03$ & $S$ & $99,78 \pm 1,02$ & $0,22 \pm 0,10$ \\
\hline 14 & $4 \mathrm{mg} / \mathrm{mL}$ & $5 \mathrm{mg} \mathrm{Ma}$ & B & Pó & S & $5,48 \pm 1,80$ & $6,50 \pm 0,15$ & $S$ & $99,73 \pm 0,05$ & $0,27 \pm 0,05$ \\
\hline 15 & $4 \mathrm{mg} / \mathrm{mL}$ & $\begin{array}{c}10 \mathrm{mg} \\
\mathrm{Ma}\end{array}$ & B & Pó & $\mathrm{S}$ & $7,36 \pm 0,04$ & $6,51 \pm 0,11$ & $S$ & $99,82 \pm 0,17$ & $0,18 \pm 0,17$ \\
\hline 16 & $4 \mathrm{mg} / \mathrm{mL}$ & $\begin{array}{l}5 \mathrm{mg} \\
\mathrm{Ma}+ \\
9 \mathrm{mg} \\
\mathrm{NaCl}\end{array}$ & B & Pó & S & $8,60 \pm 1,22$ & $6,55 \pm 0,07$ & $\mathrm{~N}$ & $86,50 \pm 0,04$ & $13,87 \pm 0,04$ \\
\hline 17 & $5 \mathrm{mg} / \mathrm{mL}$ & - & B & Pastilha & S & $3,86 \pm 3,70$ & $6,51 \pm 0,22$ & S & $99,04 \pm 0,06$ & $0,96 \pm 0,06$ \\
\hline 18 & $5 \mathrm{mg} / \mathrm{mL}$ & $\begin{array}{c}2,5 \mathrm{mg} \\
\mathrm{Ma}\end{array}$ & B & Pastilha & $\mathrm{S}$ & $1,61 \pm 0,45$ & $6,54 \pm 0,02$ & S & $99,91 \pm 0,13$ & $0,09 \pm 0,13$ \\
\hline 19 & $5 \mathrm{mg} / \mathrm{mL}$ & $5 \mathrm{mg} \mathrm{Ma}$ & B & Pastilha & S & $8,37 \pm 6,31$ & $6,47 \pm 0,24$ & S & $99,68 \pm 0,45$ & $0,32 \pm 0,08$ \\
\hline 20 & $5 \mathrm{mg} / \mathrm{mL}$ & $\begin{array}{c}10 \mathrm{mg} \\
\mathrm{Ma}\end{array}$ & B & Pastilha & $\mathrm{S}$ & $7,78 \pm 1,98$ & $6,49 \pm 0,12$ & $\mathrm{~s}$ & $99,94 \pm 0,02$ & $0,06 \pm 0,02$ \\
\hline
\end{tabular}

Todas as formulações liofilizadas pelo protocolo 4 apresentaram colapso macroscópico da matriz. A adição de manitol não ajudou na formação da pastilha do imunoconjugado liofilizado na concentração de $2 \mathrm{mg} / \mathrm{mL}$ (formulações 3, 4 e 5).

Apenas quando se utilizou a concentração de $5 \mathrm{mg} / \mathrm{mL}$, observou-se formação de 
pastilha. Contudo, apesar do bom aspecto do produto final, todas as formulações que utilizaram esta concentração (formulações 17, 18, 19 e 20) apresentaram partículas visíveis após a reconstituição com tampão acetato de amônio.

Dentre todas as formulações estudadas, apenas a formulação 16 não apresentou partículas visíveis após a reconstituição.

No entanto, a formação de agregados solúveis foi muito maior do que em todos os outros lotes e formulações estudadas, como é possível observar na FIGURA 49.

Esta formulação foi proposta por Wojdowska e colaboradores (2015) ${ }^{109}$ e segundo os autores, no desenvolvimento de uma formulação ótima, foram preparados mais de 20 lotes com diversas formulações. Infelizmente, os autores não detalharam as etapas deste desenvolvimento, nem tão pouco o protocolo de liofilização utilizado. Além disso, não foi relatada a quantidade e/ou presença de agregados solúveis e insolúveis para o produto liofilizado não radiomarcado. 


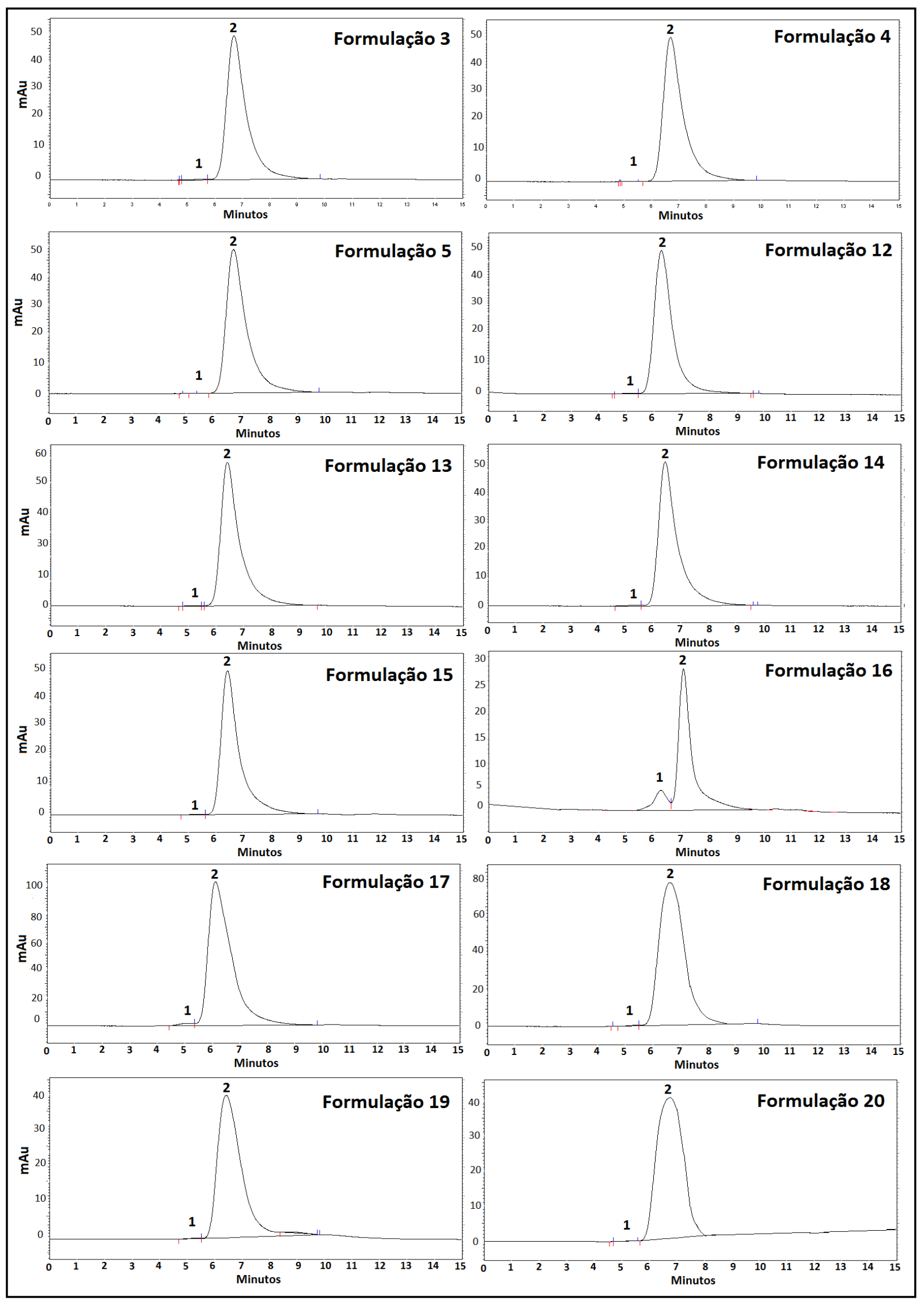

FIGURA 49 - Perfis cromatográficos por CLAE do imunoconjugado em diferentes concentrações finais e liofilizado pelo protocolo 4 . 0 imunoconjugado foi acrescido ou não de diferentes excipientes. $(1)$ = agregado; $(2)$ = anti-CD20-DOTA. 
Apesar da grande quantidade de agregados solúveis, a ausência de partículas visíveis possibilitou a continuação dos estudos com este produto.

$\mathrm{O}$ AcM conjugado ao DOTA pelo método 2 de conjugação $\left(2 \mathrm{~h}\right.$ a $\left.37^{\circ} \mathrm{C}\right)$ também foi acrescido de $5 \mathrm{mg}$ de manitol e $9 \mathrm{mg}$ de $\mathrm{NaCl}$ e liofilizado pelo protocolo 4 . Os resultados da comparação entre os AcM conjugados pelos dois métodos de conjugação e liofilizados nas condições citadas acima, estão expressos na TABELA 27.

TABELA 27 - Comparação entre o AcM conjugado pelo método 1 e 2 de conjugação, acrescido de excipientes (formulação 16) e liofilizado pelo protocolo 4. Resultados expressos em média $\pm \mathrm{DP}(\mathrm{N}=3)$.

\begin{tabular}{|c|c|c|c|c|c|c|c|c|c|c|}
\hline \multirow[b]{2}{*}{ 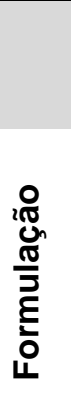 } & \multicolumn{2}{|c|}{ AMOSTRA } & \multicolumn{4}{|c|}{$\begin{array}{l}\text { AVALIAÇÃO ANTES DA } \\
\text { RECONSTITUIÇÃOO }\end{array}$} & \multicolumn{2}{|c|}{$\begin{array}{c}\text { AVALIAÇÃO } \\
\text { APÓS A } \\
\text { RECONSTITUIÇÃO }\end{array}$} & \multicolumn{2}{|c|}{ ANÁLISE POR CLAE } \\
\hline & 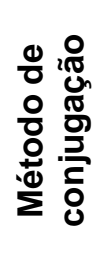 & 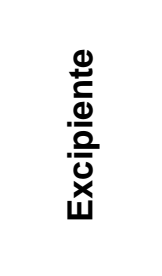 & 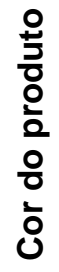 & 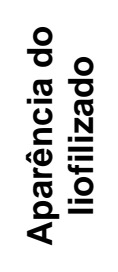 & 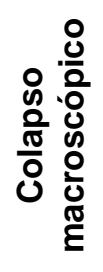 & 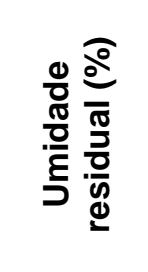 & 증 & 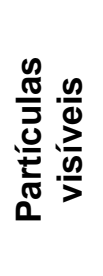 & 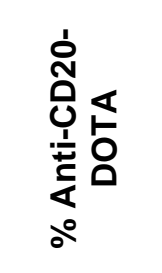 & 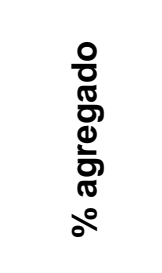 \\
\hline 16 & 1 & $\begin{array}{l}5 \mathrm{mg} \mathrm{Ma}+ \\
9 \mathrm{mg} \mathrm{NaCl}\end{array}$ & B & Pó & S & $8,60 \pm 1,22$ & $6,55 \pm 0,07$ & $\mathrm{~N}$ & $86,50 \pm 5,68$ & $13,50 \pm 5,68$ \\
\hline 16 & 2 & $\begin{array}{l}5 \mathrm{mg} \mathrm{Ma}+ \\
9 \mathrm{mg} \mathrm{NaCl}\end{array}$ & B & Pó & $\mathrm{S}$ & $8,85 \pm 1,34$ & $6,47 \pm 0,12$ & $\mathrm{~N}$ & $86,13 \pm 0,04$ & $13,87 \pm 0,04$ \\
\hline
\end{tabular}

$\mathrm{B}=$ Branco; $\mathrm{M}=$ Manitol; $\mathrm{S}=\mathrm{Sim} ; \mathrm{N}=\mathrm{Não}$

Em ambos os lotes foi observada a formação de um pó branco com microbolhas, caracterizando o colapso da matriz. Todavia, a reconstituição do produto foi rápida e completa não sendo observada presença de partículas visíveis.

Não foram encontradas diferenças entre a umidade residual $(P=0,8229)$, quantidade de imunoconjugado $(P=0,9543)$ e agregados solúveis $(P=0,9156)$ entre os dois.

Os perfis cromatográficos por CLAE, indicaram que não houve quebra do AcM ou desacoplamento do quelante devido ao processo de liofilização para os dois imunoconjugados analisados (FIGURA 50). 


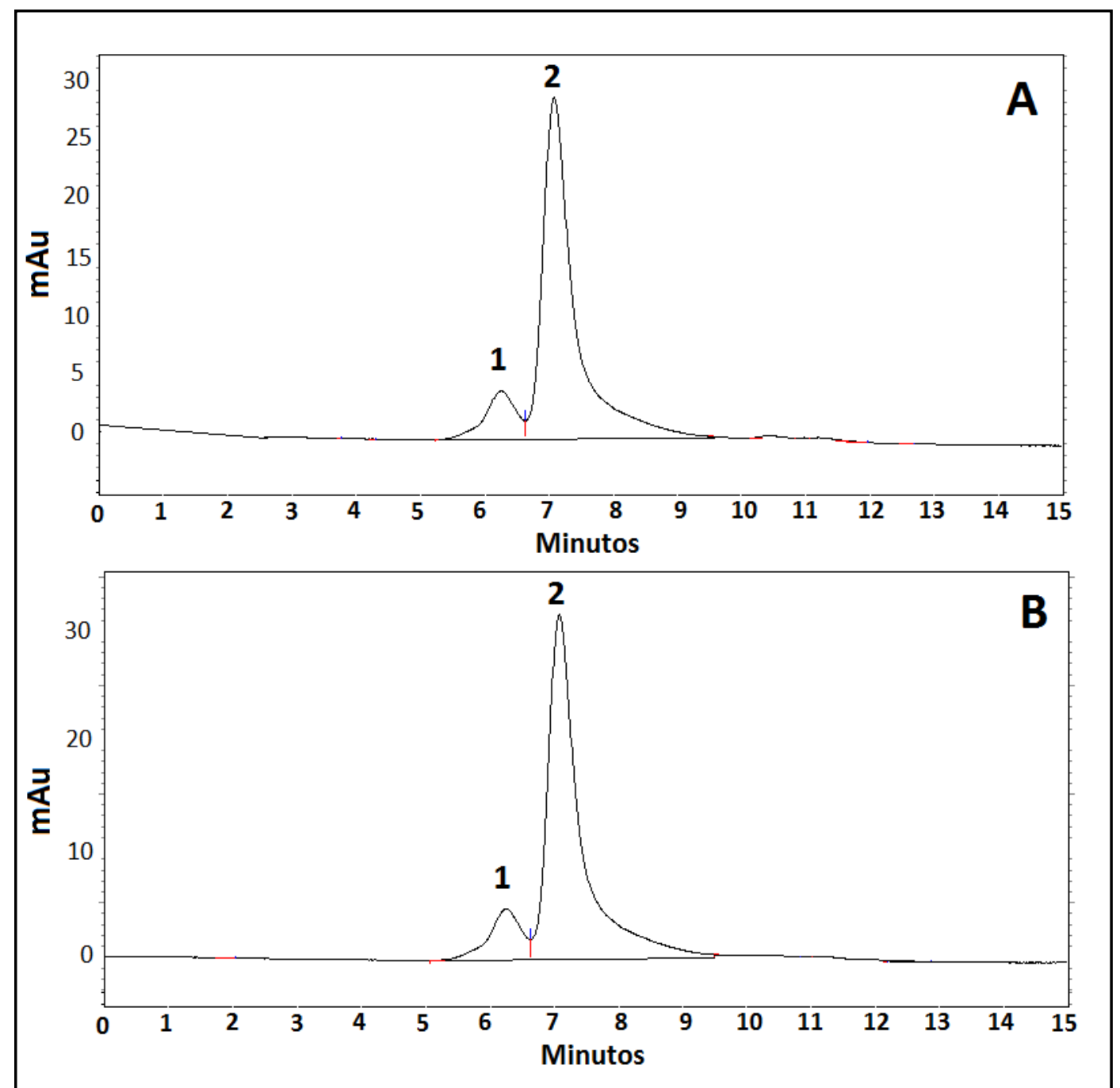

FIGURA 50 - Perfis cromatográficos por CLAE do imunoconjugado (formulação 16) liofilizado pelo protocolo 4, Em (A), AcM conjugado pelo método 1 de conjugação e em (B), AcM conjugado pelo método 2 de conjugação. (1) = agregado; (2) = anti-CD20-DOTA.

Os resultados obtidos nesta etapa permitiram concluir que o protocolo 4 foi o melhor protocolo testado e a formulação ideal a ser utilizada para liofilização do imunoconjugado é acrescentando-se $5 \mathrm{mg}$ de manitol, $9 \mathrm{mg}$ de $\mathrm{NaCl}$ e $2 \mathrm{mg}$ do imunoconjugado em $400 \mu \mathrm{L}$ de tampão acetato de amônio 0,25 M pH 6,5, conferindo uma concentração final de $4 \mathrm{mg} / \mathrm{mL}$ de imunoconjugado.

Estas foram as condições estabelecidas para a liofilização do imunoconjugado e realização dos demais ensaios. 


\subsubsection{Análise da integridade estrutural do imunoconjugado liofilizado por eletroforese em} gel de poliacrilamida

A integridade estrutural constatada por CLAE (FIGURA 50) foi confirmada pela análise em gel de poliacrilamida. Os dois imunoconjugados liofilizados e reduzidos por tampão redutor, apresentaram duas bandas no gel de poliacrilamida com peso molecular de aproximadamente $50 \mathrm{kDa}$ e $25 \mathrm{kDa}$ (FIGURA 51). Estas bandas correspondem à cadeia pesada e à cadeia leve da molécula de IgG que foram separadas devido à quebra das pontes de dissulfeto.

As mesmas bandas com o mesmo padrão de peso molecular foram observadas para o AcM não conjugado, indicando que não houve degradação do AcM devido à conjugação e liofilização (FIGURA 51).

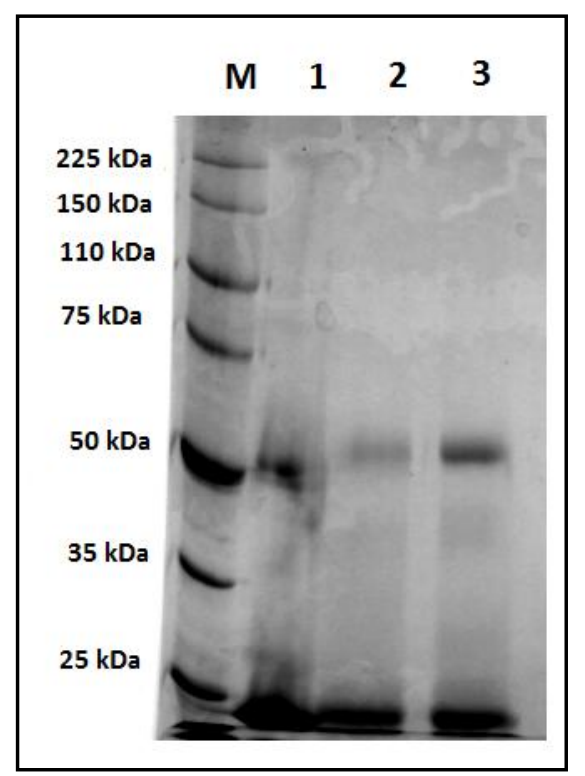

FIGURA 51 - SDS-PAGE do imunoconjugado liofilizado pelo protocolo 4 após a reconstituição. Em (1) AcM anti-CD20 não conjugado; em (2) AcM conjugado ao DOTA pelo método 1 de conjugação e em (3) AcM conjugado ao DOTA pelo método 2 de conjugação. $M=$ marcador de peso molecular.

O padrão de SDS-PAGE encontrado neste trabalho foi similar ao encontrado por Heljo e colaboradores (2013) ${ }^{96}$. Eles concluíram que o espaço encontrado entre a primeira e segunda banda, indicou que o processo de liofilização não formou novas ligações covalentes intramoleculares as quais poderiam não ser quebradas sob as condições de redução. Este resultado indica que o uso de manitol como excipiente, como já esperado, ${ }^{145}$ não levou à 
degradação via reação de Maillard.

\subsubsection{Radiomarcação com Lu-177}

O imunoconjugado liofilizado foi reconstituído e radiomarcado com baixa e alta atividade de Lu-177, sempre com atividade específica de $740 \mathrm{MBq} / \mathrm{mg}$.

A pureza radioquímica, sem purificação após a radiomarcação, foi superior a $80 \%$ para os imunoconjugados obtidos pelos dois métodos de conjugação (FIGURA 52 e FIGURA $53)$.

Apesar do rendimento de radiomarcação ter sido maior para o anticorpo conjugado pelo método 2 , esta diferença não foi significativa, tanto para a radiomarcação com baixa atividade ( $P=0,2332$ - FIGURA 52), quanto para a radiomarcação com $1.480 \mathrm{MBq}$ de Lu-177 ( $P=0,7521$ - FIGURA 53).

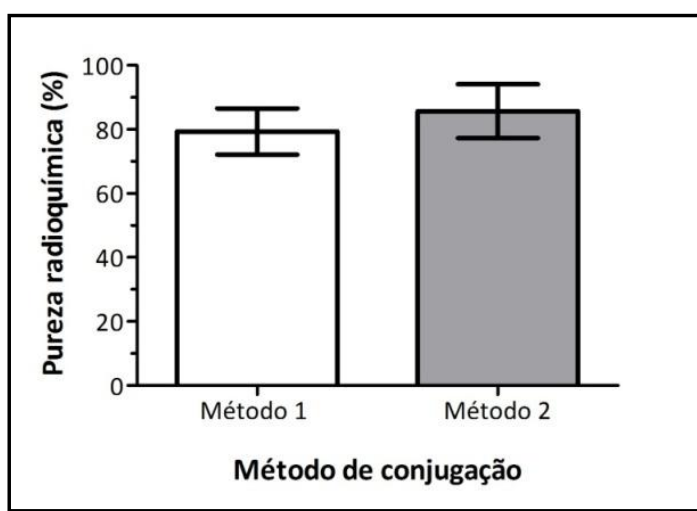

FIGURA 52 - Pureza radioquímica (imediato não purificado) do AcM conjugado pelos dois métodos de conjugação e liofilizados pelo protocolo 4. Condições de radiomarcação: $\mathbf{0 , 2} \mathbf{~ m g ;}$ $148 \mathrm{MBq}(740 \mathrm{MBq} / \mathrm{mg})$; tampão acetato de amônio 0,25 M pH 6,5. Resultados expressos em média $\pm D P(N=5)$. 


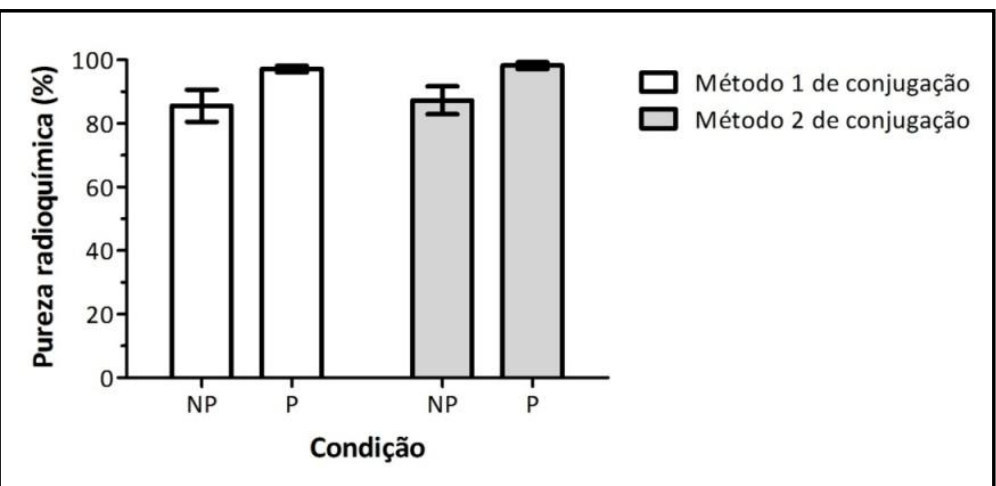

FIGURA 53 - Pureza radioquímica do AcM conjugado pelos dois métodos de conjugação e liofilizados pelo protocolo 4. Condições de radiomarcação: 2 mg; 1.480 MBq (740 MBq/mg); tampão acetato de amônio $0,25 \mathrm{M} \mathrm{pH} \mathrm{6,5} \mathrm{(NP=} \mathrm{não} \mathrm{purificado} \mathrm{e} \mathrm{P}=$ purificado). Resultados expressos em média $\pm \mathrm{DP}(\mathrm{N}=5$ para método 1 de conjugação e $\mathrm{N}=2$ para método 2 de conjugação).

Após a purificação em coluna PD-10, obteve-se um radioimunoconjugado com pureza superior a $97 \%$ em ambas as condições estudadas ( $P=0,4027)$, como observado na FIGURA 53.

Este resultado foi superior ao encontrado por Gholipour e colaboradores (2014) ${ }^{121}$ que obtiveram pureza radioquímica, pós purificação, igual a 92\% e 84\%, quando o radioimunoconjugado (rituximabe-DOTA) liofilizado foi radiomarcado com In-111 e Y-90 respectivamente (atividade específica de $566 \mathrm{MBq} / \mathrm{mg}$ ).

\subsubsection{Estudo da estabilidade do anti-CD20-DOTA- ${ }^{177}$ Lu em condições de transporte}

O imunoconjugado liofilizado e radiomarcado com alta atividade de Lu-177 teve sua estabilidade avaliada da mesma maneira que o imunoconjugado não liofilizado e radiomarcado nas mesmas condições (capítulo 5).

O AcM conjugado pelo método 1 (FIGURA 54) apresentou melhor estabilidade após o armazenamento por 24 horas à $-20^{\circ} \mathrm{C}$, seguido de armazenamento por 6 horas a 2 - 8 ${ }^{\circ} \mathrm{C}(\mathrm{P}=0,0243)$ e após 48 horas sob as mesmas condições $(P=0,0001)$, quando comparado ao AcM conjugado pelo método 2 (FIGURA 55). Todavia, ambos tiveram pureza radioquímica superior a 90\%, em todos os tempos e condições estudadas. 


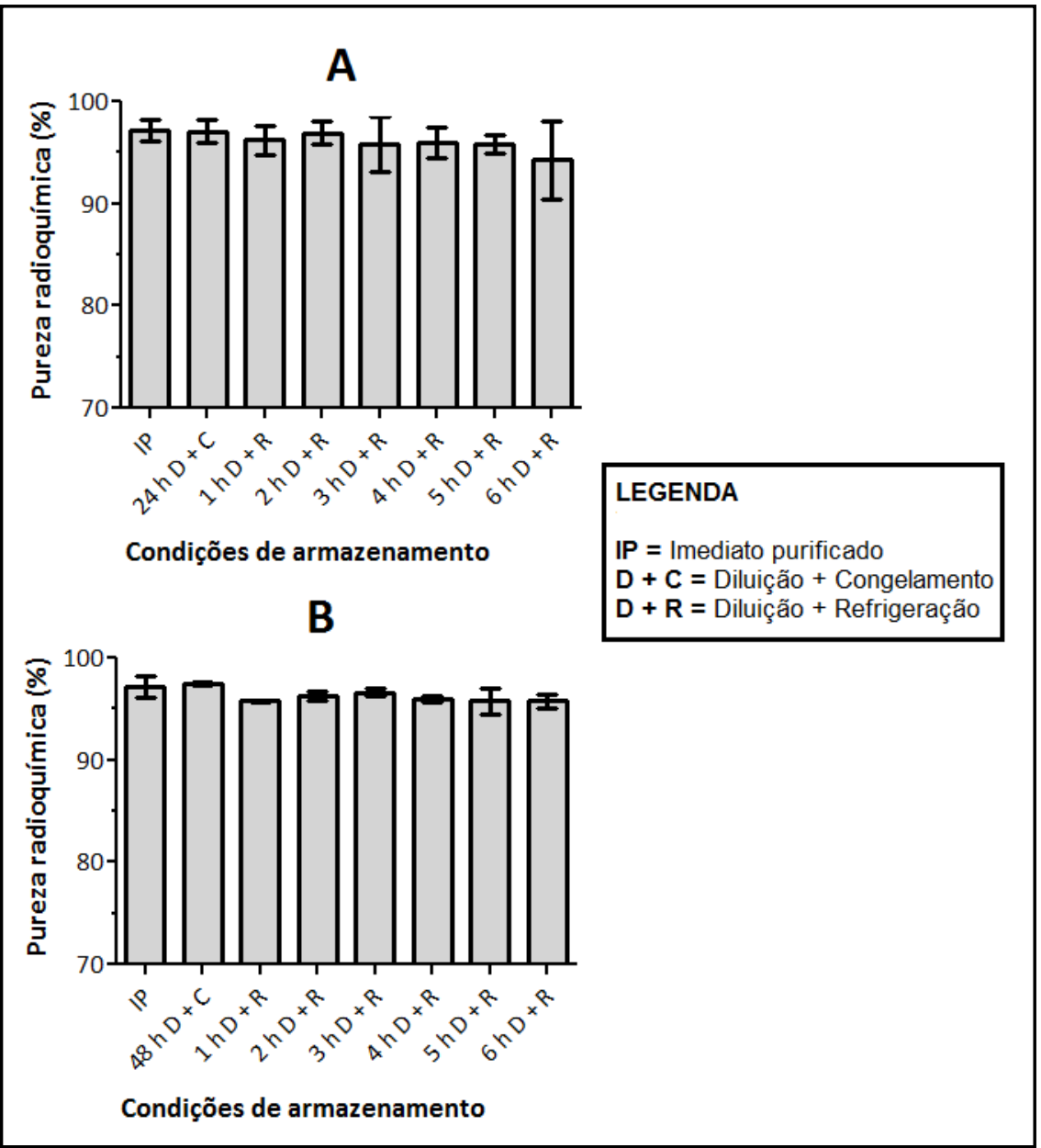

FIGURA 54 - Estabilidade do AcM conjugado pelo método 1 de conjugação, liofilizado e radiomarcado com alta atividade de Lu-177 (2 mg / $1.480 \mathrm{MBq} ; 740 \mathrm{MBq} / \mathrm{mg}$ ). Em (A), resultados da estabilidade após armazenamento por 24 horas à $-20{ }^{\circ} \mathrm{C}$, seguido de armazenamento por 6 horas a $2-8^{\circ} \mathrm{C}$ e em (B), após armazenamento por 48 horas à $-20^{\circ} \mathrm{C}$, seguido de armazenamento por 6 horas a $2-8{ }^{\circ} \mathrm{C}$. Resultados obtidos por CCD e expressos em média $\pm \mathrm{DP}(\mathrm{N}=2)$. 


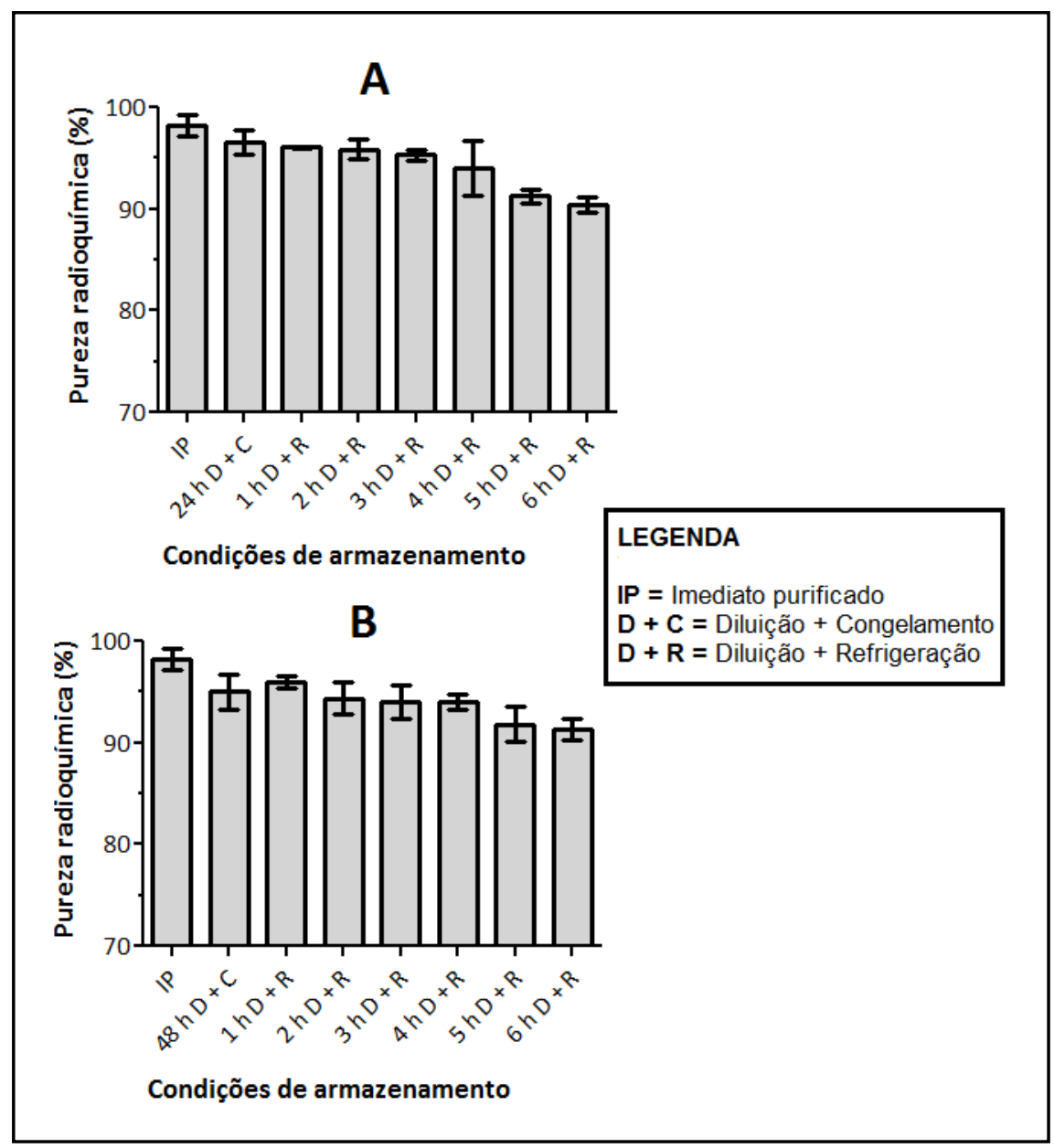

FIGURA 55 - Estabilidade do AcM conjugado pelo método 2 de conjugação, liofilizado e radiomarcado com alta atividade de Lu-177 (2 mg / $1.480 \mathrm{MBq} ; 740 \mathrm{MBq} / \mathrm{mg}$ ). Em (A), resultados da estabilidade após armazenamento por 24 horas à $-20{ }^{\circ} \mathrm{C}$, seguido de armazenamento por 6 horas a $2-8^{\circ} \mathrm{C}$ e em (B), após armazenamento por 48 horas à $-20^{\circ} \mathrm{C}$, seguido de armazenamento por 6 horas a $2-8{ }^{\circ} \mathrm{C}$. Resultados obtidos por CCD e expressos em média $\pm \mathrm{DP}(\mathrm{N}=2)$.

A instabilidade maior encontrada para o método 2 (FIGURA 55) está associada à presença, em maior quantidade, de DOTA- ${ }^{177}$ Lu quando comparado a ${ }^{177}$ Lu livre, como é possível observar na FIGURA 56. 


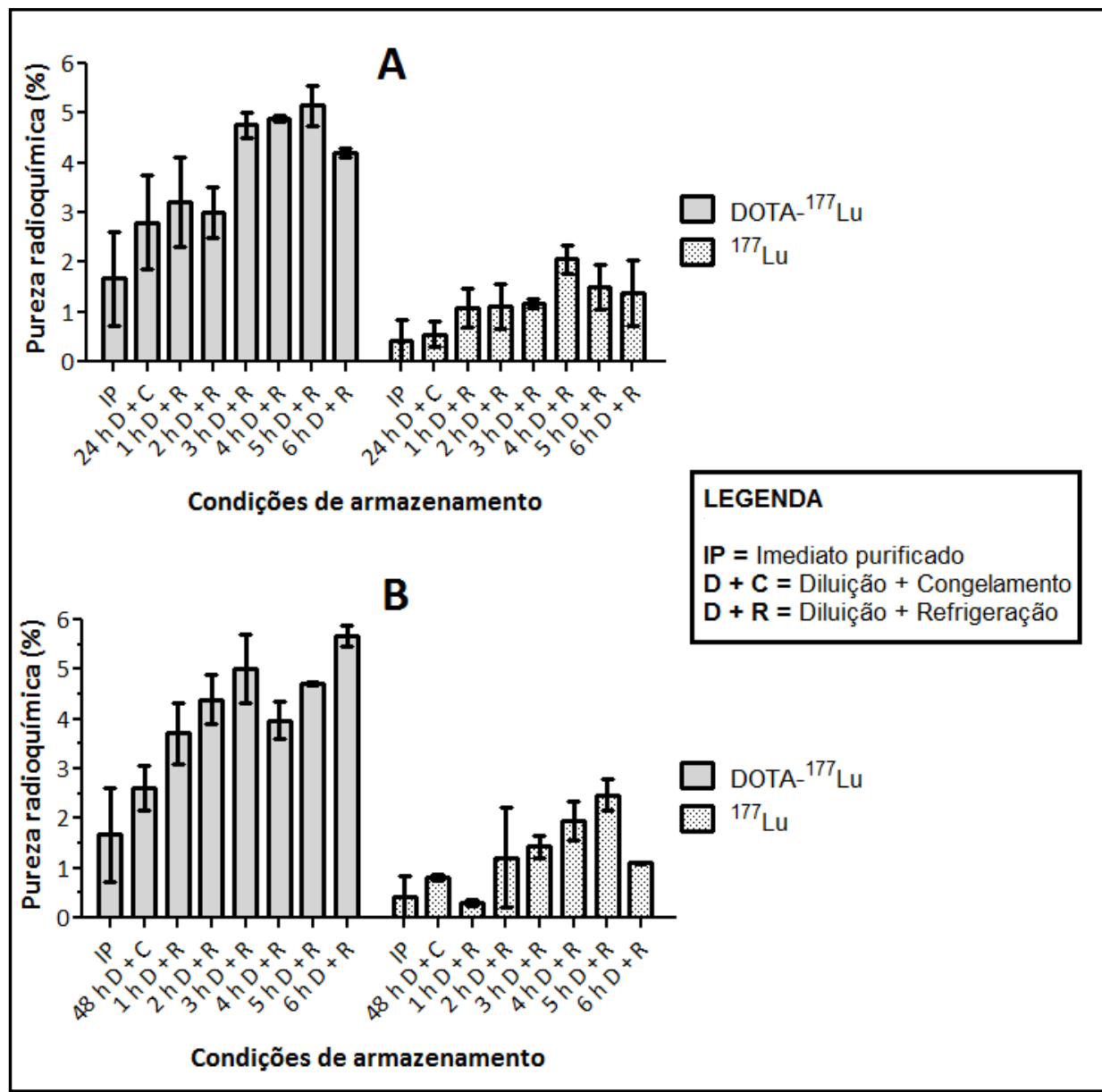

FIGURA 56 - Quantificação das impurezas presentes no estudo de estabilidade do AcM conjugado pelo método 2 de conjugação, liofilizado e radiomarcado com alta atividade de Lu-177 (2 mg / $1.400 \mathrm{MBq} ; 740 \mathrm{MBq} / \mathrm{mg}$ ). Em (A), resultados da estabilidade após armazenamento por 24 horas à $-20^{\circ} \mathrm{C}$, seguido de armazenamento por 6 horas a $2-8{ }^{\circ} \mathrm{C}$ e em (B), após armazenamento por 48 horas à $-20^{\circ} \mathrm{C}$, seguido de armazenamento por 6 horas a $2-8^{\circ} \mathrm{C}$. Resultados obtidos por $\mathrm{CCD}$ e expressos em média $\pm \mathrm{DP}(\mathrm{N}=2)$.

Observaou-se que a quantidade de DOTA- ${ }^{177} \mathrm{Lu}$ aumentou com o tempo de armazenamento do anti-CD20-DOTA $-{ }^{177} \mathrm{Lu}$ tanto para o tempo de 24 horas após a radiomarcação (FIGURA 56 A), quanto para o tempo de 48 horas após a radiomarcação (FIGURA 56 B).

Aparentemente a quantidade maior de quelantes acoplados ao AcM no método 2 de conjugação torna estas ligações mais instáveis e promove, preferencialmente, a clivagem das ligações entre o quelante e o AcM quando o anti-CD20-DOTA- ${ }^{177}$ Lu é submetido a períodos longos de armazenamento. 


\subsubsection{Análise da Imunorreatividade do imunoconjugado liofilizado}

Conforme discutido anteriormente no capítulo 5, a imunorreatividade de um AcM é a principal propriedade que se deve preservar quando se desenvolve radioimunoterápicos.

O estudo em células Raji indicou que após a liofilização, o AcM conjugado pelo método 1 de conjugação perdeu $2,5 \%$ da sua imunorreatividade quando comparado ao imunoconjugado não liofilizado (de $89,3 \%$ para $86,8 \%$ ), porém, esta diminuição não foi significativa $(P=0,8993)$. Já para o $A c M$ conjugado pelo método 2 de conjugação, não foi observada perda da imunorreatividade (de $74,3 \%$ para $74,6 \%$ ) (FIGURA 57).

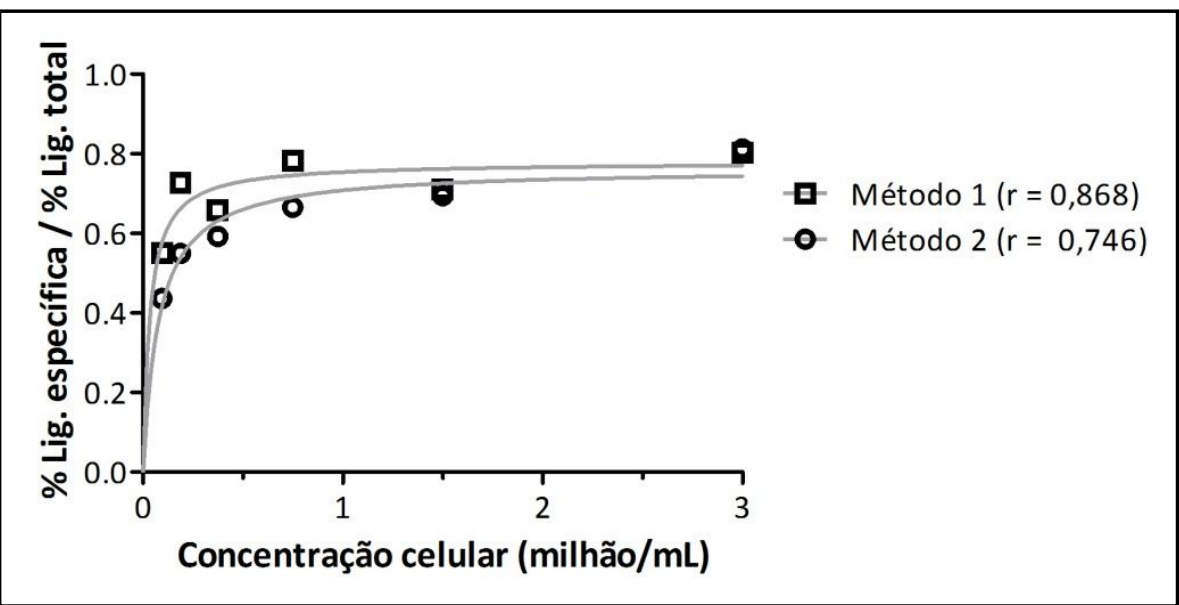

FIGURA 57 - Imunorreatividade após a liofilização do anti-CD20 conjugado pelos dois métodos de conjugação $(\mathrm{N}=3)$.

Os resultados de imunorreatividade para o imunoconjugado liofilizado foram considerados altos, comparados aos encontrados por Gholipour e colaboradores (2014) ${ }^{121}$ que obtiveram imunorreatividade de $47,3 \%$ para o rituximabe conjugado ao p-SCN-BZ-DOTA na razão molar 1:25 e liofilizado em presença de $8 \mathrm{mg}$ de manitol por miligrama de imunoconjugado, ao passo que neste trabalho, foram utilizados $2,5 \mathrm{mg}$ de manitol por miligrama de imunoconjugado.

Resultados semelhantes ao encontrado neste trabalho, também foram obtidos por Forrer e colaboradores que lioflizaram $5 \mathrm{mg}$ de rituximabe conjugado ao DOTA acrescentando $20 \mathrm{mg}$ de manitol. Esta concentração alta de manitol aparentemente preservou a imonorreatividade do AcM, já que o valor obtido foi de $84,7 \%$. A razão molar 
utilizada foi 1:10 e quatro quelantes se acoplaram ao $\mathrm{AcM}^{51}$.

A comparação mais próxima que poderia ser feita seria com os estudos realizados por Wojdowska e colaboradores (2015) ${ }^{109}$, uma vez que a mesma formulação e anticorpo foram utilizados. Todavia, os autores não relataram os resultados de imunorreatividade encontrado para o imunoconjugado liofilizado.

\subsubsection{Comparação entre o imunoconjugado não liofilizado e liofilizado}

Conforme abordado anteriormente, o desenvolvimento de um imunoconjugado liofilizado para pronta marcação busca agregar valor ao produto, aumentando o tempo de prateleira do imunoconjugado e facilitando a rotina de produção deste radiofármaco.

No entanto, se o processo de liofilização causar diminuição no rendimento de radiomarcação ou diminuição da imunorreatividade do AcM, a liofilização deixa de ser vantajosa.

Os resultados que comparam o imunoconjugado não liofilizado e liofilizado foram, até então, apresentados separadamente ao longo do capítulo 5 e 7 . Nesta seção, os principais resultados de radiomarcação com atividade alta de Lu-177 (2 mg / 1.480 MBq) e os valores de imunorreatividades obtidos são abordados conjuntamente para permitir a comparação.

Na FIGURA 58, estão apresentados os valores de pureza radioquímica obtidos para o AcM conjugado pelo método 1 de conjugação.

Não foram observadas diferenças entre as purezas radioquímicas obtidas para o anti-CD20-DOTA- ${ }^{177}$ Lu não liofilizado e liofilizado antes da purificação (INP - NL e INP - L; $\mathrm{P}=0,7515)$, bem como para o anti-CD20-DOTA- ${ }^{177} \mathrm{Lu}$ não liofilizado e liofilizado após a purificação (IP - NL e IP - L; P=0,2936). 


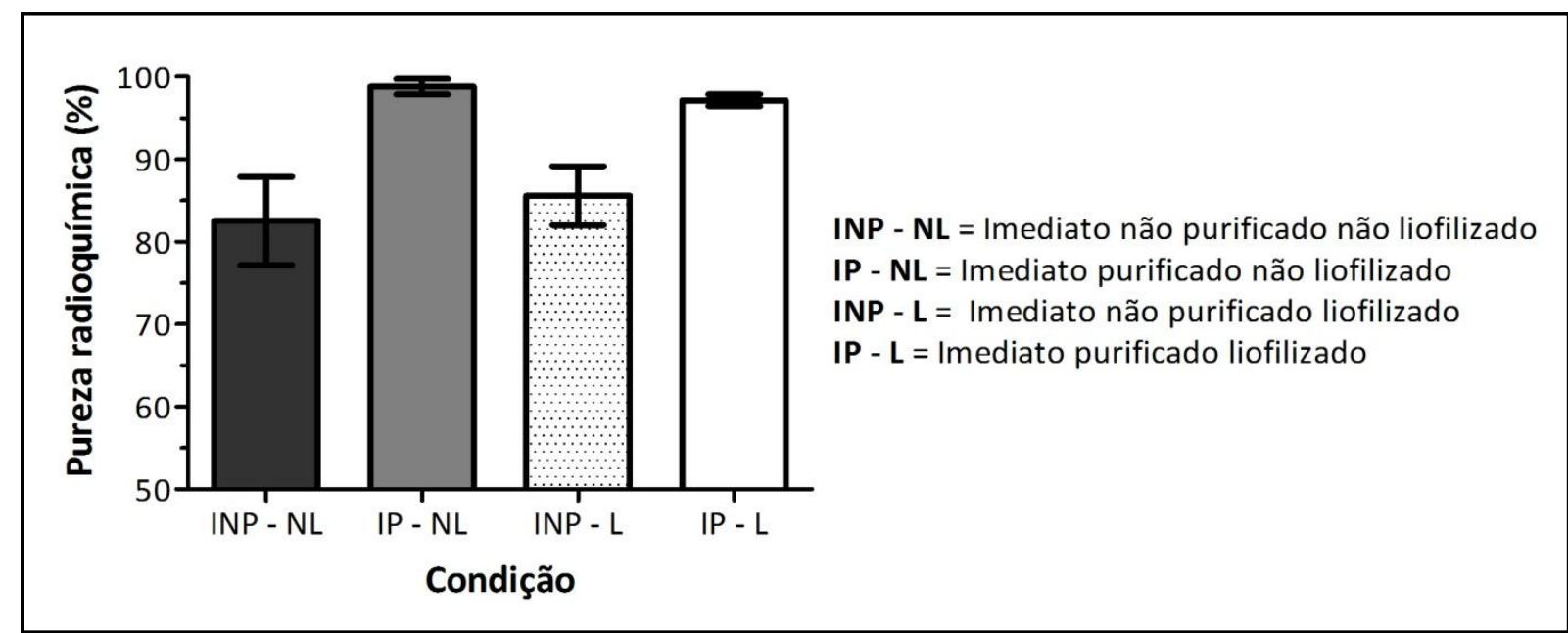

FIGURA 58 - Comparação da pureza radioquímica obtida após a radiomarcação de $2 \mathrm{mg}$ de AcM conjugado pelo método 1 e radiomarcado com $1.480 \mathrm{MBq}$ de $\mathrm{Lu}-177$ (740 MBq/mg). Radiomarcações realizadas com o imunoconjugado não liofilizado $(N=5)$ e liofilizado $(N=2)$. Resultados expressos em média \pm EPM.

Na FIGURA 59, estão apresentados os valores de pureza radioquímica obtidos para o AcM conjugado pelo método 2 de conjugação.

O método 2 de conjugação apresentou pureza radioquímica mais alta, em relação ao método 1 , apenas quando $0,2 \mathrm{mg}$ dos imunoconjugados foram radiomarcados com $148 \mathrm{MBq}$ (4 mCi) de Lu-177 e somente para os imunoconjugados não liofilizados. Estes resultados foram apresentados no capítulo 5, FIGURA 29.

No entanto, quando os imunoconjugados foram liofilizados e radiomarcados, não houve diferença na pureza radioquímica, tanto na condição de 0,2 mg / $148 \mathrm{MBq}(4 \mathrm{mCi})$, quanto na condição de $2 \mathrm{mg} / 1.480 \mathrm{MBq}(40 \mathrm{mCi})$. Estes resultados foram apresentados nas FIGURA 52 e FIGURA 53.

Também não foram observadas diferenças entre as purezas radioquímicas obtidas para o radioimunoconjugado não liofilizado e liofilizado antes da purificação (INP NL e INP - L; P=0,8543), bem como para o radioimunoconjugado não liofilizado e liofilizado após a purificação (IP - NL e IP - L; P=0,2766), conforme é possível observar na FIGURA 59. 


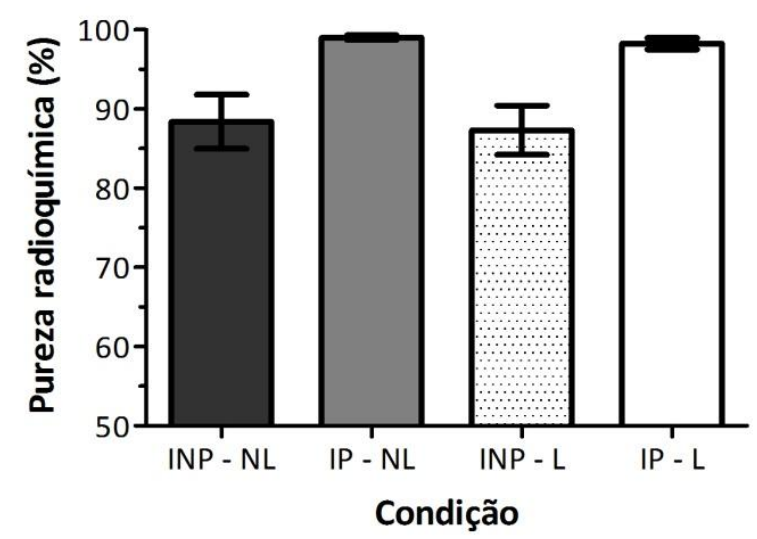

INP - NL = Imediato não purificado não liofilizado IP - NL = Imediato purificado não liofilizado INP - L = Imediato não purificado liofilizado IP - L = Imediato purificado liofilizado

FIGURA 59 - Comparação da pureza radioquímica obtida após a radiomarcação de $2 \mathrm{mg}$ de AcM conjugado pelo método 2 e radiomarcado com $1.480 \mathrm{MBq}$ de $\mathrm{Lu}-177$ (740 MBq/mg). Radiomarcações realizadas com o imunoconjugado não liofilizado $(N=5)$ e liofilizado $(N=2)$. Resultados expressos em média \pm EPM.

Estes resultados indicam que se uma etapa de purificação após a radiomarcação for empregada, ambos os métodos de conjugação fornecerão radioimunoconjugados com pureza radioquímica superior a 95\% tanto antes quanto após a liofilização.

Radiofármacos para terapia necessitam apresentar pureza radioquímica superior a $95 \%{ }^{15}$, tanto que na ausência desta pureza, a administração do ibritumomab-tiuxetan- ${ }^{90} \mathrm{Y}$ (Zevalin ${ }^{\circledR}$ ) é desaconselhada pelo fabricante ${ }^{148}$.

Natarajan e colaboradores (2015) proporam um método de síntese semiautomatizada do rituximabe-DOTA ${ }^{64} \mathrm{Cu}$ que se adequa às Boas Práticas de Fabricação e inclui as etapas de purificação após a radiomarcação e esterilização por filtro de 0,22 $\mu \mathrm{m}$ do produto final ${ }^{87}$. O desenvolvimento de um método similar facilitaria a rotina de produção, além de evitar contaminação microbiológica do produto devido à manipulação.

Analisando as curvas de ligação celular obtidas nos ensaios de imunorreatividade dos quatro imunoconjugados (FIGURA 60) (AcM conjugado pelo método 1 e 2, não liofilizado e liofilizado), observou-se que não houveram diferenças significativas no perfil de ligação às células $(P=0,5288)$. 


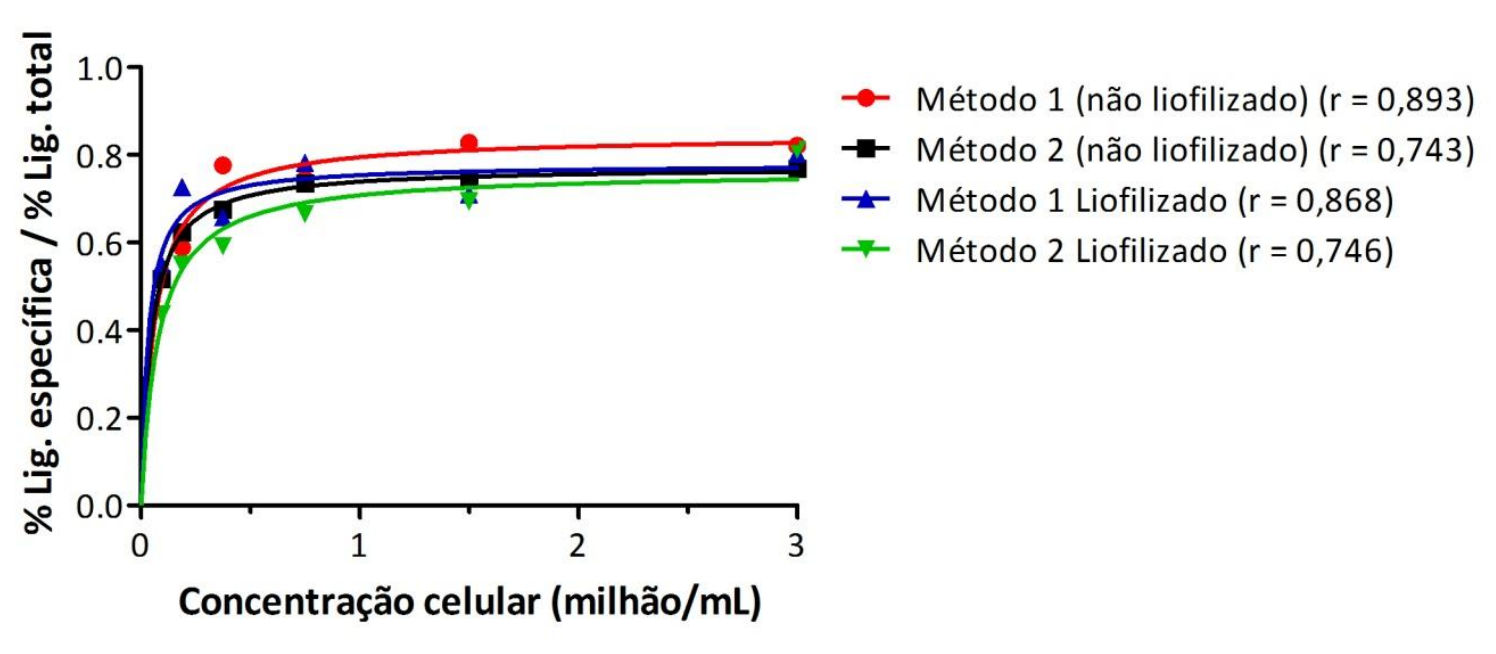

FIGURA 60 - Imunorreatividade do AcM conjugado pelos métodos 1 e 2 antes e após a liofilização $(\mathrm{N}=3)$.

Considerando que a formação de agregados proteicos indica que houve desnaturação da proteína e analisando os resultados expressos nas FIGURA 51 e FIGURA 60, conclui-se que esta desnaturação parcial não causou dano estrutural e tão pouco diminuição significativa da imunorreatividade do AcM.

Os resultados promissores obtidos para o imunoconjugado liofilizado representam maior praticidade de produção para o IPEN, uma vez que lotes grandes poderiam ser produzidos, armazenados e radiomarcado de acordo com a necessidade de produção/comercialização. Além disso, a comercialização do produto liofilizado é uma alternativa para radiomarcação em radiofarmácia centralizada ou hospitalar, como já é feito com os kits liofilizados para radiomarcação com Tc-99m. 


\subsection{CONCLUSÕES}

Os resultados encontrados nesta etapa do estudo permitiram concluir:

$\checkmark$ foi possível liofilizar o anti-CD20-DOTA, todavia houve formação de agregados indicando desnaturação parcial do AcM, em pequena porcentagem;

$\checkmark$ a desnaturação parcial não afetou consideravelmente a estrutura e a imunorreatividade do anti-CD20-DOTA;

$\checkmark$ o imunoconjugado liofilizado apresentou rendimento de marcação similar ao não liofilizado, quando radiomarcado com atividade específica de $740 \mathrm{MBq} / \mathrm{mg}$ e pureza radioquímica superior a 97\% após a purificação em coluna PD-10;

$\checkmark$ o radioimunoconjugado apresentou estabilidade alta por mais de 48 horas após a radiomarcação, sendo possível a logística para lugares distantes do centro produtor (IPEN);

$\checkmark$ todas estas características citadas acima foram evidenciadas para o imunoconjugado obtido pela conjugação ao DOTA para os dois métodos de conjugação indicando que ambos podem ser utilizados para obtenção de um imunoconjugado liofilizado com alta eficiência de radiomarcação. 


\section{CONCLUSÕES FINAIS}

A produção de um imunoconjugado para radiomarcação envolve múltipas etapas e cada uma apresenta um desafio com muitos parâmetros a serem estudados. Por este motivo, a principal contribuição deste trabalho, não foi apenas desenvolver um radioimunoconjugado nacional, mas consolidar esta tecnologia no IPEN de forma que o desenvolvimento de outros radiofármacos derivados de AcMs se tornasse possível.

Em relação ao radiofármaco estudado, destaca-se que foi possível desenvolver um imunoconjugado a partir do ACM anti-CD20 conjugado ao DOTA na razão molar 1:50. Este imunoconjugado apresentou preservação da imunorreatividade e estabilidade alta quando armazenado a $2-8^{\circ} \mathrm{C}$ por até 4 meses.

Este imunoconjugado, quando radiomarcado com atividade alta de ${ }^{177} \mathrm{Lu}$, apresentou estabilidade por um tempo que possibilita o seu transporte às clínicas distantes do centro produtor e quando descongelado, sua estabilidade se mostrou vantajosa para a rotina das clínicas médicas.

O perfil farmacocinético e a biodistribuição do radiofármaco foram compatíveis com outros radioimunoconjugados encontrados em literatura, além de apresentar apreciável captação tumoral, considerando os tempos estudados. A estabilidade alta in vivo foi constatada pela baixa captação óssea e em tecidos não alvos.

A liofilização do imunoconjugado resultou em uma pastilha colapsada e desnaturação parcial do AcM evidenciado pela formação de agregados solúveis. Considerando este aspecto, é possível realizar novos estudos com diferentes excipientes para minimizar a formação de agregados e melhorar o aspecto da pastilha, sugerem-se para estudos futuros a inclusão de polissobato 80 e trealose na formulação. 
Mesmo com estas características, a estrutura e imunorreatividade do AcM foram preservadas e foi possível obter um radioimunoconjugado com rendimento alto de radiomarcação e pureza radioquímica superior a 95\% após a purificação.

A metodologia de conjugação (método 1 ou 2 ) não promoveu diferenças significativas na pureza radioquímica, imunorreatividade e estabilidade do anti-CD20-DOTA${ }^{177}$ Lu.

Ressalta-se que as radiomarcações realizadas para o imunoconjugado liofilizado, utilizaram imunoconjugados recém liofilizados, com no máximo 5 dias após a liofilização. Portanto, não foi estudada a estabilidade do produto liofilizado.

Sendo o aumento do tempo de prateleira a principal vantagem da liofilização, não é possível concluir se o processo de liofilização aumenta ou não a estabilidade do antiCD20-DOTA. Sugere-se, portanto, estudos futuros para elucidar esta questão.

Por fim, se propõe para a finalização dos estudos pré-clínicos deste radiofármaco, a realização de estudos toxicológicos para que seja confirmada sua segurança, e assim ele possa ser estudado clinicamente em pacientes com LNH. 


\section{ANEXO A}

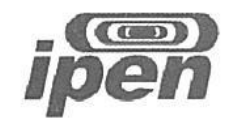

Comitê de Ética no Uso de Animais

\section{Parecer - Projeto N 97/12/CEUA-IPEN/SP}

Com base nos pareceres apresentados pelos relatores, o protocolo de pesquisa "DESENVOLVIMENTO FARMACOTÉCNICO DE PREPARAÇÃO DE RADIOIMUNOCONJUGADO BASEADA NO ANTICORPO MONOCLONAL RITUXIMAB PARA APLICAÇÃO NA TERAPIA DE LINFOMA NÃO-HODGKIN" de responsabilidade da pesquisadora DR ${ }^{\text {a }}$ ELAINE BORTOLETI DE ARAUJO foi considerado APROVADO.

Tendo em vista a legislação vigente, devem ser encaminhados, a este Comitê, relatórios anuais (parciais ou finais, dependendo da duração do projeto) referentes ao andamento da pesquisa. Após o término da pesquisa, uma cópia do trabalho deve ser encaminhada a este CEUA.

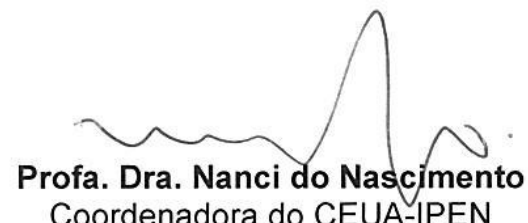

Coordenadora do CEUA-IPEN 


\section{ANEXO B}

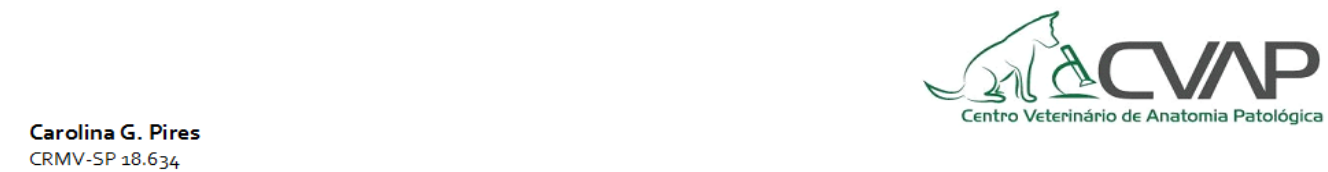

IDENTIFICAÇÃODOANIMAL

No: 1469

Nome: Camundongo SCID - Espécie: Roedor - Raça: - Sexo:F - Idade:3 meses

Proprietário(a): Adriana Vidal

Veterinário(a): Adriana Vidal - Clínica:

Material: Fragmento de formação subcutânea - Pesquisa.

\section{LAUDO ANÁTOMO-PATOLÓGICO}

\section{Avaliação macroscópica}

Encaminhado fragmento medindo $1,0 \times 0,5 \times 0,5 \mathrm{~cm}$ de superficie irregular e coloração esbranquiçada. Ao corte consistência macia e superfície lisa.

\section{Técnica histológica}

Hematoxilina \& Eosina

\section{Avaliação microscópica}

A análise microscópica do fragmento encaminhado revela proliferação neoplásica de células arredondas arranjadas de forma solida difusa, sustentadas por deliciado estroma colagenoso. Essas células exibem abundante citoplasma eosinofilico, núcleo ovalado e um ou dois nucléolos evidentes. O pleomorfismo é moderado a acentuado, e verifica-se anisocariose moderada. $O$ índice mitótico é moderado a elevado com figuras de mitoses atípicas. Entre as células neoplásicas observam-se focos de necrose.

\section{Diagnóstico:}

Quadro morfológico compatível com Linfoma.

Conferido e assinado eletronicamente por Carolina G. Pires - CRMV-Sp 18634

São Paulo, 07 de Dezembro de 2012

Rua Guajaraúna, 118 | Vila Antônio | 05376-070 | São Paulo-SP T 2872-2552 | C 8622-2552 - 8534-1514 | cvap@cvap.com.br | cvap.com.br 


\section{REFERÊNCIAS BIBLIOGRÁFICAS}

1. PRESS, O. W.; LEONARD, J. P.; COIFFIER, B.; LEVY, R.; TIMMERMAN, J. Immunotherapy of NonHodgkin's lymphomas. Hematology Am Soc Hematol Educ Program. v. 2001, n. 1, p. 221-240, 2001.

2. WALSH, G. Biopharmaceuticals: Bioquemistry and Biotechnology. Chichester, Inglaterra: John Wiley \& Sons, 2003. cap 10, p. 403-461.

3. Goldsmith, S. J. Radioimmunotherapy of lymphoma: Bexxar and Zevalin. Semin Nucl Med., v. 40, n. 2, p. 122-135, 2010.

4. JALILIAN, A. R. M., L.; KAMAKI-DEHGHAN, M.; MORADKHANI, S.; SADDADI, F. Preparation and quality control of radiometal-DOTA-rituximab. World J Nucl Med., v. 7, n. 2, p. 135-141, 2008.

5. PESCOVITZ, M. D. Rituximab, an anti-CD20 monoclonal antibody: history and mechanism of action. Am J Transplant., v. 4, p. 859-866, 2006.

6. DENARDO, G. L.; SYSKO, V. V.; DENARDO, S. J. Cure of incurable lymphoma. Int J Radiat Oncol Biol Phys., v. 66, p. S46-56, 2006. Supplement 2.

7. FORRER, F.; OECHSLIN-OBERHOLZER, C.; CAMPANA, B.; HERRMANN, R.; MAECKE, H. R.; MUELLER-BRAND, J.; LOHRI, A. Radioimmunotherapy with ${ }^{177}$ Lu-DOTA-rituximab: final results of a phase I/II Study in 31 patients with relapsing follicular, mantle cell, and other indolent Bcell lymphomas. J Nucl Med., v. 54, n. 7, p. 1045-1052, 2013.

8. RASANEH, S.; RAJABI, H.; BABAEI, M. H.; DAHA, F. J.; SALOUTI, M. Radiolabeling of trastuzumab with ${ }^{177}$ Lu via DOTA, a new radiopharmaceutical for radioimmunotherapy of breast cancer. Nucl Med Biol., v. 36, n. 4, p. 363-369, 2009.

9. PERSSON, M.; TOLMACHEV, V.; ANDERSSON, K.; GEDDA, L.; SANDSTRÖM, M.; CARLSSON, J. [(177)Lu]pertuzumab: experimental studies on targeting of HER-2 positive tumour cells. Eur J Nucl Med Mol Imaging., v. 32, n. 12, p. 1457-1462, 2005.

10. MILENIC, D. E.; WONG, K. J.; BAIDOO, K. E.; RAY, G. L.; GARMESTANI, K.; WILLIAMS, M.; BRECHBIEL, M. W. Cetuximab: preclinical evaluation of a monoclonal antibody targeting EGFR for radioimmunodiagnostic and radioimmunotherapeutic applications. Cancer Biother Radiopharm., v. 23, n. 5, p. 619-631, 2008.

11. VERA, D. R.; EIGNER, S.; BERAN, M.; HENKE, K. E.; LAZNICKOVA, A.; LAZNICEK, M.; MELICHAR, F.; CHINOL, M. Preclinical evaluation of (177)lu-nimotuzumab: a potential tool for radioimmunotherapy of epidermal growth factor receptor-overexpressing tumors. Cancer Biother Radiopharm., v. 26, n. 3, p. 287-297, 2011.

12. LEWIS, M. R.; RAUBITSCHEK, A.; SHIVELY, J. E. A facile, water-soluble method for modification of proteins with DOTA. Use of elevated temperature and optimized $\mathrm{pH}$ to achieve high specific activity and high chelate stability in radiolabeled immunoconjugates. Bioconjug Chem., $n .5, v$. 6, p. 565-576, 1994. 
13. BRASIL. Ministério da Saúde. Agência Nacional de Vigilância Sanitária. Resolução RDC no 63, de 18 dezembro de 2009. Dispõe sobre as boas prática de fabricação de radiofármacos. Diário Oficial da União. 23 dez 209; Seção 1:73-5.

14. ZIESSMAN, H. A.; O'MALLEY, J. P.; THRALL, J. H. Nuclear Medicine. 3 ed. Filadélfia, P.A.: Elsevier-Mosby, 2006.

15. SAHA, G. B. Fundamentals of nuclear pharmacy. 5 ed. New York, N.Y.: Springer, 2003.

16. SANTOS-OLIVEIRA, R. Radiofarmácia-com monografias de radiofármacos extraídos da Farmacopeia Internacional. São Paulo, S.P.: Atheneu, 2010.

17. CARVALHO, J. W. A. Princípios básicos da terapia com radionuclídeos. In: HIRONAKA, F. H.; SAPIENZA, M. T.; ONO, C. R.; LIMA, M. S.; BUCHPIGUEL, C. A. (Ed.). Medicina Nuclear. Princípios e aplicações. São Paulo, S.P.: Atheneu, 2012. p. 433-442.

18. BUCHPIGUEL, C. A.; SAPIENZA, M. T. Imagem funcional e metabóloca (PET-CT e outros). In: HOFF, P. M. G.; KATZ, A.; CHAMMAS, R.; FILHO, V. O.; NOVIS, Y. S. N. (Ed.).Tratado de Oncologia. São Paulo, S.P.: Atheneu, 2013. v. 1. p. 1031-1048.

19. STRICKER, T. P.; KUMAR, V. Neoplasia. In: KUMAR, V.; ABBAS, A. K.; FAUSTO, N.; ASTER, J. C. (Ed.). Patologia - Bases patológicas das doenças. 8. ed. Rio de Janeiro, R.J.: Elsevier, 2010.

20. ALVES, V. A. F.; MELLO, E. S.; FILHO, A. L. Noções básicas de patologia e imunoistoquímica. In: HOFF, P. M. G. K., A; FILHO, V. O.; NOVIS, Y. S. N. (Ed.). Tratado de oncologia. São Paulo, S.P.: Atheneu, 2013. v.1. p. 9-20.

21. CHAMMAS, R., Biologia do Câncer: uma breve introdução. In: HOFF, P. M. G. K., A; FILHO, V. O.; NOVIS, Y. S. N. (Ed.). Tratado de oncologia. São Paulo, S.P.: Atheneu, 2013. v.1. p. 3-8.

22. ARAÚJO, L. H. L.; VICTORINO, A. P. O. S.; MELO, A. C.; ASSAD, D. X.; LIMA, D. S.; ALENCAR, D. R.; MOREIRA, M. M. L.; FILHO, O. M.; COELHO, R. F. S.; ASMAR, S. B.; PEREIRA, B. S. V.; SCHELIGA, A., Linfoma Não-Hodgkin de alto grau - Revisão da literatura. Revista Brasileira de Cancerologia, v. 54, p. 175-183, 2008.

23. NATIONAL CANCER INSTITUTE. Non-Hodgkin Lymphoma. Disponível em: <http://www.cancer.gov/types/lymphoma/hp>. Acesso em: 15 nov. 2015.

24. AMERICAN CANCER SOCIETY. Non-Hodgkin Lymphoma. Disponível em: <http://www.cancer.org/acs/groups/cid/documents/webcontent/003126-pdf.pdf>. Acesso em: 15 nov. 2015.

25. INSTITUTO NACIONAL DO CÂNCER. Estimativa da incidência de câncer no Brasil 2014. Disponível em: <http://www.inca.gov.br/estimativa/2014/estimativa-24042014.pdf>. Acesso em: 15 nov. 2015.

26. BASTOS, D. A.; NOVIS, Y. S. Linfoma não Hodgkin. In: HOFF, P. M. G.; KATZ, A.; CHAMMAS, R.; FILHO, V. O.; NOVIS, Y. S. N. (Ed.).Tratado de Oncologia. São Paulo, S.P.: Atheneu, 2013. v. 1. p. 2461-2480. 
27. SMITH, M. R., Rituximab (monoclonal anti-CD20 antibody): mechanisms of action and resistance. Oncogene, v. 22, n. 47, p.7359-7368, 2003.

28. GOLDENBERG, D. M. Monoclonal antibodies in cancer detection and therapy. Am J Med., v. 94, n. 3, p. 297-312, 1993.

29. WRIGHT, B. D.; LAPI, S. E. Designing the magic bullet? The advancement of immuno-PET into clinical use. J Nucl Med., v. 54, n. 8, p. 1171-1174, 2013.

30. ZALUTSKY, M.R.; LEWIS, J.S. Radiolabeled antibodies for tumor imaging and therapy. In: WELCH, M.J.; REDVANLY, C.S. Handbook of Radiopharmaceuticals. England: Wiley, 2003b. p. 685-714

31. LIGIERO, T. B.; DE SOUZA ALBERNAZ, M.; DE CARVALHO, S. M.; DE OLIVEIRA, S. M.; SANTOSOLIVEIRA, R. Monoclonal antibodies: application in radiopharmacy. Curr Radiopharm., v. 6, n. 4, p. 231-248, 2013.

32. PEREIRA, D. L.; OCHOA, R. Anticorpos monoclonais em neoplasias. In: HOFF, P. M. G.; KATZ, A.; CHAMMAS, R.; FILHO, V. O.; NOVIS, Y. S. N. (Ed.).Tratado de Oncologia. São Paulo, S.P.: Atheneu, 2013. v. 1. p. 821-826.

33. GLASSMAN, P. M.; BALTHASAR, J. P. Mechanistic considerations for the use of monoclonal antibodies for cancer therapy. Cancer Biol Med., v. 11, n. 1, p. 20-33, 2014.

34. KITSON, S. L.; CUCCURULLO, V.; MOODY, T. S.; MANSI, L. Radionuclide antibody-conjugates, a targeted therapy towards cancer. Curr Radiopharm., v. 6, n. 2, p. 57-71, 2013.

35. AGÊNCIA NACIONAL DE VIGILÂNCIA SANITÁRIA. Consulta de produtos - Medicamentos. Disponível em: <http://www7.anvisa.gov.br/datavisa/Consulta_Produto/consulta_medicamento.asp $>$. Acesso em 17 nov. 2015.

36. BOROSS, P.; LEUSEN, J. H. Mechanisms of action of CD20 antibodies. Am J Cancer Res., v. 2, n. 6, p. 676-90, 2012.

37. VILLAMOR, N.; MONTSERRAT, E.; COLOMER, D. Mechanism of action and resistance to monoclonal antibody therapy. Semin Oncol., v. 30, n. 4, p. 424-33, 2003.

38. MALONEY, D. G.; SMITH, B.; ROSE, A. Rituximab: mechanism of action and resistance. Semin Oncol., v. 29, p. 2-9, 2002. Supplement 2.

39. SCOTT, S. D. Rituximab: a new therapeutic monoclonal antibody for non-Hodgkin's lymphoma. Cancer Pract., v. 6, n. 3, p. 195-197, 1998.

40. DENARDO, G.; DENARDO, S. Dose intensified molecular targeted radiotherapy for cancerlymphoma as a paradigm. Semin Nucl Med., v. 40, n. 2, p. 136-44, 2010.

41. COIFFIER, B.; LEPAGE, E.; BRIERE, J.; HERBRECHT, R.; TILLY, H.; BOUABDALLAH, R.; MOREL, P.; VAN DEN NESTE, E.; SALLES, G.; GAULARD, P.; REYES, F.; LEDERLIN, P.; GISSELBRECHT, C., CHOP chemotherapy plus rituximab compared with $\mathrm{CHOP}$ alone in elderly patients with diffuse largeB-cell lymphoma. N Engl J Med., v. 346, n. 4, p. 235-242, 2002. 
42. JIA, B.; SHI, Y.; KANG, S.; YANG, S.; HU, S.; LI, Y.; DONG, M.; WANG, W.; YANG, J.; ZHOU, L.; LIU, P.; ZHOU, S.; QIN, Y.; GUI, L.; ZHANG, C.; LIN, H.; CHEN, S.; WANG, L.; HE, X. Addition of rituximab is not associated with survival benefit compared with $\mathrm{CHOP}$ alone for patients with stage I diffuse large B-cell lymphoma Chin J Cancer Res., v. 27, n. 5, p. 516-523, 2015.

43. REPETTO-LLAMAZARES, A. H.; LARSEN, R. H.; MOLLATT, C.; LASSMANN, M.; DAHLE, J. Biodistribution and dosimetry of (177)Lu-tetulomab, a new radioimmunoconjugate for treatment of non-Hodgkin lymphoma. Curr Radiopharm., v. 6, n. 1, p. 20-27, 2013.

44. KAWASHIMA, H. Radioimmunotherapy: a specific treatment protocol for cancer by cytotoxic radioisotopes conjugated to antibodies. Scientific World Journal., p. 1-10, 2014.

45. LARSON, S. M.; CARRASQUILLO, J. A.; CHEUNG, N. K.; PRESS, O. W. Radioimmunotherapy of human tumours. Nat Rev Cancer., v. 15, n. 6, p. 347-360, 2015.

46. POUGET, J. P.; LOZZA, C.; DESHAYES, E.; BOUDOUSQ, V.; NAVARRO-TEULON, I. Introduction to radiobiology of targeted radionuclide therapy. Front Med (Lausanne)., v. 2, n. 12, 2015.

47. KOPPE, M. J.; BLEICHRODT, R. P.; SOEDE, A. C.; VERHOFSTAD, A. A.; GOLDENBERG, D. M.; OYEN, W. J.; BOERMAN, O. C. Biodistribution and therapeutic efficacy of (125/131)I-, (186)Re-, (88/90)Y-, or (177)Lu-labeled monoclonal antibody MN-14 to carcinoembryonic antigen in mice with small peritoneal metastases of colorectal origin. J Nucl Med., v. 45, n. 7, p. 12241232, 2004.

48. YEONG, C. H.; CHENG, M. H.; NG, K. H. Therapeutic radionuclides in nuclear medicine: current and future prospects. J Zhejiang Univ Sci B., v. 15, n. 10, p. 845-863, 2014.

49. JACKSON, M. R.; FALZONE, N.; VALLIS, K. A. Advances in anticancer radiopharmaceuticals. Clin Oncol., v. 25, n. 10, p. 604-609, 2013.

50. ZALUTSKY, M.R. Radionuclide Therapy. In:

VÉRTES, A.; NAGY, S.; ZOLTÁN, K. (Ed.). Handbook of Nuclear Chemistry. Netherlands: Kluwer Academic Publishers, 2003a. v. 4. p. 315-348.

51. FORRER, F.; CHEN, J.; FANI, M.; POWELL, P.; LOHRI, A.; MÜLLER-BRAND, J.; MOLDENHAUER, G.; MAECKE, H. R. In vitro characterization of (177)Lu-radiolabelled chimeric anti-CD20 monoclonal antibody and a preliminary dosimetry study. Eur J Nucl Med Mol Imaging., v. 36, n. 9, p. 1443-1452, 2009.

52. HENS, M.; VAIDYANATHAN, G.; WELSH, P.; ZALUTSKY, M. R. Labeling internalizing antiepidermal growth factor receptor variant III monoclonal antibody with (177)Lu: in vitro comparison of acyclic and macrocyclic ligands. Nucl Med Biol., v. 36, n. 2, p. 117-128, 2009.

53. TOLMACHEV, V. Choice of radionuclide and radiolabelling. In:

STIGBRAND, T.; CARLSSON, J.; ADAMS, G. (Ed.). Targeted Radionuclide Tumor Therapy. Biological Aspects. New York, N.Y.: Springer, 2010. Cap. 8, p. 145-174.

54. MÄCKE, H. R.; GOOD, S., Radiometals (non-Tc, non-Re) and bifuncional labelling chemistry.In: VÉRTES, A.; NAGY, S.; ZOLTÁN, K. (Ed.) Handbook of Nuclear Chemistry. Kluwer Academic Publishers: Holanda, 2003. v. 3, p. 279-314. 
55. BOSWELL, C. A.; TESAR, D. B.; MUKHYALA, K.; THEIL, F. P.; FIELDER, P. J.; KHAWLI, L. A. Effects of charge on antibody tissue distribution and pharmacokinetics. Bioconjug Chem., v. 21, n. 12, p. 2153-2163, 2010.

56. MACKLIS, R. M.; POHLMAN, B. Radioimmunotherapy for non-Hodgkin's lymphoma: a review for radiation oncologists. Int J Radiat Oncol Biol Phys., v. 66, n. 3, p. 833-841, 2006.

57. JACOBS, S. A., Yttrium ibritumomab tiuxetan in the treatment of non-Hodgkin's lymphoma: current status and future prospects. Biologics, v. 1, n. 3, p. 215-227, 2007.

58. TOMBLYN, M., Radioimmunotherapy for B-cell non-hodgkin lymphomas. Cancer Control., v. 19, n. 3, p. 196-203, 2012.

59. KNOX, S. J.; GORIS, M. L.; TRISLER, K.; NEGRIN, R.; DAVIS, T.; LILES, T. M.; GRILLO-LOPEZ, A.; CHINN, P.; VARNS, C.; NING, S. C.; FOWLER, S.; DEB, N.; BECKER, M.; MARQUEZ, C.; LEVY, R. Yttrium-90-labeled anti-CD20 monoclonal antibody therapy of recurrent B-cell lymphoma. Clin Cancer Res., v. 2, n. 3, p. 457-470, 1996.

60. MONDELLO, P.; CUZZOCREA, S.; NAVARRA, M.; MIAN, M. ${ }^{90}$ Y-ibritumomab tiuxetan: a nearly forgotten opportunity. Oncotarget, p. 1-13, 2015.

61. WITZIG, T. E.; GORDON, L. I.; CABANILLAS, F.; CZUCZMAN, M. S.; EMMANOUILIDES, C.; JOYCE, R.; POHLMAN, B. L.; BARTLETT, N. L.; WISEMAN, G. A.; PADRE, N.; GRILLO-LÓPEZ, A. J.; MULTANI, P.; WHITE, C. A. Randomized controlled trial of yttrium-90-labeled ibritumomab tiuxetan radioimmunotherapy versus rituximab immunotherapy for patients with relapsed or refractory low-grade, follicular, or transformed B-cell non-Hodgkin's lymphoma. J Clin Oncol., v. 20, n. 10, p. 2453-2463, 2002.

62. WITZIG, T. E.; HONG, F.; MICALLEF, I. N.; GASCOYNE, R. D.; DOGAN, A.; WAGNER, H., JR.; KAHL, B. S.; ADVANI, R. H.; HORNING, S. J. A phase II trial of RCHOP followed by radioimmunotherapy for early stage (stages I/II) diffuse large B-cell non-Hodgkin lymphoma: ECOG3402. Br J Haematol., v. 170, n. 5, p. 679-686, 2015.

63. ILLIDGE, T. M.; MAYES, S.; PETTENGELL, R.; BATES, A. T.; BAYNE, M.; RADFORD, J. A.; RYDER, W. D.; LE GOUILL, S.; JARDIN, F.; TIPPING, J.; ZIVANOVIC, M.; KRAEBER-BODERE, F.; BARDIES, M.; BODET-MILIN, C.; MALEK, E.; HUGLO, D.; MORSCHHAUSER, F. Fractionated ${ }^{90} \mathrm{Y}$-ibritumomab tiuxetan radioimmunotherapy as an initial therapy of follicular lymphoma: an international phase II study in patients requiring treatment according to GELF/BNLI criteria. J Clin Oncol., v. 32, n. 3, p. 212-218, 2014.

64. PERSKY, D. O.; MILLER, T. P.; UNGER, J. M.; SPIER, C. M.; PUVVADA, S.; STEA, B. D.; PRESS, O. W.; CONSTINE, L. S.; BARTON, K. P.; FRIEDBERG, J. W.; LEBLANC, M.; FISHER, R. I. Ibritumomab consolidation after 3 cycles of CHOP plus radiotherapy in high-risk limited-stage aggressive Bcell lymphoma: SWOG S0313. Blood, v. 125, n. 2, p. 236-241, 2015.

65. KOECHLI, V.; KLAESER, B.; BANZ, Y.; MUELLER, B. U.; PABST, T. Consolidation of first remission using radioimmunotherapy with yttrium-90-ibritumomab-tiuxetan in adult patients with Burkitt lymphoma. Leuk Res., v. 39, n. 3, p. 307-310, 2015.

66. KAMINSKI, M. S.; TUCK, M.; ESTES, J.; KOLSTAD, A.; ROSS, C. W.; ZASADNY, K.; REGAN, D.; KISON, P.; FISHER, S.; KROLL, S.; WAHL, R. L. ${ }^{131}{ }^{\text {I-tositumomab therapy as initial treatment for }}$ follicular lymphoma. N Engl J Med., v. 352, n. 5, p. 441-449, 2005. 
67. PRESS, O. W.; UNGER, J. M.; BRAZIEL, R. M.; MALONEY, D. G.; MILLER, T. P.; LEBLANC, M.; GAYNOR, E. R.; RIVKIN, S. E.; FISHER, R. I. A phase 2 trial of CHOP chemotherapy followed by tositumomab/iodine- 131 tositumomab for previously untreated follicular non-Hodgkin lymphoma: Southwest Oncology Group Protocol S9911. Blood. v. 102, n. 5, p. 1606-1612, 2003.

68. FISHER, R. I.; KAMINSKI, M. S.; WAHL, R. L.; KNOX, S. J.; ZELENETZ, A. D.; VOSE, J. M.; LEONARD, J. P.; KROLL, S.; GOLDSMITH, S. J.; COLEMAN, M. Tositumomab and iodine-131 tositumomab produces durable complete remissions in a subset of heavily pretreated patients with lowgrade and transformed non-Hodgkin's lymphomas. J Clin Oncol., v. 23, n. 30, p. 7565-7573, 2005.

69. KAMINSKI, M. S.; RADFORD, J. A.; GREGORY, S. A.; LEONARD, J. P.; KNOX, S. J.; KROLL, S.; WAHL, R. L. Re-treatment with I-131 tositumomab in patients with non-Hodgkin's lymphoma who had previously responded to I-131 tositumomab. J Clin Oncol., v. 23, n. 31, p. 7985-7993, 2005.

70. VOSE, J. M.; BIERMAN, P. J.; LOBERIZA, F. R.; ENKE, C.; HANKINS, J.; BOCIEK, R. G.; CHAN, W. C.; WEISENBURGER, D. D.; ARMITAGE, J. O. Phase II trial of 131-lodine tositumomab with highdose chemotherapy and autologous stem cell transplantation for relapsed diffuse large $B$ cell lymphoma. Biol Blood Marrow Transplant., v. 19, n. 1, p. 123-128, 2013.

71. VOSE, J. M.; CARTER, S.; BURNS, L. J.; AYALA, E.; PRESS, O. W.; MOSKOWITZ, C. H.; STADTMAUER, E. A.; MINESHI, S.; AMBINDER, R.; FENSKE, T.; HOROWITZ, M.; FISHER, R.; TOMBLYN, M. Phase III randomized study of rituximab/carmustine, etoposide, cytarabine, and melphalan (BEAM) compared with iodine-131 tositumomab/BEAM with autologous hematopoietic cell transplantation for relapsed diffuse large B-cell lymphoma: results from the BMT CTN 0401 trial. J Clin Oncol., v. 31, n. 13, p. 1662-1668, 2013.

72. PRESS, O. W.; UNGER, J. M.; RIMSZA, L. M.; FRIEDBERG, J. W.; LEBLANC, M.; CZUCZMAN, M. S.; KAMINSKI, M.; BRAZIEL, R. M.; SPIER, C.; GOPAL, A. K.; MALONEY, D. G.; CHESON, B. D.; DAKHIL, S. R.; MILLER, T. P.; FISHER, R. I. Phase III randomized intergroup trial of CHOP plus rituximab compared with CHOP chemotherapy plus (131)iodine-tositumomab for previously untreated follicular non-Hodgkin lymphoma: SWOG S0016. J Clin Oncol., v. 31, n. 3, p. 314-320, 2013.

73. GLAXO SMITH KLINE. GSK to discontinue manufacture and sale of the BEXXAR ${ }^{\circledR}$ Therapeutic Regimen (2013). Disponível em: <https://us.gsk.com/en-us/media/press-releases/2013/gsk-todiscontinue-manufacture-and-sale-of-the-bexxar-therapeutic-regimen-tositumomab-andiodine-i-131-tositumomab/ > . Acesso em 15. nov. 2015.

74. PRASAD, $V$. The withdrawal of drugs for commercial reasons: the incomplete story of tositumomab. JAMA Intern Med., v. 174, n. 12, p. 1887-1888, 2014.

75. LAM, K.; SCOLLARD, D. A.; CHAN, C.; LEVINE, M. N.; REILLY, R. M. Kit for the preparation of (111)In-labeled pertuzumab injection for imaging response of HER2-positive breast cancer to trastuzumab (Herceptin). Appl Radiat Isot., v. 95C, p. 135-142, 2014.

76. LAM, K.; CHAN, C.; DONE, S. J.; LEVINE, M. N.; REILLY, R. M. Preclinical pharmacokinetics, biodistribution, radiation dosimetry and acute toxicity studies required for regulatory approval 
of a Clinical Trial Application for a Phase I/II clinical trial of (111)In-BzDTPA-pertuzumab. Nucl Med Biol., v. 42, n. 2, p. 78-84, 2015.

77. MARQUEZ, B. V.; IKOTUN, O. F.; ZHELEZNYAK, A.; WRIGHT, B.; HARI-RAJ, A.; PIERCE, R. A.; LAPI, S. E. Evaluation of (89)Zr-pertuzumab in Breast cancer xenografts. Mol Pharm., v. 11, n. 11, p. 3988-3995, 2014.

78. RASANEH, S.; RAJABI, H.; BABAEI, M. H.; DAHA, F. J. ${ }^{177}$ Lu labeling of Herceptin and preclinical validation as a new radiopharmaceutical for radioimmunotherapy of breast cancer. Nucl Med Biol., v. 37, n. 8, p. 949-955, 2010.

79. RASANEH, S.; RAJABI, H.; HOSSEIN BABAEI, M.; JOHARI DAHA, F. Toxicity of trastuzumab labeled ${ }^{177}$ Lu on MCF7 and SKBr3 cell lines. Appl Radiat Isot., v. 68, n. 10, p. 1964-1966, 2010.

80. BANDER, N. H.; MILOWSKY, M. I.; NANUS, D. M.; KOSTAKOGLU, L.; VALLABHAJOSULA, S.; GOLDSMITH, S. J. Phase I trial of ${ }^{177}$ lutetium-labeled J591, a monoclonal antibody to prostatespecific membrane antigen, in patients with androgen-independent prostate cancer. $J$ Clin Oncol., v. 23, n. 21, p. 4591-4601, 2005.

81. ALMQVIST, Y.; STEFFEN, A. C.; TOLMACHEV, V.; DIVGI, C. R.; SUNDIN, A. In vitro and in vivo characterization of ${ }^{177}$ Lu-huA33: a radioimmunoconjugate against colorectal cancer. Nucl Med Biol., v. 33, n. 8, p. 991-998, 2006.

82. ALMQVIST, Y.; ORLOVA, A.; SJOSTROM, A.; JENSEN, H. J.; LUNDQVIST, H.; SUNDIN, A.; TOLMACHEV, $\mathrm{V}$. In vitro characterization of ${ }^{211} \mathrm{At}$-labeled antibody $\mathrm{A} 33$-a potential therapeutic agent against metastatic colorectal carcinoma. Cancer Biother Radiopharm., v. 20, n. 5, p. 514523, 2005.

83. HERBERTSON, R. A.; TEBBUTT, N. C.; LEE, F. T.; GILL, S.; CHAPPELL, B.; CAVICCHIOLO, T.; SAUNDER, T.; O'KEEFE, G. J.; POON, A.; LEE, S. T.; MURPHY, R.; HOPKINS, W.; SCOTT, F. E.; SCOTT, A. M. Targeted chemoradiation in metastatic colorectal cancer: a phase I trial of 131IhuA33 with concurrent capecitabine. J Nucl Med., v. 55, n. 4, p. 534-539, 2014.

84. VERHEIJEN, R. H.; MASSUGER, L. F.; BENIGNO, B. B.; EPENETOS, A. A.; LOPES, A.; SOPER, J. T.; MARKOWSKA, J.; VYZULA, R.; JOBLING, T.; STAMP, G.; SPIEGEL, G.; THURSTON, D.; FALKE, T.; LAMBERT, J.; SEIDEN, M. V. Phase III trial of intraperitoneal therapy with yttrium-90-labeled HMFG1 murine monoclonal antibody in patients with epithelial ovarian cancer after a surgically defined complete remission. J Clin Oncol., v. 24, n. 4, p. 571-578, 2006.

85. DAHLE, J.; REPETTO-LLAMAZARES, A. H.; MOLLATT, C. S.; MELHUS, K. B.; BRULAND, O. S.; KOLSTAD, A.; LARSEN, R. H. Evaluating antigen targeting and anti-tumor activity of a new antiCD37 radioimmunoconjugate against non-Hodgkin's lymphoma. Anticancer Res., v. 33, n. 1, p. 85-95, 2013.

86. NATARAJAN, A.; GOWRISHANKAR, G.; NIELSEN, C. H.; WANG, S.; IAGARU, A.; GORIS, M. L.; GAMBHIR, S. S. Positron emission tomography of 64Cu-DOTA-Rituximab in a transgenic mouse model expressing human CD20 for clinical translation to image NHL. Mol Imaging Biol., v. 14, n. 5, p. 608-616, 2012.

87. NATARAJAN, A.; ARKSEY, N.; IAGARU, A.; CHIN, F. T.; GAMBHIR, S. S. Validation of 64Cu-DOTArituximab injection preparation under good manufacturing practices: a PET tracer for imaging of B-cell non-Hodgkin lymphoma. Mol Imaging., v. 14, p. 1-11, 2015. 
88. Kang, H. J.; Lee, S. S.; Kim, K. M.; Choi, T. H.; Cheon, G. J.; Kim, W. S.; Suh, C.; Yang, S. H.; Lim, S. M. Radioimmunotherapy with (131)I-rituximab for patients with relapsed/refractory B-cell non-Hodgkin's lymphoma (NHL). Asia Pac J Clin Oncol., v. 7, n. 2, p. 136-145, 2011.

89. LEAHY, M. F.; SEYMOUR, J. F.; HICKS, R. J.; TURNER, J. H. Multicenter phase II clinical study of iodine-131-rituximab radioimmunotherapy in relapsed or refractory indolent non-Hodgkin's Iymphoma. J Clin Oncol., v. 24, n. 27, p. 4418-4425, 2006.

90. LEAHY, M. F.; TURNER, J. H. Radioimmunotherapy of relapsed indolent non-Hodgkin lymphoma with 1311-rituximab in routine clinical practice: 10-year single-institution experience of 142 consecutive patients. Blood, v. 117, n. 1, p. 45-52, 2011.

91. ILLIDGE, T. M.; BAYNE, M.; BROWN N. S.; CHILTON, S.; CRAGG, M. S.; GLENNIE, M. J.; DU, Y.; LEWINGTON, V.; SMART, J.; THOM, J.; ZIVANOVIC, M.; JOHNSON, P. W. Phase $1 / 2$ study of fractionated (131)I-rituximab in low-grade B-cell lymphoma: the effect of prior rituximab dosing and tumor burden on subsequent radioimmunotherapy. Blood, v. 113, n. 7, p. 14121421, 2009.

92. WAGNER, J. Y.; SCHWARZ, K.; SCHREIBER, S.; SCHMIDT, B.; WESTER, H. J.; SCHWAIGER, M.; PESCHEL, C.; VON SCHILLING, C.; SCHEIDHAUER, K.; KELLER, U. Myeloablative anti-CD20 radioimmunotherapy +/- high-dose chemotherapy followed by autologous stem cell support for relapsed/refractory B-cell lymphoma results in excellent long-term survival. Oncotarget, v. 4, n. 6, p. 899-910, 2013.

93. AUDICIO, P. F.; CASTELLANO, G.; TASSANO, M. R.; REZZANO, M. E.; FERNANDEZ, M.; RIVA, E.; ROBLES, A.; CABRAL, P.; BALTER, H.; OLIVER, P. [177Lu]DOTA-anti-CD20: labeling and preclinical studies. Appl Radiat Isot., v. 69, n. 7, p. 924-928, 2011.

94. KAMESWARAN, M.; PANDEY, U.; DHAKAN, C.; PATHAK, K.; GOTA, V.; VIMALNATH, K. V.; DASH, A.; SAMUEL, G. Synthesis and Preclinical Evaluation of (177)Lu-CHX-A"-DTPA-Rituximab as a Radioimmunotherapeutic Agent for Non-Hodgkin's Lymphoma. Cancer Biother Radiopharm., v. 30, n. 6 , p. $240-246,2015$.

95. FORRER, F.; OECHSLIN-OBERHOLZER, C.; CAMPANA, B.; MAECKE, H.; MUELLER-BRAND, J.; LOHRI, A. Is there need for radioimmunotherapy? Results of a phase $\mathrm{I} / \mathrm{Il}$ study in patients with indolent B-cell lymphomas using lutetium-177-DOTA-rituximab. Q J Nucl Med Mol Imaging., v. 56, n. 6, p. 544-550, 2012.

96. HELO, V. P.; FILIPE, V.; ROMEIJN, S.; JISKOOT, W.; JUPPO, A. M. Stability of rituximab in freezedried formulations containing trehalose or melibiose under different relative humidity atmospheres. J Pharm Sci., v. 102, n. 2, p. 401-414, 2013.

97. NIKULA, T. K.; CURCIO, M. J.; BRECHBIEL, M. W.; GANSOW, O. A.; FINN, R. D.; SCHEINBERG, D. A. A rapid, single vessel method for preparation of clinical grade ligand conjugated monoclonal antibodies. Nucl Med Biol., v. 22, n. 3, p. 387-90, 1995.

98. COOPER, M. S.; SABBAH, E.; MATHER, S. J. Conjugation of chelating agents to proteins and radiolabeling with trivalent metallic isotopes. Nat Protoc., v. 1, n. 1, p. 314-317, 2006. 
99. SABBAH, E. N.; KADOUCHE, J.; ELLISON, D.; FINUCANE, C.; DECAUDIN, D.; MATHER, S. J. In vitro and in vivo comparison of DTPA- and DOTA-conjugated antiferritin monoclonal antibody for imaging and therapy of pancreatic cancer. Nucl Med Biol., v. 34, n. 3, p. 293-304, 2007.

100. DADACHOVA, E.; CHAPPELL, L. L.; BRECHBIEL, M. W. Spectrophotometric method for determination of bifunctional macrocyclic ligands in macrocyclic ligand-protein conjugates. Nucl Med Biol., v. 26, n. 8, p. 977-982, 1999.

101. LAEMMLI, U. K. Cleavage of structural proteins during the assembly of the head of bacteriophage T4. Nature, v. 227, p. 680-685, 1970.

102. MASSICANO, A. V. F. Estudo da conjugação e radiomarcação do anticorpo monoclonal rituximab para aplicação em terapia radionuclídica. 2011. Dissertação (Mestrado) - Instituto de Pesquisas Energéticas e Nucleares, São Paulo.

103. MOHSIN, H.; JIA, F.; SIVAGURU, G.; HUDSON, M. J.; SHELTON, T. D.; HOFFMAN, T. J.; CUTLER, C. S.; KETRING, A. R.; ATHEY, P. S.; SIMÓN, J.; FRANK, R. K.; JURISSON, S. S.; LEWIS, M. R. Radiolanthanide-labeled monoclonal antibody CC49 for radioimmunotherapy of cancer: biological comparison of DOTA conjugates and ${ }^{149} \mathrm{Pm},{ }^{166} \mathrm{Ho}$, and ${ }^{177}$ Lu. Bioconjug Chem., v. 17, n. 2, p. 485-492, 2006.

104. MISRI, R.; SAATCHI, K.; NG, S. S.; KUMAR, U.; HÄFELI, U. O. Evaluation of (111)In labeled antibodies for SPECT imaging of mesothelin expressing tumors. Nucl Med Biol., v. 38, n. 6, p. 885-896, 2011.

105. LIU, S.; EDWARDS, D. S. Bifunctional chelators for therapeutic lanthanide radiopharmaceuticals. Bioconjug Chem., v. 12, n. 1, p. 7-34, 2001.

106. SOLOMONS, G. T. W.; FRYHLE, G. B. Química Orgânica. 7.ed. Rio de Janeiro, R.J.: LTC - Livros técnicos e científicos, 2002. v. 2.

107. MIER, W.; HOFFEND, J.; KRAMER, S.; SCHUHMACHER, J.; HULL, W. E.; EISENHUT, M.; HABERKORN, U. Conjugation of DOTA using isolated phenolic active esters: the labeling and biodistribution of albumin as blood pool marker. Bioconjug Chem., v. 16, n. 1, p. 237-240, 2005.

108. NELSON, D.L.; COX, M.M. Lehninger Principios de Bioquímica. 3 ed. São Paulo: Savier, 2002.

109. WOJDOWSKA, W.; KARCZMARCZYK, U.; MAURIN, M.; GARNUSZEK, P.; MIKOLAJCZAK, R. Standardization of Procedures for the Preparation of (177)Lu- and (90)Y-labeled DOTARituximab Based on the Freeze-dried Kit Formulation. Curr Radiopharm., v. 8 n. 1, p. 62-68, 2015.

110. PIPPIN, C. G.; PARKER, T. A.; MCMURRY, T. J.; BRECHBIEL, M. W. Spectrophotometric method for the determination of a bifunctional DTPA ligand in DTPA-monoclonal antibody conjugates. Bioconjug Chem., v. 3, n. 4, p. 342-5, 1992.

111. KUKIS, D. L.; DENARDO, G. L.; DENARDO, S. J.; MIRICK, G. R.; MIERS, L. A.; GREINER, D. P.; MEARES, C. F. Effect of the extent of chelate substitution on the immunoreactivity and biodistribution of 2IT-BAT-Lym-1 immunoconjugates. Cancer Res., v. 55, n. 4, p. 878-884, 1995. 
112. BRADY, E. D.; CHONG, H. S.; MILENIC, D. E.; BRECHBIEL, M. W. Development of a spectroscopic assay for bifunctional ligand-protein conjugates based on copper. Nucl Med Biol., v. 31, n. 6, p. 795-802, 2004.

113. ALIREZAPOUR, B.; A, R. J.; BOLOURINOVIN, F.; MORADKHANI, S. Production and Quality Control of [(67)Ga]-DOTA-trastuzumab for Radioimmunoscintigraphy. Iran J Pharm Res., v. 12, n. 2, p. 355-366, 2013.

114. ROSSIN, R.; KOHNO, T.; HAGOOLY, A.; SHARP, T.; GLINIAK, B.; ARROLL, T.; CHEN, Q.; HEWIG, A.; KAPLAN-LEFKO, P.; FRIBERG, G.; RADINSKY, R.; EVELHOCH, J. L.; WELCH, M. J.; HWANG, D. R. Characterization of ${ }^{64} \mathrm{Cu}$-DOTA-conatumumab: a PET tracer for in vivo imaging of death receptor 5. J Nucl Med., v. 52, n. 6, p. 942-949, 2011.

115. MOHSIN, H.; FITZSIMMONS, J.; SHELTON, T.; HOFFMAN, T. J.; CUTLER, C. S.; LEWIS, M. R.; ATHEY, P. S.; GULYAS, G.; KIEFER, G. E.; FRANK, R. K.; SIMON, J.; LEVER, S. Z.; JURISSON, S. S. Preparation and biological evaluation of ${ }^{111} \mathrm{In}$-, ${ }^{177} \mathrm{Lu}$ - and ${ }^{90} \mathrm{Y}$-labeled DOTA analogues conjugated to B72.3. Nucl Med Biol., v. 34, n. 5, p. 493-502, 2007.

116. REILLY, R., The immunoreactivity of radiolabeled antibodies--its impact on tumor targeting and strategies for preservation. Cancer Biother Radiopharm., v. 19, n. 6, p. 669-672, 2004.

117. LINDMO, T.; BOVEN, E.; CUTTITTA, F.; FEDORKO, J.; BUNN, P. A., Determination of the immunoreactive fraction of radiolabeled monoclonal antibodies by linear extrapolation to binding at infinite antigen excess. J Immunol Methods 1984, 72 (1), 77-89;

118. MOREAU, M.; RAGUIN, O.; VRIGNEAUD, J. M.; COLLIN, B.; BERNHARD, C.; TIZON, X.; BOSCHETTI, F.; DUCHAMP, O.; BRUNOTTE, F.; DENAT, F, DOTAGA-trastuzumab. A new antibody conjugate targeting HER2/Neu antigen for diagnostic purposes. Bioconjug Chem., v. 23, n. 6, p. 1181-1188, 2012.

119. ABBAS, A. K.; LICHTMAN, A. H. Cellular and molecular immunology. 5. ed. Filadélfia, P.A.: Elsevier Saunders, 2005.

120. GHOLIPOUR, N.; VAKILI, A.; RADFAR, E.; JALILIAN, A. R.; BAHRAMI-SAMANI, A.; SHIRVANIARANI, S.; GHANNADI-MARAGHEH, M. Optimization of ${ }^{90} Y$-antiCD20 preparation for radioimmunotherapy. J Cancer Res Ther., v. 9, n. 2, p. 199-204, 2013.

121. GHOLIPOUR, N.; JALILIAN, A. R.; KHALAJ, A.; JOHARI-DAHA, F.; YAVARI, K.; SABZEVARI, O.; KHANCHI, A. R.; AKHLAGHI, M. Preparation and radiolabeling of a lyophilized (kit) formulation of DOTA-rituximab with ${ }^{90} \mathrm{Y}$ and ${ }^{111} \mathrm{In}$ for domestic radioimmunotherapy and radioscintigraphy of non-Hodgkin's lymphoma. Daru, v. 22, n. 58, 2014.

122. LU, S. X.; TAKACH, E. J.; SOLOMON, M.; ZHU, Q.; LAW, S. J.; HSIEH, F. Y. Mass spectral analyses of labile DOTA-NHS and heterogeneity determination of DOTA or DM1 conjugated anti-PSMA antibody for prostate cancer therapy. J Pharm Sci., v. 94, n. 4, p. 788-797, 2005.

123. CHAKRABARTI, M. C.; LE, N.; PAIK, C. H.; DE GRAFF, W. G.; CARRASQUILLO, J. A., Prevention of radiolysis of monoclonal antibody during labeling. J Nucl Med., v. 37, n. 8, p. 1384-1388, 1996.

124. RITSCHEL, W. A.; KEARNS, G. L. Binding of drugs to biological material. In: RITSCHEL, W. A.; KEARNS, G. L.. Handbook of basic pharmacokinetics including clinical applications, Whashington American Pharmacist Association: 2009. p. 105-115. 
125. WANG, W.; WANG, E. Q.; BALTHASAR, J. P. Monoclonal antibody pharmacokinetics and pharmacodynamics. Clin Pharmacol Ther., v. 84, n. 5, p. 548-558, 2008.

126. PUJATTI, P. B. Marcadores moleculares derivados da bombesina para diagnótico de tumores por SPECT e PET. 2012. Tese (Doutorado) - Instituto de Pesquisas Energéticas e Nucleares, São Paulo.

127. KHOJASTEH, S. C.; WONG, W.; HOP, C. E. C. A. Drug Metabolismcand Pharmacokinetics Quick Guide. Nova York, N.Y.: Springer, 2011.

128. STORPIRTIS, S.; GAI, M. N.; DE CAMPOS, D. R.; GONÇALVES, J. E. Farmacocinética Básica e Aplicada. Rio de Janeiro, R.J.: Guanabara Koogan, 2011.

129. LARA, P. F.; ROMALDINI, J. H. Farmacocinética. In:

ZANINI, A. C.; OGA, S. (Ed.) Farmacologia Aplicada.. Atheneu: São Paulo, 1979. pp 35-42.

130. SANTOS, B. F. Camundongos mutantes mais utilizados. In:

ANDRADE, A.; PINTO, S. C.; OLIVEIRA, R. S. (Ed.) Animais de laboratório: criação e experimentação, Rio de Janeiro, R.J.: Editora FIOCRUZ, 2002. p 308.

131. CHANG, A. J.; DESILVA, R.; JAIN, S.; LEARS, K.; ROGERS, B.; LAPI, S. ${ }^{89}$ Zr-Radiolabeled Trastuzumab Imaging in Orthotopic and Metastatic Breast Tumors. Pharmaceuticals (Basel)., v. 5, n. 1, p. 79-93, 2012.

132. STILLEBROER, A. B.; FRANSSEN, G. M.; MULDERS, P. F.; OYEN, W. J.; VAN DONGEN, G. A.; LAVERMAN, P.; OOSTERWIJK, E.; BOERMAN, O. C. ImmunoPET imaging of renal cell carcinoma with (124)I- and (89)Zr-labeled anti-CAIX monoclonal antibody CG250 in mice. Cancer Biother Radiopharm., v. 28, n. 7, p. 510-515, 2013.

133. PITOMBO, R. N. d. M., Liofilização. In:

PESSOA JR., A.; KILIKIAN, B. V. (Ed.). Purificação de Produtos Biotecnológicos, São Paulo, S.P.: Manole, 2005. p. 988.

134. JENNINGS, T. A. Lyophilization: Introduction and Basic Principles. New York, N.Y.: Informa Healthcare, 2008. p. 646.

135. TANG, X.; PIKAL, M. J., Design of freeze-drying processes for pharmaceuticals: practical advice. Pharm Res., v. 21, n. 2, p. 191-200, 2004.

136. WANG, W. Lyophilization and development of solid protein pharmaceuticals. Int J Pharm., v. 203, n. 1-2, p. 1-60, 2000.

137. TRAPPLER, E. Lyophilization equipment. In: CONSTANTINO, H. R.; PIKAL, M. J. (Ed.). Lyophilization of Biopharmaceuticals, Arlington, V.A.: American Association of Pharmaceutical Scientists, 2004. v. 2, p. 3-41.

138. MURGATROYD, $K$, The freeze drying process. In:

CAMERON, P. (Ed.). Good Pharmaceutical Freeze-Drying Practice. New York, N.Y.: Informa Healthcare, 1996. 
139. REMMELE, R. L.; KRISHNAN, S.; CALLAHAN, W. J. Development of stable lyophilized protein drug products. Curr Pharm Biotechnol., v. 13, n. 3, p. 471-496, 2012.

140. TELSTAR Liofilização. Disponível em: <https://rdstationstatic.s3.amazonaws.com/cms/files/438/EBook_Liofilizacao.pdf>. Acesso em 15 maio. 2013.

141. CARPENTER, J. F.; PIKAL, M. J.; CHANG, B. S.; RANDOLPH, T. W. Rational design of stable Iyophilized protein formulations: some practical advice. Pharm Res., v. 14, n. 8, p. 969-975, 1997.

142. CHANG, B. S. Freeze-drying process development for protein pharmaceuticals. In CONSTANTINO, H. R.; PIKAL, M. J. (Ed.). Lyophilization of Biopharmaceuticals, Arlington, V.A.: American Association of Pharmaceutical Scientists, 2004. v. 2.

143. SHAMBLIN, S. L. The role of water in physical transformations in freeze-dried products. In: CONSTANTINO, H. R.; PIKAL, M. J. (Ed.). Lyophilization of Biopharmaceuticals, Arlington, V.A.: American Association of Pharmaceutical Scientists, 2004. v. 2, p. 686.

144. POLAK, R. Preparação, avaliação físico-química e biológica in vitro de pericárdio bovino conjugado com fibroína de seda/quitosana via liofilização e irradiação. 2010. Dissertação (Mestrado) - Universidade de São Paulo, São Paulo.

145. STOTZ, C. E.; WINSLOW, S. L.; HOUCHIN, M. L.; D'SOUZA, A. J. M.; JI, J.; TOP, E. M. Degradation pathway for lyophilized peptides and proteins. In: CONSTANTINO, H. R.; PIKAL, M. J. (Ed.). Lyophilization of Biopharmaceuticals, Arlington, V.A.: American Association of Pharmaceutical Scientists, 2004. v. 2.

146. CLELAND, J. L.; LAM, X.; KENDRICK, B.; YANG, J.; YANG, T. H.; OVERCASHIER, D.; BROOKS, D.; HSU, C.; CARPENTER, J. F. A specific molar ratio of stabilizer to protein is required for storage stability of a lyophilized monoclonal antibody. J Pharm Sci., v. 90, n. 3, p. 310-321, 2011.

147. COSTANTINO, H. R., Excipients for use in lyophilized pharmaceutical peptide, protein and other bioproducts. In:

CONSTANTINO, H. R.; PIKAL, M. J. (Ed.). Lyophilization of Biopharmaceuticals, Arlington, V.A.: American Association of Pharmaceutical Scientists, 2004. v. 2.

148. ZEVALIN. Infusão. Estados Unidos: IDEC Pharmaceuticals Corporation, 2002, Bula de remédio. 